\title{
THE USE OF LAND VALUE TAXATION IN NEW ZEALAND \\ (1891 - 1991)
}

\author{
By \\ Dylan Hobbs
}

\begin{abstract}
A thesis
submitted to the Victoria University of Wellington in fulfilment of the requirements for the degree of Doctor of Philosophy
\end{abstract}

School of Accounting and Commercial Law,

Victoria University of Wellington

2019 




\section{Contents}

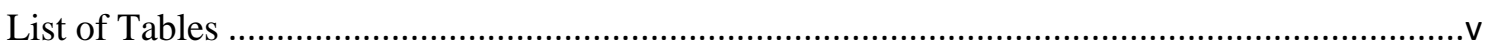

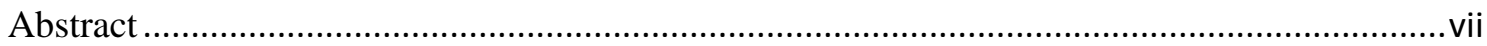

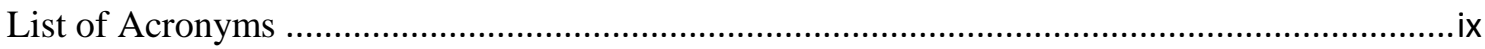

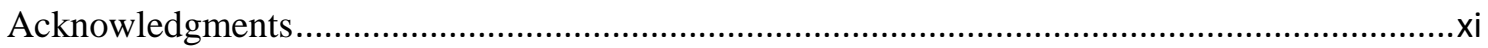

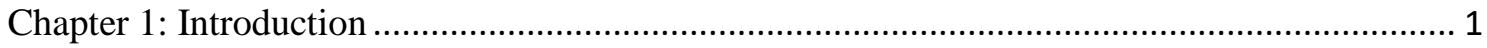

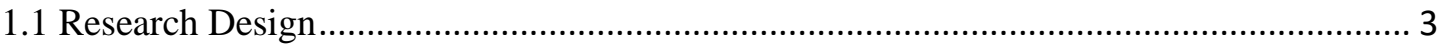

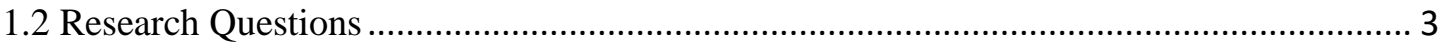

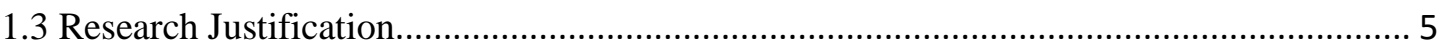

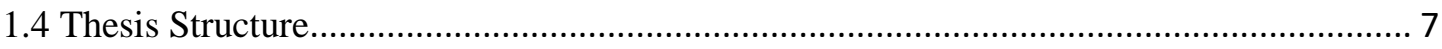

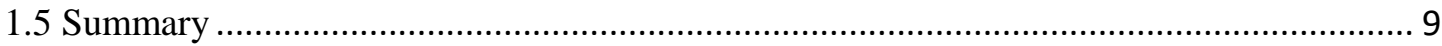

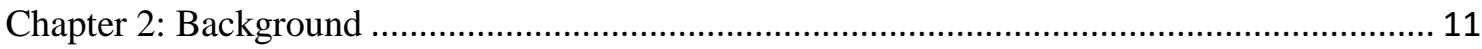

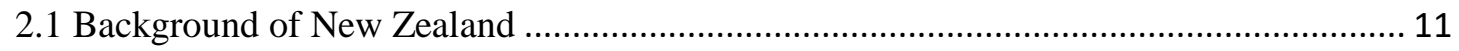

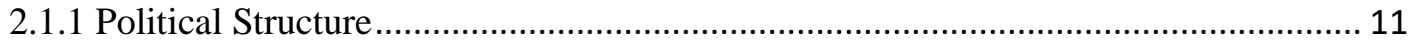

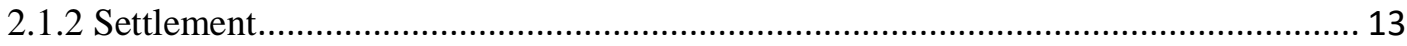

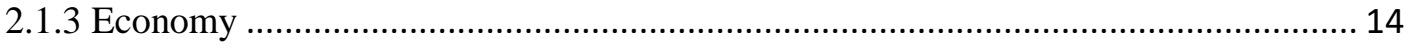

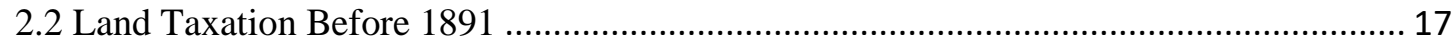

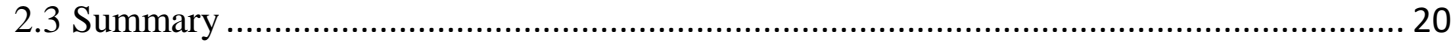

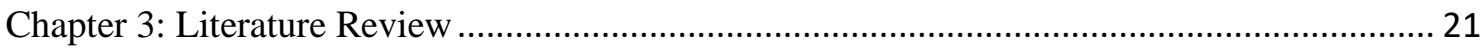

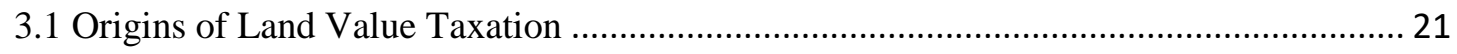

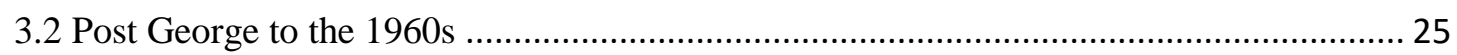

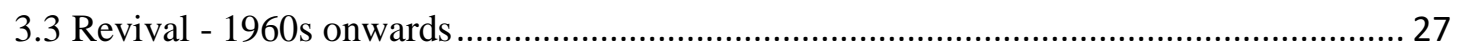

3.3.1 Economic Impacts of Land Value Taxation................................................................ 27

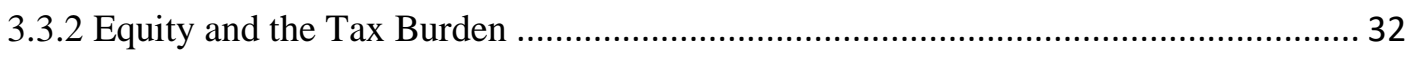

3.4 Previous Research Considering Land Taxation in New Zealand..................................... 36

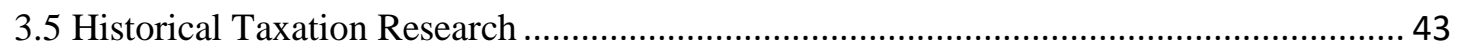

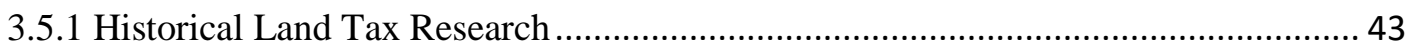

3.5.2 Historical New Zealand Tax Research........................................................................ 50

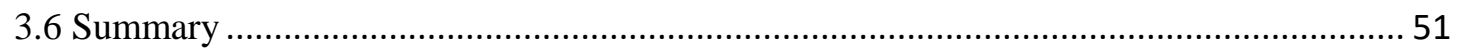

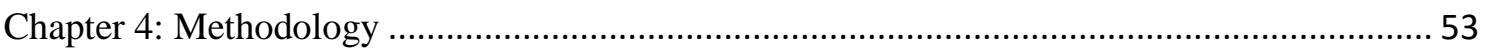

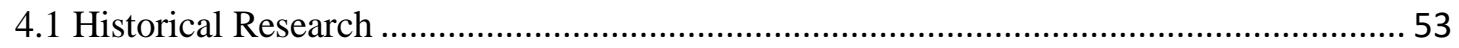

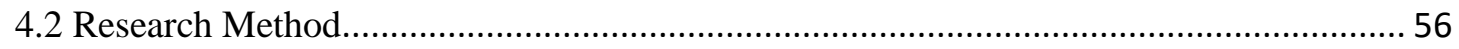

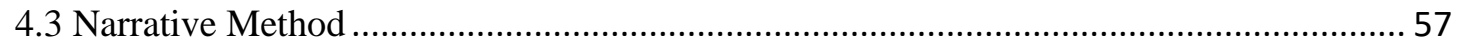

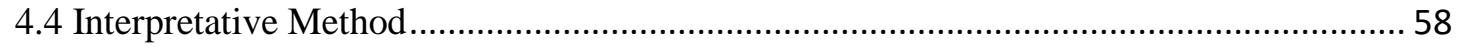

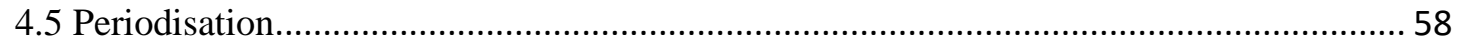

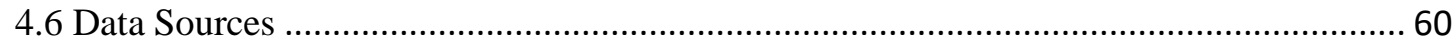




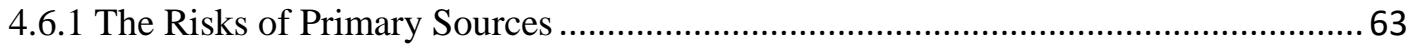

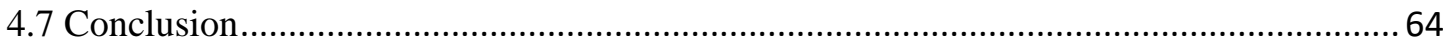

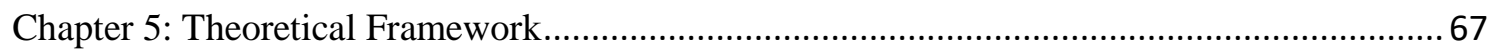

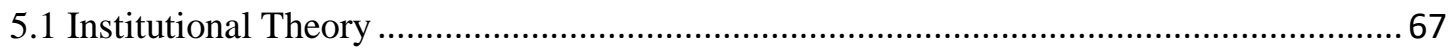

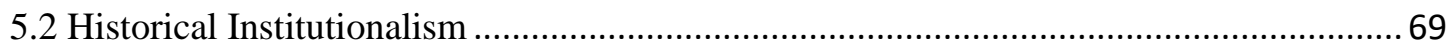

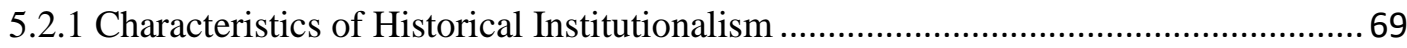

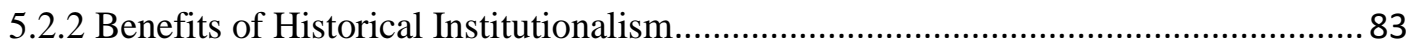

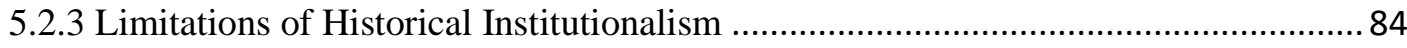

5.2.4 Previous Tax Studies using Historical Institutionalism............................................ 86

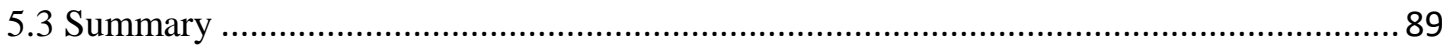

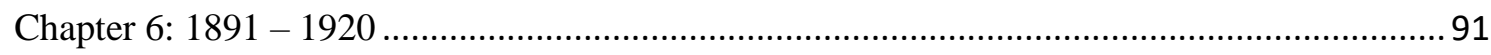

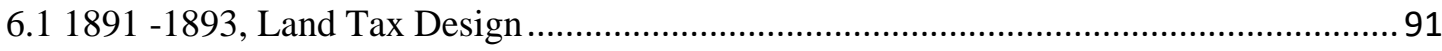

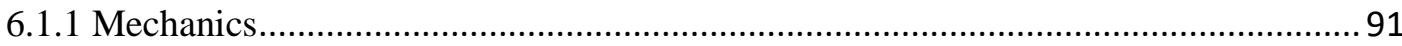

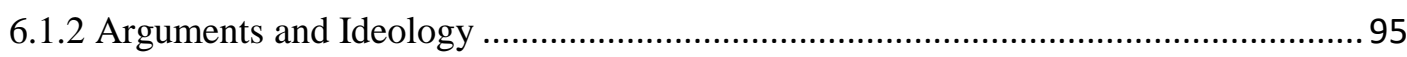

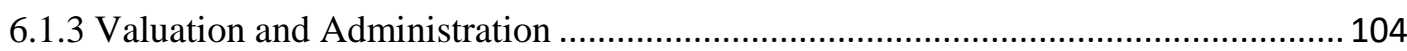

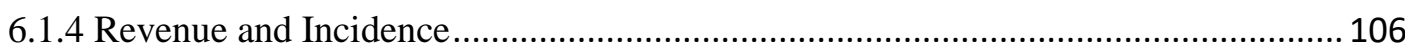

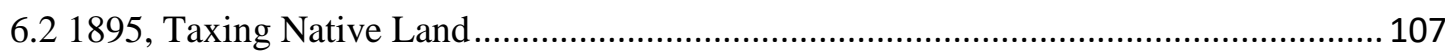

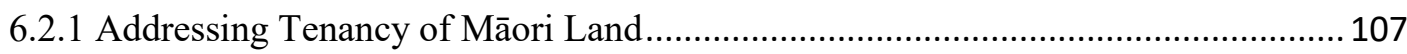

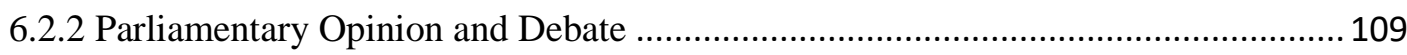

6.2.3 Later Developments In Taxing Māori Land ............................................................ 112

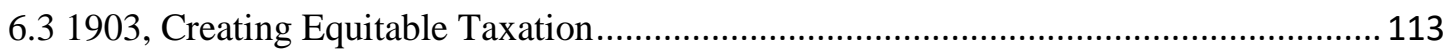

6.3.1 Altering Graduation Brackets and the Absentee Tax ........................................... 113

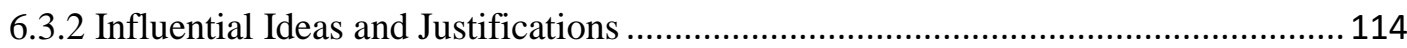

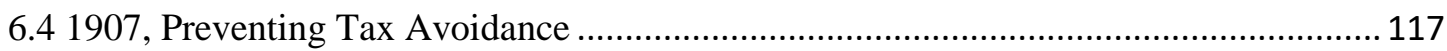

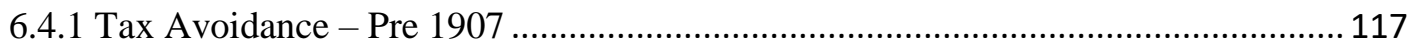

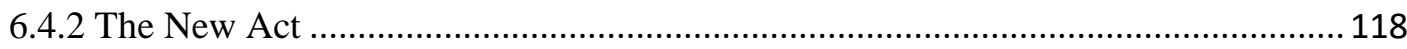

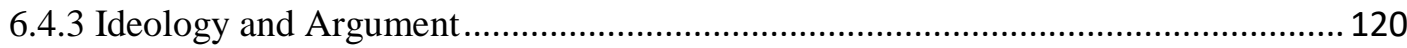

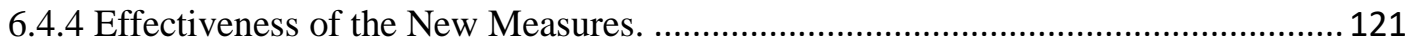

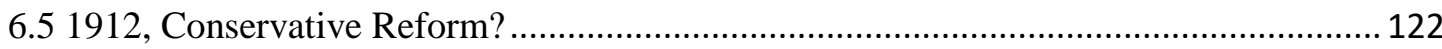

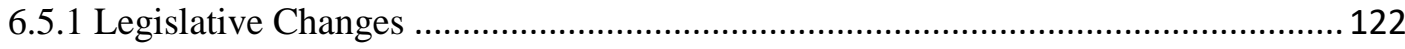

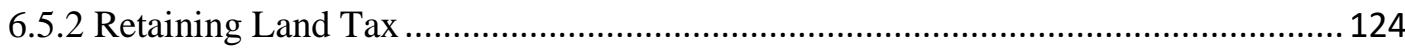

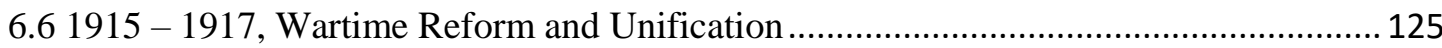

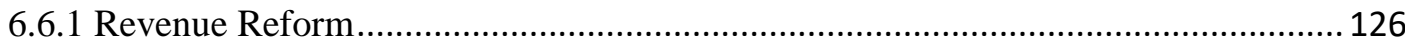

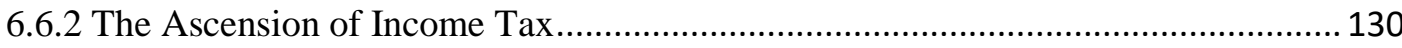

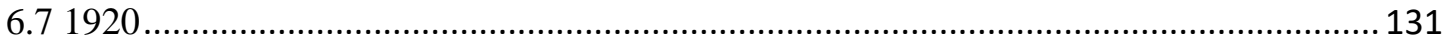

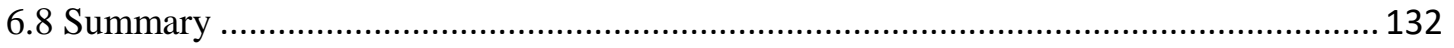




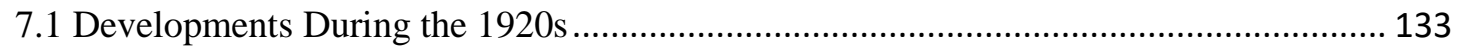

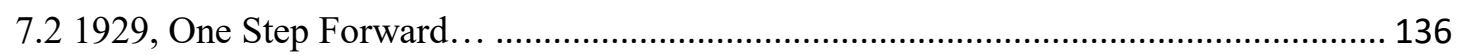

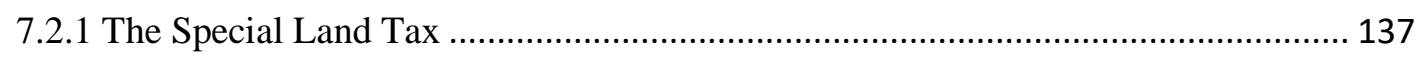

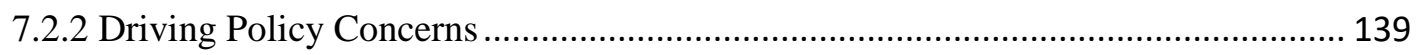

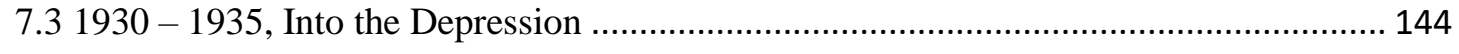

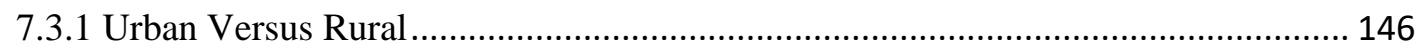

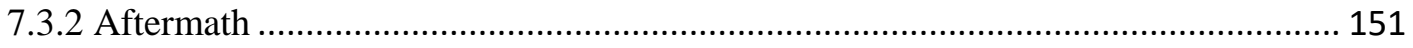

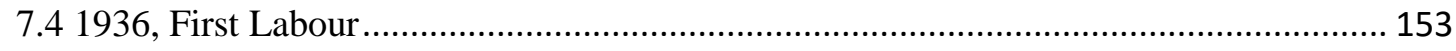

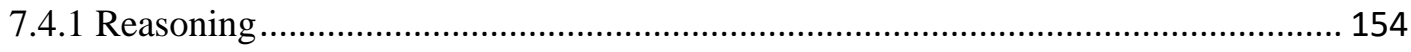

7.5 The Continued Decline of Land Tax 1937 - 1949..................................................... 158

7.5.1 Revenue Following the Reintroduction of Graduation ........................................ 158

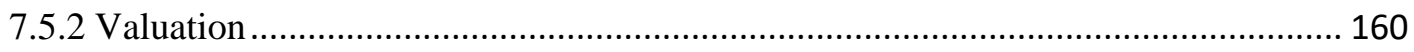

7.5.3 The Special Committee into Land and Income Tax ............................................. 164

7.6 1952, The Gibbs Taxation Committee and the National Response. ............................... 166

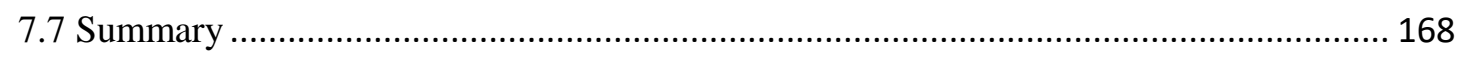

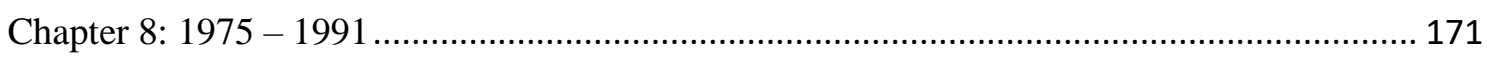

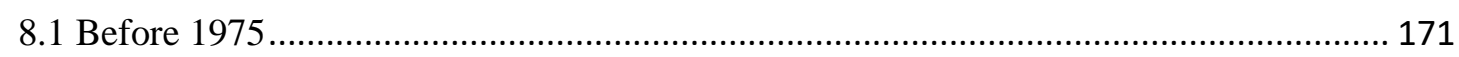

8.21976 - 1984, The Search for More Money ……………………................................ 173

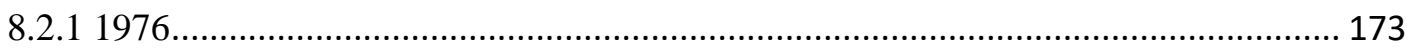

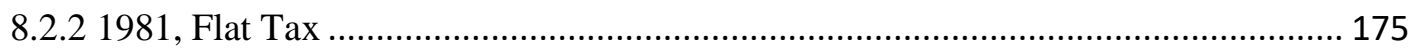

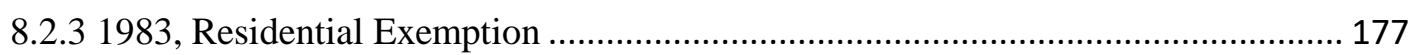

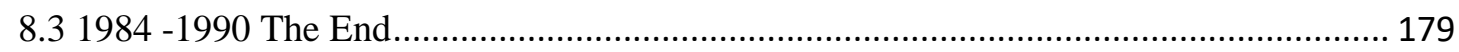

8.3.1 The Valuation of Wellington and 1988 Tax Relief................................................. 180

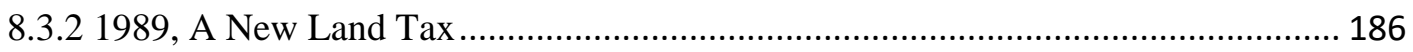

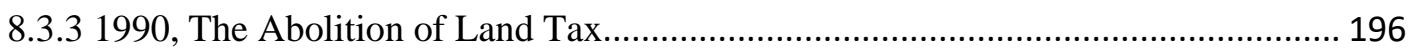

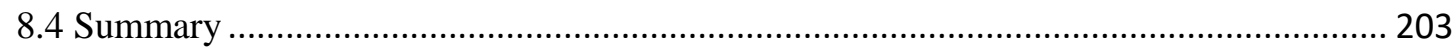

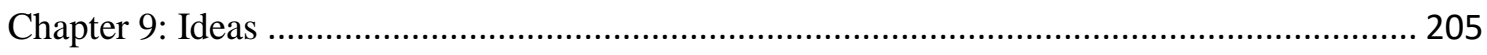

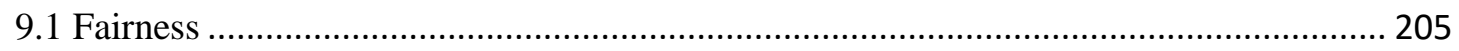

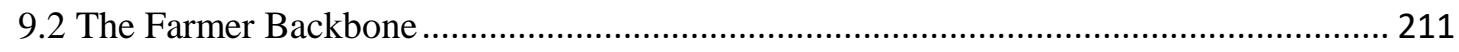

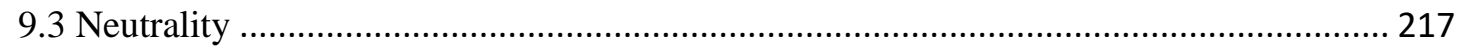

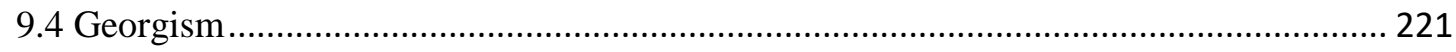

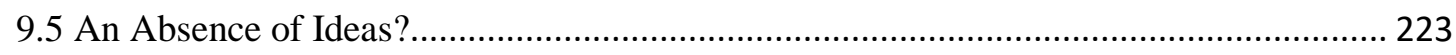

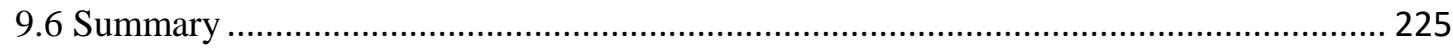

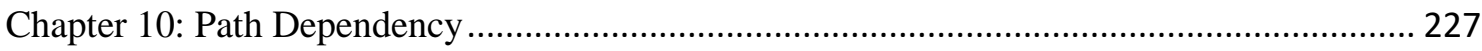

10.1 The Elements of Path Dependency ................................................................... 227 


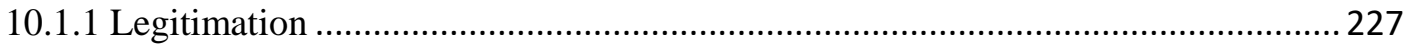

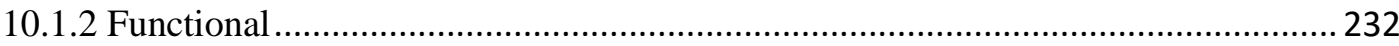

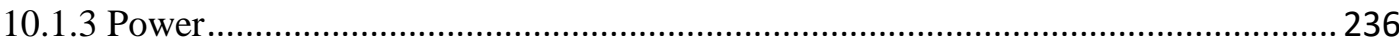

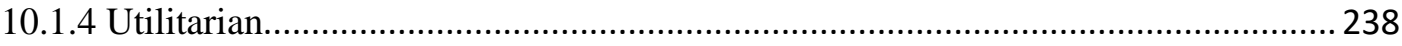

10.2 The Effect of Strong Land Tax Path Dependency..................................................... 242

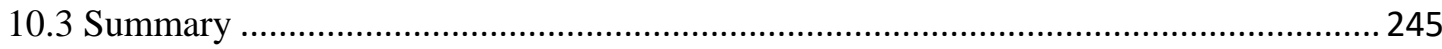

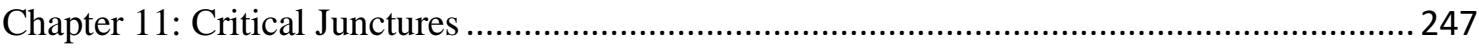

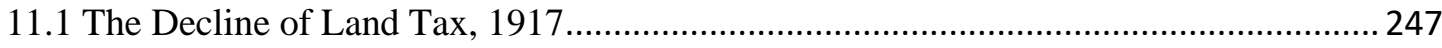

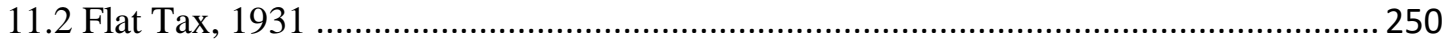

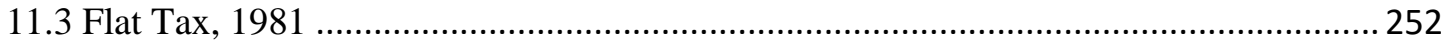

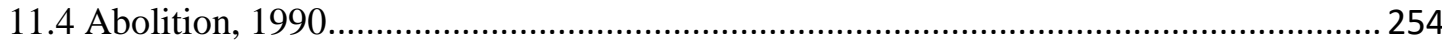

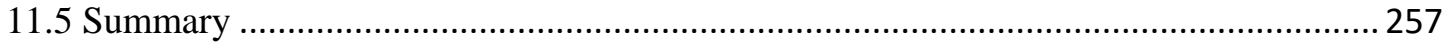

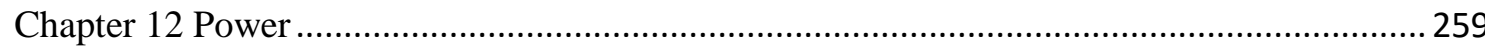

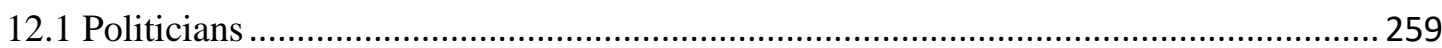

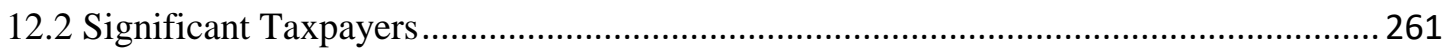

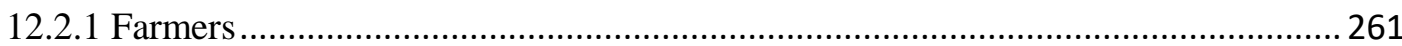

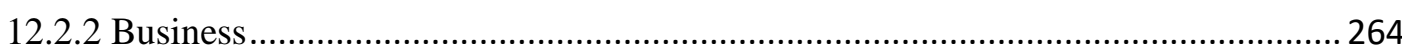

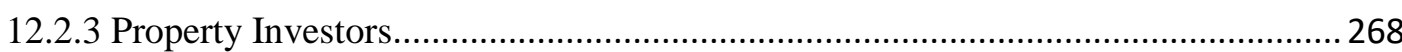

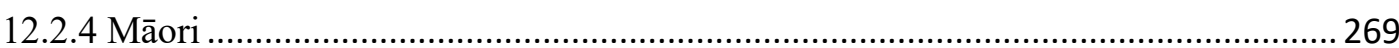

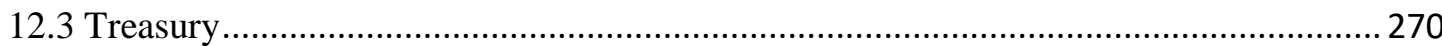

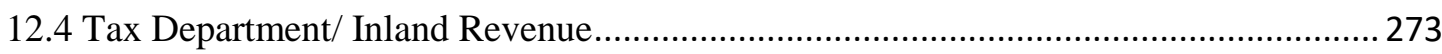

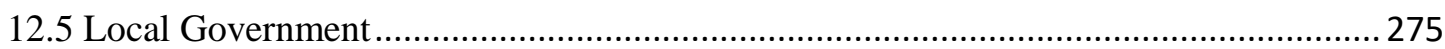

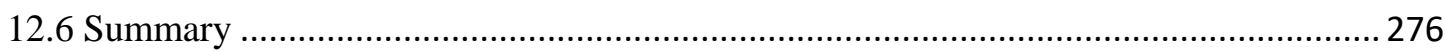

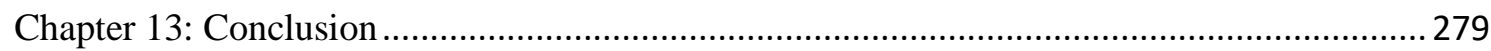

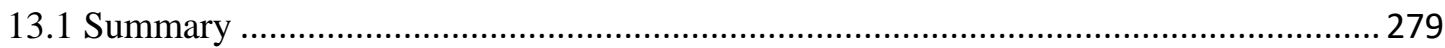

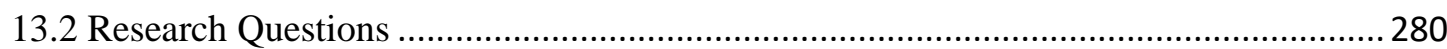

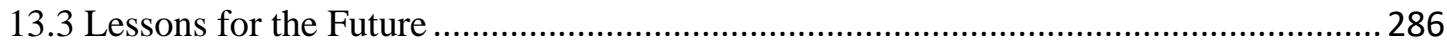

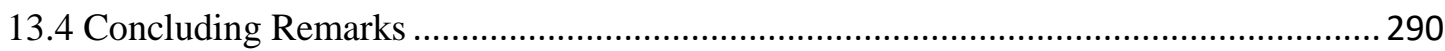

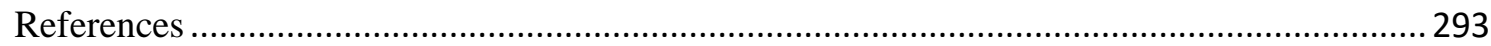

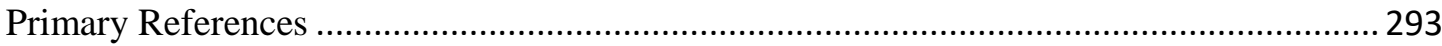

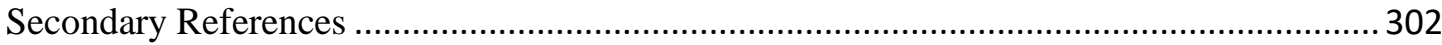

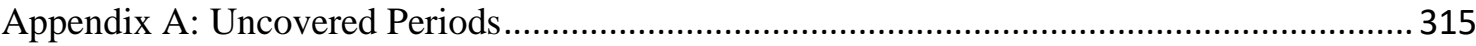

Appendix A.1 1921-1929, The Remainder of the Reform Government ................................ 315

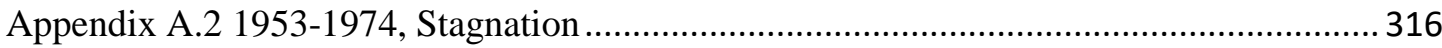

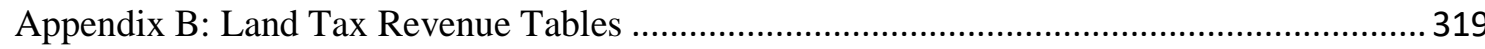




\section{List of Tables}

Table 1. New Zealand Government Revenue and Expenditure, 1927-1936 ................ 145

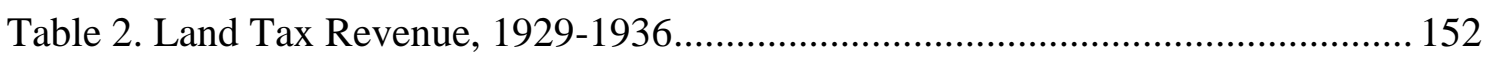

Table 3. Land Tax, Income Tax and Total Tax Revenue, 1936-1956 ......................... 160

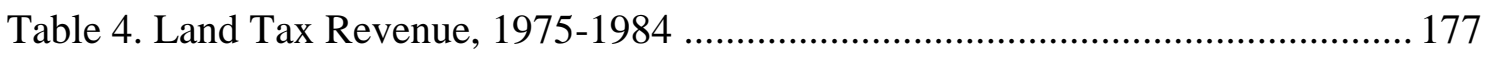

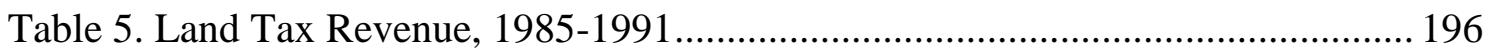

Table 6. Land Tax Revenue - Nominal and Inflation Adjusted, 1893-1966 ................ 319

Table 7. Land Tax Revenue - Nominal and Inflation Adjusted, 1967-1991 ................ 321

Table 8. Land Tax, Income Tax and Total Tax Revenue, 1893-1966 .......................... 322

Table 9. Land Tax, Income Tax and Total Tax Revenue, 1967-1991 ........................ 324 


\begin{abstract}
This thesis examines the historical use of land value taxation by the New Zealand government over the period 1891 - 1991. The study adopts qualitative research methods to explore how land taxation policy progressed over the century and what were the relevant influences on policy direction. The primary aim of the study is to examine how the land value tax policy used in New Zealand developed over time, what drove changes to it and, ultimately, why it was abolished.

To this end the study adopts a historical institutionalist framework to analyse the influence of institutional factors on the development of land tax policy. Particular attention is paid to the influence of ideas, path dependency, critical junctures and power. The research itself is an interpretive narrative history, primarily drawing from historical document sources including government records and publications, legislation, parliamentary debate records, court records and media coverage.

By addressing this topic, this research informs future debate as to the suitability of land taxation for use as a tool to influence the property market or as a method of wealth taxation. In addition it offers an explanation as to how methods of taxation can become obsolete and eventually be abolished, in a New Zealand context.
\end{abstract}




\section{List of Acronyms}

AJHR - Appendices to the Journals of the House of Representatives

GST - Goods and Services Tax

MP - Member of Parliament

NZOY - New Zealand Official Yearbook

NZPD - New Zealand Parliamentary Debate (Hansard)

WCC - Wellington City Council 


\section{Acknowledgments}

Firstly I would like to thank my supervisors, Professor Lisa Marriott and Associate Professor Andrew Smith. Their contributions have been extremely helpful to the production of this work. For their assistance, plentiful patience, willingness to go the extra mile to help me and introducing me to the joys of academic conferences I am extremely grateful.

Lastly I would like to thank my parents. In addition to providing me with support and proof reading, they were happy to listen when I attempted to explain my research. As what was supposed to be a four year trip to university to obtain an undergraduate degree extended to become almost a decade of study, they have been very understanding. 


\section{Chapter 1: Introduction}

This study examines the taxation of land in New Zealand from 1891 to 1991. Land taxes are a form of wealth taxation where taxpayers are taxed based on their ownership of land. This thesis is primarily concerned with land value based taxes, as used by the New Zealand Government, which tax only the market value of land. There are other types of land taxation which may be based on physical characteristics (e.g. the number of hectares owned) or income earning potential. Some methods are more esoteric, such as that used in 1877 in the Australian colony of Victoria, which taxed land based on acreage owned and its capacity to bear sheep (Coleman \& McKerchar, 2008), while taxation of land based on its value when put to its best possible use is the theoretical ideal (Oates \& Schwab, 1997). The most common method of taxing land is as part of a property tax, which traditionally taxes the value of the land and any improvements made to it, such as buildings constructed. Historical taxation of land in Britain most closely aligned to the property tax model (Smith 1776, pp. 1427-1428). These types of land taxation are not the focus of this research; while they are mentioned where relevant, the main focus is taxation of land based upon market value.

The taxation of land values has a long and varied history. Brought to international prominence in 1879 by journalist and self-taught economist Henry George, the land value tax gained many supporters internationally (Bonaparte, 1987). Despite this, land value tax proponents had little success in encouraging governments to implement their ideas, which were often dismissed as being unworkable (Bonaparte, 1987; Netzer, 2001). New Zealand went against this trend.

From 1891 the New Zealand Liberal Government created and implemented its own model of a national land value tax. In an attempt to make the tax more popular and equitable the Liberals created a graduated land tax with a variety of exemptions. ${ }^{1}$ It became part of the entrenched political structure and was maintained through multiple changes of government for several decades, with occasional modifications. Despite its longevity the New Zealand Government choose to abolish land tax in 1990.

$1 \quad$ NZPD, Volume 73, 4 August 1891, page 96, Rt. Hon. John Ballance. 
Historically land value taxes were proposed as a progressive tax system that would help alleviate inequality (George, 1879, p. 407). This had the additional benefit of trying to prevent land monopolies; which would make more land available for purchase by the general public at a lower price as it discouraged speculation, particularly by foreign buyers (Bird, 1960). Concerns about these issues remain common in modern New Zealand society. ${ }^{2}$ These concerns have recently seen proposals to reintroduce land taxes to address inequality and the wider issues with New Zealand's property market, ${ }^{3}$ particularly in circumstances where other tax options are limited. ${ }^{4}$ Despite some consideration, and the recommendation of the 2010 Tax Working Group, ${ }^{5}$ land taxes are seen as unpopular with New Zealanders ${ }^{6}$ and there has been little political will to implement a new one.

The objective of this research is to examine the historical establishment and operation of national land value taxation in New Zealand. More specifically, this work studies: how and why this approach to land value taxation was adopted, and how New Zealand operated a tax that had often, in both research and other countries, been dismissed as too administratively and politically complex to be practical. It is hoped that the conclusions reached will help inform the design of future tax policy surrounding land and wealth taxation in general.

2 Tom Hunt, 21 Jan 2019, Tax More: Oxfam Calls For Wealth Tax To Tackle Growing Inequality, https://www.stuff.co.nz/national/110039777/tax-more-oxfam-calls-for-wealth-tax-to-tacklegrowing-inequality, Retrieved 12 August 2019.

3 Rosanna Price, 26 Apr 2016, Housing Crisis: What You Need To Know About Land Tax, https://www.stuff.co.nz/business/money/79295795/housing-crisis-what-you-need-to-knowabout-land-tax, Retrieved 20 June 2019.

4 After New Zealand signed up to the Trans Pacific Partnership it was noted by the Prime Minister that a land tax could be imposed to circumvent the limits it had imposed restricting land sales to foreign buyers. Refer note 3 .

5 Tax Working Group, A Tax System for New Zealand's Future, 2010, page 50-51.

6 Stuff.co.nz, 17 Apr 2019, Sir Michael Cullen 'not in the least surprised' at capital gains tax rejection, https://www.stuff.co.nz/business/industries/112112394/sir-michael-cullen-notsurprised-at-capital-gains-tax-rejection. 


\subsection{Research Design}

This thesis investigates the use of land value taxation at a national level in New Zealand, adopting an interpretative historical narrative approach. The research is archival based, utilising historical documents and information, similar to previous historical land value tax studies by Bird (1960), McLean and Nou (2006) and Dilley (2013) that primarily considered tax policy development and application. As such the primary sources of information are historical legislation, parliamentary debate records, government reports and documents, and the writings and transcribed speeches of individuals involved with the development of land value taxation. These sources are supplemented through the use of archived press coverage and relevant court cases.

Due to the breadth of the topic chosen, this thesis adopts a periodisation approach to allow for more in depth analysis. The research will focus on three key periods in the history of land value taxation in New Zealand: 1891-1920, 1929-1952, and 1975-1991. Why these specific periods have been chosen is explained in Chapter 4.

A historical institutional framework is employed in this research. This is used to examine political and social institutions in New Zealand to establish how important institutional features were to the development of national land taxes policies. Additionally the framework is used to examine how key historical ideas, individuals and groups shaped land taxation policy, and the level of influence they had.

\subsection{Research Questions}

The history of New Zealand's land tax is long, with the tax lasting 100 years. During that time there are several governments, numerous events occur and there are many legislative changes. In an effort to gain a better, more detailed, understanding of the topic this thesis addresses three questions. These are outlined below.

1. How did the New Zealand model of land value taxation arise and why was it adopted over potential alternatives?

After the publication of Henry George's Progress and Poverty (1879) land value taxation proposals became more common internationally (Young, 1916). The taxation approaches considered were generally similar however, and followed the model designed by George; a flat tax rate that applied to all land. The approach adopted in New Zealand, what Dilley (2013) calls "the New Zealand model”, was significantly different; a graduated land tax 
with a variety of exemptions and higher rates for foreign landholders. This New Zealand approach to taxing land values was not obviously drawn from pre-existing literature or theorising on the subject but over time expanded to the international land value tax movement, reaching Australia and the United States. ${ }^{7}$ While the model was not adopted unopposed, existing literature does not explain why it was chosen over the more theoretically-established alternatives. The first research question addressed in the thesis addresses this deficiency.

The second research question addressed in this thesis is:

2. How did the New Zealand land tax mitigate the administrative and political problems predicted to arise from the use of land value taxation?

Much of the literature and debate surrounding land value taxation, both historical and modern, stresses the political and practical difficulties of implementing and operating such a tax system. The idea that land tax was too complex to be applied and would not be supported by the electorate often caused significant problems internationally, as land value tax proposals were hindered by proponents' inability to convincingly explain how they would work ${ }^{8}$ or generate sufficient support. Despite these expectations, New Zealand adopted land value tax, continued to use it for some time and did so with significant public support. This question attempts to establish what problems were faced in the use of land value taxation, how they were overcome and how proponents created and maintained public support.

The third and final research question addressed in this thesis is:

3. To what extent did land tax policies privilege particular groups and why did particular groups gain concessions?

Who should pay land taxes has long been a source of debate. Georgist taxes are proposed to apply to all land at a flat rate, and this has led to concerns as to their equity. Conversely

7 By December 1893 the model was being considered by the Australian labour movement and implemented by the Labor government in 1910 (Dilley, 2013) while campaigners in the United States attempted to implement land value taxes based on it from, at least, 1912 (Gilbert, 1916).

$8 \quad$ Notably the attempts Liberal Government of the United Kingdom from 1909 to 1914 to introduce land value taxes suffered due to neither Chancellor David Lloyd George nor his advisors having any clear plan how the policy would function or be administered (McLean \& Nou, 2006). 
the New Zealand land tax was designed to target particular types of landholders, including a variety of exemptions and different rates based on a taxpayer's individual circumstances. This created a tax that could vary dramatically with taxpayer circumstances and potentially lead to distortions. Over time these exemptions changed as successive governments altered the legislation based on ideology or to benefit their supporters. This question aims to establish which groups benefited from, or were least disadvantaged by, the imposition of land tax, why they did so, how these groups changed over time and what led to the design choices that caused these benefits.

\subsection{Research Justification}

While this study is historically focused, it deals with an attempted solution to modern political issues. Similar to 1890 , New Zealand presently faces significant issues surrounding land affordability and inequality; with discussion of rising house prices in particular being a regular feature in New Zealand media. Despite the heavy coverage of the problem, there has been little parliamentary action to address it. The most significant attempts have been the introduction of the bright line test ${ }^{9}$ to the Income Tax Act $^{10}$ and the Kiwibuild policy, ${ }^{11}$ neither of which have been especially effective solutions to land affordability.

However, there has been some consideration that a land tax should be implemented. Beyond potentially serving as a general check on the property market, land tax has been recommended to fulfil particular goals. These include discouraging foreign land

9 Norman Gemmell, 25 May 2015, Tax To Stop 'Bad' Behaviour Dents Level Playing Field, https://www.stuff.co.nz/dominion-post/comment/68846497/tax-to-stop-bad-behaviour--dentslevel-playing-field, Retrieved 12 April 2020.

10 Income Tax Act 2007, sCB 6A.

11 Brad Flahive, 4 Jul 2018, Kiwibuild: How To Get Yourself In The Running For The Government's New Homes, https://www.stuff.co.nz/business/property/105221626/kiwibuild-how-to-getyourself-in-the-running-for-the-governments-new-homes, Retrieved 12 April 2020. 
ownership, ${ }^{12}$ discouraging land banking ${ }^{13}$ and acting as a general revenue source. ${ }^{14}$ These are all policy aims that New Zealand's historical land tax tried to achieve. A study of historical land taxation in New Zealand can give insight into how a new land tax could work. At its most basic this helps policy makers to better assess whether land taxation could be effective in the roles it is being proposed for, but a more detailed examination of the problems land tax faced and why it was abolished can forewarn policy makers of potential issues, allowing them to design policy to mitigate said problems. Hopefully this may lead to better, and more effective, tax law.

In a New Zealand context this has an additional element. Reece (1993) notes that the taxation of land in New Zealand is intertwined with the taxation of capital gains. Specifically New Zealand's lack of a dedicated capital gains tax meant that instead the land tax was used to bring capital gains within the tax base. A better understanding of how land tax developed in New Zealand can also help inform why New Zealand lacks a capital gains tax and why the New Zealand tax system's preferential treatment of property developed.

In addition to informing future attempts to tax land, this study also provides analysis of how tax policies in general can be developed to have significant popular support and acceptance, as was achieved by the New Zealand land tax for much of its existence.

This study additionally contributes to filling a significant gap in existing literature. Literature surrounding the use of land value taxation has come far from the state it was prior to 1960 but there are still gaps (Netzer, 2001). Studies into land taxes at a national level are rare, particularly in a non-theoretical context. Limited use of land taxes has also made studies examining how land value tax policies are developed or how they evolve over their existence uncommon. Furthermore, this study examines land tax development

\footnotetext{
12 Tom Pullar-Strecker, 26 April 2016, Economists Lukewarm On Land Tax Idea, https://www.stuff.co.nz/business/industries/79308676/economists-lukewarm-on-land-tax-idea, Retrieved 16 July 2019.

13 Grant Robertson and Stuart Nash, 17 April 2019, The Government's Response To The Recommendations of The Tax Working Group, http://taxpolicy.ird.govt.nz/news/2019-04-17government-responds-twg-recommendations, Retrieved 16 July 2019.

14 The 2010 Tax Working Group report recommended the reintroduction of a national land tax as a base broadening exercise to bring currently untaxed property within the tax base. Refer note 5
} 
through the theoretical framework of historical institutionalism. This has not been done before and the thesis makes an additional contribution by applying an established framework in a new context. This study also adds to literature surrounding historical taxation in New Zealand.

\subsection{Thesis Structure}

The structure of this thesis is as follows:

Chapter 2: Background

This chapter lays out the relevant historical conditions in New Zealand prior to and during the introduction of national land value taxes. Issues covered include an overview of New Zealand's political structure and economy, and land taxation before 1891 .

\section{Chapter 3: Literature Review}

This chapter provides a detailed review of previous literature surrounding land value tax research and historical New Zealand tax research. It is divided into three sections considering general land value tax research (both internationally focused works and those focusing on the New Zealand land tax), historical studies of land value taxation and an overview of general New Zealand historical tax research.

Chapter 4: Methodology

This chapter describes the historical methodology adopted in this study and justifies its choice. This also covers the underlying assumptions, advantages and limitations of the methodology.

Chapter 5: Theoretical Framework

This chapter discusses the chosen theoretical framework, historical institutionalism, its benefits and limitations and why it was chosen.

Chapter 6: 1891-1920

This chapter chronicles the historical introduction and development of land value taxation in New Zealand. The key events are the 1891 introduction, the early issues that arose and why land tax was not abolished when the government changed in 1912. 


\section{Chapter 7: 1929-1952}

This chapter follows the same approach as Chapter 6 focusing on changes to land value taxation before, during, and after, the Great Depression. Key events include the 1929 special tax, the 1931 abolition of graduation and the reforms made by the First Labour Government in 1936.

Chapter 8: 1975-1991

This chapter follows the same approach as Chapters 7 and 8, following the reinvigoration, growing exemptions and eventual 1990 abolition of the land tax in New Zealand. Major issues include the conversion of land tax into a revenue tool, the 1989 reforms and abolition itself.

Chapter 9: Ideas

This chapter focuses on the key ideas that have informed the land tax debate and how they influenced land tax policy and public reception. The ideas focused on are fairness, the farmer backbone, neutrality and Georgism.

\section{Chapter 10: Path Dependency}

This chapter examines how land tax was maintained until 1990, despite changing governments which supported it to varying degrees and an often unclear purpose. Particular attention is paid to development of the various feedback mechanisms which sustained path dependency.

\section{Chapter 11: Critical Junctures}

This chapter examines how major events managed to disrupt land tax's path dependency, bringing changes to a generally static policy. Four potential critical junctures are analysed within this chapter: the land tax changes during the First World War, the flat land tax introduced during the Great Depression, the flat land tax introduced in 1981, and the 1990 abolition.

\section{Chapter 12: Power}

This chapter examines groups who were influential in land tax development and how they pushed, or attempted to push, tax policy in directions more favourable to them. Groups 
include politicians, farmers, businesses, Māori, property investors, local government, Treasury and Inland Revenue.

Chapter 13: Conclusion

This chapter summarises the findings of this research, answers the research questions and makes recommendations for future policy based on its findings.

\subsection{Summary}

This chapter provides an introduction and brief outline of this thesis. The chapter provides relevant background to the research topic and sets out the three research questions that the research will focus on. The chapter also justifies this research, explaining it potential benefits. A more detailed description of these elements of this thesis is provided in later chapters. 


\section{Chapter 2: Background}

This chapter presents background information that helps understand the historical development of land value taxation in New Zealand and the environment that it was developed within. There are two parts to the chapter; the first examines the characteristics of New Zealand while the second examines land taxation before 1891.

\subsection{Background of New Zealand}

New Zealand is a former British colony, a current member of the British Commonwealth, and is located in the South Pacific. Settled later than many colonies, it benefited from a greater degree of settlement planning (Woodruff \& Ecker-Racz, 1965) and new ideas as to how colonies should operate (Belich, 1996). Due to its location New Zealand was comparatively isolated from the rest of the Anglo-Saxon world prior to the advent of jet travel resulting in a culture distinct from other countries (Woodruff \& Ecker-Racz, 1965), but with close links to the United Kingdom. It adopted the British system of currency (pounds, shillings and pence), which was retained until decimalisation in 1967. Despite being a member of the so-called "white empire" (Belich, 2001) New Zealand has a significant indigenous population who have lived there since hundreds of years before European settlement (Belich, 1996).

\subsubsection{Political Structure}

As a former colony, New Zealand inherited much of its governmental and legal structures from the United Kingdom, operating as a Westminster style parliamentary democracy with a common law legal system. The country is a constitutional monarchy, retaining the British monarch as official head of state. Voting rights were initially limited to male property owners but were extended to any "British subject" by 1893 (Atkinson, 2015).

The New Zealand Parliament originally consisted of two houses. The most important was the lower house, the House of Representatives, where the legislative power was concentrated and whose members were elected under a first past the post electoral 
system. ${ }^{15}$ The country is led by the Prime Minister ${ }^{16}$ who, as is standard with Westminster style systems, appoints members of the government to serve as cabinet ministers. Like the United Kingdom, New Zealand lacks a written constitution. The cabinet has significant, though loosely defined, power and exists as an element of constitutional convention rather than the legislation. The system has a notorious lack of checks and balances during the period under study, and has permitted a strong Prime Minister to dominate the cabinet and through cabinet the government caucus, effectively allowing the individual to control Parliament (Belich, 2001).

Parliament originally included an upper house, the Legislative Council, whose members were appointed by the Governor rather than elected. This was intended to act as a revising chamber analogous to the British House of Lords but was abolished in 1950. The chamber could amend or reject the majority of bills passed by the House but was prohibited from amending money bills (Christie, 1924). Following attempts in 1890 by the outgoing Atkinson ministry to use the Council to block the program of the new Liberal government, its power was dramatically reduced and it had little real influence after 1893 (Belich, 2001, pp. 42-43). Significant provincial or state government which could have countered central government power was also non-existent following the abolition of the provinces in 1876 (Belich, 1996).

Party politics was established in New Zealand from 1890 with the formation of the Liberal Party, who dominated politics until 1912. While the opposition was generally classed as conservatives there was no formal opposing party until the creation of the Reform Party in 1909. Since 1909 New Zealand generally operated a two party political dynamic throughout most of the period covered by this study. The rise of the leftwing Labour party, formed in 1916, saw three major parties operating at the same time; Labour, Reform and the Liberals/United, ${ }^{17}$ but the two party dynamic was restored in 1938 when Reform and United merged to form the conservative National party. National and Labour have since

\footnotetext{
15 While this system is used for all periods covered this study, it was changed to a Mixed Member Proportional system in 1994.

16 The title Premier was used from 1869 to 1907 before being changed to Prime Minister when New Zealand was granted dominion status. The Prime Minister title was used informally from 1891.

17 The United Party was formed in 1927 from the remnants of the Liberal Party.
} 
remained the country's dominant political parties. ${ }^{18}$ A substantial number of members of both right leaning parties (Reform and National) came from farming backgrounds resulting in significant rural influence in Parliament and "farmer governments" dominating New Zealand for much of the twentieth century (Belich, 2001, p. 402). From 1881 to 1945 a country quota system operated, under which rural electorates had a smaller population than their urban equivalents. This inflated the number of rural seats, increasing rural influence in Parliament.

While the powers were seldom used, it is worth noting that New Zealand did not have legislative independence for much of the period studied, with the British Parliament maintaining the power to legislate for the country. This situation persisted until the country adopted the 1931 Statute of Westminster in 1947, making the country a sovereign nation (Belich, 2001).

\subsubsection{Settlement}

For the purposes of understanding land value taxation it is also important to note the environment, geography and settlement of New Zealand. While this becomes less important over time, it is particularly relevant in the late nineteenth and early twentieth centuries when land taxes were being used as part of a plan to encourage settler farming and an increasingly agrarian society.

New Zealand is a small country, the climate is mild with regular rainfall and the majority of land was suitable for both settlement and year round farming (Stewart, 1909a), aside from some particularly mountainous regions (Reeves, 1911). This resulted in a reasonably dispersed population with fewer people concentrated in cities. During the country's earlier history, it was argued that this climate was problematic from a land use perspective. Unlike the United States, Canada or Australia where harsh climates, notably deserts or frozen terrain, limited the practicality of excessively large landholding, in New Zealand there were few limits on profitable landholding beyond ones financial means

18 From the 1950 s to 1985 a third party, Social Credit, also contested elections but seldom won seats and had little influence (Belich, 2001). 
(Stewart, 1909a). Home ownership in New Zealand has traditionally been widespread, with rates above international standards (Davison, 1995).

\subsubsection{Economy}

From 1891 - 1991 the New Zealand economy was heavily focused on agricultural production. Prior to the 1880s the country's major export had been wool, produced on larger farms of 500-2000 acres (Belich, 2001). Meat and dairy farming took off in the 1890s following the advent of refrigerated shipping in the 1880s (Belich, 2001). This made smaller farms, of 100-200 acres, viable and "protein exports" to the United Kingdom became New Zealand's primary export by the 1900s (Belich, 2001, p. 68). The number of significant farms (those greater than 100 acres) in the country has remained reasonably constant at 40,000 since 1920 (Belich, 2001). While there were periods, notably between 1890 and 1910, where access to land was easier and the number of farms increased significantly, outside these, establishing new farms tended to be difficult (Belich, 2001).

From 1950 wool became more important as its price boomed in the build up to the Korean War (Ministry for Culture and Heritage, 2012). Wool prices continued to boom until 1967, increasing New Zealand's export returns but masking economic problems (Anderson, 2011), including falling prices for other agricultural commodities. From 1967 wool prices fell significantly, triggering a balance of payments crisis (Anderson, 2011) and causing a rise in both inflation and unemployment (Ministry for Culture and Heritage, 2016).

The New Zealand agriculture industry was subject to significant government oversight and assistance. As early as 1922 the government began formally coordinating exports (Harrington, 2005). From the 1960s, as part of attempts to accelerate the growth of agricultural exports, government assistance to farmers was further expanded to include low cost borrowing, input subsidies, a supplementary minimum price scheme and favourable tax treatment (Harrington, 2005). These were often significant but were rolled back during economic reforms between 1984 and 1995.

Agricultural exports remained the primary focus of the New Zealand economy throughout the studied period. Until relatively recently there was little diversification into other 
products. While agricultural production was often technologically advanced, high labour costs, a small domestic market and limited ability to achieve economies of scale hindered wider industrialisation (Singleton, 2008). The exports receipts from agricultural products paid for imports including manufactures, intermediate inputs, consumer goods and oil but this focus left the economy vulnerable to weather changes, commodity price fluctuations and the purchasing arrangements of those buying the products (Harrington, 2005). It also had the side effect of farmers being seen as more important than other members of society and the inhabitants of urban centres being seen as secondary (Reeves, 1903).

Between 1900 and 1960 New Zealand's agricultural economic base was effective, producing GDP per capita and standards of living that were among the highest in the world (The Maddison Project, 2007). However, from the 1950s growth slowed dramatically and its world ranking fell to the bottom half of the developed world. This decline coincided with a global depression in commodity prices following the post war boom, a further collapse in wool prices in the 1960s and many countries in the Northern Hemisphere introducing restrictions on agricultural imports and subsidies for their own farmers (Singleton, 2008). All of these events reduced New Zealand's export potential. From the 1970s severe economic problems arose which governments attempted to fix in a variety of ways.

As with any economy, throughout its history the New Zealand economy cycled through periods of growth and contraction. From 1891 to 1991 the New Zealand economy was subject to three significant periods of depression which are relevant to this study: the Long Depression, the Great Depression and the economic crisis arising between the late 1960 s and the 1990s.

The Long Depression stretched from 1879 to 1895 and was at its worst from 1886 to 1892 (Belich, 2001). It started following the peaking of gold production in the 1860s and falls in global commodity prices in the late 1870 s that continued to drop until the 1890 s (Belich, 2001). Access to borrowing, which had previously funded both the development of New Zealand's extractive industries and government expenditure on new infrastructure, leading to the economic boom of the early 1870 s, was greatly restricted ${ }^{19}$

19 Government borrowing never stopped, even at the depression's height but was now required for debt servicing rather than purchasing new infrastructure. 
as British investors lost confidence (Belich, 2001). The period was characterised by severe difficulties raising government revenue, deflation, rising unemployment and worsening working conditions. Importantly, immigration levels also fell while emigration levels rose, leading to a net migration loss of about 20,000 people for the $1885-1890$ period (Belich, 2001). For a country both heavily dependent on immigration and that held itself out as an immigrant's paradise, net emigration was a serious concern and how to combat "the exodus" (Belich, 2001), as it was known, was a serious issue for Parliament in the early 1890 s.

The Great Depression starting in 1929 was a global event and is widely known, requiring little elaboration. How the Depression affected New Zealand relative to the rest of the world is difficult to accurately establish. While New Zealand's export receipts fell by 44 percent during the period, unemployment was lower than either the United States or Britain $^{20}$ and the price of goods fell faster than wages, maintaining purchasing power. Conversely underemployment was widespread, levels of consumption fell and malnutrition was not uncommon. Even the wealthy, for whom the depression was not overly harsh, cut their spending as if it was.

The economic crisis that arose from the late 1960s was a combination of events that caused significant problems for the New Zealand economy. In relatively quick succession prices for wool (and other agricultural products to a lesser extent) collapsed, New Zealand lost access to its traditional British export market as Britain entered the European Economic Community and the oil shocks occurred. Unlike New Zealand's previous depressions, inflation and interest rates remained high throughout, ${ }^{21}$ increasing the cost living for citizens. Unemployment remained low by modern standards, not passing 2 percent until 1980 but it increased rapidly from the late 1980s. ${ }^{22}$

20 Somewhere between 10 and 32 percent depending on the measurement used, $12 \%$ is the most common. (Belich, 2001).

21 Reserve Bank of New Zealand, Graph Data, www.rbnz.govt.nz//media/ReserveBank/Files/Statistics/Key\%20graphs/graphdata.xlsx?la=en, Retrieved 20 May 2016.

22 Reserve Bank of New Zealand, Interest rates on lending and deposits, www.rbnz.govt.nz/statistics/b3, Retrieved 20 May 2016. 
Throughout the period the government struggled with rising expenditure and insufficient revenue. Its early response included the development large scale energy projects, known as 'Think Big', in an attempt to develop heavy industries (Belich, 2001) and an increasingly erratic set of interventionist economic policies cumulating in a wage and price freeze in the early 1980s (Belich, 2001). After the 1984 election of the Fourth Labour Government, a policy of widespread economic deregulation was adopted.

\subsection{Land Taxation Before 1891}

The concept of taxing land in New Zealand is almost as old as the country's government (Goldsmith, 2008) however, success prior to 1891 was limited. Of the previous attempts, the most noteworthy was the 1878 land value tax passed by the short-lived government of Sir George Grey, an advocate of land taxes since his time as the colony's governor. This policy raised several issues that would become common in later land tax debates and implementations. Proclaimed as the "policy of the masses" (Drummond, 1907, p. 45), the land tax was part of a plan to create a more progressive and equitable tax system that was less dependent on customs duties, which Sir George Grey felt fell too heavily on the poor, rather than primarily being a means to increase tax revenue (Grey, 1878; Goldsmith, 2012). It was also noted that substantial government spending on road and rail infrastructure was significantly increasing the value of land and it was felt that part of the costs of these infrastructures and their maintenance should be borne by landowners (Harris, 2002).

The 1878 tax predates the Georgist model and was instead heavily influenced by elements of the 1877 Victorian Land Tax and the 1842 United Kingdom Income Tax Act (Harris, 2002). The 1878 land tax was levied at a flat rate of $1 / 2 \mathrm{~d}$ for every $£ 1$ of land value excluding any improvements, ${ }^{23}$ unlike the later graduated taxation. Land was valued based on what it could be sold for after deducting the value of any improvements ${ }^{24}$ and was assessed every three years by commissioners. ${ }^{25}$ In cases where the land tax remained

\footnotetext{
23 Land Tax Act 1878, s3-4.

$24 \quad$ Land Tax Act 1878 s4.

$25 \quad$ Land Tax Act 1878 s20.
} 
unpaid for three months, the land tax commissioner was granted the power to sell the relevant land in order to obtain payment. ${ }^{26}$ The act also included an anti-avoidance rule that voided actions taken to "evad[e] the payment of land-tax". ${ }^{27}$

While Sir George Grey's land tax was broad in scope it, like the later land tax New Zealand adopted, included a variety of exemptions based on value, with the tax only applying to landholdings worth more the $£ 500,{ }^{28}$ and excluding land used for particular purposes. ${ }^{29}$ Any land owned by Māori was also exempt unless it was leased to non-Māori, in which case the tenant was treated as the owner for tax purposes. ${ }^{30}$

Sir George Grey's land tax did not last long. While not particularly heavy, the land tax created considerable opposition from large land owners (LeRossignal \& Stewart, 1910) and in 1879 the ministry, never particularly strong (Drummond, 1907), collapsed due to a combination of personality conflicts and opposition to the land tax (Reeves, 1903). At the same time the New Zealand economy entered the Long Depression. With the government's accounts forecasting significant deficits and the availability of credit reduced, the new conservative government and its Treasurer, Harry Atkinson, realised the government needed to raise more revenue from taxation. To this end Harry Atkinson converted the land tax into a property tax ${ }^{31}$ which taxed all personal and real property

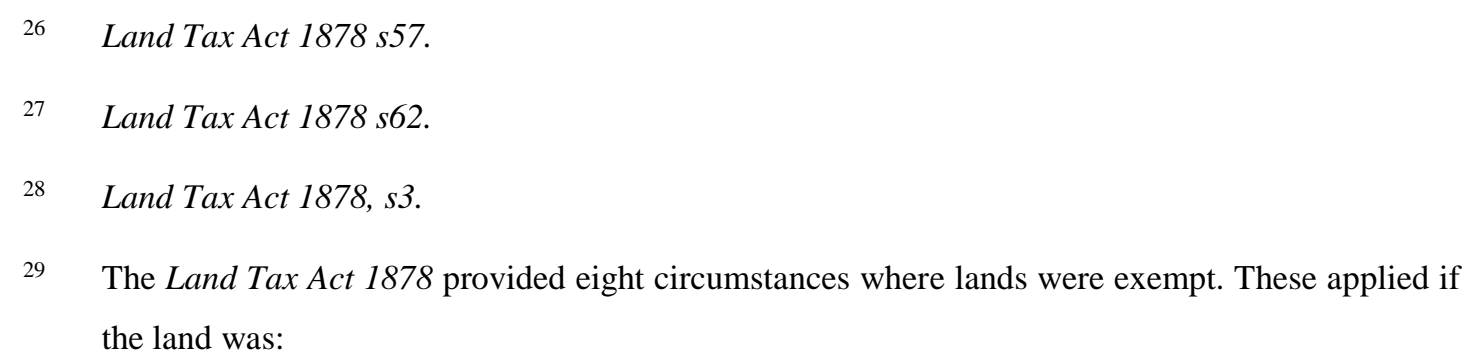


(including land) above the $£ 500$ exemption level at a rate of $1 \mathrm{~d}$ per $£ 1 .{ }^{32} \mathrm{He}$ claimed that this property tax was based on the American model, specifically the New York property tax of 1869 (Harris, 2002). This new property tax also had a variety of exemptions, most of which had existed under the land tax while also introducing new ones. ${ }^{33}$ From an operational perspective the major change was to move the assessment focus from direct assessments made by commissioners to returns made by taxpayers. ${ }^{34}$

From its implementation this new property tax was seen as unfair and widely despised by the New Zealand electorate (Drummond, 1907; Brooking, 2014). Small farmers disliked its falling on farm improvements (LeRossignal \& Stewart, 1910), retailers and manufacturers disliked its lack of relation to their profit levels or the productivity of capital, while tradesmen believed they paid too much compared to the largely untaxed professionals and salary earners, and many argued that income from property was being taxed too harshly compared to income from labour (Reeves, 1903, pp. 258-259; LeRossignal \& Stewart, 1910). There was also a public suspicion of evasion by the wealthy who owned property, such as shares, that could be easily concealed (LeRossignal \& Stewart, 1910).

There were similar views of the tax outside New Zealand. In a newspaper article lamenting the demise of Sir George Grey's land tax, Henry George himself suggested the property tax was driving both settlers and capital from New Zealand and described it as having "blighted the prospects of the colony", ${ }^{35}$ though he offered no evidence. Similarly when the government of South Australia tried to introduce legislation copying the New Zealand property tax it was defeated and described in the press as "the most monstrous

$32 \quad$ Property Assessment Act 1879 s12.

33 Property Tax Assessment Act 1879 s26 kept all of the land exemptions of the land tax while also introducing a new exemption for public health uses. New exemptions not applicable to land, and therefore of limited relevance to this study, were life insurance policies, in use agricultural implements and vessels.

$34 \quad$ Property Tax Assessment Act 1879 s30-32.

35 Wanganui Herald, 19 August 1890, Henry George and the N.Z. Exodus, Page 2. 
measure ever presented to a Legislature, and that it is based almost entirely upon the New Zealand Act is no recommendation to it."36

The widespread discontent led to several Liberal politicians advocating to abolish the property tax and reintroducing some method of land value tax as an alternative (Brooking, 2014). The property tax was abolished by the Liberal Government when they implemented their land tax in 1892.

While the 1878 land tax can be considered a failure, Sir George Grey had campaigned under a Liberal banner and, though his administration predated official formation of the Liberal Party, it contained many members who would be members of the 1890 Liberal Government. The most notable among these was treasurer John Ballance, who introduced the 1878 land tax, (Reeves, 1903) and became the Premier in the 1890 government.

\subsection{Summary}

This chapter lays out background information important to understanding the history and development of land value taxation in New Zealand. This is broken down into two sections. The first outlined the relevant background of New Zealand, covering its political structure, settlement and economy. The second briefly discussed the methods of land taxation used before the implementation of the 1891 land tax.

A basic understanding of the economy of New Zealand is helpful in comprehending the development of land value taxation over time. Most notably land tax developments are often influenced by farming, a major economic activity during the studied period. This was due to the tax being levied based on land ownership and the tax's aims to encourage wider landholding and agrarian pursuits. Other important influences on land tax development include the existence, or lack thereof, of industries not dependent on land usage and how capital to fund development was sourced.

36 South Australian Register, 13 September 1883, The Property Tax Assessment Bill, Page 4 


\section{Chapter 3: Literature Review}

Over the course of this literature review chapter three different types of taxes will be referred to: land value taxes, property taxes and split rate taxes. Land value taxes (also referred to as site value taxes and often shortened to land taxes in a New Zealand context) are the primary focus of this work. These are taxes based solely on the value of land and ignore any improvements made to that land, most commonly any buildings built on it. Property taxes, sometimes referred to as improved value or capital improved value taxes, are the taxation of land and the improvements made to it. These types of taxes aim to tax the total capital value of a property. Property taxes are common internationally and their similar tax base means they are regularly used as a contrasting measure to establish the effectiveness of land value taxation. Finally some jurisdictions use what is called a split rate tax. This is a specific type of property tax that taxes land and improvements at different tax rates, often in an attempt to achieve the theoretical benefits of land value taxes without further limiting the tax base.

\subsection{Origins of Land Value Taxation}

Taxation of land value, despite its limited use, is not a new idea, appearing in the works of classical economists David Ricardo and John Stuart Mill in 1817 and 1848 respectively. Ricardo and Mill both noted in their writings that the demand for land increased as economic development increased, causing land prices to rise. This allowed landowners to profit without doing anything. Both Ricardo and Mill recommended taxing land values to reduce increases in land prices and to redistribute, what they saw as, unearned income for the good of wider society (Ricardo, 1817; Mill, 1848).

Within a New Zealand context Mill deserves closer examination. Mill's work was well known by New Zealand politicians and his views on land reform were not dissimilar to the policies later adopted by New Zealand's Liberal Party in the 1890s (Rogers, 1963). Mill's work on land taxation stemmed from his analysis of Adam Smith's (1776) canons of taxation and his support for land reform. While Mill agreed with Smith's canons, he felt that equality required more examination. Mill did not think the graduated taxation of income or property being considered by others at the time was a fair way to reduce inequality, instead seeing such taxation as a penalty on industry (Mill, 1848, p. 567). Instead, Mill believed that taxation should fall most heavily on unearned amounts. To this 
end, Mill advocated heavy taxation of inheritances and land. Mill argued that land was advantaged over other property and income producing assets. As a natural monopoly, consistently increasing demand triggered "enormous" increases in land value without any effort from landowners (Mill, 1871, p. 8).

At the same time Mill advocated the reform of British landholding. Seeing existing land laws as the remains of a system designed to prop up the ruling class, Mill wanted to remove land ownership from the wealthy few and encourage the settlement of "small cultivators" upon all usable land (Mill, 1871, p. 4). Ideally, Mill thought land ownership should be held by the state, utilised by citizens under a leasehold system (Mill, 1871, pp. 3-4), but did not propose mandatory nationalisation of land.

Mill proposed land tax as the solution to both problems. Land tax was a means by which the state could appropriate "wealth, created by circumstances, to the benefit of society, instead of allowing it to become an unearned appendage to the riches of a particular class" (Mill, 1848, p. 572). Mill envisioned a land tax that would tax the "future unearned increase of the rent of land" (Mill, 1871, p. 3). When the tax was implemented all land would be valued and taxation would be levied on any future increases in value, not dissimilar to an accrual basis capital gains tax. Where value increases could be shown to be the result of improvements they would not be taxable (Mill, 1871, p. 11). While increases in value would be taxed heavily, it would not be the total amount to allow for inaccurate estimates. However, under Mill's proposal, landowners would not punished for past behaviour; only future gains would be taxed and, if landowners did not what to pay the tax, they would be able to sell their land to the state for the value recorded when the tax was implemented. Mill hoped that his land tax would reduce the future benefits of land ownership, discouraging people from holding it and allowing the state to gradually buy land back. (Mill, 1871, p. 15).

Land value taxation rose to much greater public prominence due to the work of Henry George who, in 1879, published Progress and Poverty. In Progress and Poverty George built on the earlier works of Ricardo and Mill (George, 1879) and then took analysis of land value taxation further, investigating in detail both the policy reasons for, and implications of, adopting a land tax system (Netzer, 2001). While land taxes had been in use before George's writing (and indeed before the writing of the classical economists on which he drew), previous methods often focused on the physical characteristics of land, 
such as the size of holdings, and did not account for changing land values. George advocated taxation of land based solely on value, with regular revaluations and any improvements made to land being exempt, as a means to fully capture economic rent. The plan was to heavily tax the economic rents arising from the ownership of land and natural resources so that the benefits of natural resources would flow to the wider community (Foldvary, 2006), while still allowing people to own the value they create and not decreasing incentives for efficient production. It was believed that this would drive down land prices and end land speculation while encouraging development (George, 1879). While George's aims were similar to those of Mill, George wanted to tax the entirety of the unearned increment, not just future gains. This meant a Georgist land tax would fall on total land values, not just gains made after its implementation, and was consequently harsher than Mill's proposal.

In arguing in favour of land value taxation, George set down four principles which he felt good taxation should strive to achieve:

"1. That it bear as lightly as possible upon production-so as least to check the increase of the general fund from which taxes must be paid and the community maintained.

2. That it be easily and cheaply collected, and fall as directly as may be upon the ultimate payers - so as to take from the people as little as possible in addition to what it yields the government.

3. That it be certain - so as to give the least opportunity for tyranny or corruption on the part of officials, and the least temptation to law-breaking and evasion on the part of the taxpayers.

4. That it bear equally - so as to give no citizen an advantage or put any at a disadvantage, as compared with others." (George, 1879, p. 408)

George argued that land value taxation was capable of meeting all these criteria. He reasoned it would not decrease production as other taxes did; rather it could increase it by “destroying speculative rent" (George, 1879, p. 413) and encouraging land to be utilised. Additionally the inability to move or hide land, and the ability to readily establish its value 
would make the tax easy to collect, certain and difficult to avoid. ${ }^{37}$ While George's principles were very similar to Adam Smith's canons of taxation, on tax equality George disagreed with Smith's “contribute toward the support of the government as nearly as possible in proportion to their respective abilities" (Smith, 1776). He thought that it was too difficult to apply practically and that income was a poor measure of ability to pay. Instead he argued that since his proposed land tax did not tax the products of individuals' labour, only unearned benefits, it was "the most just and equal of all taxes" (George, 1879, p. 421). Based on these principles he reasoned that land value taxation was the best form of taxation available to governments and should be adopted.

In addition to the other suggested benefits of the introduction of land value taxation, George believed that a comprehensive land value tax, with no exemptions and a sufficient rate, could raise enough revenue to pay for all government expenditure, allowing for the abolition of all other forms of tax (George, 1879, p. 406). This would reduce taxes that hamper production and encourage productive labour. While the single tax idea is one of the better known aspects of Georgism it has not been especially influential. The idea of replacing all taxation with land taxation gave rise to the "single tax" movement which continues to be raised by more ardent Georgists, and has given them "a cranky reputation which has prevented their ideas from being taken as seriously as they deserve to be" (McLean, 2004, p. 10). Within a New Zealand context George has been described as the "populariser and propagandist" of the Liberal period (Rogers, 1963, p. 155) but the single tax part of Georgism was not a major consideration. Abolishing all other taxes was never implemented, or given serious attention, by Parliament. While in the 1890s the Liberal Government did contain single tax supporters and members who had spoken favourably of it, ${ }^{38}$ uncertainty surrounding its workability made it a severe risk to the government's already precarious revenue. Consequently, the no exemptions and high tax rate elements of George's land tax model were generally focused upon.

\footnotetext{
37 George noted that other taxes (specifically income tax, excise duties and property taxes) were regularly avoided by incorrect or false valuations. He argued that land valuations had a higher degree of certainty and would be more accurate.

38 Poverty Bay Herald, 8 May 1891, Government Proposals.
} 


\subsection{Post George to the 1960s}

Despite Progress and Poverty becoming one of the most read and influential books of the early twentieth century (Czech, 2009) the movement had little political or practical success at the time (Young, 1916) and academic attitudes to land value taxation generally remained disinterested or hostile until the 1960s (Netzer, 2001). Throughout the pre1960s period, economists saw land and property taxes as "a dying, anachronistic institution" (Netzer, 2001, p. 98). This was based on previously poor tax administration, the collapse of revenue from property taxes during the Great Depression and the increased use of income and sales taxes. As late as 1956 economists were declaring that land and property taxation would, within twenty years, have "become an all but forgotten relic of an earlier fiscal age" (Mitchell, 1956). Gaffney went further, blaming the limited interest on the influence of land barons in establishing the dominant economics schools in the United States and then populating them with anti-George faculty (Gaffney, 1994).

Overall academic disinterest resulted in little research being done into the topic and that that did exist had several problems, as outlined by Netzer (2001, p. 99), including:

- There were few significant contributions to the theoretical literature since George himself;

- The definition of land value taxation was not clear, with advocates frequently arguing for different taxes or approximations that had little in common with George's original ideas;

- Scientific literature surrounding the effects of land value taxation in practice was very limited. There were anecdotes from some non-American parts of the English speaking world but they were not convincing;

- Land value taxation required very good valuation practices to be successful but proponents were often willing to accept poor ones and argued on those bases and;

- There was limited work on the capitalisation of taxes into land prices.

While not noted by Netzer, substantial, analytical critiques of the theory of land value taxation were also rare. Most economists and textbooks in the pre-1960s academic climate did not mention it, or did so with only a few brief derogatory comments (Brown, 
1949). ${ }^{39}$ Of the research that was produced into land value taxation before the 1960 s most tended to be descriptive rather than analytic, while work on the single tax was largely Georgist apologetics (Klemme, 1947).

There were some significant contributions to the literature of land value taxation before the 1960s. The most significant contribution was the work of Harry Gunnison Brown who, starting in the 1920s, put George's theory into the language of contemporary economics. Brown also noted the deadweight losses and economic distortions of other taxes compared to theoretical land value taxes, arguing the latter to be a superior choice to encourage production. He also attempted to broaden the audience for and influence of Georgist ideas and theory beyond students at university (Ryan, 2002).

Some works also arose from Australia and New Zealand studying their land value tax regimes (LeRossignal \& Stewart, 1908; Stewart, 1909a; 1909b; Heaton, 1925) but the majority were largely descriptive. Anecdotal evidence from New Zealand and Australia was also put forward but was unpersuasive and tended to have "the character of visions seen by the devout" (Netzer, 2001, p. 99).

Among the more notable work arising in Australia, in the 1940s Hutchinson produced a series of analytical works into the effects of land value taxation there. One of the first empirical studies into the effects of land value taxation, these works split Australian states depending on whether they based their taxation on land values or property. The states were then compared to establish differences between the volumes of land used for crop production, number of houses built and the value of houses built. Hutchinson found that the states using land value taxation had a larger increase in land used for crops, more houses built and more valuable houses (Hutchinson, 1945) but more recently the method of his analysis has been criticised due to not controlling for relevant influences beyond the tax type (Wyatt, 1994). The work was seized on by Brown to argue for more consideration to be given land value taxation (Brown, 1949) and both its conclusions and methodology helped inform later research in the 1980s (Edwards, 1984).

\footnotetext{
39 For example, economist Francis Walker refused to discuss George's ideas of land value tax in his book Political Economy, merely commenting "I will not insult my readers by discussing a project so steeped in infamy" (1887, p. 418).
} 


\subsection{Revival - 1960s onwards}

From the 1960s the academic community began to take land value taxation more seriously, rather than dismissing the idea as it had previously. This resulted in a significant increase in both the quantity and quality of research produced. As such, a substantial volume of research arose surrounding the impacts of adopting land value taxation. Broadly this fell into three categories that considered land tax's economics, its equity and its potential as an urban development tool. Since New Zealand never considered using land tax for urban development, only the first two categories will be focused on.

\subsubsection{Economic Impacts of Land Value Taxation}

\subsubsection{Revenue Potential}

By the 1970s researchers were conducting studies into the potential to use land value taxation to replace income tax in the United States, moving towards George's single tax idea. The results were mixed, ranging from insufficient revenue (Follain, 1986), uncertain and doubtful (Douglas, 1978), to uncertain but optimistic (Oates, 1973; Grosskopf, 1981) and adequate revenue potential (Gaffney, 1970; Stone, 1975). Cord (1985) argued that full taxation of economic rent on its own would have been insufficient to fund all government spending in the United States (both state and federal) in 1981, raising about two thirds of the required revenue, but expected that the shortfall could be made up through the continuation of user charges. He also expected that a tax on land values would collect less revenue but could still replace taxes on labour and capital. More recently, given the significant increase in government spending since George's writing and the general assumption of an insignificant tax base, most researchers have doubts as to the potential revenue arising from land value taxes, so the single land tax idea is seldom seriously considered for use as the sole source of government revenue (Roakes, 1991; Wyatt, 1994; Gaffney, 2009).

Despite this there are still some advocates of the single tax. Foldvary (2006) estimated, based on Cord (1985), that in the United States a land value tax that fully captured land rents would be sufficient to fund 60 percent of spending by the federal, state and local governments, or all government spending if transfer payments were eliminated. Gaffney (2009) similarly argues that standard data sources that are used to estimate land tax revenue and evaluate its potential omit significant portions of the potential tax base and 
generally undervalue land. Based on this he concludes, as he did in 1970, that the broad based single tax is still more than sufficient to raise the revenue required for the government to operate.

Additionally, some advocates argue that the removal of other taxes would eliminate the lost output other taxes cause (Foldvary, 2006; Gaffney, 2009) and encourage significantly faster economic growth (Tideman, Akobundu, Johns, \& Wutthicharoen, 2002), both of which would increase land rent and therefore tax collected both immediately and over time (Foldvary, 2006).

\subsubsection{Efficiency}

One of the most common arguments for the implementation of land value taxes is their efficiency. The tax is generally argued to be neutral with respect to land use (Netzer, 2001) and should not decrease the supply of sites offered "since no possible response to the tax can improve the situation [for landowners], assuming that landowners have been making maximum use of their sites prior to the imposition of the tax" (Netzer, 1966, pp. 204-205). In contrast, most researchers agree that property taxes are not neutral as they place a levy on any structures on land, causing them to impede and slow down development (Roakes, 1996).

However, debate has arisen as to whether a land value tax actually is neutral. The work of Shoup (1970), Bentick (1982) and Mills (1981) indicate that land value taxes may distort the timing of land development. They theorise that such taxes encourage earlier development of land at the expense of effective development when land uses are mutually exclusive, in order to obtain revenue streams more quickly to offset the payment of the tax. Other researchers have objected to these findings pointing out that the effect depends on the use of a particular assessment practice (Wildasin, 1982; Tideman, 1982); if land value is assessed based on the best possible use it should be neutral even if uses are mutually exclusive (Oates \& Schwab, 1997).

\subsubsection{Valuation and Administration}

Most proponents of land value taxation agree that it requires the accurate valuation of land to function effectively and give taxpayers certainty. Whether sufficiently accurate land values are possible at a reasonable cost is subject to debate. Existing valuation

methods used for property taxes are often seen as expensive and inaccurate, with land only valuation widely seen as more difficult (Netzer, 2001) and requiring different 
methods (Roakes, 1991). George argued that the immovable and public nature of land would make it difficult to hide from tax assessment, but he gave little consideration to the accuracy of good faith assessments beyond saying they could be assessed with definitiveness (George, 1879, p. 417). The lack of argument did not make this compelling reasoning and Heaton (1925) recorded in Australia that by 1917 some landowners were simply not filling land tax returns for land they owned, despite George's claims that the immoveable nature of land would make this difficult. In addition valuations in Australia were not definite, with the Federal and State governments often disagreeing about the value of properties.

Modern work has recognised potential issues surrounding establishing land values to a sufficient degree of accuracy. Roakes (1991) noted that mass appraisal valuing techniques often overvalue land creating both inaccuracy and an imbalance between taxpayers based on valuation methods used on their property. A general tendency to overvalue land owned by the poor and slums also results in decreased tax progressivity (Gaffney, 1972). The problem can be mitigated through the use of special valuations but this increases administration costs. A lack of empty land parcels in cities also makes comparative valuation difficult (Netzer, 2001). Mills (1998) argued that the likelihood of valuation errors would limit the potential advantages of land value taxation. Chapman, Johnston, and Tyrrell (2009) conversely argue that such concerns overstate the problem and that, even with high rates of valuation error, land value taxes would still be less distorting than property taxes, and assessors are able to create reasonably accurate measurement tools despite a lack of comparators.

The appropriate method of land valuation is also debated. Since the purpose of George's proposal was to fully tax economic rent, a somewhat abstract and not easily measurable concept, multiple valuation bases have been proposed. The most common are the present market value of land, generated economic rent and land value based on best possible use. Market value is the easiest to administer but distorts improvement decisions towards the fastest option (Mills, 1981) while the possibility that land value taxation may cause a significant decrease in the price of land reduces its revenue potential. Generated economic rent and land value based on best possible use are more ideologically pure, aligning better with George's original intentions, are more likely to encourage positive land development and are less affected by potential falls in market prices. Both concepts are somewhat abstract though and very difficult to measure and administer. Land value based on best 
possible use additionally requires establishing what the best possible use for a piece of land is. This results in concerns surrounding the practicality of actually operating the tax system.

\subsubsection{Effects on Economic Growth}

As mentioned above in Section 3.3.1.1, land tax proponents argue that increased use of land value taxation will increase economic growth through a combination of encouraging more productive investment in capital (Feder, 1993) and the reduction of other taxes that discourage production (Foldvary, 2006; Gaffney, 2009). This stimulation of private investment and production should lead to an increase in employment opportunities and/or wages and a decrease in the costs of construction materials (Becker, 1970). In addition, a tax on land values can be expected to reduce interest costs, providing more credit for industry development (Becker, 1970). ${ }^{40}$

Evidence that this theory holds true in practice is limited. By 1961 New Zealand officials could find no evidence land tax was encouraging economic growth (Hagman, 1964). Similarly Oates and Schwab (1997) argued that the results of their study did not support arguments that land value taxation stimulated economic activity; rather its advantage was in providing governments with a revenue source that "had no damaging side effects on the ... economy" (p. 19).

\subsubsection{Price of Land and Housing}

Research has also raised questions as to how the introduction of land value taxation would affect prices charged for land. Like many areas surrounding land value taxation, the effect is difficult to estimate and there is no clear consensus as to what it would be. Netzer (1966) argues that the tax should have no effect on the total costs of land ownership, provided that the tax only falls on the unearned, surplus land values. Becker (1970) agreed that the total costs would remain constant but was unsure about the how the price of land would be affected, suggesting that it could either fall, due to tax capitalisation, or rise, based on increased demand. Foldvary (2006) conversely expected that the tax would result in a significant decrease in the price of land, depending on the applied rate, due to

\footnotetext{
40 Tax capitalisation theory presumes that as a land tax lowers the price of land, interest costs decline equal to the increased tax levy (Gaffney, 1973).
} 
the capitalisation of taxes into land prices. ${ }^{41}$ The potential fall in land values resulting from a land tax has led to concerns that it may cause wipe-out effects for property owners with mortgages, as their lands become worth less than the debts which they owe on them (Hagman, 1978).

Accurate predictions are made more difficult by many land value taxation plans advocating its adoption as a replacement for other methods of taxation, most commonly property taxes. In these cases a potential fall in land prices, caused by increasing the taxation of land, should be offset by a reduction/removal in the taxation of improvements, causing land rents and therefore land prices to increase (Gaffney, 1973). This makes it difficult to predict how land prices will be affected in such situations and further increases the difficulty of predicating changes land price that would result from introducing a land value tax.

There has however been some suggestion that a land value tax may actually increase land values, at least in some areas. Areas that see high demand for land, construction and intensification, such as central cities, would potentially see an increase in prices (Roakes, 1991; Wyatt, 1994) as the removal of the tax on property outweighed the increased tax on land (Grosskopf \& Johnson, 1982). Feldstein (1977) argues that the use of land as a low risk investment in investment portfolios would see land prices rise alongside the increased capital investment the tax hopes to stimulate, ${ }^{42}$ provided total savings levels also increased.

Evidence of how land value taxation affects land prices is contradictory. Hutchinson (1945) indicates that the tax caused land prices to fall in Australia but the study does not control for other variables that could influence land prices such as levels of government spending and services provided for an area. Edwards (1984), despite conducting a similar study, failed to find any significant effect on housing prices, increase or decrease. Harrisburg, Pennsylvania, on the other hand, had significant falls in its land values in the

41 Foldvary (2006) constructs a theoretical example that suggests a tax rate of $20 \%$ in order to collect $80 \%$ of land rent. He predicts this would lead to a price for taxed land that is one-fifth that of untaxed land.

42 As capital investment rises Feldstien (1977) argues that demand will also increase for land as investors attempt to balance out larger volumes of risker capital investment. This increase in demand will push land prices up. 
decade before they adopted land value taxation and significant rises afterwards (Rybeck, 1977).

Coleman and Grimes (2010) estimated that the implementation of a low rate (1 percent), but comprehensive, land value tax in New Zealand ${ }^{43}$ would cause an immediate fall in land prices of 16.7 percent while the New Zealand Treasury and Inland Revenue Department predicted a fall of 26.4 percent once other factors were accounted for (Inland Revenue Department \& New Zealand Treasury, 2009). While the departments agree with Netzer's 1966 analysis and do not think this would have a significant effect on buyers that purchase land after the introduction of the tax (the fall in land prices should be offset by increased future tax payments resulting in no change to the total cost of land ownership) they argue that the fall in land prices would constitute a lump sum tax on those that own land at the time of introduction. The potential fall in existing land values led to the departments, like Hagman (1978) earlier, raising concerns that it could force some home owners into a negative equity situation, which could also cause problems for lenders.

\subsubsection{Equity and the Tax Burden}

Despite George's assertion that land value taxes were the fairest of all taxes, equity issues surrounding them have still been raised. The disparate groups that support land value taxation, particularly at the single tax level, can make it difficult to clearly establish the equity implications of its use. Modern proponents often align, to varying degrees, with one of two different political ideologies: left wing or 'geo-libertarian', although there is some overlap between the two.

These two groups tend to have dramatically different views as to what constitutes equity in taxation. Geo-libertarians tend to follow George's thinking that land value taxes are

43 This was envisioned as a new, separate tax administered by central government rather than as a replacement for any existing property tax, which are generally operated by local governments. Additionally this was not conceived as a 'single tax' proposal and did not intend to replace any other taxes As such, any potential offsetting of price falls due to a decrease in property taxes, as predicted by Gaffney (1973), would not eventuate. 
among the fairest of all taxes as they do not penalise production ${ }^{44}$ and allow individuals to keep the total proceeds from their labour. They see land value taxation as an alternative to the taxation of productive activity, which could be used to replace or lessen existing taxes such as income tax, while any extra revenue required can be raised through user charges. This limits the role of government in people's lives while still providing the means for it to raise necessary revenue (Foldvary, 2006). Left wing proponents conversely see land value taxation as an overlooked method of effective wealth taxation that would primarily fall on the wealthy and taxes 'unearned' increases in land value which they see as rightfully belonging to the wider community (Gaffney, 1970). This results in reducing the tax burden on the poor and allows for greater redistribution. Some also contend that the tax will cause a fall in land prices which will make land ownership available to poorer individuals and families (Wyatt, 1994).

Whether the burden of land value taxation falls more heavily on the rich or the poor is debated. Gaffney (1972) argued that property taxation was progressive, using arguments equally applicable to land value taxation. Gaffney's primary argument is that land ownership is heavily concentrated in the hands of the wealthy, more so than income is. The wealthy own a greater value of land each, which granted them substantial additional benefits, while a significant portion of the population owns no land at all. This results in a tax that applies to a limited number of, primarily rich, individuals, lessening the burden on the poor and resulting in a progressive tax. This appears to have been the belief in Australia and New Zealand, where Woodruff and Ecker-Racz (1965) found that the primary reason for the adoption of land value taxation by local government was an expectation by the majority of ratepayers that they could shift their tax burden onto the wealthy few.

Additionally Gaffney argues land and property are an effective tax shelter. Gaffney identifies how farmland can be organised to generate tax deductions to offset tax payable on other income while generating little taxable income itself, but he notes that general property ownership can offer similar opportunities. While these methods are available to generally wealthy landowners, normal taxpayers do not have the same options, making the overall tax system more regressive. Taxation of land offsets these benefits, making

44 Advocates argue that that higher taxation of land values will move the burden from effective land users to unproductive land users (Foldvary, 2006). 
the system more progressive. Gaffney also argues that the reduction of interest rates caused by the tax ${ }^{45}$ will have a redistributive effect because interest rates generally have a heavier impact on the poor, while land taxes do not (Gaffney, 1973).

How applicable Gaffney's analysis is to the international land situation is debatable. Gaffney's analysis is United States focused, where he estimates that about half of the adult population are renters who do not their own homes, with brief mention of the $18^{\text {th }}$ century United Kingdom, where land ownership was concentrated in the hands of the aristocracy. In countries with levels of home and land ownership less concentrated among the rich, Gaffney's analysis may not hold, as the middle and lower classes fall more heavily within the tax base. Indeed international differences in land ownership patterns make it difficult to generalise any distributional effects of land value taxes across countries, states or cities (Franszen, 2009).

Land value taxation's use as an equitable wealth tax is hindered by it only taxing one component of wealth (Inland Revenue Department \& New Zealand Treasury, 2009). Unlike Gaffney, Plummer (2009) notes that land value tax would be progressive if land value as a percentage of wealth increased as wealth and incomes increased but instead land becomes a smaller portion of wealth as wealth increases, suggesting that land value taxes may be regressive. Coleman and McKerchar raise similar issues, describing the Australian land taxes (both historical and modern) as "inherently regressive" (2008, p. 292). Such concerns are long standing. Woodruff and Ecker-Racz (1965) describe the use of land value taxation in Australia as causing "economic distress [to be] suffered by a fairly large number of relatively poor people" (Woodruff \& Ecker-Racz, 1965, p. 51). They suggest the variety of exemptions and hardship provisions in the New Zealand and Australian land value taxes indicated that some vulnerable groups, particularly the elderly, were finding it difficult to retain their homes under the pure tax and were not in a position to purchase new ones, prompting legislative changes. Barrett and Veal (2012), quoting Plummer, raise similar equity concerns in their analysis of the New Zealand application of a modern land value tax. They note that the elderly, who often have fixed incomes while owning their homes, are the most likely to be negatively affected, while

\footnotetext{
$45 \quad$ See 3.3.1.4: Effects on Economic Growth.
} 
the middle class, particularly in Auckland, would likely be affected more than the wealthy.

Wyatt (1994) notes that under existing property tax regimes there tends to be a systematic undervaluation of land used for industrial or commercial proposes compared to residential land, resulting a higher relative tax burden on homeowners compared to businesses. Gaffney (1972) counters that such maladministration is the fault of administrators and can be fixed. Despite these assertions though Pennsylvania, the United States state where cities most frequently tax land values (commonly through a split rate system), ranks as one of the worst for assessment accuracy (Wyatt, 1994) suggesting that these valuation issues persist under land value tax systems, transferring the tax burden to homeowners.

In addition, much of the equity theory of land value taxation is based on the assumption that land speculation is socially undesirable and should be limited as much as possible (Roakes, 1991). This has been controversial with Walker (1971) suggesting that land speculators performed a desirable function by assuming the risks associated with delaying development and possibly preventing premature development of land. While it should be noted that the same effects can be achieved through government regulation and zoning, Walker (1971) challenges the view that land speculation is unhelpful and it would be fairer to increase the tax burden on poorly-utilised land, further confusing the equity situation.

Like most elements of land value taxation, studies into where the burden falls are mixed. Neuner, Popp, and Sebold (1974) determined that replacing the existing property tax in San Diego, California with a land value tax would move the burden from hotels, commercial, industrial and public land to residential, general business and agricultural land. Conversely Smith (1970) conducted a similar experiment for San Bernardino, California and found that the tax burden would decrease for family residential, commercial and industrial land uses. Despite their very different results both papers noted that among residential landowners the elderly were expected to face the greatest increase in the tax burden.

Such contradictory studies are a repeating occurrence. More recently England and Zhao (2005) examined the effect of replacing property taxation with land value taxation for Dover, New Hampshire. They found that the tax was likely regressive and would increase the tax burden on single family residential property. In contrast Bowman and Bell (2008) 
attempted to replicate England and Zhao's study in Roanoke, Virginia and found the opposite result. They conclude that a pure land value tax would reduce the aggregate tax burden for residential property and likely be more progressive than the existing property tax. Plummer (2010) conducted a similar analysis of properties in Tarrant County, Texas and found that land value taxation would shift the tax burden away from single family residential properties and on to other property classes.

Concerns have been raised about the liquidity effect, since land value tax is charged without relation to any cash flow (Oates \& Schwab, 1997; Inland Revenue Department $\&$ New Zealand Treasury, 2009). In situations where credit availability is constrained or land does not produce income (such as residential homes) some landowners may struggle to find available cash to make their annual tax payment and could force landowners to sell their holdings (Barrett \& Veal, 2012). Such concerns are long standing; Reeves (1911) briefly noted this was a possibility under the New Zealand land tax (though different terminology was used). The New Zealand Inland Revenue and Treasury (2009) noted that liquidity issues, like several negative elements of the tax, were most likely to affect the elderly. The extent of the effect is difficult to establish though; it should be limited when landowners have access to credit or personal reserves, and Bourassa's (1990) empirical study in Pennsylvania was unable to find any evidence of liquidity problems occurring.

\subsection{Previous Research Considering Land Taxation in New Zealand}

In 1909 William Downie Stewart published a pair of articles examining land regulation and ownership in New Zealand. Stewart noted that unlike North America, where much land would be too frozen or dry for much of the year to be useful, the majority of land in NZ was suitable for year round farming. This meant that the only practical "limit to the extent of country the farmer can stock is the limit of his purse" (Stewart, 1909a, p. 89) leading to potential land monopoly problems. In his evaluation of how effective the graduated land tax had been in mitigating these problems Stewart was unconvinced. Before 1907 the graduated tax seemed to have no discernible impact on ownership and was subject to significant avoidance. The State was aware that it lost at least $£ 19,000$ between 1905 and 1907 due to eight specific avoidance methods (Stewart, 1909b, p. 149). The tax did however provide a backstop to the Land for Settlement Act 1894, helping to 
ensure land was not overvalued to prevent government acquisition through the compulsory purchase rules. Stewart's work built on earlier, descriptive research into the New Zealand land tax system by LeRossignal and Stewart (1908) which could find limited benefits of the tax but wide popular support from the general public and politicians.

Shortly after Stewart, William Pember Reeves (1911), formerly a minister in the New Zealand Liberal government, ${ }^{46}$ published an overview of the use of land taxation in Australasia, considering the established land taxes in New Zealand and several Australian states ${ }^{47}$ and attempted to predict the effect of the then recently passed Australian Federal land tax. Reeves asserted that while the aim of any tax policy was to raise revenue, for many of the Australasian land taxes this was secondary; the primary concern was breaking up the large estates and encouraging subdivision of land. Unlike Stewart, Reeves's analysis was more technical and focused heavily on figures, including tax rates, revenue collected and land ownership statistics. From these Reeves concluded that while land value taxes tended to alarm large land owners they do not seem to be particularly burdensome or successful in encouraging wider land ownership and he did not expect the Australian Federal tax to be more effective. Reeves had earlier come to a similar conclusion in his 1903 book State Experiments in Australia and New Zealand where he commented that the seeming shrinkage of the great estates was mostly caused by other factors but "a share of the credit must be given to the land tax, comparatively small as that share is" (p. 264).

Reeves also, briefly, addresses potential concerns surrounding the valuation of unimproved land, saying that distinguishing between gross land value and unimproved land value had presented little difficulty and the he believed that assessed and recorded land values were not much below sales values. In contrast to his rest of the paper, Reeves offers no evidence for either of these points and does not acknowledge the widespread

\footnotetext{
46 William Pember Reeves served as a government minister until he left in 1896 to become the New Zealand Agent General in London. He was one of the Liberal government's most important ministers when the 1891 land tax was passed.

47 Specifically Victoria, New South Wales, South Australia, and Western Australia.
} 
evasion of the tax known to have been occurring in New Zealand at the time (Stewart, 1909a; 1909b; Goldsmith, 2008).

In 1949 Groves briefly covered the land taxes existing in Australia and New Zealand in his overview of the tax systems existing in both countries. His findings were not kind, describing these systems as "relatively moderate, not very productive of revenue, and probably not very effective in limiting the size of holdings" (Groves, 1949, p. 10), though the study was primarily descriptive with little analysis.

In 1965 Woodruff and Ecker-Racz studied the effects of land value and property taxation in New Zealand and Australia in an attempt to find lessons for a potential implementation in the United States. ${ }^{48}$ In it they drew parallels between the introduction of land taxation in Australia and New Zealand and the "trust busting" movement in the United States, which utilised similar rhetoric of defending the small and weak from abuses of the powerful (Woodruff \& Ecker-Racz, 1965). In contrast to LeRossignal and Stewart (1908) and Stewart's (1909a; 1909b) writings, Woodruff and Ecker-Racz conclude that historically the land tax's sharply progressive rates, which fell heavily on large landholders, did help break up large estates and worked as Georgist theory expected, though other economic and social factors were believed to also have influence. By the 1960s though, they found land value taxation was seldom a significant factor in business decisions and had minor social and economic impact.

To establish the influence of the land value tax on urban development, the authors conducted a visual survey and comparison of properties existing under land value and property based tax systems. They found no indication that land use was affected differently by the use of land value taxation compared to property taxation (Woodruff $\&$ Ecker-Racz, 1965). However, it was noted that the use of land value taxation seemed to have resulted in a higher quality of property valuations than was found in the United States.

While attempting to explain the lack of any effect caused by land value taxation, Woodruff and Ecker-Racz (1965) considered two likely possibilities: the tax rates and the

\footnotetext{
48 The study was sponsored by the Lincoln Foundation, an American think tank set up to promote Georgism and land value taxation. To this day it remains a major source of published research into the topic.
} 
introduction of tax exemptions. The authors argued that the land tax rates in New Zealand and Australia were too low $^{49}$ to influence behaviour in almost all cases, an argument supported by conversations they had had with real estate agents, planners and bankers. The other factor they saw limiting the potential effectiveness of the land value taxes was the variety of tax exemptions offered by both countries, particularly those for agricultural land and certain types of homeowners. These exemptions reduced the negative equity issues arising from the tax but limited the ability of the tax to influence behaviour. Overall Woodruff and Ecker-Racz (1965) argued that the land value tax could have had much more of the economic impact predicted by George but the social impacts were politically intolerable, leading to it being blunted.

Finally Woodruff and Ecker-Racz (1965) noted views among New Zealand and Australian tax experts who felt that the land taxes would be more successful and constructive if they also taxed improvements to land. While the authors pass no judgment on these views, they are the opposite of what theory surrounding land value taxation would suggest.

There have been, later, empirical studies of land value taxation in New Zealand. Roakes (1991) conducted studies of the influence of the land value taxation on property development in Auckland and Wellington from 1970 to 1987. New Zealand was chosen due to its position in Woodruff and Ecker-Racz's 1965 work and the presence of both land and property taxation. Auckland and Wellington were chosen due to the different methods of valuation used by the local councils for rating purposes; over the examined period Auckland rates were primarily based on property values while Wellington's were based on land values. Auckland and Wellington were also the only two cities in New Zealand where there was a significant volume of land valuable enough for the national land tax to be a significant expense.

The results found that while Wellington was more intensely developed than Auckland, as land value tax theory would suggest, this could not be linked to the taxation of land rather than property values, with Wellington's limited usable land seeming a more likely cause. Overall the national land tax was found to have no effect on developments in either city

49 They calculated that the average rates were equivalent to $0.5 \%-1 \%$ of the improved capital value of residences, well below the tax rates in most of the United States. 
and there was no difference between the cities that could be linked to the chosen ratings base, similar to the findings of Woodruff and Ecker-Racz (1965). This suggested that land value taxation was economically neutral (Netzer, 2001; Ryan, 2002) but also indicated that many of the expected benefits of the tax, such as encouraging land development, did not arise (Roakes, 1991). The researchers do note however that the cities' physical differences, the low tax levels and the long assessment cycles may limit the wider application of their results.

Reece (1993) examined the reason for the abolition of the New Zealand land tax. He considered the likelihood of five potential reasons:

1. The tax was unpopular with taxpayer lobby groups;

2. The tax was unpopular with reformist politicians in the government who found it did not fit with their "level playing field doctrine";

3. The Treasury was unhappy with the existing incomplete tax base and preferred abolition to continuation;

4. Local government wanted abolition so it could expand its own taxation to fill the created void;

5. The New Zealand economy no longer needed the tax.

Of these factors, Reece (1993) considers the argument that the abolition was caused by taxpayer lobby groups to be unconvincing, despite one willing to claim credit. ${ }^{50}$ However, a lack of evidence makes it difficult to establish if the abolition was electorally significant for the government. The desires of local government as the reason for abolition are also seen as unconvincing as that would require central government politicians and bureaucrats to have consideration for local government in the absence of any central government benefit. Reece finds more evidence that the New Zealand economy may have no longer needed the land tax based on government tax reviews recommending abolition from 1967 onwards. Of the final two reasons he finds Treasury distaste to be unlikely, as Treasury's concerns with the tax were addressed in the 1989 reforms, while there is some evidence, though not conclusive, supporting that reformist politicians within the government drove abolition as they saw the land tax as giving rise to distortions and unfairness. Reece also examines the suggestion that either the treasury or the Minister's

50 The Real Estate Institute of New Zealand claimed that its lobbying had led to the abolition. 
office may have advocated abolition as an attempt to show deficiencies in New Zealand's taxation of capital gains in an attempt to strengthen future capital gains tax reform. He notes though the argument requires "an almost Machiavellian twist for its plausibility" (p. 240) and that he could find no evidence to support it in public documents.

Overall, Reece (1993) concludes that the abolition was caused by a combination of the identified factors, though it is difficult to establish their relative importance, high inflation and New Zealand's atypical capital gains rules. As such he believes the New Zealand situation is unlikely to be applicable to land value taxation in other countries.

Over the course of his analysis Reece (1993) also notes three key elements of the New Zealand land tax regime from before abolition. First, that rapidly increasing property values from the 1960s onwards lead to taxpayers being 'caught' above the static exemption level, leading to tax bracket creep and new exemptions being added to the tax base (particularly for primary residences and agricultural land). Second, New Zealand's lack of a capital gains tax meant that the land tax was bringing otherwise untaxed income, which most jurisdictions would tax, within the tax base. Finally in 1989 the government lowered the rate of land tax but abolished the majority of the exemptions greatly expanding the base with the intention of increasing the revenue the tax collected, possibly intending to rehabilitate to tax for continued future use. Any such plans were halted with the tax's abolition.

More recent work has considered the desirability of reintroducing land tax to New Zealand. Written after New Zealand's Tax Working Group proposed the introduction of a new land tax, rather than a capital gains tax, Barrett and Veal's (2012) primary focus is, unlike most New Zealand land tax research, on the practicalities of introducing a new land tax and how desirable it would be to do so. ${ }^{51}$ To this end, Barrett and Veal (2012) apply Adam Smith's four maxims, in addition to considering the effects on investment and urban planning and political plausibility, to the Coleman-Grimes model adopted by the Tax Working Group. ${ }^{52}$ Barrett and Veal (2012) conclude that such a tax would be

51 The paper also briefly considers both New Zealand's historical land tax and the theory behind it, noting the problematic exemptions in the original and arguing that they undermined its usefulness before abolition.

52 From Coleman and Grimes (2010). This is a land tax with a low flat rate based solely on land value and no exemptions. 
efficient, convenient and sufficiently certain (with good assessor practices, training and standards having the potential to limit the risk of inaccurate valuation). The equity issue is less clear. The authors note George's arguments on the issue and that the tax falls entirely on landowners. However, the expected effect on the elderly and Māori, ${ }^{53}$ and the fact that land generally becomes a smaller portion of wealth as wealth increases are noted as problems.

When considering the political plausibility of introducing a land tax to New Zealand, Barrett and Veal (2012) expect that a land tax would be unpopular with the middle classes and would likely have many political modifications made before passing which would limit its usefulness. The authors speculate that such resistance could be allayed through dramatic changes to the tax system, replacing the comprehensive income base with a land value base, and phasing the changes in over time, though arrangements would likely need to be made for the poor and elderly. Barrett and Veal (2012) conclude that land taxation may be useful as an alternative tax base to income tax, but would not be a good substitute for introducing capital gains taxation.

Similar issues are considered by Gupta (2016) and Mangioni (2018). Gupta (2016) concluded that a land tax could be implanted by the New Zealand government but likely not in an efficient or equitable manner and would be vulnerable to political interference. Mangioni (2018) concluded that a new New Zealand land tax would need regular revaluations and few exemptions to be effective and accurate valuations may be complicated. However, he suggests it could provide a useful revenue source and its introduction should be considered.

53 Barrett \& Veal (2012) note that Māori owned land is often underdeveloped compared to general land, even after accounting for land quality and location, so Māori would bear a higher tax burden relative to their wealth than most of the population. Since George conceived his land value taxation plan partly in an attempt to prevent indigenous people being driven from their lands, the authors consider the possibility that a modern version of the tax could drive Māori from their land "politically unimaginable". There is historical precedent for these concerns; Hooper and Kearins (2008) note that during the Liberal era many taxes fell disproportionally on Māori. Their analysis does not mention the national land tax but local rates, which also used land as a tax base, are singled out. 


\subsection{Historical Taxation Research}

\subsubsection{Historical Land Tax Research}

Historical studies of land taxation also exist. Heaton (1925), in a primarily descriptive work, studied both the Australian federal and state level land taxes from South Australia's 1884 implementation until the early 1920s. The work was principally narrative, concerned with the reasons why land value taxation was implemented in Australia. Heaton (1925) draws from legislation and government reports as the primary base for his analysis, supplemented by court cases where relevant.

Heaton (1925) identified the reasons for adoption as a need for revenue, "tapping the unearned increment" (p. 410) and breaking up the large estates. Despite this Heaton (1925) notes that there were no spectacular results, with only limited land redistribution occurring in the period where Australian land taxes were at their highest (Bird, 1960). Absentee landholders did reduce their holdings by about half over the same period, but Heaton (1925) notes their holdings were considerably less significant than had been claimed. Unlike much of the modern research into land value taxation, Heaton (1925) also noted the problems with operating a land value tax, particularly valuation and fight back from landed interests who fought the Federal government through the Australian courts over several issues, ranging from the Federal Parliament's authority to levy the tax at all to land valuations.

In 1960, as academic interest in land tax was reawakening, Bird (1960) produced a historical paper focusing solely on Australia's progressive federal land tax, which was abolished in 1952. Bird (1960), like Heaton (1925), also covered the reasons for the tax's introduction, noting that Georgist theory did have some influence but stressing that the primary factors were indigenous, specifically aims to break up the large estates and to encourage more widespread ownership of land. The work was more focused on the operation and eventual decline of the tax however. Like Heaton (1925), Bird's (1960) work is a primarily narrative study and draws on the same sources, mainly legislation and government reports, but the topic's focus on the tax's operation results in a much heavier use of court cases. Bird (1960) charts how the progressive nature of the tax lead to problems as authorities tried to make it both easy to collect and difficult to avoid. This led to the creation of a very technical and complex tax law that was then subject to significant volumes of long and costly litigation. Like Heaton (1925), Bird (1960) mentions the problems that arose from land valuation, which worsened the legal disputes, 
particularly since the Federal government lacked its own land valuation department, unlike New South Wales or New Zealand.

Unlike many studies, Bird (1960) did not make significant attempts to evaluate the effectiveness of the tax, stating that the regular alterations to both the rates and exemption levels made any such assessment difficult.

Beckett (1985) studied the use of a land tax ${ }^{54}$ in $17^{\text {th }}$ and $18^{\text {th }}$ century England, particularly the debate surrounding whether land taxes or excise taxes would be a better method of funding the country's heavy expenses. Beckett (1985) compares both the land tax and excise taxes, either proposed or in effect during the period, considering their revenue potential, administrative practicality and political opposition. Beckett's (1985) analysis draws on a range of sources, from then recently published histories to relevant books, essays and pamphlets published during the seventeenth century, parliamentary records and the personal records of involved politicians. Overall Beckett (1985) concludes that heavier use of excise taxes would have been preferred by the government but was politically unacceptable, causing them to fall back on the land tax despite its lesser revenue potential.

While not a true land value tax, Beckett's (1985) analysis highlights that the policy faced many similar problems. These included the tax raising limited revenue and having valuation problems, both in obtaining correct assessments and those assessments then not being regularly updated, which further limited the revenue raised. Equity issues were also raised. Concerns were raised that the burden would fall too heavily on those in the more remote parts of the country who predominantly invested in land as they could not invest in other assets. These concerns were further compounded by different parts of England being taxed at different rates. Equity issues were also noted from the opposite perspective. Since 1643 a line of thought had arisen that since the poor had rights that were also protected by the state, they should help pay for its upkeep. Land taxes in this period did not fall on the poor, who could not afford to own land. Beckett suggests this may have been one factor as to why they were seen as unfavourable compared to excise duties.

\footnotetext{
54 The land tax used in this period was not a land value tax as defined under Georgist theory. It was charged based on the actual rental values of land but could be affected by factors such as land improvements and productivity. It also taxed goods in some circumstances.
} 
Dwyer's 1980 thesis, A History of the Theory of Land Value Taxation, and his 2014 work, Taxation: A Lost History, provide a comprehensive history of the theory and debates surrounding the use of land value taxation. Over the course of both works Dwyer covers the development of rent and land value taxation theory from the work of John Locke until the present day, in addition to covering and contributing to the arguments surrounding the efficiency and equity of the tax. Dwyer supplements the general history of land value taxation theory with analysis and historical documents considering the use of land value taxation in Australia and, to a lesser extent, New Zealand, focusing on the taxes' revenue potential and administrative practicality.

McCluskey and Franzen's 2001 work for the Lincoln Institute of Land Policy adopted a case study approach to reviewing the effectiveness of land value taxation. The research uses case studies of five countries; South Africa, Kenya, Australia, New Zealand and Jamaica, to review how land value taxes are utilised at a local government level and to establish trends and arising issues. The work is not entirely historical, considering the past, present and potential future uses of land value taxes in the jurisdictions. The study provides an overview of each country's use of land value taxation, with the breadth of the project limiting the ability to cover the more intricate details of each system. Due to the scope of the topic, much of the historical information comes from more recent secondary sources, unlike many other works covered in this section, though the relevant tax legislation and government reports (both historical and modern) are also used.

Based on New Zealand, and to a lesser extent Australian, developments McCluskey and Franzen (2001) argue that countries seem to shift away from the use of land value taxes and towards the adoption of property taxes as they become more developed. ${ }^{55}$ However, they note that the primary reason for the change seems to be practicality and political considerations, rather than deficiencies with the land tax system. They note particular practical difficulties as being the issues surrounding valuations and the complexities of statutory definitions and legal precedents that often arise. Despite this trend of movement away from the use of land value taxation as countries develop, McCluskey and Franzen

55 Local governments in New Zealand have been moving away from using land value taxation since the 1980s. This pattern was still continuing 10 years after McCluskey and Franzen's study was published with the 2010 amalgamation of the Auckland region's councils expanding the use of property taxation to much of the region who had previously based their taxes on land values. 
(2001) argue that land value taxation operated mostly successfully in the jurisdictions they covered. Those issues that did arise, particularly administrative problems in Jamaica and Kenya, were problems associated with taxation and governance structures of those countries rather than inherent problems with land value taxes.

McLean and Nou (2006) also studied the taxation of land values in a British context, considering the failure of attempts to implement land value taxation from $1909-1914$. In an analytic narrative study drawing upon both primary archival research and secondary literature, McLean and Nou (2006) analysed the attempts of the Liberal government to implement land value taxation, as part of a group of measures to raise more government revenue, ${ }^{56}$ and why they failed. McLean and Nou's (2006) study is more politically focused than other work surrounding land value taxation; its primary concern is why the policy failed rather than what the policy itself was.

McLean and Nou (2006) put forward two, not mutually exclusive, explanations for the failure of land value taxes in Britain. The first focuses on individual missteps by Liberal Chancellor of the Exchequer, and the driver of land value taxation adoption, David Lloyd George and the impracticality of land value taxes. Essentially David Lloyd George and his advisors were unable to explain how they would actually value land reliably for tax purposes, a problem worsened by the Chancellor's tendency to make radical promises on the hoof, carelessness of policy details and tendency to alienate officials that could have helped (McLean \& Nou, 2006). McLean and Nou (2006) argue that while "incompetence and impracticality" (p. 586) clearly played a part, they are insufficient to explain the lack of adoption on their own. This leads to their second explanation; the power of landed interests. Though previous laws that had threatened the material interest of landowners had passed, ${ }^{57}$ the group's increased veto power allowed them to prevent the passage and adoption of land value taxation in Britain.

The broadest historical study of the use of land taxes in Australia is by Coleman and McKerchar (2008). In an analytic narrative history, the authors trace the development and

\footnotetext{
56 These measures included increased alcohol and death duties, a progressive income tax and land value taxation, of which land value taxation was the smallest.

57 McLean and Nou note previous cases were the British Parliament had passed legislation against landed interests, such as the Irish Land Acts of 1870, 1881 and 1903, making the land value taxation rejection from 1909-1914 unusual.
} 
use of land taxation in Australia at both state and federal level from first settlement in 1788. The work is supplemented by the consideration and analysis of common features and issues arising under various historical land taxes and the identification of issues present in contemporary Australian land taxes. Coleman and McKerchar's (2008) work considers a longer time period than other studies but, like McCluskey and Franzsen (2001), the breadth of the study limits the potential for more detailed analysis of the referred to land tax policies.

Coleman and McKerchar's (2008) analysis of issues historically arising from land taxes argues that the tax proved ineffective at breaking up the large estates in Australia, so policy issues that arose were primarily related to its ability to raise revenue. They suggest that common policy concerns focused on who the tax burden fell upon, the allowed exemptions, a lack of harmonisation between states and central government and administrative difficulties and costs surrounding land valuation. In addition fluctuations in land values made the tax base unstable. Modern issues relate to the difficulties identifying property subject to tax, ascertaining taxpayer liability and continued high administrative costs for assessment and collection.

Overall Coleman and McKerchar (2008) conclude, that despite its issues and failure to break up the large estates, the use of land value taxation in Australia does not appear to be under threat as it forms an important component of states' limited capacity to raise revenue.

Similar to McLean and Nou (2006), Dilley (2013) also focuses on the historical politics surrounding land value taxation, though his focus is the 1910 Australian Federal land tax that was introduced by the Australian Labor Party. Dilley's (2013) work is a detailed analytic narrative history. Much like the earlier works of Heaton (1925), Bird (1960) and Coleman and McKerchar (2008), Dilley (2013) considers why Australia adopted the Federal land tax and what were the international influences on the policy. While previous work has considered international influences on the Australian policy, these are generally limited to Henry George, and occasionally classical British economists, and the level of their influence tends to be viewed as minimal. Dilley (2013) expands this focus to consider how connections within the international labour movement and the New Zealand experience with national land value taxation shaped the Australian policy. 
Dilley's (2013) work concentrates on the development of the Federal land tax policy within the Australian labour movement. This results in a more individualist narrative than focusing on implementation at a national level, as per Heaton (1925) and Stewart (1909a; 1909b). Instead Dilley (2013) showcases divisions within the Australian land reform movement, such as the appropriate land value tax model, or whether alternative policies (like land nationalisation) would be better. The downside of this narrowed focus is that it limits consideration of the influence of groups unconnected to the Australian labour movement. This narrower, but more detailed, focus has seen Dilley (2013) use of a wider range of sources than many other historical studies of land value taxation. While parliamentary debates and tax legislation are still used, the research also uses range of media sources from the relevant period (including newspaper reports, letters to the editor, and editorials) and records from early Labor Party conferences. This results in a more detailed description and analysis of the debate surrounding the adoption of land value taxation than has generally appeared in previous studies.

Dilley (2013) concludes that, while the Australian labour movement's desire to implement a land value tax policy did originally stem from British influence and Georgist theory, policy development was influenced much more by the New Zealand experience and developments in land value taxation. He observes that by November 1893, conflict had arisen within the Australian labour movement between single tax Georgists and proponents of the New Zealand model. By 1897 the tax's original Georgist design had been supplanted in Federal Labor Party policy by the New Zealand model, which remained dominant thereafter, despite attempts in 1898 and 1902 to restore Georgist purity. By 1905 the Labor Party's policy platform incorporated the details and principles of the New Zealand legislation and the 1910 Act was closely modelled on the New Zealand legislation. Dilley (2013) also notes the failure of British financial interests to disrupt the policy arguing that this arose due to a booming Australian economy, the globalisation of debt and the ability to look at New Zealand to establish if threats to withdraw capital had eventuated there. Despite failure in 1910, Dilley (2013) notes that those interests did have significant influence in Australian politics in less benign circumstances. 


\subsubsection{Other Relevant Historical Research}

While not strictly a study into land value taxation, Bonaparte's 1987 study is also worth mentioning. The study examines the acceptance of Henry George's theory of land value taxation and its influence across the world and through time, using Marxism as a comparison in an attempt to understand why the former does not have the influence of the latter. Bonaparte (1987) notes that, while Georgism developed a strong following in the English speaking world, it had much less support elsewhere and resulted in very few policy adoptions even in countries where it had many supporters. Bonaparte (1987) attributes this to a combination of Georgist supporters not engaging in politics and technical difficulties in attempting to implement the tax system in developing countries.

Jinno and DeWit's (1998) study into the Japanese property tax revolt of the 1990s also raises issues of interest when considering land value taxation. The Japanese property tax regime, as it existed at the time, consisted of a range of levies, the most important of which were a fixed assets tax, administered by the Ministry of Home Affairs, and a much smaller land value tax, administered by the Ministry of Finance. ${ }^{58}$ Jinno and DeWit (1998) recount that when faced with high levels of land speculation and rapidly rising land prices, property tax reform was considered as a solution. Problems arose from this when the Ministry of Finance, arguably more focused on securing itself access to an increased tax base than land price control, argued for increased use of land value taxation (which it controlled) to solve the problem. This lead to significant conflict with the Ministry of Home Affairs, which stood to lose considerable revenue from change. Jinno and DeWit (1998) argue that this conflict and its politicisation of the tax system led to the tax revolt, forcing both ministries to decrease their relevant taxes and leading to no improvement in land speculation levels.

These conflicts between different parts of government over implementing a land value tax are seldom considered in other research. While land value taxes are often proposed as national taxes, existing taxes on land are usually found at local levels. This can lead to competition between the different levels of government for control of land as a tax base. There is precedent for this as several Australian states unsuccessfully sued the Federal

58 In the Japanese context the Ministry of Home Affairs levies taxes at subnational levels (comparable to state and local level elsewhere) while the Ministry of Finance collects national level taxes. This results in conflict between the two ministries. 
Government to prevent the land tax being collected in their states shortly after its 1910 implementation (Bird, 1960).

Also relevant is Mares and Queralt's (2015) paper The Conservative Origin of Income Taxation. While the paper is focused on the history of income tax adoption and the reasons why countries adopted it, it also highlights the influence of powerful groups, particularly landowners, in deciding national tax policies. The paper's key finding is that countries with higher levels of landholding inequality adopted income taxes more quickly, suggesting the motivation for adopting income taxes was not to make taxation more progressive. Mares and Queralt (2015) argue that this is the result of the landed elite trying to minimise their own tax bills while moving the burden on to other classes, notably the emerging mercantile middle classes who they saw as a threat. This mirrors the British situation documented by McLean and Nou (2006) where the House of Lords would accept a progressive income tax but not a smaller land value tax. Their conclusions highlight the struggle land value tax proponents historically faced trying to implement their ideas and adds credence to the writings of modern proponents, such as Gaffney (1973) and Netzer (1984), who have suggested that the idea's lack of use and acceptance has social and political roots due to land owners marginalising an idea that is against their best interests.

\subsubsection{Historical New Zealand Tax Research}

New Zealand histories tend to focus on social changes at the expense of economic history (Easton, 2007); as such significant works on the history of taxation in the country are rare. Popular New Zealand general histories, such as those by Belich (1996, 2001), King (2003) and Sinclair (1991), seldom refer to taxation, generally doing so only when it is politically significant. Goldsmith's 2008 political history of New Zealand taxation provides a general overview of the types of taxation utilised in New Zealand and how these grew over time. His work provides a descriptive general history, however, both its scope and its intended popular audience limit its potential for in-depth analysis.

Academic historical New Zealand tax literature has been likewise limited but has seen developments recently. Most relevant to this study, due to the work covering a similar time period and its equity considerations, Vosslamber (2010) conducted analysis into the vertical equity of income tax paid by employees in New Zealand from 1891 to 1984 and how this compared with the rhetoric used to justify the tax. The study models the effect 
of the income tax laws on nine theoretical taxpayers based on income level (high, medium or low) and domestic situation (unmarried, married or married with no children) to illustrate the vertical equity of the New Zealand income tax and these results are then compared to the political rhetoric on the subject. Vosslamber's (2010) work adopts an inductive approach that follows Michael Stanford's (1986) model of history, which sees it as a combination of the seen and the unseen. ${ }^{59}$ The work's primary sources are government publications, legislation, New Zealand Parliamentary Debates and court cases.

In a similar vein Littlewood (2012) produced a history of the use of death and gift duties in New Zealand. Littlewood's (2012) study is more narrative than Vosslamber's (2010) work, focusing on how gift and death duties in New Zealand developed over time and the relevant political influences. Again the work bases its analysis heavily on historical legislation, New Zealand Parliamentary Debates and relevant court cases.

There have been a variety of other New Zealand based historical tax research that is less relevant to the context of this study. These works range from Vosslamber's other studies, focusing on the Black Budget of 1958 (2012a), the introduction of New Zealand's progressive income tax (2012b) and the influence of Friedrich Hayek on New Zealand's tax depreciation policy (2014), to Hooper and Kearins's work $(2003 ; 2008)$ which took a different approach to other research and instead considered historical taxation from the perspective of Māori and how its use was linked to Māori disenfranchisement.

\subsection{Summary}

Land tax is an old idea but it has historically been seen poorly by academics, which limited research into it. Since the 1960s there has been more serious analysis but land taxation remains a niche topic of research. As such land tax research is less comprehensive than can be found for other taxes and there is limited agreement as to how

\footnotetext{
59 The Stanford model sees history as unobservable past events which leave behind evidence. This seen evidence then shapes historians interpretations and forms the basis of an unseen construction of events in the historian's mind. This construction may then become a historical communication, such as an article or a report. These communications trigger an unseen response in the public mind which may lead to actions being taken. These actions may become historical events, beginning the process again.
} 
land taxation works, or should work, and what its effects would be. There is some historical research into the land taxation considering implementation and operation but seldom does a single study do a detailed analysis of both.

Research into historical taxation in a New Zealand context is similarly niche but the field has grown in recent years. 


\section{Chapter 4: Methodology}

This research is an interpretive historical narrative that studies the land value taxation in New Zealand from 1891-1991. This chapter presents this methodology in more detail, the data sources used for the research and the periodisation approach adopted to deal with the long time period studied.

\subsection{Historical Research}

The influences on the development of tax policy are many and varied making it difficult to study in the context of a single historical field. To better examine land tax development this research contains elements of political, social and economic history. Political history investigates the tax policies adopted by politicians in New Zealand while social and economic history consider the various factors that influenced those policies and the context in which they arose.

Views as to what historical study is vary between historians. Carr describes it as "the study of causes" (1961, p. 94) while Tosh suggests that it is a process that aims to sustain the widest definition of memory as accurately as possible (2010, p. 2). For its part, this study mostly reflects Stanford's (1986) approach to history. Stanford's model of history sees it as the interaction of unseen historical events and seen history as a story. It proposes that while past events themselves are not observable, they leave behind a variety of observable evidence. This evidence then shapes historians interpretations and forms the basis of an unseen construction of events in the historian's mind. The historian may then develop this construction so that it becomes a seen historical communication, such as a thesis, article or report. These communications trigger an unseen response in the public mind, though not necessarily the response the historian predicted or intended. Finally the response in the public mind may lead to actions being taken. At this point the process becomes open ended; actions taken may become studied historical events themselves leading the sequence to begin again. The model focuses heavily on relationship evidence and interpretation, noting that, while interpretation is based on evidence, the conclusions drawn extend beyond it. Conclusions are not simple restatements of historical evidence but rather the product of a variety of influences on the historian (Stanford, 1986, p. 6).

When studying history it is important to justify why it should be examined. In a popular context history can be seen as pointless, a view exemplified by Henry Ford's often quoted 
comments that "History is more or less bunk" and "[history] means nothing to me", ${ }^{60}$ but researchers find it hard to dispute its usefulness (Kerkhoff, 2011, p. 118). Key among these uses is the ability of history to "see through political and administrative fads and fashions of the day and enable[s] us to get a perspective on more fundamental differences and similarities between present and obsolete structures, operations and policies" (Raadschelders, 2000, p. 13). In the context of evaluating modern practices this has dual benefits. First historical studies can show how issues were dealt with in the past, revealing what Tosh (2010, p. 34) calls "an inventory of alternatives". These alternatives, some of which may otherwise have been ignored, give modern decision makers more potential choices to deal with issues. Secondly, in attempting to explain how modern thoughts and practices arose, historical study can challenge the assumptions that underpin them, potentially overturning them if they are based on fallacies (Parker, 1997, p. 112; Tosh, 2010, p. 42), and offering indications as to precedents, influences and outcomes for contemporary issues (Previts, Parker, \& Coffman, 1990, p. 5). As Raadschelders notes, our perceptions of reality are "bound by both time and place" (Raadschelders, 2000, p. 13). Historical study allows for the breaking of both these constraints and permits researchers to see ideas in a new context. This is particularly useful in the context of policy focused research such as this as it helps inform the best potential means of solving modern political problems and allows ideas to be examined from a wider variety of perspectives in order to ascertain their potential effects.

Some historians see the study of historical events as being a useful predictive tool, a view often exemplified by George Santayana's famous quote "those who cannot remember the past are condemned to repeat it" (1905, p. 284). While the practice of viewing history as a highly cylindrical process where events constantly repeat over time and basing predictions on such repetition has generally been discredited (Tosh, 2010, p. 38), sequential predictions, based on the expectation that certain facts will repeat themselves and people will not reinvent what already exists, can be useful (Tosh, 2010, p. 41). Rather than focusing on historical changes, sequential predictions are based on identifying the influences that lead to those changes. From there historians can ascertain whether the same influences are present in a modern context and, if so, attempt to predict whether modern events are likely to follow a similar pattern. Such a process is not foolproof and

60 Chicago Tribune, 25 May 1916, page 10. 
even in situations where all influences are present it may be a long time before predicted events transpire, if at all (Tosh, 2010, p. 41).

This predicative ability may be more useful in the context of studying taxation policy than it would be examining other historical topics. Avi-Yonah (2003, p. 2234) suggests that the evolution of tax law follows a cylindrical path rather than a linear progression, with old policies regularly resurrected at later point. This means that the results of historical taxation research are more likely to have a practical, present-day application than in other fields.

Steinmo (2008) highlights additional benefits of historical study from an institutionalist perspective, arguing that it leads to a better understanding of events and agent behaviour. Steinmo sees history as a series of interconnected, rather than independent, events and to properly understand present decisions and why they are being made, past events and historical context must be considered. To this end Steinmo notes that agents can learn from historical events and alter their actions and expectations accordingly as they adapt to changes in their environment (2008, p. 127). This means choices that are made in the past can have a significant impact on future choices. Agents adapting there behaviour based on past events is particularly relevant when considering politically charged topics such as tax policy as fear of repeating actions that previously resulted in significant loss of political support can have a significant influence on politician's actions. In an example particularly relevant to this study, Littlewood (2012, p. 94) argued the generally very cautious changes to tax policy of New Zealand's Third Labour Government stemmed from fears of repeating the electoral fallout similar to that which resulted from radical tax changes in the Second Labour Government's 1958 budget.

Stanford's model and its focus on interpretation highlights one of the greatest difficulties in historical research however, attempting to arrive at "an objective knowledge of the past ... through the subjective experience of the researcher" (Stanford, 1986, p. 27). With any historical research the selection of data and the interpretation of evidence are influenced by the subjectivity of the researcher, who makes a series of value judgements influenced by their views (Tosh, 2010, p. 190). The differing values can lead to historians having different judgments as to what is defined as important (Zinn, 1991). To highlight this, Tosh (2010, p. 190) considers the case of social relations in pre-industrial England; liberal 
and conservative historians usually view these as reciprocal while historians of a more radical bent tend to view them as exploitive.

The potential of historians to influence their findings has long been recognised, giving rise to one of the most common criticisms of historical research; the inability to present a truly unbiased narrative. While historians often aim to present history in a neutral manner (Tosh, 2010), others have queried whether such a presentation of history, and even the facts underpinning it, is possible (Merino, 1998, p. 604). Historian Howard Zinn argued that there was no such thing as objective history but the problem was the omission or emphasis of data (Zinn, 1991). Zinn stressed that this bias was not necessarily deliberate but could occur either consciously or subconsciously. Conversely it has been suggested that objectivity in history means attempting to portray events as they really were rather than adopting a strict positivist interpretation (Parker, 1997, p. 134). This implies an attempt by historians to limit their biases to produce representative works.

A biased history that aligns with a particular view is not necessarily bad, and can still be informative but these biases should be acknowledged and recognised rather than ignored (Tosh, 2010, p. 189).

In the interests of transparency my biases should be noted. I am generally sympathetic to the principle aims of land taxation. I believe that housing should be affordable for people and government should intervene when it is not. Similarly I am supportive of progressive taxation and think the wealthy should pay heavier tax than the poor. These beliefs may influence how I view conflicting evidence. My views are also shaped by the time period and culture in which I live. This will influence how I view aspects of land tax policy debate, particularly those where modern values differ significantly from those of the examined periods, such as on issues of race. While history should not be judged by modern values (Tosh, 2010, p. 192) the differences can be jarring.

\subsection{Research Method}

This thesis consists of qualitative research. Qualitative research is designed to study phenomenon where people are participants and is therefore most popularly used in the social sciences. It investigates why and how decisions were made in an attempt to gain a deeper understanding of experiences and "present authentic interpretations that are sensitive to specific social historical contexts" (Neuman, 2004, p. 85). However, this has 
resulted in qualitative research being criticised as producing results that can only apply to the cases studied and difficult to generalise to a wider context.

This study examines the development of New Zealand's tax policy over a century. Land tax itself was heavily politicised and influences on its development were varied, including ideas, actors' power and preceding events. In some cases rhetoric, and what actors believed the land tax did, were more important to policy development than actual results. This resulted in a situation where a variety of policy influences coexist, with varying levels of influence. This is a topic well suited to qualitative research. Many of land tax's influences, such as ideas, are difficult to meaningfully quantify, limiting the potential to use quantitative research to examine land tax development. However, a qualitative study allows consideration a wider range of these influences, and how they interact with each other. This allows a better understanding of land tax development over a century to be reached.

\subsection{Narrative Method}

This thesis adopts a narrative approach to history. Narrative history is the historian's basic technique for "conveying what it felt like to observe or participate in past events" (Tosh, 2010, p. 150). The narrative method has been accepted as the natural means of writing history (Funnell, 1998). The method, stylised after the research methods used in the natural sciences (Previts, Parker, \& Coffman, 1990), takes an idea, individual or event, follows it over a period of time and then relates it to readers in a style not dissimilar to a story. This retelling tends to be a description of relevant actions and events that occurred, focusing on facts with little to no deeper analysis. This heavily fact-based focus means that narrative history does not require a theoretical framework. Notwithstanding this tendency of narrative history, this thesis is more complex than a simple retelling of historical events.

Despite the prevalence of narrative method in historical research, its lack of deeper analysis can lead to problems. The focus on placing events in their correct chronological order can convey a misleading appearance of historical causation (Tosh, 2010, p. 155). Additionally narrative recollections tend to be simplifications of history, struggling to maintain more than two or three narrative threads (Tosh, 2010, p. 155). This simplification tends to result in some causes or outcomes being ignored. Such omissions 
leads to accusations that narrative history has the ability to reinforce particular perspectives, based on the sources it uses. White argues that "for any given subject there are many true histories" (1965, p. 227), noting how points of view can alter the historical narrative while the substance remains correct. Narrative histories however can enshrine particular views while excluding and denying others (Funnell, 1998, p. 144) based on the narrative threads they focus on. Considering a wider variety of sources can help mitigate these problems.

\subsection{Interpretative Method}

In addition to the narrative approach this thesis also adopts an interpretive approach. Interpretative history seeks to solve the key problem of narrative history; the lack of deeper analysis. Rather than focusing strictly on the story of history, this method seeks to "evaluate relationships and provide interpretations in the manner of a social science", explaining historical events and actions rather than merely describing them (Previts, Parker, \& Coffman, 1990, p. 2). However, purely interpretative history has a tendency to forgo historical immediacy and can result in analytical explanations that are unworkable in light of the flux of events (Tosh, 2010, p. 157). In practice, good historical research requires the combined use of both narrative and interpretative approaches to history (Tosh, 2010, p. 158). This is the method adopted by this thesis as it aims to explain the development of land tax in New Zealand and the variety of societal and political pressures that influenced this.

Unlike a narrative approach, interpretative history is often helped by the use of a theoretical framework, as explained in Chapter 5. While this aids with understanding complex historical relationships and interactions that occur and their significance (Miller, Hopper, \& Laughlin, 1991, p. 398), imposing a particular framework may predispose researchers towards evidence that emphasises it and may lead them to ignore relevant sources that do not conform. In this thesis effort has been made to collect information from a variety of sources to limit this possibility (see section 4.6).

\subsection{Periodisation}

Periodisation separates historical chronology into specified divisions of time and is a key tool used in historical studies. While the division of historical events into distinct, separate 
periods can be somewhat artificial (Gerhard, 1956, p. 900) and is dependent upon both hindsight and the historian's bias (Carr, 1961, p. 63), most historical research relies on at least an implicit scheme of periodisation, recognising that "certain facts are at the core of what is going on, while others are more or less subsidiary to them" (Burnham, 1993, p. 67). This helps prevent history from becoming a continuous succession of facts (AviYonah, 2005, p. 314) and creates "an organized prioritization of vast and otherwise unmanageable flows of raw data" (Burnham, 1993, p. 66).

When a periodisation approach is adopted the choice of periods is critical. Not all periods are of equal importance and the chosen periods can influence the conclusions drawn from a study (Lieberman, 2001, p. 1018). This requires any historical research to clearly justify its chosen periods. Best practice to do this is generally for historians to group events with some persistent uniform character when deciding upon divisions, even if those divisions remain open to question (Phillips, 1994, p. 263). In this thesis, rather than attempting to cover the entire history of the use of land value taxes in New Zealand, three specific time periods central to the development of land tax policy are focused on:

Period 1. 1891 - 1920: Starting with the election of New Zealand's Liberal government, this period covers the establishment of land taxes and the early changes to the law to create a functioning tax system. Additionally the period includes the first change of government after the introduction of land taxes, with the aim of understanding how the policy had become entrenched and why former opponents did not abolish it.

Period 2. 1929 - 1952: This period covers operation of the now established land tax and how it changed in response to the challenges of the Great Depression and the election of a radically left wing Labour government.

Period 3. 1975 - 1991: This period covers the decline and eventual abolition of land tax in New Zealand. This period covers two very different governments: the interventionist Third National Government and the neoliberal Fourth Labour Government. The period sees land tax increase in importance to become a useful revenue tool but concludes with its 1990 abolition.

The periods chosen span 100 years providing key details and background as to what influenced development of land tax policy. This long time span is necessary due to the gradual nature of many changes to the tax policy. It also helps prevent the distorted 
"snapshots" that arise when attempts are made to analyse social processes using a single point in time (Pierson, 1996, p. 126).

The majority of previous studies of land value taxation have not required or employed a periodisation approach. Many studies, particularly older ones, covered the entirety of the tax regimes. This was workable for authors like Reeves (1911) and Stewart (1909b), who were writing in the early 1900s and only had to cover twenty years of history, covering a century of policy development is more difficult. Studies that are of this length, such as Coleman and McKerchar's (2008) study of land value taxation at all levels in Australia from 1788 onwards, tend to be high level overviews, lacking more detailed analysis. As such, they often explain what happened but have less focus on why. This study aims to achieve a more detailed analysis, examining why land value taxation in New Zealand developed as it did. To this end the use of periodisation results in a more focused study than attempting to examine the entirety of the time period. While the periods 1921-1929 and 1953-1974 are not the focus of this study brief overviews of the periods are included in appendix A.

\subsection{Data Sources}

Historical data sources come in two forms: primary and secondary. Primary sources are those derived from original accounts while secondary sources are not first-hand accounts. The distinction is less clear cut than it first appears and the same source may be primary or secondary based on context (Tosh, 2010, p. 91). Their proximity to the event means that primary sources are less likely to contain errors and are therefore preferred by historians. Secondary sources can have issues relating to how their author interpreted evidence and the conclusions they drew, and are therefore less favoured.

Organised activities such as governments tend to leave the greatest volume of primary evidence (Tosh, 2010, p. 104). Following previous similar studies that primarily considered land value tax policy development and application, ${ }^{61}$ this research made heavy use of governmental sources. These sources include historical legislation and bills, parliamentary debate records, votes and proceedings, government reports, reviews and documents and recorded speeches of politicians, both in and outside the house. Many

\footnotetext{
61 Bird (1960), McLean and Nou (2006), and Dilley (2013) - see Chapter 3 for more details.
} 
government documents are kept by standard practice or are required to be kept by legislation and are stored in the National Archives. Most of the older documents are freely accessible but some of the more recent documents are subject to restrictions and require official permission to access. These restrictions generally affect documents less than 30 50 years old and therefore mostly affect the third chosen period. Cabinet documents are used where relevant and available, as they can provide information concerning private government discussions that cannot be found elsewhere. However, cabinet documents often do not contain detailed discussion of land tax policy. Since this study is focused on how and why land tax policy was developed, files from government departments and Hansard, which cover those policy issues in more detail, are generally preferred.

Personal papers and correspondence of key individuals involved with the development of land tax policy, such as former Governor and Premier Sir George Grey and former Prime Ministers and Ministers of Finance Walter Nash and Robert Muldoon, were also used. Many of these were also be found in the National Archives. Books and autobiographies published by relevant individuals were also considered when relevant.

Court cases also provide information. Issues that were serious enough to reach the courts often showcase significant problems in applying tax legislation and can be the drivers of later legislative change. Additionally court judgments often include discussion of Parliament's aims and intentions when adopting or changing particular sections of the law.

This study utilises a wider variety of sources than many previous studies into land value taxation. Those studies have tended to focus on land tax laws and their legal development or their effectiveness. This has led to a heavy focus on the use of legislation, parliamentary debate records, government documents and court cases. While these provide useful information, this work adopts a broader scope similar to that used by Dilley (2013), supplementing these sources with historical media coverage, newspapers, journal articles and books. Articles and opinion pieces can provide information, analysis and commentary of issues as they were seen at the time and without the bias of modern hindsight, while letters to the editor can give glimpses into the feelings of the general public. All of these sources help understand the environment in which tax policy development occurred. Although drawing conclusions based on these is difficult, understanding elements of the public debate is helpful in explaining policy decisions. This must be offset by 
acknowledging the potential editorial biases in press coverage and a tendency of the majority of New Zealand media before the 1980s to have a strongly pro-government viewpoint (Belich, 2001, p. 402). ${ }^{62}$ The use of these sources expands this research beyond that of most previous studies of historical land taxation in New Zealand which seldom considered them, instead primarily focusing on the legislation itself and parliamentary records. This is done to get a better idea of the social, economic and political environment that policy development was occurring in.

Significant volumes of historical press coverage have been preserved in searchable digital archives, aiding accessibility and usefulness. These searches do not always translate the text contained in articles properly though requiring multiple searches with different keywords to ensure that relevant sources are found.

Some secondary sources are used to help provide relevant information and context surrounding events and can be used to alleviate a lack of primary data. While these are easier to locate they have issues of researcher bias, credibility, interpretation and representativeness and are therefore used carefully. The majority of sources used in this thesis are primary.

The main secondary source used is James Belich's Paradise Reforged: A History of the New Zealanders from the 1880s to the Year 2000 (2001). The work, a general history of New Zealand, provides a useful overview of New Zealand society throughout the period covered by this thesis and offers a wider context for the environment that land tax development occurred within. While there are other general histories of New Zealand, most prominently Michael King's Penguin History of New Zealand (2003) and Keith Sinclair's A History of New Zealand (1991), Belich's was chosen because it covers the entire period studied and does so with a higher level of detail. More importantly Paradise Reforged has a strong focus on social history. Given that New Zealand's land tax was as much a social policy as it was an economic one, a socially focused history is useful, providing information about other social changes that occurred alongside the land tax, allowing commonalities to be seen.

62 This has sometimes been argued to be a pro National Party bias but that may be the result of the National Party being the most common party of government after 1948 (Belich, 2001). 


\subsubsection{The Risks of Primary Sources}

While primary sources are useful evidence, their use is not without risks. Broadly there are four types of risk associated with primary sources: authenticity, credibility, representativeness and meaning (Scott, 1990, p. 19). The first three risks are discussed below; meaning is an element of interpretation and covered by Section 4.1.

Credibility refers to the degree which evidence is undistorted, sincere and free from error (Scott, 1990, p. 7). Credibility issues can arise due to deliberate actions, such as the author or a source lying, or be accidents, such as an author trying to present a sincere account but relying on incorrect assumptions (Scott, 1990, p. 23). The heavily political nature of land tax makes credibility a serious concern surrounding many of the sources this work utilises. Many primary sources used in this study are the product of individuals or organisations with agendas and the sources were often produced for the purpose of swaying public opinion. Such documents can emphasise elements that support the speaker or author while ignoring elements that do not, or even lie outright. This is particularly common with Hansard and other comments by politicians but also appears in media coverage. Documents produced by government departments tend to be less deliberately manipulative (although many still have particular biases) but may contain accidental errors. For example, the accuracy of some Treasury produced documents surrounding land tax administration is hindered by the department's incomplete understanding of the topic.

This thesis offsets the risks surrounding credibility through the use of a wide variety of sources. Utilising a wide variety of sources allows claims to be cross-referenced between them to ensure accuracy and removes much of the risk of relying on incorrect information. Additionally, while many utilised sources are biased, those biases are usually stated or easily discerned. This allows sources to be read and evaluated knowing that they have a particular point of view. Inaccurate sources can be useful in research, provided they are recognised as such (Scott, 1990, p. 24). Many biased sources are useful in identifying how individuals or groups felt about land tax policy.

Representativeness is a particular concern with the archival documents. Ideally consulted sources should be a representative sample of the all the relevant documents that were originally produced, but not all of those original documents survived or are available 
(Scott, 1990, pp. 6, 25). An atypical sample risks distorting a work's conclusions. This thesis draws on a wide variety of sources in an attempt to get a representative sample but it is not known successful this was. There is no comprehensive record of all the documents the government produced about land tax, so it is impossible to say if the used sources are representative, but there does appears to be some gaps where sources are not available. Most notability, few files from the tax department, particularly before 1952, are held by Archives New Zealand and therefore few tax department files are available for this research. Given the importance of the tax department to tax policy, the department's files would have been very useful. Available sources that are linked to missing sources are used to get some of the information that would be otherwise unavailable. In cases where government departments interact, such the Department of Native Affairs' work surrounding the taxation of Māori land, this be very useful and informative, but it is not a perfect solution and still leaves gaps. While all attempts were made to acquire a representative array of sources, there is a selection bias based on what was available that cannot be resolved.

Authenticity is whether a document is what it purports to be (Scott, 1990, p. 19). While authenticity is a potential concern in this study, it is less so than credibility or representativeness. Since the majority of sources used in this work were drawn from official, curated resources, such as Hansard, and National Library newspaper collections, there is little chance they are not legitimate. Files from Archives New Zealand potentially have authenticity issues but the risk is still low. Documents found in the archives were generally in good condition and very few files were handwritten, limiting potential copy errors. The date and authorship was generally easily established because sources included that information as standard practice. While fraudulent documents were highly unlikely, documents being part of larger files meant that plenty of similar documents to compare potential fakes against.

\subsection{Conclusion}

This chapter outlines the methodology adopted in this research in order to study the use of land value taxation in New Zealand from 1891 to 1991. The study's methodology draws elements from the disciplines of both history and political science and utilises a qualitative, historical approach. 
The data used in this study comes from both primary and secondary sources. The majority of information comes from primary sources including historic legislation, parliamentary debate records, government reports, court cases and personal papers and correspondence of important individuals. Insight into the thoughts of the general public is obtained through historic media coverage and letters to the editor. Secondary sources are less widely used but are used to provide context and information when primary records cannot be found. Due to the length of time under consideration a periodisation approach has been adopted splitting the study into three periods: 1891-1920, 1930-1952 and 1975-1991. The findings are presented using a dual narrative-interpretative approach. 


\section{Chapter 5: Theoretical Framework}

This research adopts the theoretical framework of historical institutionalism to study the use of land taxation in New Zealand from 1891 - 1991. While some previous studies of land taxation have been done without using a theoretical framework, historical institutionalism is a useful tool to help explain the 'why' in the development of New Zealand's very ideologically driven land tax and the political influences on its design. This chapter presents a detailed outline of historical institutionalism, covering general institutional theory, the specifics of historical institutionalism; including its characteristics, benefits and limitations, and an overview of previous studies in taxation that have adopted a historical institutionalist framework.

\subsection{Institutional Theory}

Institutional theory focuses on the influence of institutions on political outcomes and social change. The theory is employed in a wide variety fields including history, political science and economics.

Despite the theory's wide use there is no fixed definition as to what it comprises or what can be classified as an institution, with a variety of definitions offered by different authors. Thelen and Steinmo's definition that institutional theory covers "the whole range of state and societal institutions that shape how political actors define their interests and that structure their relations of power to other groups" (1992, p. 2) is the one most closely followed in this study. It is widely accepted within political science that institutions are influential but the manner in which they are influential is less clear (Steinmo \& Tolbert, 1998).

Institutions themselves can be defined most basically as rules (Steinmo, 2008, p. 124) but may arise in a variety of forms, both formal and informal. Hall's (1986, p. 19) definition of institutions as "the formal rules, compliance procedures, and standard operating practices that structure the relationship between individuals in various units of the polity and economy" is one of the most widely accepted in the context of historical institutionalism (Thelen \& Steinmo, 1992, p. 2). Ikenberry (1988, p. 226) builds on this, distinguishing between different varieties of institutions that can arise, resulting in a definition of three parts; "the specific characteristics of government institutions, to the more overarching structures of state, to the nation's normative social order". Olson and 
March (1989, p. 160) offer a similarly broad definition, defining institutions as "collections of interrelated rules and routines that define appropriate actions in terms of relations between roles and situations".

Where the line should be drawn in regards to what is an institution can be controversial and the broadness of some of these definitions has been criticised by Steinmo (1993, p. 12). Steinmo argues that such definitions are too vague to leave anything out, catching both things that are irrelevant and diluting the concept of an institution so that it undermines its analytic utility. Thelen and Steinmo (1992, p. 2) therefore argue that a narrower interpretation is more useful ${ }^{63}$ and, since institutional theorists acknowledge that institutions cannot explain everything, a narrower definition would not clash with the theory. However, Crawford and Ostrom note that what is classified as an institution will change depending on the "theoretical question of interest, the time scale posited, and the pragmatics of a research project" $(1995$, p. 582) so broader definitions may be helpful in some studies.

It is important to note that institutions are not seen in institutional theory as determining the behaviour of individuals themselves, rather they provide a structure within which behaviour happens which helps researchers understand why that behaviour occurred (Immergut, 1998, p. 21). This does not mean that institutional theory sees institutions as a neutral part of the political process (Steinmo, 1993, p. 7; Thelen, 1999, p. 394). Rather institutions influence the choices individuals make and which options are possible and/or acceptable, while empowering or disempowering particular groups within them (Hall \& Taylor, 1996, p. 941; Thelen, 1999, p. 385). Immergut (1998, p. 20) describes them as acting as "filters that selectively favour particular interpretations either of the goals toward which political actors strive or of the best means to achieve these ends". This means that differing institutional structures between countries may result in both differing policy decisions and considered policy options (Skocpol, 1992, p. 48).

\footnotetext{
63 Thelen and Steinmo specifically challenge the third portion of Ikenberry's previously quoted definition the "normative social order" suggesting that while norm may pose behavioural constraints these are not necessarily institutional constraints (1992, p. 29).
} 
The institution used in this study is broadly the New Zealand state, but more specifically land tax itself. Over its existence, land tax provided a framework which various actors, including politicians, government departments and taxpayers, operate within.

\subsection{Historical Institutionalism}

This thesis analyses the use of land value taxation in New Zealand through the use of historical institutionalism, a branch of institutional theory. Historical institutionalism arose in response to the structural functionalism theories prominent in political science studies in the 1960s and 1970s (Hall \& Taylor, 1996, p. 936), though many of its concepts and ideas can be found in earlier work (Steinmo, 2008, p. 122). Historical institutionalism, at its broadest, attempts to show how political struggles are arbitrated by their institutional setting (Ikenberry, 1988, p. 225; Thelen \& Steinmo, 1992, p. 2). It is not a particular theory or research method but is best understood as an approach to the study of political science and social change (Steinmo, 2008, p. 118). As such it encompasses a wide variety of research methods and approaches: some research using historical institutionalism may be comparative or may focus on trends in a single macro context; some may draw heavily on primary sources while others may synthesise the findings of secondary works, while explanations may focus on strategic choice or cultural drivers (Skocpol \& Pierson, 2002, p. 2). Since the 1980s historical institutionalism has become "one of the most influential theoretical perspectives in in political analysis and policy studies" (Béland, 2005, p. 1).

\subsubsection{Characteristics of Historical Institutionalism}

Historical institutionalism is one of the three original varieties of "new institutionalism", the other two being rational choice institutionalism and sociological institutionalism (Hall \& Taylor, 1996, p. 936) while a fourth, discursive institutionalism, arose later (Schmidt, 2011, p. 47). This group of theories are united through the central analytical point that institutions provide the strategic context in which "political actors make policy choices ... fram[ing] actors' strategic choices and thereby shaping public policy" (Steinmo \& Tolbert, 1998, p. 165). Works using the theory emphasise sequence and timing, focusing on how existing patterns and interactions help shape those that come afterward (Thelen, 1999, p. 388). In this context, history is seen as a form of political theory that helps explain institutional development and researchers explain development "by emphasising 
historical contingencies and irregularities" (Alawattage \& Wickramasinghe, 2009, p. 702). Future changes and events are seen as "largely, but not entirely, dependent on those that proceed them" (Campbell, 2010, p. 91) and there is a heavy focus on incremental mechanisms of self-reinforcing change (Widmaier, 2016, p. 729).

The key difference between the branches of new institutionalism is how they understand people. Historical institutionalism stands between the mutually incompatible premises of rational choice institutionalism and sociological intuitionalism (Hay \& Wincott, 1998, p. 951; Steinmo, 2008, p. 126). Historical institutionalism sees people as both as "normabiding rule followers and self-interested rational actors" (Steinmo, 2008, p. 126) rather than one or the other. Institutions may influence actors' preferences and interests (Campbell, 1997, p. 32) but, an individuals' behaviour in a given situation depends on the rules, the context and the individuals themselves. In the context of historical institutionalism, the belief as to whether people simply follow rules or if they are strategic actors is largely secondary to the questions of why particular choices were made or a particular outcome was reached. A significant political outcome is likely to be best understood as the product of strategic actions and obeying rules (Steinmo, 2008, p. 126). A historical institutionalist can then examine the historical evidence to attempt to establish what type of behaviour (self-interested, altruistic or habitual) was more important.

In a historical institutionalist analysis of politics and policy making, institutions are fundamental. Institutions affect the power and influence held by actors, be they bureaucrats, elected officials or interest groups (Béland, 2005, p. 3), over policy outcomes while also influencing actors' definitions of their personal interests, based on their institutional responsibilities and relationships to other actors. This results in institutions affecting both "the degree of pressure an actor can bring to bear on policy and the likely direction of that pressure" (Hall, 1986, p. 19), although said actors remain relatively autonomous (Béland, 2005, p. 3). Additionally Thelan and Steinmo (1992, p. 10) note that institutions have a dual existence within the framework. While they shape and constrain political strategies and actions, those institutions are themselves a product (either intentionally or not) of the previous political strategies and actions (Thelen \& Steinmo, 1992, p. 10), resulting in a gradually changing political environment as actors change their institutions. 
Skocpol and Pierson (2002, p. 3) suggest a recognisable historical institutionalist approach is characterised by three important features:

1. "address[ing] big substantive questions that are inherently of interest to broad publics as well as to fellow scholars";

2. "tak[ing] time seriously, specifying sequences and tracing transformations and processes of varying scale and temporality";

3. "analys[ing] macro contexts and hypothesiz[ing] about the combined effects of institutions and processes rather than examining just one institution or process at a time".

In addition to the above, historical institutionalism has a number of other characteristics linked to it. These are described below.

\subsubsection{Path Dependency}

From a historical institutionalist viewpoint, the choices made when institutions are formed or policy formulated have a continued, constraining influence on future developments (Greener, 2005, p. 1). This tendency of institutions towards political inertia where they self-reinforce is known as path dependency (Skocpol \& Pierson, 2002, p. 6). In a path dependent system outcomes trigger feedback mechanisms that, in the aftermath of a critical juncture, reinforce particular elements into an institution over time (Skocpol \& Pierson, 2002, p. 6). These feedback mechanisms can take various forms, including:

- High set up costs, which see actors incentivised to continue an institution in an attempt to recover those costs,

- Learning effects, where actors gradually develop better understanding of an institutions' systems and are able to exploit this to improve institutional efficiency,

- Coordination effects, where benefits to actors engaging in an activity increase as other actors adapt their behaviour to it,

- Adaptive expectations, where actors expect others to act in a certain way and therefore act in the same way so as not to be left behind. (Deeg, 2005, p. 171).

These are what Mahoney (2000, p. 508) terms "utilitarian mechanisms of cost-benefit analysis" when an institution is reproduced based on the rational cost benefit analysis of 
actors. Outside the realm of economics, feedback mechanisms can be further expanded to include the following explanations:

- Functional, where an institution is reproduced because it is believed to serve a useful function within the system,

- Power, where institutions continue due to the backing of an elite group of actors,

- Legitimation, where actors believe an institution is morally right and should therefore be continued (Mahoney, 2000, p. 517).

Mahoney suggested that different institutions would be reinforced by different types of feedback mechanisms, and those feedback mechanism could reinforce particular characteristics within an institution (Mahoney, 2000, p. 517). For example, an institution maintained based on utilitarian feedback mechanisms may be less efficient, as actors within it prioritise maintaining their personal benefits. Conversely an institution where power is the dominant mechanism may focus on empowering a particular elite group. Importantly, the methods for reversing path dependency within an institution can also change based on the feedback mechanisms that sustain it (Mahoney, 2000, p. 509). Mahoney suggests the following mechanisms that would undermine each feedback mechanism:

- Utilitarian: competitive pressures or learning processes.

- Functional: changing institutional needs, possibly resulting from exogenous shocks.

- Power: the weakening of the elites and the strengthening of weaker groups.

- Legitimation: changes in the values of actors (Mahoney, 2000, p. 517).

While Mahoney focused on explaining institutional path dependency through a single type of feedback mechanism (either utilitarian, functional, legitimation or power), other works have examined multiple types of feedback mechanism within a single institution. Horton (2006) examined the development of the British civil service from establishment to the time of writing, considering both how legitimation, power and functional feedback mechanisms developed to maintain civil service practice, and how those feedback mechanisms were eroded before changes occurred. Broschek (2010) and Knutsen (2012) conducted similar analysis, of federalism in Canada and Germany, and China's HIV policy respectively, but only focused on legitimation and power feedback mechanisms. 
Feedback mechanisms see actors' returns increase for behaving in ways consistent with the past, continuing the institution (Campbell, 2010, p. 91). While actors have agency and are not compelled to align their behaviour with feedback mechanisms, most will do so either because they believe in an institution, covet the rewards for consistent behaviour, or fear the consequences of acting against feedback mechanisms (Bell, 2017, p. 726). Feedback mechanisms strongly discouraging deviant behaviour limits the ability of actors to significantly alter institutions quickly outside critical junctures, but there is some scope for them to choose to try to enact more gradual changes (Schneiberg, 2005, p. 103).

As actors continue to behave in line with feedback mechanisms and time progresses, particular legacies are established, based on past institutional behaviour or institutionalised ideas. As feedback mechanisms reward actors for behaviour consistent with these legacies, the process sees institutional structures constrain policy options available to actors, further limiting the scope for change (Campbell, 2010, pp. 91-92). This means that while small variations early on may have a significant influence on the later character of an institution, as time passes existing institutional attributes become deeply entrenched so even small changes become very difficult. The influence may even extend beyond the collapse of an institution itself as new institutions, built on the vestiges and "institutional sediments" (Immergut \& Anderson, 2008, p. 349) of the past may be shaped by those that came before them.

Traditionally historical institutionalist study focused on the general stability of institutions and their inability to change outside punctuated equilibrium (Thelen \& Steinmo, 1992, p. 15). This approach focused on the influence of external shocks in institutional development but minimised the agency of people (Steinmo, 2008, p. 130). More recent work has recognised change is possible without external shocks but requires a significant level of pressure to be applied (Peters, 2005, p. 79). The stability of institutions makes significant changes or reforms difficult in most circumstances, but does allow for more minor changes. This allows actors to make small changes at the fringes of institutions that, over time, can fundamentally alter the existing institutions (Streeck \& Thelen, 2005, p. 8). Even within a path dependent system these more minor changes are necessary for an institution to survive. Streeck and Thelen (2005, p. 24) argue that institutions cannot remain static, requiring active maintenance to adapt to developments in the political and economic environment in which they exist, otherwise they risk atrophying. 
Path dependency is particularly important in in the context of political institutions. By design, political institutions tend be difficult to overturn (Pierson, 2000, p. 261). Political structures are "unusually prone to positive feedback, and the capacities for reversing course are often weak" (Pierson, 2004, p. 44). Their creators often want to prevent successors from undoing their work and to encourage a stable political system to aid them in fulfilling their goals (Pierson, 2004, p. 43). Opportunities for changes in political institutions are additionally limited, as actors who risk losing out from a particular change tend to have incentives to create political resistance. Resistance from those actors who may be made worse off by changes can outweigh the capacity of the beneficiaries of policy change to generate political support, and may lead to the modification or abandonment of policy initiatives (Christiansen \& Klitgaard, 2010, p. 185). The scope of political authority and power imbalances, in addition to a lack of transparency and "mechanisms for restoring efficiency, such as competition and learning" (Immergut \& Anderson, 2008, p. 354) further increase the potential for path dependency to develop in political contexts. Over time this may lead to policy alternatives no longer being considered viable options (Skocpol \& Pierson, 2002, p. 6) while political actors become locked into particular positions (Grube, 2014, p. 112).

When analysing political outcomes that are the result of path dependency, analysis should adopt a longer time frame (Immergut \& Anderson, 2008, p. 354). The order in which political actors arise "will often matter a great deal" (Pierson, 2004, p. 73). The competitive advantages of the first actors to achieve influence within a political space may be self-reinforcing, severely disadvantaging those who enter later. The sequencing of events is critical to the emergence of future paths. The influence of events and how they unfold will differ significantly based on their historical context and the order in which they occur (Immergut \& Anderson, 2008, p. 355). Examining political events within the context of their history and examining the sequencing can help identify links between processes and the consequences of their relative timing, while giving more insight into the positive feedback mechanisms in institutional development (Pierson, 2004, pp. 77-78).

When analysing taxation, path dependency also has an important role. Over time individuals adapt to an established tax system, regardless of its inefficiencies or other problems. This results in them developing a vested interest in the system's preservation (Eccleston, 2006, p. 101) and makes changing that system more difficult. 
In the context of the New Zealand land tax this is particularly important. Over time the revenue collected varied, the taxpayer base changed dramatically and the land tax became increasingly unfit for the purpose it was supposed to fulfil (Reece, 1993, p. 227). Land tax systems were established, and continued, based on assumptions that were later shown to be wrong (notably the 1893-1948 discretionary valuation system). Despite this, most changes to the land tax and its mechanisms tended to be small and gradual, as predicted in a path dependent situation, even when significant problems arose with the existing system. From a research perspective this raises several important issues: what elements were reinforced that established the land tax's development path and eventually led to this obsolescence, and how and what were the critical events that eventually interrupted path dependent cycles and led to the major reforms that pepper land tax history.

Similarly, the feedback mechanisms that entrenched and continued land tax changed over time. Initially there is a strong legitimation force which maintained land tax into the $1920 \mathrm{~s}$ following the collapse of the Liberal government, and later resurrected it in the 1930s, after utilitarian, functional and power mechanisms had largely waned. By the 1970s and 1980s however, land tax's primary feedback mechanisms were functional. It persisted due to its usefulness as a growing revenue source in a tough economic climate. The significant change in land tax's feedback mechanisms over time raises questions as to why they occurred.

\subsubsection{Critical Junctures}

The logical problem of path dependency is trying to explain institutional change through analysis of mechanisms that primarily stymie it (Campbell, 2010, p. 93). Path dependency helps researchers understand the stability and persistence of institutions but other tools are needed to explain why change occurs. One such tool is critical junctures. These are events or choices, generally exogenous, that are large and have a significant influence on future institutional makeup and policy developments (Assensoha \& Wahabb, 2008, p. 301 ); triggering the processes of institutional or policy change when a path dependent progression would otherwise be expected (Hogan, 2007, p. 885). Campbell (2010, p. 93) suggested that events like wars and energy crises were good examples of critical junctures.

Critical junctures are characterised by the adoption of a particular institutional arrangement on occasions when there are multiple alternatives available and once a 
selection occurs it becomes increasingly difficult to return to the previous situation as time progresses (Mahoney, 2000, p. 513). Such occasions generally see a weakening of path dependent feedback mechanisms, weakening restrictions on actors' agency and giving them more freedom over how they act or change institutions than they otherwise would have (Capoccia \& Kelemen, 2007, p. 347). Pierson (2004, p. 44) identifies the following four criteria for a critical juncture:

1. Multiple equilibria; "under a set of initial conditions conducive to positive feedback, a range of outcomes is generally possible."

2. Contingency; "relatively small events, if occurring at the right moment can have large and enduring consequences."

3. Sequencing and timing; "A critical role ... In these path-dependent processes, when an event occurs may be crucial. Because early parts of a sequence matter much more than later parts, an event that happens "too late" may have no effect, although it might have been of great consequence if the timing had been different."

4. Inertia; "once such a process has been established, positive feedback will generally lead to a single equilibrium. This equilibrium will in turn be resistant to change."

While the concept implies speed, it is not clear how long a critical juncture lasts. Once a critical juncture occurs its length is likely to be based on how the political system functions and the importance of the decisions being made (Greer, 2008, p. 221).

Critical junctures emphasise institutional changes resulting from significant events (Eccleston, 2007, p. 9) and direct attention towards these; as in order to understand how new institutional orders are created it is important to consider the political dynamics that exist in moments of flux. This narrow focus on large events can lead to problems however. An analysis of critical junctures explains why revolutionary changes occur but struggles to explain more gradual evolutions that occur within a path dependent system or changes that result from internal processes (Campbell, 2010, p. 93). The focus on the key events also means that triggers of institutional change may be identified but the processes and actor actions that shaped those changes are not (Campbell, 2010, p. 93). Essentially analysis of critical junctures can identify the trigger of a change but is less useful in explaining why that change took a particular form. 
Critical junctures play an important role in this study. The periodisation used is conducted with reference to critical junctures in the life of land taxation. The chosen time periods were selected to cover times when land tax seems to have significantly diverged from its previous path and there were multiple potential junctures. These events take on a variety of forms ranging from the elections of particular parties (notably the Liberals in 1890 and Labour in 1935) to economic events (such as the Great Depression and the Black Tuesday crash of 1987) and both world wars. This also sees some events included that are similar to previous critical junctures, although not necessarily junctures themselves, providing useful points of comparison.

While critical junctures do not explain all the changes made to the New Zealand land tax or the form those changes took, many changes do appear to have been triggered by particular events, making those events an important consideration.

\subsubsection{Ideas}

In response to the difficulties traditional historical institutionalism has in explaining institutional change, more researchers have attempted to incorporate ideas into the framework. The use of ideas in older political research was not particularly common (Steinmo, 2008, p. 130). Much of social science analysis and many theoretical bases, such as rational choice institutionalism, Marxism and pluralism, generally considered interests to be the driving force in politics; ideas are often viewed as "either justifications or simply "noise" (Steinmo, 2008, p. 130). Before the 1990s little work had been done to examine the importance of ideas but this eventually changed as researchers, "often in reaction to radical choice theory" began to consider the influence of ideas in policy development (Campbell, 2002, p. 21). Steinmo (2008, p. 130) suggests that historical institutionalism, not being committed to a specific grand theory or framework, has made this adoption easier and allowed ideas to take on an important role in historical institutionalist analysis.

The adoption of ideas allows for a more sophisticated understanding of the interaction between institutional structures and individuals, acknowledging that exposure to new ideas can alter an individual's preferences, influencing their actions (Hall \& Taylor, 1998, p. 940), and helping to explain the reasons and ways in which institutions themselves change. Hall demonstrated how embedded ideas framed political decisions, eventually acting in a manner similar to templates in his 1989 analysis of the influences of Keynesian thought across nations (Hall, 1989). This was later built on by Blyth who argued that the 
concept of interest itself made little sense without comprehending the ideas individuals use to understand their interests (Blyth, 1997, p. 245). While there was longstanding debate as to whether interests or ideas drove development of public policy, this assumed that one was exclusive of the other (Campbell, 2002, p. 22). Works such as those suggested by Blyth and Steinmo, who described attempts to view ideas and interests as independent variables as "quite useless debate" (Steinmo, 2003, p. 207), instead considered interaction between ideas and interests, noting that ideas may colour how actors "define their interests in the first place" (Campbell, 2002, p. 22).

Hay and Wincott (1998, pp. 956-957), in advocating the importance of using ideas in historical intuitionalist analysis, saw ideas as "cogitative filters", helping to shape individuals' perceptions as to what is "feasible, legitimate, possible and desirable". Hall and Taylor argue that ideas are more than that. Rather they see ideas as the "building blocks of action" (Hall \& Taylor, 1998, p. 962), providing both a structure for actors to work within and elements for them to work with. In this case the adoption of ideas by political actors can be seen as a learning process; a deliberate attempt to adjust policy aims and methods in response to previous experience or new information (Hall, 1993, p. 278). This implies that, despite existing institutional limitations on choices, actors will attempt to find solutions that address problems in a better manner (Pedersen, 2007, p. 63). The study of ideas allows historical institutionalists to better capture elements of both constraint and creativity in the political process (Hay \& Wincott, 1998, p. 956), resulting in a better understanding of political changes. This understanding is enhanced by the tendency of historical institutionalists to consider a broad variety of ideas as potentially influential, ranging from the causal information to moral visions. This opens up a broader range of understanding as to how ideas embodied by institutions can affect individuals (Hall \& Taylor, 1998, p. 961).

Historical institutionalism also has an additional perspective on ideas, in comparison to their use within the context of sociological institutionalism, considering how administrative fit influences the transfer of ideas (Pedersen, 2007, p. 63). Historical institutionalism sees bureaucracy as influencing the adoption of ideas and as being more receptive to ideas that align with the interests and biases said bureaucracy has institutionalised (Pedersen, 2007, p. 63). Alongside this, ideas that influence institutions in the long term may become embedded within the institution itself, creating constituencies that will defend them in the future (Campbell, 2002, p. 31). This can make 
it considerably more difficult for ideas that contradict the established orthodoxy to alter policy development and adds another consideration to institutional path dependency.

While ideas can prove influential on the development of institutions and policy, they are not all influential in the same way. In his review of literature examining how ideas influence policy outcomes, Campbell (2002, pp. 22-29) set out several types of ideas and noted the different ways in which they influenced policy. These are outlined below:

1. Cognitive Paradigms and World Views: taken for granted beliefs that specify cause and effect relationships. These tend to be in the background of policy debates, limiting the options that actors will consider when developing policy. Cognitive paradigms and world views can vary significantly over time and between countries, creating different responses to similar problems.

2. Normative Frameworks: taken for granted assumptions about values, attitudes, identities and shared expectations. Like cognitive paradigms and world views they are also in the background of policy debates, limiting options based on what is likely to be seen "as acceptable and legitimate rather than useful means to an end" (Campbell, 2002, p. 23). Normative values form guidelines that shape what is an appropriate political option and may override actors' self-interest, leading people to support institutions that do not benefit, or are detrimental to, them (Immergut \& Anderson, 2008, p. 358).

3. World Culture: cognitive paradigms and normative frameworks that apply across multiple countries (Campbell, 2002, p. 25). These can help explain why multiple countries adopt similar policies, even when it is not in their interest to do so.

4. Frames: how policy makers bring normative, and sometimes cognitive ideas, to the foreground of policy debate and use them to justify policy choices. Ineffective framing for policy proposals can significantly undermine the viability of new policy proposals while reframing existing policy can be an important part of implementing policy change (Campbell, 2002, pp. 26-27).

5. Programmatic Ideas: in contrast to cognitive paradigms and normative frameworks, these are precise ideas that offer a particular technical solution to a problem (Campbell, 1998, p. 386). These generally consider how existing institutions should be used in a particular situations and align with established paradigms (Campbell, 2002, p. 28). This can result in ideas based on repeating existing practice, where actors repeat previous actions that have been established 
to work in the past. Within a political system, strongly expressed programmatic ideas can be used to establish clear policy solutions that are more likely to be adopted because policy makers can more easily understand them (Campbell, 1998, p. 400). They can also provide a single focus to more easily rally political collations of disparate interests (Campbell, 2002, p. 29).

The role of ideas in the political process is not straightforward. Upon studying the debates surrounding tax cuts in the United States House of Representatives from 1962-1984, Bergman and Pagnucco (2010) noticed that ideas being advocated often did not align with the ideology of those championing them ${ }^{64}$ and that tax cut proposals they examined, whether of Keynesian or neoliberal ideological origin, were largely defended with similar arguments. Similarly Asiskovitch's (2009, p. 235) work found that the public justifications for policy may not actually align with actors' ideas or ideology. In an attempt to explain their findings Bergman and Pagnucco suggest that ideas may play different roles at different stages of the political process; actively helping to shape policy in the early stages while being supported more opportunistically in the later stages as politicians try to best defend their already chosen positions from a range of politically acceptable claims. Bergman and Pagnucco see ideas as helping to inspire policy but losing importance as moderations and compromises are made to broaden a policy's support. By the time a policy is debated, arguments are primarily used to justify the positions politicians have taken "for a variety of reasons among which ideology is secondary at best" (Berman \& Pagnucco, 2010, p. 364) but ideas do influence what arguments are seen as politically acceptable. Like institutions, ideas are recognised as not being a neutral influence on policy and they tend to advantage some interests over others (Steinmo, 2003).

The ability of ideas to have an influence on policy decisions is one of the key reasons why this study adopts a historical institutionalist framework. While the use of a historical institutionalist approach to ideas is not common in previous land value taxation studies, many earlier works contain similar concepts. The works of LeRossignal and Stewart

\footnotetext{
64 For example Bergman and Pagnucco note that during the 1962 debate of tax cuts conservative Republicans criticised the policy for being insufficiently Keynesian while Democrats defended it as encouraging capital investment and claiming that the cuts would pay for themselves.
} 
(1908), Bird (1960) and Woodruff and Ecker-Racz (1965) ${ }^{65}$ all consider the influence of Georgist ideas and theories on the development of land taxation in New Zealand and Australia. Since these authors viewed this, and the more traditional need for governments to raise revenue, as insufficient to explain both the establishment of the system and the peculiarities of its design they considered a variety of other ideas, often rooted in concerns about equality and land ownership, which could have influenced the development of the tax system. Reeves (1903, p. 252) went into considerable detail about the New Zealand land situation and the populist desire that all families should be able to own their own homes as influences on the creation of New Zealand's land tax. At the other end of the time period, Reece's (1993) analysis of the New Zealand tax gives significant consideration and discussion to the potential influence of the neoliberal economic ideology, that dominated the New Zealand Treasury in the 1980s, on the tax's repeal, though it is highly speculative and little evidence is offered. Even popular histories, intended for a more general audience, such as Belich (2001) and Goldsmith (2008), note the potential influence of particular ideologies, ideals and values on alterations to the New Zealand land tax. The use of ideas, and a theoretical framework that incorporates them, allows this study to build on the elements that previous works identified, helping to establish their accuracy and applying a theoretical framework better designed to consider ideas in hopes of understanding their relationship to land tax development as a whole and how they interrelate to each other.

Another reason why use of ideas is beneficial to this study is the historical influence of ideas in New Zealand generally. Throughout New Zealand's history ideas have a significant impact on the national culture and development, ranging from the enlightened ideals at the beginning of the nineteenth century that lead to a more peaceful British colonisation (Belich, 1996), to the idea of creating a "Better Britain" which persisted from European settlement until the 1980s (Belich, 2001). Attempting to analyse policy changes and developments within the New Zealand political system without considering how ideas affected them, would ignore vital context and make understanding difficult. The time periods chosen in this study encompass a range of ideas, both economic and

65 All of which predate institutional theory itself. 
social, which have the potential to influence land tax policy in New Zealand, particularly due to the tax's dual social and economic roles.

\subsubsection{Types of Gradual Institutional Change}

As noted earlier path dependent institutions, particularly those in a political context, are resistant to change outside of a critical juncture but do allow for more gradual changes to occur. As outlined by Streeck and Thelen (2005, p. 31), these changes broadly fall within one of the following five categories:

1. Displacement: When other models emerge, calling into question existing institutional practices and slowly increasing in importance relative to the dominant institutional structure. Alternative models can be sourced internally through reactivation or rediscovery but may also be external. This process is generally slow and requires actors to actively cultivate it.

2. Layering: The process where actors add new elements to existing institutions while keeping existing elements intact. These new elements operate largely independently from the existing institution but grow faster and over time may supplant the old approach as they drain support from it. Such change may arise from elements grafted onto an institution in an attempt to fix or stabilise it.

3. Drift: When institutions are neglected and remain static in the face of a changing external environment. While institutions themselves largely are unchanged, the new setting sees that their effects and influence are altered.

4. Conversion: Institutions are directed towards new goals and purposes. Unlike the traditional feedback mechanisms within a path dependent institution which expect actors to adapt their behaviour to existing institutions, conversion sees institutions adapted to the interests of actors. This may be a response to environmental changes or new actors gaining power.

5. Exhaustion: The process of institutional collapse rather than change. Unlike institutional drift, where the institution itself may remain even if it loses its "grip on social reality" (Streeck \& Thelen, 2005, p. 29), an institution facing exhaustion sees its processes undermine itself.

When considering gradual change, ideas tend to be more influential in cases of displacement or conversion (Widmaier, 2016, p. 729). Broadly aligning with Streeck and Thelen (2005), Bell (2011) suggested three approaches for gradual, agent driven, 
institutional change where agents may reinterpret or "construct the experience of their institutional situation", make new sense of past rules or exploiting their institutions win power struggles and "reshape their institutional environment" (Bell, 2011, p. 895).

\subsubsection{Benefits of Historical Institutionalism}

A key benefit of historical institutionalism is the ability to cover longer time periods than other methods of institutional analysis and a larger number of institutions. This is particularly prevalent when compared to research done using rational choice institutionalism where political analysis, at least in an American context, has tended to reduce its focus to more diminutive terms, of both time frame and relevant institutions (Skocpol \& Pierson, 2002, p. 20; Hall \& Taylor, 1996, p. 950). Historical institutionalism adopts a much broader scope (Hall \& Taylor, 1996, p. 950), allowing its analysis to focus on "large, substantively compelling empirical puzzles and the longer term processes that shape the political context in which contemporary politics are made" (Thelen, 2002, p. 104). Thelen argues that this may be the most significant contribution made by historical intuitionalism to institutional research.

The ability to cover long time periods and a greater variety of institutions is key to the use of historical institutionalism in this research. The land value tax adopted in New Zealand was developed over, and existed for, significant periods of time. As explained in Chapter 4, a long time period is necessary to understanding the policy's development due to the gradual nature of changes and to help prevent distorted snapshots from occurring (Pierson, 1996, p. 126).

Another benefit of historical institutionalism that is particularly useful for this study is the framework's focus on politics. Historical institutionalists tend to examine the state more closely in their analysis than they would when using other frameworks. The state is not seen as "a neutral broker among competing interests but as a complex of institutions capable of structuring the character and outcomes of group conflict" (Hall \& Taylor, 1996, p. 938). Meanwhile political and social institutions can create a distinctive national character. To facilitate analysis, historical institutionalism also considers the institutional power relationships that arise in a political context, how institutions can affect actor agency to move actors in a particular direction, and how they increase the power of some actors while reducing that of others (Hall \& Taylor, 1998, p. 961). This creates an 
understanding of politics that acknowledges conflict and competition between actors and institutions. This understanding contrasts to sociological institutionalism's the oddly "bloodless" understanding that can miss how clashes between actors shape institutional change and with a more complex understanding of human motivation than rational choice institutionalism (Hall \& Taylor, 1996, p. 954).

A greater focus on politics and power is particularly helpful in the study of tax policy. Tax policy tends to be highly politically charged; its ability to personally affect voters on a large scale often invoking strong reactions from people (Eccleston, 2007, p. 2), making politics a key influence in how taxation methods develop. Historical institutionalism's focus on politics can help make the political influences on development more visible; particularly since it considers the non-neutrality of the state and the possibility of different state institutions being in conflict with each other rather than acting as single uniform entity. ${ }^{66}$

The main advantage of using an historical institutionalist framework for this study is that it allows ideas and their influence to be incorporated into the analysis. As explained previously, land value taxation as used in New Zealand was initially a policy more of social planning than revenue collection (Reeves, 1903, p. 252). In order to better understand the development of land tax it is necessary to know and consider the ideas, philosophies, and values, of both involved actors and wider society, that had influence in the policy making process.

\subsubsection{Limitations of Historical Institutionalism}

Historical institutionalism has often been criticised for being eclectic and its inability to explain institutional change (Pedersen, 2007, p. 62). The eclectic nature means it gets the benefits of the different perspectives of the other institutionalisms, considering both the utilitarian and cultural approach to relationships between institutions, actors and behaviour, but is much less focused on how this happens than the other institutionalisms are (Hall \& Taylor, 1996, pp. 939-940). Meanwhile historical intuitionalism's focus on path dependency tends to produce analysis that emphasises the stability and inertia of institutions, with changes being seen as rare and incremental, while the mechanisms by

\footnotetext{
66 As is shown by Jinno and DeWit (1998). This is covered in more detailed in Section 5.2.4.
} 
which changes do occur are given little consideration (Pedersen, 2007, p. 60). This can lead to difficulties in situations where institutions do change more significantly, as the traditional framework struggles to explain this (Hall \& Taylor, 1996, p. 951). In research into a policy that developed over a century, which saw significant changes and eventually was completely repealed, an inability to explain change could be problematic.

However, the issue can be remedied and this study takes steps to limit the inability to explain changes, through the inclusion of ideas (Section 5.2.1.3) and the recognition of gradual change (Section 5.2.1.4). The introduction of ideas into the traditional historical institutionalist framework compensates for the difficulties of accounting for institutional change and provides a mechanism for explaining such changes. As noted previously, the transfer of ideas is seen as a learning process where actors attempt to adjust policy aims and methods (Hall, 1993, p. 278). Over time this may lead to particular ideas spreading through an institution, causing institutional changes as "policy communities die or mutate, or because the ideas mutate themselves", in a manner similar to a virus (Pedersen, 2007, p. 63). In this manner it is possible for this study to better consider and account for institutional changes that occur over the time period studied while giving a better insight into influences on policy development through alterations in the institutional environment. Consideration of Streeck and Thelan's (2005) methods of gradual institutional changes also helps produce an analysis where institutions are seen as much less static.

While not necessarily a problem, analysis carried out using a historical institutionalism framework often has limited generalisability of its findings. Steinmo and Tolbert (1998, p. 171) note in their criticism of Steinmo's 1993 historical institutionalist study into taxation in Sweden, the United Kingdom and the United States (Steinmo, 1993) that the framework does not necessarily offer explanations that are applicable beyond the cases studied; this is despite suggesting that the work and results likely have implications and applications beyond those three countries. Difficulties with the generalisability of conclusions beyond a chosen sample is a common criticism that historical institutionalism shares with much qualitative research (Neuman, 2004). This situation is not ideal but the problem is reduced by acknowledging that the intent of this study's findings is to inform future domestic tax policy as opposed to that of countries outside the study. Further, this study sees the reduced generalisability as an acceptable trade-off to allow a deeper understanding of how and why land taxation in New Zealand developed. 


\subsubsection{Previous Tax Studies using Historical Institutionalism}

Traditionally, institutional theory has been used to analyse differences between states in their approaches and development of welfare systems and economic development but the approach has also been applied successfully to studies of taxation, where it has been used to help address the limited previous research into the politics of taxation (Radaelli, 2005; Eccleston, 2006; Marriott, 2008). Studies of taxation utilising institutional theory have included studies using a historical institutional approach. Although the use of theoretical frameworks, in general, while studying land value taxation are rare, there have been several previous studies of the development of other methods of taxation that have successfully adopted a historical institutionalist perspective.

Steinmo and Tolbert (1998) produced a study into whether institutions had an effect on the levels of tax paid by citizens in developed countries, based on and extending the model used in Steinmo's 1993 work. Adopting a historical institutional framework, the study attempts to overcome the issue of limited generalisability of results, common in institutional work of all types (Steinmo \& Tolbert, 1998), so the authors combine it with regression and cluster analysis of a sample of most of the world's OECD countries. Historical institutionalism, and a narrower definition of an institution, are used to focus the study on particular types of institutions in the political and economic realm that the authors argue are important to the shaping of tax policy. This results in a heavy focus on the government structure, party dominance and the strength of labour organisations. Notably Steinmo and Tolbert do not treat the control of government by left or right wing parties as a measure of institutions, instead viewing it as an element of public preference. Based on their results, Steinmo and Tolbert conclude that institutional factors, both political and economic, likely have a strong influence on tax levels in developed nations, though they are not the sole determinants of them.

Steinmo (2003) also adopted a historical institutionalist perspective to analyse the development of tax policy in the twentieth century. His article is heavily focused on the influence of ideas in tax policy over the period. It considers policy ideas, beliefs, values and interests, how they are related to each other and how they influence policy evolution. Steinmo argues that throughout each major period of the twentieth century different ideas have dominated the thinking of fiscal policy makers, leading to significant differences in 
tax policy. The study heavily focuses on the tax reform that arose in the United States under the Reagan administration and the shift of tax concerns from equity, in the first half of the century, to tax efficiency towards the end. Steinmo uses historical institutionalism to focus on political structures relevant to tax policy creation and how previous policy actions were key influences on future policy choices, though often not in ways that would have been intended. From this, Steinmo argues that dissatisfaction with previous tax policies and a growing belief that policy makers could not be trusted to implement tax policies fairly or efficiently (Steinmo, 2003, p. 230), allowed new ideas to be adopted. Tax policy was then changed to reflect those ideas while globalisation and the associated threat of capital outflow provided an effective justification.

Historical institutionalism has also been used to examine the development of, and response to, specific taxes. Jinno and DeWit (1998) used historical institutionalism to examine the 1990s property tax revolt in Japan. The study is an attempt to establish the origins of the revolt, and why it grew over several years, more accurately than popular accounts which "reduced the incident to a tax grab gone awry" (Jinno \& DeWit, 1998, p. 234). Jinno and DeWit use historical institutionalism to focus on the influence of institutional factors in the revolt, notably the Japanese bureaucracy and the competition between the ministries of Finance and Home Affairs for tax revenues.

The focus on bureaucracy leads the authors to a historical institutionalism framework over a rational choice institutionalism one. This allows them to both treat institutions as having specific goals and direction, and recognise bureaucrats themselves as personally exerting influence over policy making rather than simply acting as agents of political principles. It also allows the research to more accurately reflect the Japanese environment where such bureaucratic activism was a common element of fiscal politics (Jinno \& DeWit, 1998). The historical institutional framework also permits Jinno and DeWit to examine the wider environment the revolt occurred in and the relevant factors that helped shape it.

Casey (1996) utilised an institutional analysis comparable to Jinno and DeWit to study the failure of the British poll tax under the Thatcher government. ${ }^{67}$ Similar to Jinno and

67 The analysis does not explicitly identify as being a historical institutionalist analysis but it follows the work and approach to institutionalism used by Thelen, Skocpol, Steinmo and Hall. 
DeWit, Casey uses the theory to focus on government and bureaucratic institutions and the conflict between central and local government. Casey pays particular attention to the ideological differences between different government branches, notably the right-wing Thatcherism of central government versus the socialism prevalent in local administrations.

Eccleston has also made use of historical institutionalism to study taxation. In his studies, Eccleston (2006; 2007) draws heavily on historical institutionalism to analyse consumption tax reform. In this he focuses on the highly political nature of changes to taxation compared to the majority of policy areas (Eccleston, 2007) and considers the influence of ideas. Eccleston considers that due to this political nature, understanding taxation reform requires an appreciation of both the forces that drive reform and those that hinder it. To this end, he notes the importance of state structures, following the previous work of Steinmo (1993) while, similarly to Jinno and DeWit (1998), he notes that tax policy can be influenced by conflicts between various sections and levels of government. He also considers the influence of party politics on policy. These studies have a very detailed focus on the political intricacies of developing tax reform policies.

In a comparative study of the politics of income taxation in Brazil and South Africa, Lieberman (2001) uses a historical institutionalist framework to analyse development of income tax in the two counties in an attempt to explain why the income tax system of South Africa was more progressive and successful than that found in Brazil. While both countries spent the twentieth century controlled by governments who generally favoured the wealthy, using the framework, Lieberman suggested the key element of difference was determined by who actors felt were members of their community. In racially segregated South Africa, the white elite felt community with poorer whites and were willing to pay more in tax to support the white lower classes. This led to a feeling among the white elite that the state served their community and resulted in a more cooperative approach to income tax between the elite and the state. Conversely in Brazil, where region rather than race was salient, these cross class linkages did not develop. Therefore, the state was seen as being in service to others, causing relations between actors and the state to be more adversarial and leading to the development of less effective income taxation. In another comparative tax study adopting a historical institutionalist framework, Marriott (2008) examined the politics of retirement savings taxation in New Zealand and Australia. 
Marriott focused on four components, environment, institutions, power and ideas, that influenced policy development. In the studied cases, she found that environment, power and institutions played an enabling role but ideas advanced the policy itself, driving policy proposals while also validating them. Marriott (2017) has also applied a historical institutionalist framework to analysis of the tax treatment of facilitation payments made to overseas public officials and foreign trusts.

Other taxation studies that have adopted elements of historical institutionalism as part of a wider institutional analysis of tax policies that combines elements of multiple new institutionalisms. The approach used to do this is demonstrated by work undertaken by Kerkhoff (2011). Kerkhoff's study, an analysis of reforms in Dutch tax collection during the eighteenth century, uses an "eclectic institutionalism" (Kerkhoff, 2011, p. 1) taking elements from each of the rational choice, sociological and historical institutionalisms in an attempt to better understand historical processes and mechanisms over time. The idea is built upon the works of Hall and Taylor (1996; 1998) and Thelen (2002) who argued that the various new institutional models could be used in this way to provide better solutions to research questions. From historical institutionalism Kerkhoff adopts the concepts of path dependency, critical junctures and the focus on bureaucracy and its influence on public servants to help explain key elements of institutional persistence. Other eclectic institutionalist works have tended to adopt similar elements from historical institutionalism based on similar reasons. Thelen (2002, p. 104) separately notes that the key strengths of historical institutional analysis used in such methods are a better understanding of institutional configurations and development, the broader influence of institutional structures on the identities of actors and their relationships and the ability to cover much longer stretches of time.

\subsection{Summary}

This chapter outlines the theoretical framework used in this research. A historical institutionalist approach is adopted allowing for a better understanding of the development of land value taxation. A historical institutionalist approach is the most appropriate framework as it allows the study to focus on a wide time period, consider a wide variety of institutional influences and their development, and contemplate how ideas affect the development of policy. This allows for an analysis that considers a broader 
puzzle and gives significant weight to the development and power of politics and their context. While previous studies in land value taxation have not used a historical institutionalist approach, there are sufficient previous studies in other areas of taxation which demonstrate the framework's suitability. 


\section{Chapter 6: 1891 - 1920}

This chapter covers land taxation in New Zealand from its introduction in 1891 to 1920. It examines policy design, how the Liberal government created a new tax system from the ground up while making it functional, and dealing with a variety of ideological influences and practical restrictions. It also covers later amendments designed to fix problems that arose, the advent of a conservative government and the effects of the First World War.

\section{1 $1891-1893$, Land Tax Design}

\subsubsection{Mechanics}

The Liberals won the 1890 election campaigning on the adoption of a land tax, but there was no consensus on what it should look like, with disagreement over graduation, exemptions, the treatment of improvements and scope. The policy began to take shape when Richard Seddon, then Minister for Mines, declared the government's intent to introduce a graduated tax on land. ${ }^{68}$

When the Liberals introduced their first tax bill to Parliament, a land and income tax had been settled on, consisting of three main parts: an ordinary land tax, a graduated land tax and an income tax (the last is outside the scope of this study). Most of its mechanics were set out in the Land and Income Assessment Act 1891, but some elements, notably tax rates for the ordinary land tax, were to be included in subsequent legislation.

The ordinary land tax was intended as the main revenue raising tax but the name was something of a misnomer. Rather than implement a pure land value tax, the 1891 ordinary land tax continued to be levied on the improved value of land. It was essentially a continuation of the property tax, but with a deduction for the first $£ 3,000$ of improvements. ${ }^{69}$ Landowners holding less than $£ 500$ worth of land were fully exempt and a diminishing deduction existed for landholdings valued between $£ 500$ and $£ 2,500$. The 1892 tax act levied the ordinary tax at a flat rate of $1 \mathrm{~d}$ per pound of land value which

\footnotetext{
68 Grey River Argus, 8 April 1891, page 2.

$69 \quad$ Land and Income Assessment Act 1891, Schedule A 1(2).
} 
would be retained throughout its life. From 1893, taxation was levied on the unimproved land value, which removed improvements from taxation and created an actual land tax. ${ }^{70}$

To ensure that taxation fell on actual land ownership, a deduction for mortgages, provided they were registered with the government, was allowed. This deduction was for the mortgage itself, not the interest paid on it. However, a secondary mortgage tax was imposed on lenders for amounts they loaned. The mortgage tax initially taxed any mortgage lender except banking companies but changes in 1892 saw the exemption of friendly societies, public savings banks, sinking funds and public charitable institutions. ${ }^{71}$ The mortgage tax was levied at the same rate as the ordinary tax until 1902 when it was decreased to $3 / 4 \mathrm{~d}$ per pound of mortgage.

The second land tax was the graduated tax. Graduated land taxation was not directly adapted from Georgist theory. The idea predates both the Liberal Government and the publication of George's work. Introducing graduated taxes was a popular idea in New Zealand for much of the latter nineteenth century. The Press newspaper (Christchurch) was advocating in editorials for a graduated tax on real property based on the theory of $\mathbf{J}$ S Mill as early as $1867 .{ }^{72}$ References to a graduated tax specifically on land begin appearing in the press from the mid-1870s, often in reporting of attempts to implement such a policy in the Australian colonies. ${ }^{73}$ When Premier Sir George Grey proposed it in 1878 it was met with widespread applause ${ }^{74}$ and favourable media coverage. ${ }^{75}$ Despite not being implemented, graduated land tax became common among the manifestos of 1880s liberal political societies.

$70 \quad$ Land and Income Assessment Acts Amendment Act 1893, s11(1).

71 NZPD, Volume 73, 12 August 1891, page 278; Land and Income Assessment Act Amendment Act 1892, s3.

72 The Press, 9 December 1867, page 1, The Press.

73 The Press, 30 November 1872, Australian News.

74 Evening Post, 11 March 1878, Special To The Post. The Press on Sir George Grey. The Blueskin Msytery. (From Our Own Correspondent.) Dunedin.

75 The Bay of Plenty Times, 20 November 1879, The Bay of Plenty Times; Manawatu Herald, 23 November 1880, The Financial Position. 
The 1891 graduated tax fell on all estates with a land value greater than $£ 5,000$ and was charged in addition to the ordinary land tax, so liable estates would pay both. It had originally been introduced with five tax brackets ${ }^{76}$ but this ballooned to the 14 tax brackets. Unlike modern income taxes, the total value of land was taxed according to the highest bracket it fell within. It also lacked the mortgage deduction of the ordinary tax. In cases where the owner was an absentee, defined as anyone who had been absent from the colony for a period of three years or greater, graduated tax payable was increased by 20 percent. ${ }^{77}$

In 1893 graduated tax was increased for the first time, to offset the full exemption of improvements. This added two new brackets, increased the tax on estates worth more than $£ 15,000$ and raised the maximum rate. ${ }^{78}$

Despite the land tax's Georgist influence, the 1891 Assessment Act contained several exemptions. Designed, according to John Ballance, to protect "a large class of the country's most deserving settlers", ${ }^{79}$ the act exempted land used for the following ten purposes:

i. A place of worship or residence of clergy;

ii. Any public school;

iii. The site of any university, college, public library, athenaeum, mechanics institute, public museum, or school of mines;

iv. A public cemetery;

v. The ground or place of meeting of an agricultural society;

vi. A place of meeting for a friendly society, masonic lodge or registered building society;

vii. Public and non-profit charitable institutions;

viii. Public gardens, domains or other public reserves and all public roads and streets;

ix. Land owned and occupied by Māori only and not leased to or occupied by anyone other than the Māori owner;

\footnotetext{
76 Financial Statement 1891, AJHR, 1891 Session II, B-06.

$77 \quad$ Land and Income Assessment Act 1891, Schedule B.

78 Land and Income Assessment Acts Amendment Act 1893, s11(2).

79 Refer note 1.
} 
x. Any public railway, including land used as permanent way, yards, stations, sheds and all land used for purposes of traffic only but not further. ${ }^{80}$

Lands owned by the Crown (although not those held upon any express or implied trust), ${ }^{81}$ government railways and local bodies were not liable for tax under the act. The majority of these exemptions were adapted from the 1878 land tax and the property tax. ${ }^{82}$ The following year this was further expanded to include any land held by friendly societies, savings banks and sinking funds, ${ }^{83}$ while 1893 saw the exemption of all lands and mortgages of building societies. ${ }^{84}$ These new exemptions were justified similarly to the old; as organisations "doing a lot of good in the colony", ${ }^{85}$ part of a recurring theme of determining policy concessions based on deservingness. Similarly, 1892 saw provisions for tax relief in situations of hardship incorporated. ${ }^{86}$

Land valuation was conducted by the tax department ${ }^{87}$ triennially and recorded in public assessment rolls. For the appeals process the government elected to maintain the boards of assessment review system ${ }^{88}$ that had been used by the property tax. Noting feelings among the population that board appointees tended to be men with a personal interest in keeping the land values of large estates low, John Ballance suggested that the new boards would focus on appointing people less sympathetic to the wealthy. ${ }^{89}$

The act originally included two anti-avoidance measures. The first was a general antiavoidance rule, originally included in the 1878 land tax, voiding any covenants or

\footnotetext{
$80 \quad$ Land and Income Assessment Act Amendment Act 1891, s16(1).

$81 \quad$ Land and Income Assessment Acts Amendment Act 1893, s3(1).

82 See Chapter 2.2.

$83 \quad$ Land and Income Assessment Act Amendment Act 1892, s3.

84 Land and Income Assessment Acts Amendment Act 1893, s4.

85 NZPD, Volume 82, 11 September 1893, page 138, Hon. Joseph Ward.

$86 \quad$ Land and Income Assessment Act Amendment Act 1892, s10.

87 Between 1891 and 1991 the department now known as Inland Revenue was known by multiple names. The phase "tax department" is used to refer to all of them.

$88 \quad$ Land and Income Assessment Act 1891, s21.

89 NZPD, Volume 73, August 1891, page 97, Rt. Hon. John Ballance.
} 
arrangements made for "evading the payment of tax". 90 The second was a compulsory purchase measure allowing the Commissioner of Taxes to acquire land for 10 percent above its recorded value if it was believed to be undervalued. ${ }^{91}$ Some opposition members thought this was a conflict of interest as the Commissioner controlled the land valuation process $^{92}$ but landowners did have the right to appeal valuations they thought unfair to the valuation boards. However, the same principle also applied in reverse and landowners who thought their land had been overvalued could compel the Commissioner to either reduce the valuation or purchase the land at the landowner's valuation. ${ }^{93}$ The 1892 amendments saw these rules changed to be more strident, limiting the period when purchases could be made (within one year of the assessment roles being released) and only after an owner had refused to consent to a new, higher valuation. The appeal process remained but was moved to the Supreme Court. ${ }^{94}$

\subsubsection{Arguments and Ideology}

The 1891 election campaign had committed the Liberals to abolishing the property tax but not established a replacement. The 1891 Act was an uneasy compromise between the Liberals' factions, their promises to the electorate and the practicalities of the situation that they found themselves in. The first policy draft drew the ire of the single tax supporters for being insufficiently radical ${ }^{95}$ and the parliamentary opposition took issue with almost every aspect of what they suggested was "the very worst drawn Bill ever presented to this legislature". ${ }^{96}$ The Legislative Council was almost universally against land taxation ${ }^{97}$ but lacked the power to overrule the government on matters of finance.

\footnotetext{
$90 \quad$ Land and Income Assessment Act 1891, s40.

$91 \quad$ Land and Income Assessment Act 1891, s30; Refer note 89.

92 NZPD, Volume 73, 18 August 1891, page 348, Hon. Sir John Hall.

$93 \quad$ Land and Income Assessment Act 1891, s31.

$94 \quad$ Land and Income Assessment Act Amendment Act 1892, s12-13.

95 The Press, 23 June 1891, Sir G. Grey's Party.

96 NZPD, Volume 73, 4 August1891, page 108, Mackay John Scobie Mackenzie.

97 NZPD, Volume 74, 26 August 1891, page 15, Hon. Edward Stevens.
} 


\subsubsection{Improvements}

The issue that most split the Liberals was allowing the continued taxation of improvements. John Ballance and supporters justified this as a means to ensure sufficient revenue in light of the colony's poor finances ${ }^{98}$ and the prevailing sentiment among the government was that a pure land tax would be preferred but the financial position would not permit it. ${ }^{99}$ The similarity to the property tax alienated the government's more ardent land taxers, who objected to any taxation of improvements as an abandonment of Georgist principles. ${ }^{100}$ They were somewhat placated by seeing the Land and Income Assessment Act 1891 as a step in the right direction and better than the property tax.

The opposition also took issue with elements of the taxation of improvements; notably the arbitrary nature of the assumption that land improvements would be exhausted in 10 years ${ }^{101}$ and worried that the tax threshold on improvements would discourage people improving land. ${ }^{102}$ This led to a coalition of government and opposition MPs attempting twice during the committee stage to fully exempt, or severally limit, the taxation of improvements without success. ${ }^{103}$ Most of the concerns were settled in 1893 when the government (now led by Richard Seddon following John Ballance's death) exempted all improvements from taxation.

\subsubsection{Fairness}

The other major debate surrounding the legislation was the issue of fairness. Both the government and the opposition agreed that the incidence of taxation should be fair, but disagreed on what that was. The Liberal position focused heavily on the inequality of the existing property tax, arguing it was a system where the majority of people were taxed for the benefit of large landowners. The land taxes were justified as a more equitable

\footnotetext{
98 NZPD, Volume 73, 4 August 1891, page 100, Rt. Hon. John Ballance.

99 NZPD, Volume 73, 25 August 1891, page 554, Hon. Sir Patrick Buckley.

100 NZPD, Volume 73, 4 August 1891, page 115, William Rees.

101 NZPD, Volume 73, 4 August 1891, page 103-104, Hon. John Bryce.

102 NZPD, Volume 73, 4 August 1891, page 105, Hon. John Bryce.

103 NZPD, Volume 73, 7 August 1891, page 251.
} 
alternative, ${ }^{104}$ moving the tax burden onto the shoulders of those able to best afford it ${ }^{105}$ and creating an "equality of sacrifice". ${ }^{106}$ Liberal members envisioned a more redistributive system where wealth could be used for the benefit of general society. ${ }^{107}$ There was also hope that the new system would reduce the tax burden on productive industry and encourage expansion. ${ }^{108}$

The reasoning was not merely that the wealthy were able to pay more but also that they should pay more. ${ }^{109}$ This was because the wealthy had obtained significant benefits from the previous system, notably increasing land values due to government infrastructure spending, ${ }^{110}$ a core Georgist argument. Even opponents of the land tax acknowledged that the large landowners had previously paid too little tax. ${ }^{111}$

While the government expressed strong rhetoric about creating a fairer tax system, its impact was limited by continued dependence on customs duties when raising tax revenue. Some Liberals argued that land taxes should be further expanded to form a greater portion of revenue ${ }^{112}$ to make the equity of sacrifice goal more likely. ${ }^{113}$

The opposition instead argued for fairness based on a horizontal equity system. ${ }^{114}$ This mind-set saw significant ill feeling towards the graduated tax which they saw as penal, ${ }^{115}$ confiscatory or "evil", ${ }^{116}$ depending on the speaker's level of hysteria. This was often

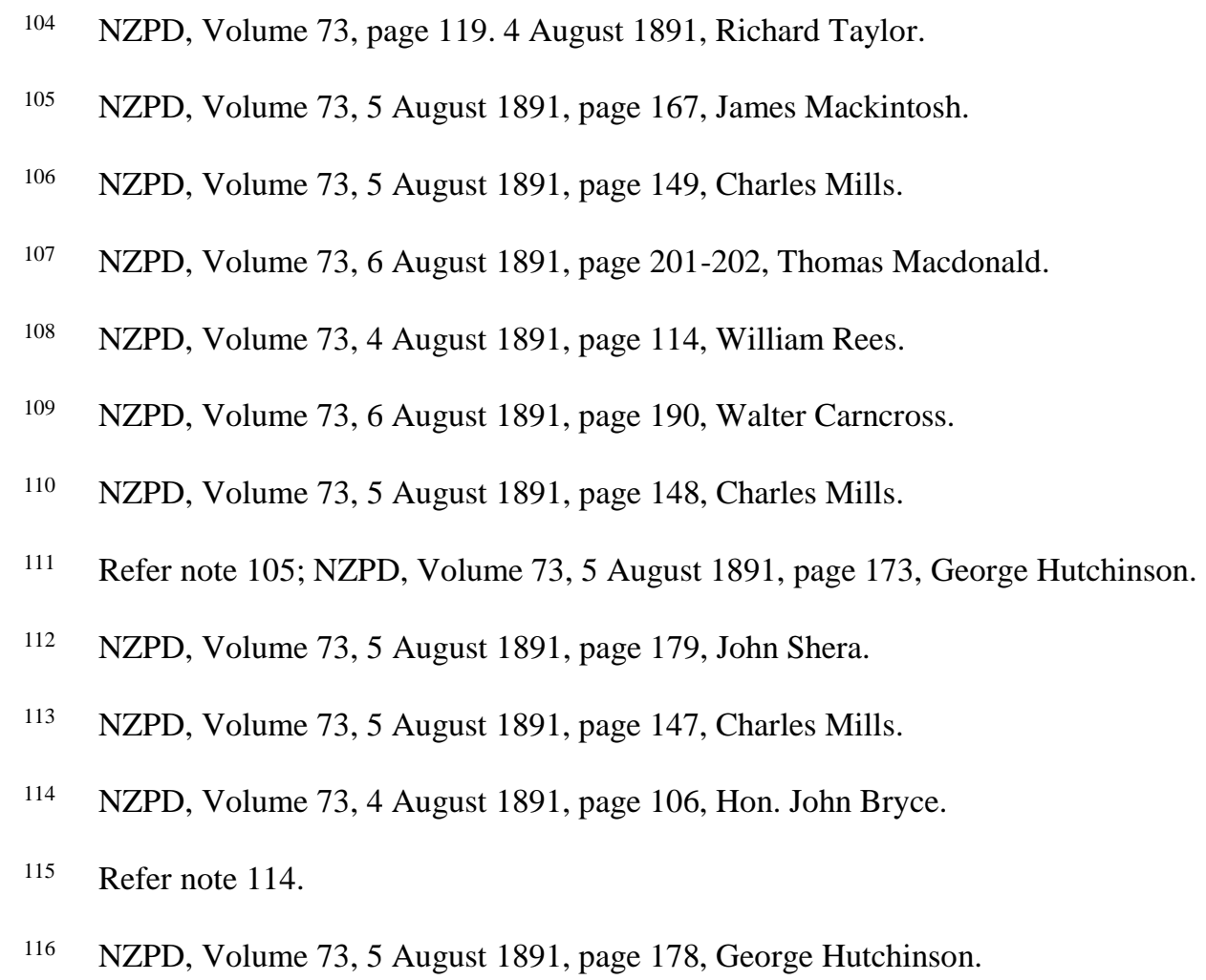


articulated as punishing people for success ${ }^{117}$ or hard work. ${ }^{118}$ The opposition felt the purpose of taxation was only to fund government not engage in redistribution, ${ }^{119}$ or implement social policy. From a similar line of thinking there was some suggestion that all tax exemptions should be removed so that everyone paid some direct tax which would hopefully give the poor an interest in how politicians were spending their money. ${ }^{120}$

While the opposition saw the whole land tax as unfair they thought two elements were particularly so. The compulsory purchase rules were seen as unjust ${ }^{121}$ because they could be used to forcibly acquire land and could theoretically be used to abuse taxpayers. ${ }^{122}$ However, particular issue was taken with the lack of a mortgage exemption in the graduated tax. Opponents argued that this was not only unfair, taxing assets taxpayers did not truly own, but caused the tax to fall most heavily on the poor. ${ }^{123}$ While technically possible, most of the hypotheticals used to prove this point were cases where the farmer would be insolvent and beyond the help of even the most generous tax exemptions. ${ }^{124}$

\subsubsection{Agricultural Fairness}

A particular element of the fairness argument was who would benefit and suffer under the new tax system. The Liberals were adamant that they were not introducing class taxation ${ }^{125}$ but were happy that the policy may fall harshly on holders of unimproved land, speculators and "land monopolists". ${ }^{126}$ The right sort of "deserving" settlers, land improvers and small farmers were not expected to be taxed heavily. ${ }^{127}$ In particular, small

\footnotetext{
117 NZPD, Volume 73, 18 August 1891, page 366, William Buckland.

118 NZPD, Volume 73, 5 August 1891, page 152, Hon. Sir John Hall.

119 NZPD, Volume 74, 26 August 1891, page 3, Hon. Robert Pharazyn.

120 NZPD, Volume 73, 6 August 1891, page 191, Walter Carncross.

121 NZPD, Volume 73, 5 August 1891, page 146, Thomas Mackenzie.

122 NZPD, Volume 73, 5 August 1891, page 153, Hon. Sir John Hall.

123 NZPD, Volume 73, 4 August 1891, page 111, Mackay John Scobie Mackenzie.

124 NZPD, Volume 73, 5 August 1891, page 163, Hon. William Pember Reeves

125 NZPD, Volume 73, 6 August 1891, page 195, David Pinkerton.

126 NZPD, Volume 73, 4 August 1891, page 98-99, Rt. Hon. John Ballance.

127 Refer note 98.
} 
farmers were expected to receive significant relief ${ }^{128}$ and be able to access better land as speculation was curbed. ${ }^{129}$ The opposition maintained that the tax policy was biased in favour of towns, ${ }^{130}$ particularly Auckland, ${ }^{131}$ and designed to shift tax burden of the urban rich $^{132}$ onto rural communities. ${ }^{133}$

For similar reasons many worried that the full exemption of improvements would disadvantage rural property, believing that it primarily benefited expensive townhouses. ${ }^{134}$ The policy was seen as heavily taxing farmers while falling only lightly on capitalists and other types of capital investment. ${ }^{135}$ There were fears this would discourage farming, ${ }^{136}$ thereby injuring the national economy. ${ }^{137}$ To combat this perceived urban bias, lower tax rates for rural land ${ }^{138}$ were proposed, but not adopted by the government. Instead the Liberals exempted agricultural income from income tax to offset the burden of land taxes. ${ }^{139}$ This ensured most small farmers paid no direct tax.

Special rules for farmers were not only justified with reference to fairness and the economy. A recurring theme of the debate was that farmers were a better type of citizen. They were portrayed living lives of hardship away from civilisation where they were "doing the heroic work of colonisation" ${ }^{140}$ and "work[ing] the land". ${ }^{141}$ While it is not

\footnotetext{
128 Refer note 109.

129 NZPD, Volume 73, 5 August 1891, page 170, Alfred Saunders.

130 Refer note 102.

131 NZPD, Volume 73, 18 August 1891, page 367, Edward Wright.

132 NZPD, Volume 73, page 143. 5 August 1891, Thomas Mackenzie.

133 Refer note 131.

134 NZPD, Volume 73, 5 August 1891, page 171, Alfred Saunders.

135 NZPD, Volume 73, 4 August 1891, page 118, Robert Thompson.

136 NZPD, Volume 73, 5 August 1891, page 142, Thomas Mackenzie.

137 Refer notes $102 ; 136$.

138 NZPD, Volume 73, 6 August 1891, page 188, Hugh Valentine.

139 NZPD, Volume 73, 5 August 1891, page 160, Hon. William Pember Reeves.

140 Refer note 114.

141 NZPD, Volume 73, 5 August 1891, page 154, Hon. Sir John Hall.
} 
stated explicitly, there is a strong implication among speakers that farmers therefore deserve preferential treatment.

\subsubsection{Absentee Landholding}

Another element of fairness discussed was the treatment of absentee landowners. Generally disliked by the public and seen as an aspect of British society colonists were trying to leave behind (Belich, 2001), absentees were characterised as speculators who did not improve land. Additionally since New Zealand tax revenue was primarily raised from customs duties, which absentees did not pay, they were seen as not contributing towards society. ${ }^{142}$ This made them a social problem to be remedied and proposals to tax them more heavily received support from both government and opposition members. For some members at least, the desire to increase taxation of absentees appeared to be further influenced by simple xenophobia. ${ }^{143}$ Absentees did have some defenders, most commonly in the Legislative Council, who argued that absentees could use land as productively as other landowners, ${ }^{144}$ and were worried the proposal would drive out foreign capital. $^{145}$

Despite the rhetoric, absentee landholders were relatively few in number; of the 230 landholdings in New Zealand greater than 10,000 acres, only 15 were owned by absentees. ${ }^{146}$ However, the majority of absentee owned properties were unimproved. While the few improvements would have been a concern given the Liberals' focus on developing land, absenteeism does not appear widespread.

\subsubsection{Taxation of Māori}

The next major aspect of the fairness debate concerned the taxation of Māori. Despite Māori land having been exempt from the previous property tax there was criticism of the situation continuing. Some politicians saw the Māori exemption as encouraging racial

\footnotetext{
$142 \quad$ Refer note 106.

143 NZPD, Volume 73, 6 August 1891, page 185, John Duthie.

144 NZPD, Volume 74, 26 August 1891, page 17, Hon. Charles Bowen.

145 NZPD, Volume 73, 18 August 1891, page 356, William Russell.

146 Land- And Income-Tax Department, Further Report By The Commissioner, AJHR, 1892 Session I, B-20a.
} 
separatism ${ }^{147}$ and disproportionally placing the tax burden on Europeans. ${ }^{148}$ It was also thought that land taxes could be used to open up more Māori land for settlement, ${ }^{149}$ and prevent the rise of a wealthy Māori aristocracy. ${ }^{150}$ In light of the debate whether land taxes were confiscatory and the government's denials, the suggestion that they should deliberately be used to alienate Māori land highlights an interesting disparity in how lawmakers saw European and Māori landholders. It is also a breach of Henry George's aims to use land value taxation to limit European appropriation of native lands, another example of MPs picking elements of his work to champion while ignoring pieces that were inconvenient.

John Ballance did not disagree with the preceding arguments or suggest an ideological reason Māori were not being taxed, rather the policy was based entirely on pragmatism; he simply did not believe that such a tax could be enforced or Māori made to pay it. ${ }^{151}$

\subsubsection{Land Policy Aims and Subdivision}

The graduated tax also contained elements of land policy. It was designed to break up the large estates and prevent land monopoly. ${ }^{152}$ The theory was much the same as that proposed by George; heavy taxation of land would make it uneconomical to hold land in its unimproved state, driving landholders to sell and preventing land speculation. ${ }^{153}$ This was part of a plan to prevent the widespread landlordism of Britain being replicated in New Zealand. The government argued that the existing conditions were impeding the colony's progress and inflating land prices beyond the reach of normal colonists. ${ }^{154}$

The value of breaking these estates was questioned by the opposition. A common argument was that it was unnecessary as either it was still possible for anyone who wanted

\footnotetext{
147 NZPD, Volume 73, 5 August 1891, page 176, George Hutchinson.

148 NZPD, Volume 73, 6 August 1891, page 197-198, Edward Smith.

149 NZPD, Volume 73, 6 August 1891, page 199, Edward Smith.

150 NZPD, Volume 73, 6 August 1891, page 203, Thomas Macdonald.

151 NZPD, Volume 73, 6 August 1891, page 185, Rt. Hon. John Ballance.

152 NZPD, Volume 73, 5 August 1891, page 158, Hon. William Pember Reeves.

153 Refer note 126.

154 NZPD, Volume 73, 5 August 1891, page 168, Alfred Saunders.
} 
land to acquire it ${ }^{155}$ with sufficient effort, ${ }^{156}$ or that the large landowners already wanted to subdivide but a lack of viable purchasers was preventing them from doing so. ${ }^{157}$ William Pember Reeves challenged this, asserting that the lack of purchasers was because the land owners were charging excessive prices; ${ }^{158}$ particularly given the difficulties acquiring credit during the depression. Others asserted that: breaking the estates up would be detrimental to the colony's economy and employment rate, ${ }^{159}$ much of the country could only be economically farmed in large blocks; ${ }^{160}$ that it could lead to the "abandonment of agriculture"; it would make exports uncompetitive against "Russian serfs, Hindus and other coloured people"; ${ }^{161}$ and it risked causing New Zealand to "retrograde in civilisation, ranking with and like the states of South America", ${ }^{162}$ further adding to xenophobic undercurrents present elsewhere in the debate. If subdivision was necessary, the government simply buying the large estates at a reasonable price was suggested as a preferable means. ${ }^{163}$

\subsubsection{Degrees of Radicalism}

There was another element to the land tax debate; whether the government was using it as a platform to later introduce much more radical policy measures: either the Georgist single tax ${ }^{164}$ or land nationalisation. ${ }^{165}$ Neither idea was popular with the conservative opposition who viewed Henry George as "a man whose doctrine it is that individual possession of land was robbery". ${ }^{166}$ The government was clearly not introducing a single

\footnotetext{
155 NZPD, Volume 73, 6 August 1891, page 184, John Duthie.

156 NZPD, Volume 74, 26 August 1891, page 8. Hon. Robert Pharazyn.

157 NZPD, Volume 73, 5 August 1891, page 155, Hon. Sir John Hall.

158 NZPD, Volume 73, 5 August 1891 page 161, Hon. William Pember Reeves.

159 NZPD, Volume 73, 5 August 1891, page 180, Edwin Blake.

NZPD, Volume 73, 18 August 1891, page 358, Arthur Rhodes.

161 Refer note 155.

162 Refer note 155.

163 Refer note 138.

164 Refer note 102.

165 NZPD, Volume 73, 4 August 1891, page 113, Mackay John Scobie Mackenzie.

166 NZPD, Volume 73, 18 August 1891, page 351, Hon. Sir John Hall.
} 
tax or nationalisation in 1891-1893 but the concerns were not without basis in the longer term. Much of the early land tax was a matter of pragmatism rather than desire and the government had little ideological commitment to the exact design of their policy. The Premier had previously expressed sympathy for both the single tax ${ }^{167}$ and land nationalisation, ${ }^{168}$ and both ideas had support from Liberal allies. Advocates of both ideas hoped to use the 1891 legislation as a starting point for future developments. ${ }^{169}$

\subsubsection{Conservative Alternatives}

While most of the opposition wanted to maintain the existing property tax, alternatives were discussed. Rather than the land tax, legislators William Russell and Sir George Whitmore suggested a broad based income tax. ${ }^{170}$ Sir George Whitmore hoped this would push the tax burden onto urban professionals, who largely escaped the property and land taxes, and whom he believed should pay the most. ${ }^{171}$ William Russell, appropriating the government's equality of sacrifice reasoning as justification, wanted everyone to pay some income tax but suggested that it could be graduated to help the poor. ${ }^{172}$ He reasoned that "if a man has a large income, it is perfectly reasonable that he should pay out of that income a larger proportion to the necessities of the State", ${ }^{173}$ but thought applying a similar principle to landholding was an attempt to stir up class conflict. ${ }^{174}$ William Russell's income tax proposal was not widely supported in 1891-93 but became more so in later decades.

\footnotetext{
167 Refer note 38

168 Refer note 151.

169 NZPD, Volume 82, 11 September 1893, page 152, William McLean.

170 NZPD, Volume 73, 25 August 1891, page 557-558, Hon. Sir George Whitmore.

171 Refer note 170.

172 NZPD, Volume 73, 18 August 1891, page 357, William Russell.

173 Refer note 172.

174 Refer note 172.
} 


\subsubsection{Valuation and Administration}

Despite the importance of valuation to modern land tax literature, the Liberals paid it little heed, content to largely reuse the system from the property tax. The 1891/2 valuation involved 208,459 valuations nationally and cost $£ 33,000$. ${ }^{175}$ LeRossignol's (1907) review of the process suggested that there was little to no bribery or corruption (p. 276) and that these valuations were likely about 10 percent lower than the true market value but officials claimed there were no insuperable difficulties in making the valuations based solely on land value.

Objections arose from less than 10 percent of valuations, ${ }^{176}$ but there were legitimate issues. At least once the Tax Commissioner tried to tax someone on land they no longer owned and refused their appeal, ${ }^{177}$ and there were cases of some owners in joint ownership arrangements not being recorded. ${ }^{178}$ The biggest problem however, was the Cheviot estate. The tax department valued it at $£ 304,826$ while the owners valued it at $£ 260,220$. Unable to agree a value the owners triggered the compulsory purchase rules and demanded the government either purchase the estate for $£ 260,220$ or revalue it down to that. ${ }^{179}$ In the midst of economic depression the cost was high (about 86 percent of the year's land tax revenue), but the government faced the potential collapse of the tax base if Cheviot was devalued, as other large estates would demand similar treatment (Drummond, 1907). To protect the tax the government purchased the land, later settling small farmers on it (Reeves, 1903).

The original valuation process also saw the tax department performing both their own valuations and those for local government. While preventing duplication of work this created work not relevant to administering the land tax that was costly and time

\footnotetext{
175 Statistics New $\quad$ Zealand, $\quad$ NZOY http://www3.stats.govt.nz/New_Zealand_Official_Yearbooks/1893/NZOYB_1893.html, Retrieved 18 September 2019. Land And Income-Tax Department, Report By The Commissioner, AJHR, 1892 Session I, B-20.

177 Hawkes Bay Herald, 5 April 1892, Appeals From Land Tax Valuations.

178 Hawkes Bay Herald, 15 April 1892, Some Queer Valuations.

179 Cheviot Estate, Copies Of Correspondence Relating To The Acquisition Of The, By The Government, AJHR, 1893 Session I, C-09.
} 
consuming, and local government did little to help. The Commissioner also thought high local rates were causing taxpayers to challenge land tax valuations they would have otherwise accepted. ${ }^{180}$

By 1893 the government signalled its intent to abolish the triennial valuation and make local councils produce their own valuation rolls. The Tax Commissioner expected land values to be reasonably static, not require frequent adjustments, and that it would significantly reduce administration costs. ${ }^{181}$ This land value assumption proved flawed once New Zealand left the economic depression, and LeRossignol (1907) believed it resulted in an undervaluation of land by 1907. In 1894 triennial valuation was replaced by periodic revaluations when the Tax Commissioner thought they were necessary. ${ }^{182}$ It was assumed that land would be regularly revalued but some places were skipped. In 1920 the Prime Minister admitted that 12 counties had not been revalued within the last five years and one was last assessed in $1897 .{ }^{183}$

From 1896 the valuation process was split into a separate valuation department headed by the Valuer General, ${ }^{184}$ although the Commissioner of Taxes could still order valuations be performed. While this separation of powers could provide checks on the Commissioner's authority, both the positions were filled by the same man until 1905. ${ }^{185}$ From 1905 the offices were held by different people but they both had strong connections to the tax department. This left the potential for corruption and in 1910 the Commissioner of Taxes was forced to resign after he was found to have colluded with a valuer to obtain false valuations for his personal landholdings. ${ }^{186}$ Corruption does not appear to have been widespread however.

\footnotetext{
180 Refer note176.

181 Refer note 175.

182 Land and Income Assessment Acts Amendment Act 1894, s9.

183 New Zealand Herald, 12 July 1920, Valuations For Land Tax.

184 Government Valuation of Land Act 1896.

185 Statistics New Zealand, NOY 1905, http://www3.stats.govt.nz/New_Zealand_Official_Yearbooks/1905/NZOYB_1905.html, Retrieved 18 September 2019.

186 Charges Against Mr. Peter Heyes. AJHR, 1910 Session I, B-19.
} 


\subsubsection{Revenue and Incidence}

On implementation, estimates of land tax revenue were nonspecific, but generally more than the $£ 354,167$ the property tax had raised. ${ }^{187}$ In 1892 land taxes raised about $£ 300,000$, including $£ 67,880$ from the graduated tax and $£ 668$ from the absentee tax. ${ }^{188}$ This was only 12.8 percent of tax revenue raised that year and much less important than the $£ 1,642,590^{189}$ raised by customs duties. The full exemption of improvements in 1893 dropped revenue further and it remained about $£ 280,000$ per annum for the next decade. ${ }^{190}$ Revenue was of secondary importance to the land taxes' social policy aims however. ${ }^{191}$ This meant that when first levied in 1892, it fell on 12,557 land owners out of the colony's $91,501{ }^{192}$ The reach of the graduated tax was even more limited being paid by only 1,491 taxpayers in total ${ }^{193}$ and the highest brackets were sparsely populated. ${ }^{194}$ Among those few liable, generally the county's wealthiest residents, it was not particularly harsh (Belich, 2001, p. 44), with an average payment of $£ 45$.

As to the incidence of taxation, farmers were the largest group of taxpayers and contributed a significant portion of revenue under both the land and property tax systems. Following the adoption of land taxation, the number taxed fell from 8,611 to 4,760 but the amount they paid rose slightly to $£ 88,218 .{ }^{195}$ The severe contraction in the tax base suggests that concerns about the tax falling on small farmers were overblown. At the same

\footnotetext{
187 NZPD, Volume 73, 5 August 1891, page 156, Hon. William Pember Reeves.

188 Refer note 175.

189 Refer note 175.

190

$\begin{array}{llll}\text { Statistics } & \text { New } & \text { Zealand, } & \text { NZOY }\end{array}$ http://www3.stats.govt.nz/New_Zealand_Official_Yearbooks/1902/NZOYB_1902.html,

Retrieved 18 September 2019.

191 NZPD, Volume 73, 18 August 1891, page 371. Rt. Hon. John Ballance.

192 Refer note 175.

193 Refer note 175.

194 Statistics Relating To The Value And Area Of Freehold Land In The Colony, AJHR, 1907 Session I, B-17a.

195 Refer note 175.
} 
time the number of professional, merchant and worker taxpayers fell from the 10,492 paying under the property tax to 3,114 under land tax and their tax liability fell from $£ 73,854$ to $£ 36,778$. ${ }^{196}$ At first glance the Liberals seem to considerably increase the burden on farmers, but once the revenue from income tax is accounted for, the tax paid by professionals, merchants and workers increased significantly and farmers paid a similar portion of tax as they did previously. ${ }^{197}$ The narrowing of tax base meant that those still liable, generally the wealthy, paid much more.

\subsection{5, Taxing Native Land}

Three significant changes to the land tax were proposed in 1895: fixing the yearly payment date, fixing the tax rate beyond one year and making Māori land taxable in certain circumstances. Of these, only the third passed.

\subsubsection{Addressing Tenancy of Māori Land}

The changes regarding Māori land legitimised existing practice. Following the implementation of the land tax, the tax department had levied land taxes on European tenants renting native land. This was despite not having the power to do so under the existing law, which levied tax only on the owner of property. Richard Seddon declared the practice was both legal and proper based on the Government's legal advice and that the taxation of Europeans renting Māori land had always been intended. ${ }^{198}$

The problem arose due to the exemption in Section 16(1) i of the 1891 Act. This exempted Māori owned land when it was occupied by the Māori owner, with the Act making no mention of a rental situation. The section read as allowing Māori to be taxed on any land they rented out, an interpretation strengthened by both the 1878 land tax and the property tax including specific sections declaring the tenant's liability in such situations ${ }^{199}$ while

\footnotetext{
196 Refer note 175.

197 Refer note 175.

198 NZPD, Volume 90, 12 September 1895, page 166, Hon. Richard Seddon.

199 Land Tax Act 1878 s6 and Property Assessment Act 1885 s32.
} 
no similar section was included in the 1891 Act. Concerns about this had been raised in $1891^{200}$ but no action was taken.

The Commissioner of Taxes interpreted the law as allowing the taxation of rented Māori land, arguing that there was no sound reason "why Native lands from which rent is being received, and which have benefited equally with other lands from the progress of settlement and the expenditure of public money, should any longer be treated as exempt". ${ }^{201}$ Collecting the tax from tenants was a practical measure due to the difficulty of collecting the land tax from Māori themselves. Tenants were expected to deduct tax they paid from rent payable, moving the burden onto the Māori owners, ${ }^{202}$ and the Commissioner actively was encouraging tenants to do so. ${ }^{203}$ This plan lacked any obvious legal authority and, since the Commissioner was also telling tenants that legislation to allow rent to be withheld for tax paid was planned, ${ }^{204}$ the lack of authority must have been known. The department considered imposing the graduated tax on Māori but decided that the difficulty of "correctly grouping the lands belonging to tribes or individual Natives", 205 meant it was inadvisable to do so.

The government's solution to the problem was to legislate the Commissioner's scheme. Māori owned land rented out would be taxable ${ }^{206}$ and the tax would be paid by the tenant, who would then deduct it from the rent owed. ${ }^{207}$ As a concession, land tax on native land was charged at half the normal rate. ${ }^{208}$ To ease the difficulties of establishing Māori ownership for administration purposes, the occupiers of land were declared agents of the

\footnotetext{
200 Manawatu Herald, 23 July 1891, Mr J. G. Wilson's Speech on the Financial Debate.

201 Statistics New $\quad$ Zealand, $\quad$ NZOY

http://www3.stats.govt.nz/New_Zealand_Official_Yearbooks/1895/NZOYB_1895.html

Retrieved 18 September 2019.

202 Refer note 201.

203 NZPD, Volume 90, 12 September 1895, page 172, Hone Heke.

204 Refer note 203.

$205 \quad$ Refer note 201.

206 Land and Income Assessment Acts Amendment Act 1895, s7, s8.

207 Land and Income Assessment Acts Amendment Act 1895, s7(3), s8(3).

208 Land and Income Assessment Acts Amendment Act 1895, s7(1).
} 
owner and it was sufficient to notify them of tax payable and assessments. Finally to cover the commissioner's previous practices, all previously issued assessments and notices were declared valid. ${ }^{209}$ This was rather important given the majority had already paid them. $^{210}$

\subsubsection{Parliamentary Opinion and Debate}

The treatment of Māori by the land tax had been subject to debate for some time. Colonial New Zealanders saw Māori similar to large landholders and absentees; obstructions to land settlement. ${ }^{211}$ There were fears Māori were trying to position themselves as a class of landlords ${ }^{212}$ or land monopolists, ${ }^{213}$ and charging European tenants exorbitant leases. ${ }^{214}$ Furthermore Māori were supposedly too lazy to improve their land themselves ${ }^{215}$ and it could be better used by British settlers. ${ }^{216}$ By 1895 there was significant opposition to Māori landholding in Parliament, possibly more widespread than that against the large landowners or absentees.

Increased taxation of Māori was justified similarly to taxation of the large landowners, particularly noting the fairness of the proposal. Championed by Richard Seddon and the Treasurer, Joseph Ward, who stressed that the government aimed to deal fairly with the native population ${ }^{217}$ the basic argument was that Māori should be treated the same as other colonists and granted the same protections and responsibilities. ${ }^{218}$ As such it was decried that land held by Māori was being leased untaxed while land leased by European

\footnotetext{
209 Land and Income Assessment Acts Amendment Act 1895, s10(2).

210 NZPD, Volume 91, 9 October 1895, page 223, Hon. Richard Seddon.

211 Otago Daily Times, 29 December 1891, The Native Land Question.

212 NZPD, Volume 86, 2 October 1894, page 475, William Massey.

213 NZPD, Volume 86, 21 September 1894, page 228, Patrick O’Regan.

214 NZPD, Volume 86, 21 September 1894, page 207, Edward Smith.

215 NZPD, Volume 77, 19 August 1892, page 221, Alfred Cadman.

216 NZPD, Volume 86, 21 September 1894, page 195, Thomas Mackenzie.

217 NZPD, Volume 90, 12 September 1895, page 161, Hon. Joseph Ward.

218 Refer note 198.
} 
landlords was taxed ${ }^{219}$ and that it was only fair to tax land that was producing revenue. ${ }^{220}$ Richard Seddon argued the time had come "when the natives should be called on upon to pay a fair share of taxation", ${ }^{221}$ and that Māori would not object. The argument was popular and backed by a majority of both the government and opposition. ${ }^{222}$ The concession rate was added to mitigate the risk that the tax would fall too heavily on Māori ${ }^{223}$ but the government thought "a very large number of Natives... are in just as good a position - indeed, in a better position in many cases - than many of our European land owners to pay taxation" 224 and was not overly concerned.

The new measures to tax Māori had two primary objectors, Hone Heke and Robert Stout who urged the government to rise above the need for money "and do what is just to the native race". 225 The main objection was that while Parliament believed Māori should have the same responsibilities as Europeans, Māori were not receiving the same rights as Europeans. This primarily related to the Native Land Court Act 1894. This had reestablished the Crown's right of pre-emption over the sale of Māori land which Māori believed the government intended to use to purchase native land at below market price. ${ }^{226}$ Hone Heke argued if Māori actually were treated in the same manner as Europeans they would have no objection to the new tax system. ${ }^{227}$

There was also objection to the retrospective elements of the tax, which Robert Stout and Hone Heke asserted would be a significant burden on Māori and would not have been levied on Europeans. ${ }^{228}$ Richard Seddon had little concern, viewing it as essentially

\footnotetext{
219 NZPD Volume 90, 12 September 1895, page 166, Hon. Richard Seddon.

$220 \quad$ Refer note 217.

$221 \quad$ Refer note 198.

222 NZPD, Volume 90, 12 September 1895, page 162-163, William Russell.

223 Refer note 217.

224 Refer note 198.

225 NZPD, Volume 90, 12 September 1895, page 165, Hon. Sir Robert Stout.

226 NZPD, Volume 90, 12 September 1895, page 171, Hone Heke.

$227 \quad$ Refer note 226.

228 Refer notes 203; 225.
} 
collection of debts owed to the government of which most had already been paid ${ }^{229}$ and that there would have been no objection had those being taxed been European. ${ }^{230}$ To Richard Seddon the Act was a process of dealing with tax evasion by the wealthy, European tenants and Māori landlords alike. ${ }^{231}$

The objectors also argued that it was unreasonable to assert that Māori paid no tax on their lands. They paid local rates and stamp duties as Europeans did, in addition to a native stamp duty charged on sales or leases of Māori land. ${ }^{232}$ Hone Heke ventured that Māori were paying at least as much tax on their lands as Europeans did, if not more. ${ }^{233}$ This was not unreasonable to suggest ${ }^{234}$ given the exemptions in the land tax. Those same exemptions that significantly reduced the tax paid by most landowners would not apply to Māori under the new law, despite the large number of owners for Māori land each having a relatively small personal interest, because the Assessment Act classified joint ownership as a single entity for tax purposes. Complaints against the taxation of Māori were largely ignored however, and the amendments were passed without changes.

In this context it is interesting to consider why the government stopped with this limited degree of taxation of Māori and did not further expand upon it. The possibility of imposing of graduated taxation on Māori land was raised but was again rejected as being too difficult to administer. ${ }^{235}$ There was also some concession to fairness when it was acknowledged that the number of owners of native land would likely have a very limited interest each and if the graduated tax was levied it would be unreasonably high. ${ }^{236}$ It should also be noted that the government was adept at breaking up Māori landholding without land tax, so its social policy aspects were not needed (Brooking, 1996).

\footnotetext{
229 Refer note 198.

230 Refer note 210.

231 Refer note 210.

232 Crown and Native Lands Rating Act 1882, s12.

233 NZPD, Volume 90, 12 September 1895, page 170, Hone Heke.

234 Refer note 225.

$235 \quad$ Refer note 217.

236 Refer note 217.
} 


\subsubsection{Later Developments In Taxing Māori Land}

While 1895 was the last significant reform of the land tax as it related to Māori land by the Liberal government, other issues arose over time. In 1908 the Commissioner again tried to unilaterally expand taxation of Māori, deciding to tax Māori Land Boards. Originally established to be exempt from tax, these boards administered Māori lands on behalf of various owners. The Commissioner tried to tax the aggregated total of all land administered by each board ${ }^{237}$ which would have seen lands that fell within the $£ 500$ exemption taxed. Parliament did not intercede but the Department of Native Affairs protested, questioning both the Commissioner's ability to tax the boards and the justice of the scheme, ${ }^{238}$ before advising boards not to pay. ${ }^{239}$

The dispute lasted four years. Despite initial declarations that the boards were not liable ${ }^{240}$ the Native Land Court and Solicitor General decided the boards were not tax exempt bodies and allowed limited taxation. ${ }^{241}$ Rather than tax a board's total landholding the Commissioner had to assess each administered lot separately, accounting for any appropriate exemptions, and could only tax rented land. The Commissioner's plans to tax the tenants of board administered lands, who would then deduct the payments from their rent, was also decreed illegal, despite the tax department having already implemented it. 242

Legal issues also arose over who counted as Māori for tax purposes. Over the years Parliament's definition of Māori in tax assessment acts would include or exclude "half

\footnotetext{
237 Under Secretary, Native Affairs, Memorandum for the Hon. Native Minister, 11 March 1909, Archives New Zealand MA19 24.

$238 \quad$ Refer note 237.

239 Under Secretary, Native Affairs, Memorandum for the President of Tairawhiti District Māori Land Board, 8 March 1909, Archives New Zealand MA19 24.

240 Memorandum to the Under Secretary Native Affairs: Chief Justice's Opinion, 26 February 1909, Archives New Zealand MA19 24.

241 Solicitor General, Taxation of Land Vested in Māori Land Boards, 26 August 1910, Archives New Zealand MA19 24.

242 Refer note 241.
} 
castes" to various degrees. It got so bad that in 1916 the governor required the House to sit under urgency to establish the tax position of such land owners before he would sign the latest act into law. ${ }^{243}$

\subsection{3, Creating Equitable Taxation}

\subsubsection{Altering Graduation Brackets and the Absentee Tax}

In 1903 the government decided to address the equity of the graduated tax system. In the 1903 budget Richard Seddon, the Treasurer since 1896, criticised how small increases in land values were causing significant increases in tax liability ${ }^{244}$ and was concerned that the large steps between graduations were causing taxpayers to challenge valuations at the low end of the brackets. ${ }^{245}$

This led to the first alterations of the graduated tax since 1893, although Richard Seddon stressed that there was no desire to increase tax revenue this time. ${ }^{246}$ The previous 16 brackets were replaced with 48 smaller brackets and a slower rate of increase. ${ }^{247}$ Richard Seddon aimed to lower the tax rate on land worth less than $£ 20,000,{ }^{248}$ although the reality is somewhat more complicated, ${ }^{249}$ while the tax paid on all land worth more than $£ 55,000$ was increased.

The absentee rate was increased from 20 percent extra to 50 percent as part of an attempt to make it a useful source of revenue and a substantial charge on absentee land owners. ${ }^{250}$

\footnotetext{
243 NZPD, Volume 176, 3 July 1916, page 394-395, Hon. Joseph Ward.

244 Financial Statement 1903, AJHR, 1903 Session I, B-06.

245 NZPD, Volume 126, 23 October 1903, page 736, Rt. Hon. Richard Seddon.

246 Refer note 245.

247 Land and Income Assessment Act Amendment Act 1903 s5, Schedule 1.

248 Refer note 245.

249 The old graduations not being multiples of the new ones makes the situation difficult. The tax rate on all lands valued below $£ 7,000$ and between $£ 10,000$ and $£ 11,000$ fell while, rates on all other land worth up to $£ 55,000$ either remained static or rose by $1 / 16 \mathrm{~d}$. Generally values in the upper half of the old brackets faced increased tax.

250 Refer note 244.
} 
In the 1902 tax year it raised $£ 922$ from 104 people but it was hoped that with the changes it could raise more than $£ 3,000 .{ }^{251}$ While the Liberals had claimed that the absentee tax would not have a negative effect on investment there does appear to be some suggestion otherwise. During his budget speech Richard Seddon reasoned that since New Zealand had a reputation for taxing absentees the country may as well collect sizeable revenue from it. ${ }^{252}$ While not an admission, it does suggest the policy was viewed negatively by foreigners.

The 1903 amendments were not designed to increase taxation revenue but their implementation coincides with such. After more than a decade of static revenue, from 1903 tax collected began to annually increase. Richard Seddon's aim of increasing the usefulness of the absentee tax was achieved, increasing its returns almost fourfold to $£ 3,536$, in the following tax year. Returns from the graduated tax increased by $£ 20,848$ within a year, a 26.8 percent increase. ${ }^{253}$ While some of this is likely down to increased land values, the new graduations appear to have had an effect well in excess of the $£ 3,000$ predicted.

\subsubsection{Influential Ideas and Justifications}

Fairness, like in 1891, remained the key issue behind the implementation of the new graduation system but the focus was different. Previously government rhetoric had targeted the wealthy for their lack of contribution; in 1903 the emphasis was on the plight of landowners paying the graduated tax near its thresholds. These individuals are not the poorer masses the Liberals had been appealing to in 1891, rather such landholders fell within the wealthiest 3 percent nationally. ${ }^{254}$

\footnotetext{
$251 \quad$ Refer note 245.

252 Refer note 244.

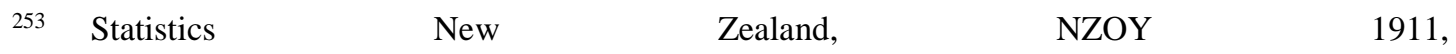
http://www3.stats.govt.nz/New_Zealand_Official_Yearbooks/1911/NZOYB_1911.html, Retrieved 18 September 2019.

254 Refer note 194.
} 
The Liberals however continued to hold up large landowners and absentees as the enemies of New Zealand society. Richard Seddon, like John Ballance before him, acknowledged potential ill-effects towards them but did not care; this was seen as incidental and an easily acceptable cost of introducing new graduations. ${ }^{255}$ The spectre of British landholding remained apparent in policy development however, with one member referring to large landholders as "rich and bloated young aristocrats". ${ }^{256}$ To this end government policy remained committed to encouraging subdivision of the large estates to prevent "the troubles ... of the Old World" being recreated in New Zealand. ${ }^{257}$ The hope was to establish a community of small freeholders, each on land worth $£ 400-£ 500$, and use taxation to restrict further expansion rather than impose a statutory limit. ${ }^{258}$ While the goal aligned with long time Liberal policy, it is worth noting that actually achieving it would exempt all land from taxation and lose the government significant revenue.

While the Liberals' message was largely based on the same ideas as it had been in 1891, the response of the opposition was different. New opposition leader William Massey remained opposed to the proposal but, unlike his predecessors, was not against the idea of raising tax on those who could afford it and did not believe the changes would adversely affect many people. ${ }^{259}$ More significantly, there was agreement that the government should actively pursue policies to encourage the subdivision of the large estates through law. William Massey did not believe the graduated tax should be the method of doing so, however, and instead proposed forced subdivision upon the owner's death. ${ }^{260}$ Despite this, other opposition members believed the graduated tax had been adopted by the country and was now too entrenched to remove so they should instead focus on trying to reduce its inequalities. ${ }^{261}$ Compared to 1891,1903 saw an opposition

\footnotetext{
255 Refer note 245.

256 NZPD, Volume 126, 23 October 1903, page 763, Hon. Charles Mills.

257 NZPD, Volume 126, 23 October 1903, page 744, Joseph Ward.

258 NZPD, Volume 126, 23 October 1903, page 761, William Herries.

259 NZPD, Volume 126, 23 October 1903, page 741, William Massey.

260 NZPD, Volume 126, 23 October 1903 page 742, William Massey.

261 NZPD, Volume 126, 23 October 1903, page 767, James Allen.
} 
who largely agreed with the government's policy aims, the disputes were instead over how those aims were to be achieved.

Attitudes towards absentees had however become more hostile, despite them still being few in number. ${ }^{262}$ In addition to the concerns that applied to large landholders in general, absentees were still seen as not contributing to the country ${ }^{263}$ and instead being actively detrimental. They were described as "a curse" 264 and even reports by the land department accused them of "retarding progress". ${ }^{265}$ Dislike of absentee ownership was not a partisan issue and was supported by members of both the government and the opposition. As such, those calling for the abolition of the absentee tax seldom objected to the principle of taxing absentees. Instead they suggested that the limited revenue it raised was not worth $\mathrm{it}^{266}$ or that simply banning all foreign ownership would more effectively solve the issue. $^{267}$

The other major area of focus was whether the land tax system was unfair to farmers. The government emphasised its support for small farmers ${ }^{268}$ and highlighted that the land tax did fall on urban land. ${ }^{269}$ Opposition arguments had developed from 1891, now primarily focusing on small farmers, but the underlying points were the same, stressing farmers' character, their hard work, supposedly precarious financial situation, ${ }^{270}$ and suggesting land tax was biased towards cities. ${ }^{271}$ Richard Seddon however noted that there was a feeling among farmers that it was "a proper thing to "have" the government" 272 and

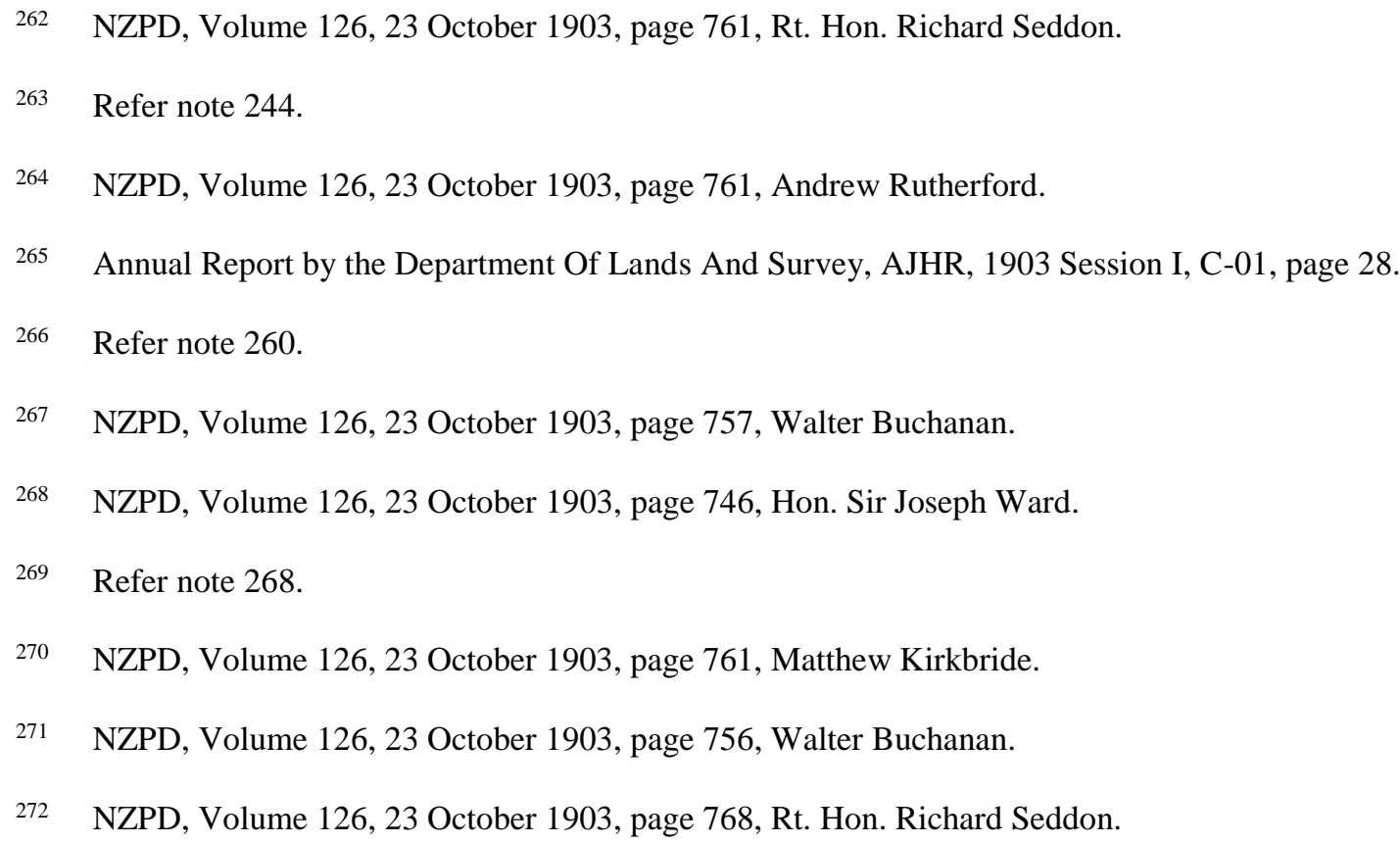

NZPD, Volume 126, 23 October 1903, page 757, Walter Buchanan.

NZPD, Volume 126, 23 October 1903, page 746, Hon. Sir Joseph Ward.

Refer note 268.

NZPD, Volume 126, 23 October 1903, page 761, Matthew Kirkbride.

NZPD, Volume 126, 23 October 1903, page 756, Walter Buchanan.

NZPD, Volume 126, 23 October 1903, page 768, Rt. Hon. Richard Seddon. 
engage in tax minimising behaviour, suggesting a prevalence and normalisation of land tax avoidance amongst them.

\subsection{7, Preventing Tax Avoidance}

\subsubsection{Tax Avoidance - Pre 1907}

Despite the land tax's anti-avoidance rules, avoidance quickly arose. Splitting, where estates were subdivided legally to reduce graduated tax liability but with no practical changes, was occurring by $1895^{273}$ and easily doable through family groups, companies, ${ }^{274}$ trusts $^{275}$ and leases. ${ }^{276}$ Initial levels were low but it grew dramatically following the 1903 graduation changes, and the loss reached almost 10 percent of graduated tax revenue by 1906 . When splitting was challenged by the Tax Commissioner, the courts usually ruled in the taxpayer's favour. ${ }^{277}$

The problem came to a head in Commissioner of Taxes $v$ Smith ${ }^{278}$ In that case one estate had been split into four, each with separate owners, to facilitate a future sale but it was run, by written agreement, as a single entity with the subdivision causing no change. The court held that despite operating as one farm the Commissioner could not tax it as a single entity. The ruling left a wide scope for tax avoidance and, apparently, lawyers had taken to saying all that was required to protect a taxpayer from graduated land tax was a good lawyer. ${ }^{279}$

\footnotetext{
273 Land-Tax And Loss Of Graduated Land-Tax, AJHR, 1907 Session I, B-24b.

274 Whiterock Estate Company (Limited) v Commissioner of Taxes- (1911) 30 NZLR 405.

275 Wellington Diocesan Board of Trustees v Commissioner of Taxes - (1907) 26 NZLR 1281.

276 The Star, 20 June 1907, The Minister Of Lands.

277 Bell v Commissioner of Taxes - (1895) 14 NZLR 438.

278 (1907) 26 NZLR 961.

279 NZPD, Volume 141, 18 September 1907, page 40, Rt. Hon. Sir Joseph Ward.
} 


\subsubsection{The New Act}

\subsubsection{Anti-Avoidance Rules}

By late 1907 the government, now under Sir Joseph Ward's leadership, had had enough and introduced new anti-avoidance rules. These proposals were described as being "very much in advance of anything we have hitherto put upon the statue-book" 280 and believed to target every method of avoidance then in practice. ${ }^{281}$ While the Act had included a general anti-avoidance rule since its inception, ${ }^{282}$ the Commissioner had never attempted to use it in Court. ${ }^{283}$ The 1907 bill introduced more specific measures, targeting the most common methods of avoidance. ${ }^{284}$

The new system moved towards taxing the possession of land and its benefits rather the legal ownership. In addition to making life tenants, equitable owners and beneficially entitled trustees liable, ${ }^{285}$ all lessees were now treated as if they were owners and liable for tax, although not to the exclusion of the actual owners. ${ }^{286}$ This stopped taxpayers leasing land from various separate entities to reduce their tax liability. This did not halt all previous avoidance through leases, transactions that had occurred prior to 27 October 1902 were not affected, but it did target those that occurred following the avoidance boom of 1903. To void the Smith decision, mentioned in the previous subsection, joint owners and occupiers were made liable for tax jointly and severally and would be assessed for graduated tax based on the total landholding rather than their individual shares. ${ }^{287}$ None of this applied to Māori land and Māori owners continued to, indirectly, pay tax while their tenants escaped it.

Companies were covered by a range of new rules. For the purposes of tax, all land they owned was treated as property of their shareholders in proportion to their interest. This

\footnotetext{
280 NZPD, Volume 141, 18 September 1907, page 36, Rt. Hon. Sir Joseph Ward.

281 NZPD, Volume 141, 18 September 1907, page 58, Hon. Robert McNab.

282 Land and Income Assessment Act 1891, s40.

283 Charles v Lysons - [1922] NZLR 902.

$284 \quad$ Refer note 280.

$285 \quad$ Land and Income Assessment Act 1907 s9, 18, 19.

286 Land and Income Assessment Act 1907 s10.

287 Land and Income Assessment Act 1907 s13, 14.
} 
land would be included in the shareholders individual tax returns. ${ }^{288}$ In cases where companies had similar shareholding they could be declared one. To trigger this 75 percent shareholding commonality was originally required; ${ }^{289}$ it was lowered to 50 percent in $1920 .^{290}$

The rules relating to the disposal of land were also overhauled. Under the amendments, no method of legal disposal would have an effect for tax purposes as long as the original owner retained possession, the rents or profits of the land. ${ }^{291}$ This would make it difficult to establish new splitting arrangements. In cases of land sales, the seller remained liable until the buyer obtained possession and 15 percent of the purchase price had been paid. ${ }^{292}$ The buyer would be liable for the land tax as soon they obtained possession, regardless of other factors, ${ }^{293}$ allowing for both parties to a land sale to be liable for tax at the same time. Subsections restricting the sales rules were added following opposition outcry. These limited its application to transactions that occurred after 27 October 1902 and where sellers owned land valued at more than $£ 40,000 .{ }^{294}$ The second limitation meant these rules applied to less than 0.4 percent of land owners. ${ }^{295}$

\subsubsection{Other Changes}

Included among the anti-avoidance measures, 1907 also saw the government abolish the tax brackets above $£ 40,000$; replacing them with a rate that increased by $1 / 5$ of a shilling for every additional $£ 1,000$ of land value until reaching a cap of $£ 2$ per $£ 100$ of value at values above $£ 200,000 .{ }^{296}$ Graduated tax was also increased by 25 percent on land worth

\footnotetext{
288 Land and Income Assessment Act 1907 s11.

289 Land and Income Assessment Act 1907 s12.

290 Land and Income Tax Amendment Act 1920 s7.

$291 \quad$ Land and Income Assessment Act 1907 s17.

292 Land and Income Assessment Act 1907 s16.

293 Land and Income Assessment Act 1907 s15.

294 Land and Income Assessment Act 1907 s16(4).

295 Refer note 194.

296 Land and Income Assessment Act 1907 s6.
} 
more than $£ 40,000$ other than business premises. ${ }^{297}$ Both of these made the graduated tax much harsher at higher values than previously; an estate with land valued at $£ 200,000$ would now pay $£ 5,000$ of graduated tax where it previously paid $£ 2,39516$ s $8 \mathrm{~d}$. ${ }^{298}$

\subsubsection{Ideology and Argument}

Unlike previous years, the parliamentary debate is not especially helpful in ascertaining political drivers of the 1907 legislation. The heavily technical nature of the Act meant that many MPs were not equipped to understand it or discuss it while the Act's method and policy aims both had largely bipartisan support. ${ }^{299}$ As such, rather than debate the Bill, MPs largely debated the broader principles of graduated land taxation. This is familiar ground, rehashing several arguments that have been in use since 1891, all of which have been discussed previously.

The government's primary justification for the policy this time was to subdivide large estates, encourage closer settlement, the Liberals' policy to settle more people on small farms as a panacea for various social ills (Belich, 2001, p. 44), and ensure landowners pay a fair portion of tax. ${ }^{300}$ This was the same justification that they had been using since 1891 despite a continued lack of evidence it actually achieved these outcomes; particularly with subdivision. The Liberals must have had at least some awareness that the graduated tax was not ending the large estates on its own as they had attempted to simply outlaw owning more than $£ 50,000$ worth of land in $1906 .{ }^{301}$ The subdivision argument seems to be being repeated based on popularity with the electorate.

\footnotetext{
$297 \quad$ Land and Income Assessment Act 1907 s7.

298 Graduated Land-Tax: Return Showing Comparison Of Payments Under Present Scale With Payments Under Proposed New Scale In Respect Of Land Other Than Business Premises, AJHR, 1907 Session I, B-24.

NZPD, Volume 141, 18 September 1907, page 45, William Massey.

300 NZPD, Volume 141, 18 September 1907, page 44, Rt. Hon. Sir Joseph Ward.

301 Land Act Amendment Bill 1906 (82-1) s11(a)i.
} 
The opposition's primary concern was still farmers. Farmers were again portrayed as hard working, self-made individuals who earned little income ${ }^{302}$ but used their limited wealth for the best advantage of the whole colony. William Massey took the idea further suggesting that mercantilism and manufacturing were comparatively lesser activities carried on for personal gain, ${ }^{303}$ making explicit what had been subtext in previous debates. That farmers were engaged in tax avoidance was difficult to deny, although some members unconvincingly tried. ${ }^{304}$ Rather this was ignored since it clashed with the selfless farmer narrative. The veneration of farmers meant the opposition particularly disliked the 25 percent increase and business premises exemption. The government had exempted business premises because subdividing them did not encourage closer settlement ${ }^{305}$ but the opposition saw it as a clear attempt to move the tax burden onto rural land. ${ }^{306}$

The government's heavy focus on subdivision also sees the return of an argument from 1891; whether there were other potential sources of land for settlement. While mention is brief, William Massey and an independent member suggested that Māori land could provide for more European settlement. ${ }^{307}$ The reasoning behind this was the same as in 1895; no usable land should be left idle when settlers could make productive use of it. ${ }^{308}$ The continued implicit assumption that Māori land was generally idle is telling however.

\subsubsection{Effectiveness of the New Measures.}

Within one year the government noted that the 1907 amendments were "highly efficient" at preventing tax avoidance. ${ }^{309}$ While politics has a tendency towards self-congratulation

\footnotetext{
302 NZPD, Volume 141, 18 September 1907, page 53, James Allen.

303 NZPD, Volume 141, 18 September 1907, page 47, William Massey.

304 NZPD, Volume 141, 2 October 1907, page 304, Donald Reid.

305 NZPD, Volume 141, 18 September 1907, page 43, Rt. Hon. Sir Joseph Ward.

306 NZPD, Volume 141, 2 October 1907, page 289, William Massey.

307 Refer note 299.

308 NZPD, Volume 141, 18 September 1907, page 64, Frederic Lang.

309 Financial Statement 1908, AJHR, 1908 Session I, B-06, page vi.
} 
this appears justified. In the year following the implementation of the new law, revenue raised by the graduated tax increased by $£ 60,071$, or 47.7 percent. ${ }^{310}$ The increase in tax rates and the anti-avoidance measures resulted in a revenue increase much larger than any previous year, without the avoidance spike that had followed the 1903 rates increase. The amendments remained largely unchanged following the fall of the Liberal government in 1912.

The new anti-avoidance rules also proved more effective in court. Before 1907 the Tax Commissioner lost the vast majority of land tax cases that were brought before the courts, afterwards the pattern was reversed. In cases concerning splitting, the Commissioner was generally successful, although the courts wondered if this was allowing the law to operate more harshly than Parliament had intended and recommended the law be changed. ${ }^{311}$ The rules surrounding land sales proved more complicated due to complexities surrounding timing $^{312}$ and situations where land was leased to tenants with a provision that the ownership would transfer to the tenants once a certain amount had been paid in rent. ${ }^{313}$ In such cases the court generally found the buyer/tenant liable but the law was not certain.

\subsection{2, Conservative Reform?}

\subsubsection{Legislative Changes}

In 1912 the Liberal government collapsed and was replaced by the Reform party. The new administration was the first time conservatives had control of taxation in more than two decades. However, dramatic tax changes were not made. As the Thames Star newspaper put it, Reform essentially "adopted the progressive policy of the Ward

\footnotetext{
$310 \quad$ Refer note 253.

311 Gaisford v Commissioner of Taxes - (1910) 29 NZLR 909.

312 Commissioner of Taxes v Gorman - (1915) 34 NZLR 1029.

313 Rhodes v Commissioner of Taxes - (1910) 29 NZLR 725; Yule v Commissioner of Taxes - [1918] NZLR 890.
} 
Administration lock, stock and barrel"; ${ }^{314}$ creating a land tax policy the Liberals unanimously voted for and claimed as their own. ${ }^{315}$

Most of the 1912 land tax changes focused on increasing the clarity of the existing legislation rather than altering it. This resulted in little change to how the land tax actually operated and important measures like the 1907 anti-avoidance measures were kept, even when Reform had previously objected to them. The graduated tax was maintained, with Reform describing it as "the most important plank in its policy" to bring about closer settlement, ${ }^{316}$ but the remaining brackets were abolished in another attempt to reduce the steep tax increases between brackets. These were replaced by expanding the 1907 formula to values below $£ 40,000$. The 25 percent increase and the business premises exemption was likewise maintained and actually expanded, reducing its threshold for application from $£ 40,000$ to $£ 30,000 .{ }^{317}$ This almost doubled the number of taxpayers liable for the additional tax to $330 .{ }^{318}$

\subsubsection{Native Land Tax Reform}

In 1912 there were some reforms to Māori interaction with land tax, the first since 1895. By this point the Commissioner of Taxation had already succeeded in expanding the land tax to native land boards without parliamentary action, so 1912's legislative changes were comparatively minor. The first change was to allow taxation of non-Māori owners on interests they held in native land as normal. ${ }^{319}$ This was designed to make it clear that Europeans who held land jointly with Māori were taxed ${ }^{320}$ but also taxed any "half-caste" Māori. ${ }^{321}$ Finally the exemption for native land was limited by declaring that any land held by Māori "as European land" (in single title rather than communal ownership) would

\footnotetext{
314 Thames Star, 14 August 1912, The "Reform" Budget.

315 NZPD, Volume 159, 29 August 1912, page 626, Rt. Hon. Sir Joseph Ward.

316 Financial Statement 1912, AJHR, 1912 Session II, B-06, page xxi.

317 Land and Income Assessment Amendment Act 1912, s44.

318 NZPD, Volume 159, 29 August 1912, page 633, Hon. William Massey.

319 Land and Income Assessment Amendment Act 1912 s10.

320 NZPD, Volume 159, 29 August 1912, page 621, Hon. James Allen.

321 Land and Income Assessment Act, 1908, s2.
} 
be taxable as normal. ${ }^{322}$ While the process was not compulsory and the conversion of Māori land had to be initiated by Māori themselves, ${ }^{323}$ any land already converted to individual title was taxable. Since land tax did not allow deductions for joint ownership, and the land boards were now taxable, converting to individual title had previously been an effective way for Māori to lower their tax bill.

\subsubsection{Retaining Land Tax}

The most significant element of Reform's alterations was what the party kept. Reform and its voter base had long argued against land taxation but did not change it once they had the power to do so. Instead they adopted the Liberal's position and rhetoric, stressing their commitment to closer settlement, the subdivision of large estates and the importance of the graduated tax in achieving these aims. ${ }^{324}$ At one point the Finance Minister bragged that Reform was increasing taxes by more than the Liberals had proposed to do. ${ }^{325}$ This led to a parliamentary debate with little opposition, Reform having adopted the Liberals land tax arguments.

This was quite a distance for conservative policy to travel, particularly since as late as February 1912 William Massey would not commit to retaining land tax. ${ }^{326}$ There were however several parliamentary elements that would make an outright repeal of the graduated land tax difficult. First, the short time between Reform taking office and the introduction of the new tax legislation would have made major reforms difficult (Reform had become the government in July 1912 while the tax legislation was introduced in August and passed by 22 October). If this was the case, changes would be expected in either 1913 or 1914, but none arose. Second, the Reform government was not especially strong in Parliament, lacking a majority and instead supported by several independent members who had previously backed the Liberals. Following the 1914 election, Reform still lacked an outright majority and had to form a coalition with the Liberals. Reform's

\footnotetext{
322 Land and Income Assessment Amendment Act 1912 s11.

$323 \quad$ Native Land Act 1909 s208.

$324 \quad$ Refer note 316.

325 NZPD, Volume 159, 29 August 1912, page 617, Hon. James Allen.

326 Bay Of Plenty Times, 28 February 1912, Questions From Mr Atmore.
} 
lack of a parliamentary majority suggests that it would have struggled to push radical alterations to the land tax through Parliament.

Reform however proclaimed both its support for, and intent to continue, the policy so it is worth considering the wider political environment this decision was taken within. The Liberals had spent the preceding 20 years not just operating a graduated land tax but thoroughly entrenching the system. They had stressed its fairness and the benefits of breaking up the large estates since 1891 with significant public resonance. While early public feeling towards the proposal may have been ambivalent, this appears to have changed over time. Indeed when the Farmers' Union declared that they needed to form their own land policy, part of the reasoning was that Liberal, labour and single taxer ideas had too heavily "soaked into the general community". ${ }^{327}$ The surveys of local government conducted by LeRossignal and Stewart indicated that the public supported the system and felt it was an equitable measure (1908, p. 19). The 1912 Egmont by-election, where a proposal by the Reform candidate to further increase the graduated tax was characterised as a populist vote grab, ${ }^{328}$ gives further indications of the graduated tax's popularity with the general public. This is not to say there was no public support for abolishing land taxes. Wealthy individuals ${ }^{329}$ and rural interests ${ }^{330}$ remained hostile but appear to have been a minority. Reform's 1912 position appears to have been a capitulation to the political reality that the land tax was popular nationally rather than ideological endorsement.

\subsection{5 - 1917, Wartime Reform and Unification}

From 1914 to 1918 New Zealand legislation was created within a unique political environment. Reform remained the largest party in Parliament but lacked a majority, necessitating a grand coalition between itself and the Liberals and resulting in the return of Sir Joseph Ward as Minister of Finance. At the same time the First World War saw the government in need of significantly increased revenue, requiring reforms of the existing tax base.

\footnotetext{
327 Clutha Leader, 13 September 1912, The Land Question.

328 Wanganui Chronicle, 31 August 1912, The Egmont Election.

329 Evening Star, 26 June 1907, By The Way.

330 Report Of Valuation Of Land Commission, AJHR, 1915 Session I, B-17b.
} 


\subsubsection{Revenue Reform}

\subsubsection{Revenue Since 1903}

Following a decade of largely static revenue, land tax receipts significantly increased throughout the 1900s. Land tax revenue remained around $£ 300,000$ from 1899-1903 331 after which it began to rise; by 1908 receipts had more than doubled to $£ 604,900 .{ }^{332}$ While there were significant spikes in graduated tax revenue following legislative changes in 1903, 1907 and 1912, from 1903 land tax revenue generally grew steadily. By 1914 land tax was paid by 44,207 taxpayers, ${ }^{333}$ collected revenue of $£ 767,451$ and was the government's fifth largest revenue source after railways, customs, postal and telegraph returns, and stamps. ${ }^{334}$

The composition of this revenue is also worth noting. The ordinary tax had remained largely unchanged since 1893 but years of altering the graduated tax saw it make up a gradually increasing portion of revenue. Initially graduated tax had made up less than 23 percent of total land tax but by 1908 it had reached 35 percent and remained around that level until 1917..$^{335}$ Absentee tax conversely declined after peaking in $1909^{336}$ and had became irrelevant as a revenue source, with the government ceasing to report its revenue after $1915 .^{337}$

\subsubsection{Legislative Changes and Unification}

Following 1912's limited alterations to the land tax, truly significant reforms arose during the First World War when revenue demands saw the government heavily motivated to increase tax collected. This was a new area of focus in land tax policy where revenue had

331 Financial Statement 1900, AJHR, 1900 Session I, B-06; Public Accounts For The Financial Year 1903-1904, AJHR, 1904 Session I, B-01.

332 Public Accounts For The Financial Year 1908-1909, AJHR, 1909 Session ii, B-01.

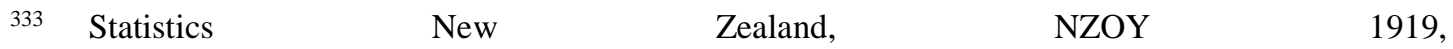
http://www3.stats.govt.nz/New_Zealand_Official_Yearbooks/1919/NZOYB_1919.html, Retrieved 18 September 2019.

335 Refer note 333.

336 Refer note 253.

337 Refer note 333. 
generally been a secondary concern; a limit on potential reforms rather than a goal. Wartime redirected it towards revenue maximisation and the social policy debate that had previously characterised land tax reform was largely absent during this period.

The major policy debate was who the additional tax burden should be placed upon. This followed similar lines to previous debates surrounding the tax burden with similar arguments. Farmers and their supporters objected to paying more tax, arguing that they were already facing financial hardship, ${ }^{338}$ despite significant wartime increases in their incomes, and their work was in the national interest. ${ }^{339}$ Instead they wanted the income tax raised, ${ }^{340}$ likely because farmers were exempt from it. Workers groups, such as trade unionists and labour movement, hoped the extra revenue could be raised by increasing the graduated tax on large landowners and increasing graduated income tax on larger incomes, ${ }^{341}$ in keeping with the progressive aims of the Liberals and limiting the burden on workers. ${ }^{342}$ Taxing large estates more heavily was popular with almost everyone. ${ }^{343}$

Initial wartime reforms did place the additional land tax burden on the wealthy. The 1915 Act levied an additional 50 percent "super tax"344 on land worth more than $£ 30,000$ that was not exempted as a business premise. ${ }^{345}$ While these changes were expected to leave ordinary land tax unchanged, graduated tax revenue was expected to increase by $£ 74,240$ (28 percent). This was borne by very few taxpayers; only 395 individuals and companies held land valued at $£ 30,000$ or more. ${ }^{346}$

\footnotetext{
338 NZPD, Volume 173, 1 September 1915, page 275, Charles Wilkinson.

339 NZPD, Volume 173, 1 September 1915, page 280, John Anstey.

340 The Star, 22 December 1915, Farmers' Union.

341 Secretary of the Christchurch Tramway Employees' Industrial Union, Letter to William Massey, 10 September 1914, Archives New Zealand T1 202 23/36.

342 Auckland Star, 3 April 1915, Labour And The War Tax.

343 NZPD, Volume 173, 1 September 1915, page 268, George Witty.

344 Financial Statement 1915, AJHR, 1915 Session I, B-06, page xxvi.

345 Finance Act 1915 s3.

346 Country-Land Owners Of Unimproved Value Of £20,000 And Upwards, AJHR, 1914 Session I, B-17a.
} 
In 1916 the land tax on mortgages was abolished, offset by income arising from mortgages becoming taxable under income tax. It was hoped that this would give relief to those with small sums invested in mortgages while increasing the tax paid by those with larger investments. ${ }^{347}$ Its main effect was to decrease land tax revenue by a third. Arguing that the government needed to raise more from land tax, ${ }^{348}$ Sir Joseph Ward proposed merging the ordinary and graduated land taxes into a single progressive land tax.

The unified land tax maintained graduation, extending progressive land taxation to land valued at less than $£ 5,000$ for the first time. Any land valued at $£ 1,000$ or less was taxed at a flat rate of $1 \mathrm{~d}$ per pound, ${ }^{349}$ as it had been under the ordinary tax. When land was valued above $£ 1,000$ the rate was increased by $1 / 32,000 \mathrm{~d}$ for every pound of excess value, capped at $7 \mathrm{~d}$ per pound. ${ }^{350}$ The 50 percent additional super tax was kept but was now levied on anyone paying land tax, rather than just those whose land was valued above $£ 30,000$. This significantly increased the number of people who had to pay the higher rate (by more than 40,000 based on land tax payers in 1914). ${ }^{351}$ The diminishing deduction of $£ 500$ from the ordinary land tax was maintained with no changes ${ }^{352}$ to help limit the impact on poorer taxpayers ${ }^{353}$ and continued exempting land worth less than $£ 500$. A diminishing deduction for mortgages up to $£ 1,500$ was also allowed on land valued at $£ 6,000$ or less. ${ }^{354}$

There was little practical change in the operation of land taxation. The existing antiavoidance rules were maintained, altered only to reference the new tax. ${ }^{355}$ Most of the

\footnotetext{
347 Financial Statement 1916, AJHR, 1916 Session I, B-06.

348 Financial Statement 1917, AJHR, 1917 Session I, B-06, page xxiv.

349 Finance Act 1917, First Schedule, Part I, 1.

$350 \quad$ Finance Act 1917, First Schedule, Part I, 2.

351 Refer note 344, page xvii.

$352 \quad$ Finance Act 1917 s4(1).

353 Refer note 348.

354 Finance Act 1917 s4(2).

355 Finance Act 1917 s7-20.
} 
existing exemptions and anti-hardship rules ${ }^{356}$ saw similar treatment. The religious exemptions were altered so that land that had previously been fully exempt from graduated tax were subject to the unified tax at a half rate instead. ${ }^{357}$ A new exemption taxing land held exclusively for non-profit purposes of any outdoor sport (except horse racing) at a half rate was also added. ${ }^{358}$ However, the business premises exemption was removed.

Native land continued to be taxed at the half rate and only when occupied by anyone other than the owner. ${ }^{359}$ The new tax meant it was now subject to graduation. The arguments that graduated taxation would be unfair given the multiple owners of such land had not changed since the last time this was considered, later leading to attempts to divide up such land blocks by Māori themselves to reduce their tax liability. ${ }^{360}$

\subsubsection{Revenue Following Amendments}

Following the 1915 reforms land tax revenue grew; receipts for the 1915-1916 year increased from $£ 799,715$ to $£ 1,048,356 .{ }^{361}$ This was made up of $£ 696,930$ from ordinary tax and $£ 351,426$ from graduated tax and paid by 45,409 taxpayers. ${ }^{362}$ While this was a significant increase, growth in income tax saw it displace land taxation as New Zealand's highest earning direct tax. The following year graduated tax revenue was maintained but the end of the mortgage tax saw revenue from the ordinary tax collapse to $£ 347,913$. ${ }^{363}$

The 1917 unification and associated changes largely rehabilitated land tax as a revenue measure, reversing the decline in both revenue and taxpayers. Revenue for the year

\footnotetext{
$356 \quad$ Finance Act 1917 s5,6,24.

$357 \quad$ Finance Act 1917 s25(2)a.

$358 \quad$ Finance Act 1917 s25(2)b.

$359 \quad$ Finance Act 1917 s26.

360 In re Mawhera Block - [1920] NZLR 894.

361 Refer note 347.

362 Refer note 333.

363 Refer note 333.
} 
increased to $£ 1,512,693$ while taxpayers rose to $51,275,{ }^{364}$ the highest ever recorded for land taxation. These increases continued in the following years and by 1920-1921 revenue was $£ 1,688,978$. Despite this it was the only the government's sixth largest revenue source and collected only 7.61 percent of total tax revenue, lower than any point in the preceding two decades. ${ }^{365}$ The number of taxpayers also continued to increase reaching 54,363 by $1920-1921$; while land tax lost its position as the highest earning method of direct taxation used in New Zealand, it continued to be paid by more people than income tax.

\subsubsection{The Ascension of Income Tax}

While changes to land tax and the revenue it collected are significant, they are of secondary importance to the growth of income taxation over the same period. Since implementation, income tax in New Zealand had performed beyond expectations with consistent growth but it had remained smaller than land tax. From 1915 legislative changes and incomes boosted by high wartime export prices saw income tax revenue increase dramatically. ${ }^{366}$ The 1915-1916 financial year saw income tax revenue surpass that of the land tax for the first time, increasing to $£ 1,392,119,{ }^{367}$ and it grew faster in the following years while being cheaper than land tax to collect. ${ }^{368}$ By the war's end, revenue from income tax was $£ 6,219,336$; an increase of 1,051 percent since war began, compared to an 89 percent increase for land tax revenue.

\footnotetext{
364 Statistics New Zealand, NZOY 1921-22, http://www3.stats.govt.nz/New_Zealand_Official_Yearbooks/1921-22/NZOYB_1921-22.html, Retrieved 18 September 2019.

365 Refer notes $253 ; 364$.

366 Refer note 347.

367 Refer note 347.

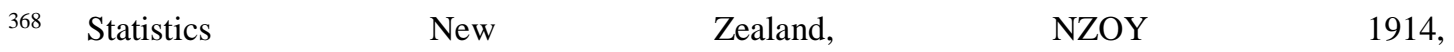
http://www3.stats.govt.nz/New_Zealand_Official_Yearbooks/1914/NZOYB_1914.html, Retrieved 18 September 2019.
} 
The number of taxpayers also increased. Traditionally income tax had been paid by relatively few individuals, about a quarter of those paying land taxes. ${ }^{369}$ From 1914 the number of individuals paying income tax increased significantly, reaching 43,280 by the war's end. ${ }^{370}$ The farmer income tax exemption was also repealed, resulting in a wider tax base. ${ }^{371}$ This was still fewer people than were paying land tax but income tax collected a much larger amount per taxpayer.

The scale of the income tax increase does not appear deliberate however. While Sir Joseph Ward did expect income tax would raise more than land tax from 1915, throughout the period he consistently underestimated the returns arising from changes to it. ${ }^{372}$ Additionally his background with the Liberals and longstanding support of land taxation do not suggest he would deliberately attempt to undermine a key legacy of his party. However, once the potential returns of income taxation were established they were not rolled back; instead use was further expanded. This effectively made land tax subordinate to income tax as a revenue source and ended the Georgist ideal of making it the government's primary revenue base. By 1917 the New Zealand tax system operated in a very similar manner to that suggested by William Russell and Sir George Whitmore in 1891; a system proposed to placate discontent in the general population while placing the tax burden on urban professionals and capitalists, while shielding farmers.

\subsection{0}

The years following the 1917 reforms saw little further change in the land tax law. The next alterations arose in 1920 and were relatively minor. The most notable was a higher rate of tax upon unimproved land operating in a manner similar to the absentee tax. This saw an additional 50 percent tax charged on land which was unimproved if the owner had owned it for more than three years. ${ }^{373}$ The possibility of taxing unimproved land more heavily had been raised multiple times since the 1891 debate. Conservatives had

\footnotetext{
369 Refer note 344 , page xvii.

$370 \quad$ Refer note 333.

371 Finance Act 1915, s11(a).

372 Refer note 344, page xvii.

373 Land and Income Tax Amendment Act 1920 s6.
} 
previously argued this targeting was a better way to discourage speculation and encourage productive land usage without punishing those already using land productively. William Massey justified it as means to "hurry up" the owners of large estates to either improve their land or subdivide it and sell it to someone who would. ${ }^{374}$ Despite the idea's long history this was the first time anyone had decided to apply it. Based on similar reasoning the tax graduations were made more rapid, and the maximum rate increased to $717 / 20 \mathrm{~d}$ per pound. This was offset by reducing the additional 50 percent super tax, which was maintained despite the war's end, to 33.3 percent. ${ }^{375}$ While Reform may have been reluctant to adopt generalised land taxation, they did seem more enthusiastic about "busting up" measures targeted at the large estates.

\subsection{Summary}

The period 1891-1920 is a significant time in the development of New Zealand land tax policy. It covers its implementation and entrenchment; the battle between ideology, revenue constraints and administrative practicality. At the same time various groups push for the dominance of their principles or to protect their interests. Ultimately the result is a reasonably effective and popular tax policy, but with continuing flaws. Also captured is the beginning of that policy's decline. Despite later attempts to revive it, land tax would never achieve the same level of importance or prestige, as it had under the Liberal government at the turn of the century.

374 Wanganui Herald, 8 September 1920, Tax Bill.

375 Land and Income Tax Amendment Act 1920 Schedule, Part I, 3. 


\section{Chapter 7: 1929 - 1952}

This chapter examines land taxation in New Zealand from 1929 to 1952 . By this point land tax policy had been established but was less important than its original designers had hoped. This chapter examines land tax's continued pattern of decline and emerging uncertainty as to its purpose.

\subsection{Developments During the 1920s}

The 1920s saw the New Zealand economy falter, entering into a sharp recession in 192122 with another downturn in 1926 (Ministry for Culture and Heritage, 2012). While overshadowed by the Great Depression, economic performance was poor throughout the decade. As production was stymied and incomes fell, taxation came under scrutiny, particularly the largely unchanged burden of land tax.

Despite this, the mechanics of land tax largely remained unchanged throughout the 1920s. Following the advice of the 1922 Committee on Taxation to cut tax levels ${ }^{376}$ the government began lowering the land tax. The wartime super tax was cut, ${ }^{377}$ eventually replaced by a 5 percent rebate in $1924,{ }^{378}$ offset by faster increases in the graduated rates and a higher maximum rate of $717 / 20 \mathrm{~d} .{ }^{379}$ These rates remained for the rest of the decade. The government did not however implement the committee's recommended flat land tax. It was argued that graduation was limiting production, and that graduated income taxation was a sufficient deterrent for large landholdings. ${ }^{380}$ While not addressed anywhere, this last point does not withstand scrutiny as large landholdings sitting underutilised or idle, a situation land tax was designed to prevent, would attract little or no income tax.

The committee also conducted a limited examination of graduated tax being charged on communally owned native land. It was suggested that this had resulted in many cases

\footnotetext{
376 Report Of The Committee Appointed To Inquire Into The Taxation Of The Dominion Of New Zealand, AJHR, 1922 Session I, B-05, page 15.

377 Land-tax (Annual) Act 1922, Schedule s3.

378 Land and Income Tax (Annual) Act 1924, Schedule Part I s3.

379 Land-tax (Annual) Act 1922, Schedule s2.

380 Refer note 376 , page 12.
} 
where the tax liability consumed most of the rent received and may be unjust. ${ }^{381}$ The government responded by introducing new rules limiting the maximum land tax liability for native land to 25 percent of the revenue derived or derivable from it, ${ }^{382}$ lowered to 10 percent in $1926 .{ }^{383}$ This did not end all the equitable issues associated with the native land tax and in 1927 the Commissioner of Taxes and the Aotea District Māori Land Board ended up in Court after the Commissioner tried to tax the board as trustees liable for the lands they administered, which would allow the disparate holdings to be taxed as a single estate and measure the 10 percent maximum against the board's higher income. The Supreme Court held the Board were agents and therefore not liable for tax. ${ }^{384}$

In 1924 there was further investigation into the tax system with the launch of a Royal Commission into land and income taxation. ${ }^{385}$ Like the Committee it too recommended a flat tax. Unlike its predecessor, it did however acknowledge that sole reliance on income tax would leave idle and unproductive land untaxed. To this end the Commission recommended that, for income tax purposes, non-productive land be deemed to generate income equal to 5 percent of its value. ${ }^{386}$ The government ignored these suggestions.

Useful information was however collected by the 1924 review, in particular the testimony of Commissioner of Inland Revenue D. G. Clark, whose view of land tax was largely uncoloured by politics. Clark defended the use of the unimproved value base, despite concerns by the Commission that it was difficult to measure, ${ }^{387}$ and approved of the additional tax on unimproved land, which he saw as a means to encourage development. ${ }^{388}$ However, he disliked any use of taxation as a social policy tool, saw no reason to limit large landholdings, objected to graduation and thought land tax

\footnotetext{
381 Refer note 376 , page 12.

382 Land and Income Tax Amendment Act 1922, s4.

383 Land and Income Tax Amendment Act 1926, s4.

384 Aotea District Maori Land Board v Commissioner of Taxes - [1927] NZLR 817.

385 The Royal Commission Into Land And Income Taxation, Land And Income Taxation, AJHR, 1924 Session I, B-05.

386 Refer note 385 , page 6.

387 Refer note 385 , page 36.

388 Refer note 385 , page 34.
} 
exemptions were incentivising speculation. ${ }^{389}$ Overall he thought there was no justification for the status quo.

Having noted declines in land tax revenue due to subdivision, ${ }^{390}$ Clark proposed an alternative approach. He suggested a flat tax of $3 d-4 d$ per $£ 1$ of land value, with the majority of exemptions and deductions abolished and an increased rate for unimproved land. Somewhat ironically given Clark's objection to the use of taxation as a social policy tool, this proposal is very close to the Georgist model, more so than anything Parliament had considered. Clark was entirely concerned with revenue potential however; he estimated that this approach would increase land tax receipts to at least $£ 2.5$ million. ${ }^{391}$ The Commission balked at the proposal arguing that such rates would fall too heavily on small farmers although Clark was adamant that it would not be too heavy and would be offset by urban taxpayers paying more. ${ }^{392}$ Demonstrating the limits of the Commissioner's influence on policy, his recommendations were ignored by the Commission and the government.

The 1924 land tax amendments saw another change not suggested by the Commission. In an attempt to deal with increasing land tax $\operatorname{arrears}^{393}$ the Crown's ability to collect unpaid tax was strengthened. ${ }^{394}$ The tax department promptly tried using this to collect unpaid tax it had previously ignored. ${ }^{395}$ This behaviour was seen as unfair and from March 1925 the Attorney General halted enforcement ${ }^{396}$ of the law pending later amendments which reduced the tax department's power. ${ }^{397}$ The Courts further limited the department by

\footnotetext{
389 Refer note 385 , page $32-33$.

390 Refer note 385 , page 32.

391 Refer note 385 , page 34.

392 Refer note 385 , page 34.

393 Financial Statement 1924, AJHR, 1924 Session I, B-06, page vii; Financial Statement 1925, AJHR, 1925 Session I, B-06, page 7.

394 Land and Income Tax Amendment Act 1924, s11.

395 Evening Post, 24 March 1925, Land Tax Arrears.

396 Refer note 395.

397 Land and Income Tax Amendment Act 1925, s2(1), s2(2).
} 
preventing enforcement against successors in title, tenants or mortgagees after obtaining a judgment against the original taxpayer. ${ }^{398}$

Throughout the 1920s land tax revenue and its importance declined, as both a percentage of total tax revenue and as a nominal amount. It fell from peaks of $£ 1,688,979$ (1921) and 16.96 percent of tax revenue (1919) to $£ 1,154,479$ and 6.73 percent in 1928 . Unlike the war period, this was not a displacement by income tax, which had decreased proportionately more. Instead it was replaced by a resurgence in customs and excise duties, again making up more the half of total tax revenue, and rising death duties, receipts of which surpassed land tax from 1923. ${ }^{399}$

\subsection{9, One Step Forward...}

The election of 1928 saw the demise of the Reform government and the election of a new United (the restructured Liberal Party) administration. Public disquiet had arisen over land availability and taxation which United and Labour used to attack Reform. Despite Reform's protests ${ }^{400}$ farmers were seen as having a privileged tax position ${ }^{401}$ while regressive taxes on the poor were rising. ${ }^{402}$ United and Labour promised to increase subdivision, ${ }^{403}$ and move the tax burden onto "those most able to pay it." ${ }^{404}$ Land tax increases were seen as a solution to these problems. Reform argued that, because of its responsiveness to income changes, income tax it should be New Zealand's primary taxation method, despite their government significantly reducing it and exempting

398 Commissioner of Taxes $v$ Wintle - [1926] NZLR 814.

399 Statistics New $\quad$ Zealand, NZOY 1929, http://www3.stats.govt.nz/New_Zealand_Official_Yearbooks/1929/NZOYB_\%201929.html, Retrieved 18 September 2019.

400 The Press, 17 August 1928, Parliament.

401 Auckland Star, 24 October 1928, Wave Of Liberalism.

402 Otago Daily Times, 30 October 1928, Election Campaign.

403 Auckland Star, 25 October 1928, Election Campaign; Auckland Star, 1 November 1928. Election Campaign.

Otago Daily Times, 13 November 1928, Eve Of Election. 
farmers from it. ${ }^{405}$ They also questioned what large estates remained that the opposition wanted to break up. ${ }^{406}$

The election saw parliamentary seats held by Reform slashed but United did not gain a majority. Instead it governed with the support of the Labour party. United appears to have been elected without a specific tax policy or even agreement between all its candidates on issues as simple as whether it should retain land tax. ${ }^{407}$

\subsubsection{The Special Land Tax}

In 1929 the United party found itself elected facing economic challenges, public concerns about societal fairness and a lack of defined policy. The government's prescription was largely a repackaging of old Liberal policy, in particular stressing closer settlement. To this end United proposed increasing the land tax in the 1929 budget. The similarity to the old Liberal platform is not surprising as the 1928 election saw the return of Sir Joseph Ward as both Prime Minister and Minister of Finance.

The Land and Income Tax Amendment Act 1929 saw two significant changes to the land tax. The first, was to lower the mortgage deduction from $£ 10,000$ to $£ 7,500$. ${ }^{408}$ The second, and most significant, was the return to a dual approach to land taxation with the introduction of the special land tax, or "Super Land Tax" as it was deemed in the popular press. The special tax applied to all rural land worth more the $£ 14,000^{409}$ and was levied as an increasing portion of ordinary land tax, up to 100 percent of land worth more than $£ 30,000$. Taxpayers who paid the special tax were still liable for the ordinary land tax. This resulted in significant increases in the land tax payable. At the top of the graduation

\footnotetext{
405 New Zealand Herald, 3 November 1928, Taxation And Tariffs.

406 Northern Advocate, 5 November 1928, On The Electoral Front.

407 Otago Daily Times, 5 November 1928, Election Notes.

408 Land and Income Tax Amendment Act 1929, s6(1).

409 Land and Income Tax Amendment Act 1929, s2.
} 
scale (values $£ 138,000$ and above) land tax was 6.21 percent of land value, ${ }^{410}$ higher than at any time previously.

Ward predicted that, out of New Zealand's 46,276 ${ }^{411}$ land tax payers, only 2400 would be affected by the changes; 1,400 paying the special tax and 1,000 by the lowered mortgage exemption. ${ }^{412}$ This was expected to raise about $£ 325,000$; $£ 25,000$ from the lowered mortgage deduction ${ }^{413}$ and $£ 300,000$ from the special tax. ${ }^{414}$

In concession to concerns raised prior to the Bill's introduction ${ }^{415}$ that the special tax could impose unduly harsh burdens on taxpayers, the act also established a Commission of Inquiry to assess such cases. ${ }^{416}$ The Commission would decide if payment of the special tax would "on any fair and reasonable grounds whatsoever, entail serious hardship for the taxpayer" while the Commissioner of Taxes could then decide to remit some or all of the tax liability. ${ }^{417}$ The Bill originally limited hardship to being "by reason of the financial position of the taxpayer" ${ }^{418}$ but was changed during the committee stage to widen grounds for relief. ${ }^{419}$ The broad definition saw the Commission grant relief to 508 taxpayers. ${ }^{420}$ It remitted $£ 118,287,{ }^{421} 39.43$ percent of the total expected earnings of the

\footnotetext{
410 After accounting for the $5 \%$ rebate.

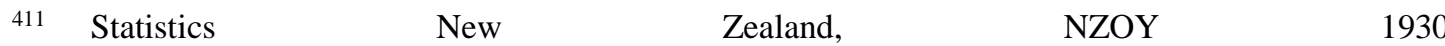
http://www3.stats.govt.nz/New_Zealand_Official_Yearbooks/1930/NZOYB_1930.html, Retrieved 18 September 2019. 
special tax. The Prime Minister was not happy with the situation, however, the government accepted the Commission's findings.

The Act also made farmers subject to income tax if they owned land with an unimproved value greater than $£ 14,000,{ }^{422}$ somewhat offset by giving a limited deduction for land tax paid. ${ }^{423}$ While income tax changes are normally outside the scope of this work, in 1929 the debate on land tax and farmers' income tax liability are heavily intertwined and cannot be discussed in isolation.

\subsubsection{Driving Policy Concerns}

By 1929 falling revenue, in both proportionate and nominal terms, had largely ended views of land tax as a major revenue source. Instead it was mostly enshrined as a corrective measure designed to encourage land subdivision. Revenue concerns were still raised however, and in 1929 there were three significant elements of land tax debate: revenue, fairness and subdivision.

\subsubsection{Revenue}

The root of revenue concerns can be found in the 1928 budget. That budget predicted a relatively small surplus ${ }^{424}$ but assumed a significant increase in revenue that never materialised, leaving the new United administration to deal with a $£ 577,252$ deficit. ${ }^{425}$ Additionally subdivision of estates had resulted in a steady shrinkage of land tax revenue for several years prior. ${ }^{426}$ The shortfall saw United and Labour call for heavier taxation ${ }^{427}$ and, while land tax changes were not sufficient to eliminate the deficit on their own, they would make a significant reduction. While most of the Reform Party simply ignored the deficit, some did address it, arguing that it was insignificant and extra revenue was not

\footnotetext{
422 Land and Income Tax Amendment Act 1929, s11(1).

423 Land and Income Tax Amendment Act 1929, s12.

424 Financial Statement, AJHR, 1928 Session I, B-06, page 17.

425 Financial Statement 1929, AJHR, 1929 Session I, B-06, page 6.

426 Refer note 425 , page 2.

427 NZPD, Volume 223, 25 September 1929 page 74, Rev. Clyde Carr; NZPD, Volume 223, 27 September 1929 page 167, Rt. Hon. Sir Joseph Ward.
} 
really needed ${ }^{428}$ or that it was a lie created as an excuse to institute a penal land $\operatorname{tax}^{429}$. Support for these positions, even within the opposition, does not appear widespread however.

\subsubsection{Fairness}

Traditionally fairness was a significant driver of tax policy and in 1929, Parliament's main concern was still who should pay the additional tax needed. Land tax was appealing to United and Labour because it was targeted and most New Zealanders did not pay it. Those few who did were generally wealthy and had been the main beneficiaries of the 1924 tax cuts. This aligned with the government's view that fairness in taxation should be based on vertical equity. The government's plan was simple, rather than raising all the required revenue from broad based taxation of the general population it would instead use the special land tax to raise a significant portion from the very wealthy. ${ }^{430}$ They were seen as most able to pay, ${ }^{431}$ and not presently paying their fair share of taxation. ${ }^{432}$

Unfortunately for the government, the primary group who had benefited from the $1920 \mathrm{~s}$ tax cuts were farmers, who were extremely resistant to any perceived rollback of those gains. While both United and Labour had campaigned on saying the existing tax system under-taxed farmers, there was significant opposition to the position from farmer organisations and Reform.

The key argument was that the proposed taxation was unfair. While government had based its fairness argument on vertical equity, opposition suggested the proposals were not neutral and were unfair to farmers and the wealthy.

Complaining that land tax was unfair to farmers was an argument as old as the tax itself, but Reform placed much more importance on it in 1929. This had two elements. The first stressed farmers character as New Zealand's best residents, ${ }^{433}$ suggested that because they

\footnotetext{
428 NZPD, Volume 223, 26 September 1929, page 78, Arthur Hall.

429 NZPD, Volume 223, 26 September 1929, page 86, Hugh Campbell.

430 NZPD, Volume 223, 25 September 1929, page 69, Cecil Clinkard.

431 NZPD, Volume 223, 25 September 1929, page 45. Michael Joseph Savage.

$432 \quad$ Refer note 412.

433 NZPD, Volume 223, 25 September 1929, page 73, Adam Hamilton.
} 
produced goods and were developing the country it was not "just, right or equitable"434 to subject them to higher taxation. The second focused on the tax's economic effect on farmers. This argued that the 1929 changes placed a significant burden on working farmers and genuine settlers ${ }^{435}$ and risked driving them off the land, despite poorer farmers not actually being affected. ${ }^{436}$ Likewise wealthier farmers were portrayed as in a state of near poverty due to increasing expenses ${ }^{437}$ that would see them bankrupted by the special tax, ${ }^{438}$ and could drag small farmers down with them. ${ }^{439}$ There was also some suggestion that the additional costs of taxation would discourage investment in farming 440 and would leave New Zealand agriculture unable to compete internationally, ${ }^{441}$ risking economic stability. In the case of the obviously rich, the special tax was argued to be punishing success, ${ }^{442}$ and a case of the democratic majority forcing unjust higher taxation on a minority who could not respond. ${ }^{443}$

The tax rates themselves, particularly the 6.21 percent, were seen as unreasonably high ${ }^{444}$ and akin to land nationalisation. ${ }^{445}$ This was seen as particularly unfair because the special tax exempted urban business, which farmers and their advocates thought was discriminatory ${ }^{446}$ and an attempt to move the tax burden off cities. United did not help the situation by giving very little justification for why urban land was exempt, beyond

\footnotetext{
434 NZPD, Volume 223, 25 September 1929, page 44, Hon. William Downie Stewart.

435 Refer note 429.

436 NZPD, Volume 223, 25 September 1929, page 58, Frank Langstone.

437 NZPD, Volume 223, 27 September 1929, page 147, Rt. Hon. Gordon Coates.

438 NZPD, Volume 223, 25 September 1929, page 55, William Lysnar.

439 NZPD, Volume 223, 26 September 1929, page 111, David Jones.

440 NZPD, Volume 223, 25 September 1929, page 74, Adam Hamilton.

441 NZPD, Volume 223, 26 September 1929, page 112, David Jones.

442 NZPD, Volume 223, 26 September 1929, page 95, Fred Waite.

443 NZPD, Volume 223, 25 September 1929, page 72, Adam Hamilton.

444 NZPD, Volume 223, 25 September 1929, page 69, Adam Hamilton.

445 NZPD, Volume 223, 25 September 1929, page 40, Hon. William Downie Stewart.

446 NZPD, Volume 223, 25 September 1929, page 68, William Polson.
} 
suggesting that city landholding tended to be of smaller areas and the government was not trying to subdivide them. ${ }^{447}$

These arguments aligned to a strong pro-farming feeling within Reform. While they were strongly critical of perceived bias towards other groups, they generally approved of bias favouring farmers. This was best showcased on income tax, which Reform felt should replace land tax for farmers ${ }^{448}$ to create more "equitable taxation" 449 as it would be "almost pleasant to pay". ${ }^{450}$ This was despite Reform members having argued for years, and some continuing to do so, ${ }^{451}$ it was unfair for farmers to pay income tax, despite everyone else doing so. Even the proposed approach would favour farmers compared to urban businesses, which generally paid both land and income taxes. This suggests that the opposition did not object to unfairness or bias within the tax system but rather that it would benefit a group other than farmers.

\subsubsection{Subdivision}

The final major element used to justify the special tax was that it would encourage land subdivision and closer settlement. ${ }^{452}$ This was one of the few areas where land tax remained preeminent as "no income tax will ever break up big estates". ${ }^{453}$ There was no significant evidence indicating that this had actually happened previously and questions as to whether it would continued to be raised. ${ }^{454}$ However, by 1929 the problems had progressed further and there were questions if the "busting up" aspect of land tax was

\footnotetext{
447 NZPD, Volume 223, 27 September 1929, page 168, Rt. Hon. Sir Joseph Ward.

448 New Zealand Herald, 24 September 1929, Land Tax Proposals.

449 Refer note 438.

450 NZPD, Volume 223, 25 September 1929, page 73, Adam Hamilton.

451 NZPD, Volume 223, 26 September 1929, page 97, Charles MacMillan.

452 Refer note 414.

453 NZPD, Volume 223, 26 September 1929, page 102, Harry Holland.

454 NZPD, Volume 223, 25 September 1929, page 48, Alexander Young.
} 
needed. ${ }^{455}$ While there was generally bipartisan support settling more people upon the land, ${ }^{456}$ there was debate as to when, if at all, subdivision was desirable. ${ }^{457}$

United and Labour backed increased subdivision and checking land aggregation as a means to settle more people upon land, while Reform backed the policy in principle. Subdivision was important to the government, particularly United who promised to restart the Liberals' closer settlement policy, ${ }^{458}$ but New Zealand society had changed since the Liberals held office. Under William Massey, the Reform government had been successful at transforming populist demand for farm ownership into demand for education and homeownership (Belich, 2001, pp. 154, 397). The opposition's views were largely adapted to this new consensus. With lessened demand for new farming opportunities, there was less pressure to subdivide existing farms. Therefore Reform only supported subdivision of farms in limited circumstances; when it was "suitable" and they were "not rendering their full measure of economic service to the community", ${ }^{459}$ qualifiers that were very non-specific. As such Reform argued that there were many farms which, for reasons of economic infeasibility or insufficient infrastructure, ${ }^{460}$ could not be subdivided $^{461}$ and therefore should not be subject to higher taxation designed to encourage subdivision. ${ }^{462}$ United's exemption of urban land suggests there were circumstances where the government saw subdivision as inappropriate, but limited explanation was given as to why. Logically this could give grounds to an exemption for farms unsuitable for subdivision but the legislation ignored the possibility.

Even when there was support for subdivision, it was often thought that land tax was not the best way to do it and there was significant support for compulsory purchase of land.

\footnotetext{
$455 \quad$ Refer notes 376 , page $12 ; 385$, page 4.

456 NZPD, Volume 223, 25 September 1929, page 41, Hon. William Downie Stewart.

457 NZPD, Volume 223, 25 September 1929, page 42, Hon. William Downie Stewart.

458 Stratford Evening Post, 17 October 1928, Land Aggregation.

459 NZPD, Volume 223, 25 September 1929, page 49, Alexander Young.

$460 \quad$ Refer note 459.

$461 \quad$ Refer note 456.

462 Refer note 448.
} 
Labour had suggested doing so during the election and remained supportive of the idea. ${ }^{463}$ Somewhat surprisingly some farmer advocates also backed it, calling for the reintroduction of the 1891 compulsory purchase rules ${ }^{464}$ their conservative forbears had decried as draconic. That in 1929 the government lacked the funds to make active use of such power is largely ignored, although that low likelihood of use would explain some of the conservative support.

The other problem with using land tax to encourage subdivision was its effect on revenue; the dual aims are inherently contradictory, achieving either one largely being at the expense of the other. Clark had noted this is $1924^{465}$ and by 1929 politicians had reached the same conclusion. Reform feared it would in the future lead to widening the special tax to more of the tax scale in order to protect the revenue base. ${ }^{466}$ Sir Joseph Ward acknowledged it in the budget but did not actually address it, heavily emphasising both the tax's revenue and its encouragement of subdivision. ${ }^{467}$ This could work in the short term, which given the budget deficit was likely the government's primary concern, but it was not a sustainable system.

Despite the opposition, the United government passed its 1929 land tax changes into law with Labour's support. This was not the end of the issue, however, and in 1930 the government found itself dealing with the politically charged special tax once again.

\subsection{0 - 1935, Into the Depression}

From 1930 the New Zealand government found itself dealing with the Great Depression. Following the deterioration of Sir Joseph Ward's health, which had been very poor since September 1929, he was forced to resign and was replaced as both Prime Minister and Minister of Finance by his deputy George Forbes. As Table 1 demonstrates, revenue

\footnotetext{
463 NZPD, Volume 223, 25 September 1929, page 52, Hubert Armstrong.

464 Refer note 429.

465 Refer note 385 , page 32.

466 NZPD, Volume 223, 25 September 1929, page 50, Alexander Young.

467 Refer note 425, page 2.
} 
initially improved and there was a modest surplus in 1930. That did not last and by 1931 revenue had dropped by 9.00 percent on the previous year, resulting in a deficit.

Table 1. New Zealand Government Revenue and Expenditure, 1927-1936468

\begin{tabular}{|l|c|c|r|}
\hline $\begin{array}{l}\text { Year ended } \\
\text { 31st March. }\end{array}$ & Revenue. & Expenditure & Surplus. \\
\hline & $f$ & $f$ & \multicolumn{1}{c|}{$f$} \\
\hline 1927 & $24,943,107$ & $24,355,965$ & 587,142 \\
\hline 1928 & $25,123,980$ & $24,944,905$ & 179,075 \\
\hline 1929 & $23,599,676$ & $24,176,928$ & $-577,252$ \\
\hline 1930 & $25,349,861$ & $25,200,882$ & 148,979 \\
\hline 1931 & $23,068,931$ & $24,708,042$ & $-1,639,111$ \\
\hline 1932 & $22,719,733$ & $24,860,552$ & $-2,140,819$ \\
\hline 1933 & $22,568,521$ & $22,528,379$ & 40,142 \\
\hline 1934 & $23,492,749$ & $24,202,027$ & $-709,278$ \\
\hline 1935 & $26,126,094$ & $24,499,595$ & $1,626,499$ \\
\hline 1936 & $26,172,368$ & $25,890,568$ & 281,800 \\
\hline
\end{tabular}

George Forbes appeared to lack any clear plan for dealing with the Depression beyond waiting and hoping something improved (Gardner, 1996). In 1931 the few measures the government did take to combat worsening depression alienated its Labour allies. Following wage cuts in the Finance Act 1931, Labour withdrew its support for the government (Gardner, 1996). In response United entered coalition with Reform, although its support came at a high cost. George Forbes remained the Prime Minister but most of the important cabinet positions, including the Minister of Finance, were ceded to Reform. Lacking much by way of ideological commonality, this alliance was mostly bound together by the goal of keeping Labour out of government.

The new cabinet, rather than reflecting a mix of backgrounds, consisted of nine farmers and one lawyer (Belich, 2001, p. 256). While Forbes may not have had plans for dealing with the depression, his replacement as Minister of Finance did. William Downie Stewart attempted to retrench New Zealand out of depression, instituting large spending cuts in an effort to balance the budget. When William Downie Stewart, the only non-farmer in the cabinet, resigned in 1933 he was replaced by Gordon Coates, who adopted a similar

\footnotetext{
468 Statistics New

Zealand,

NZOY

1937 http://www3.stats.govt.nz/New_Zealand_Official_Yearbooks/1937/NZOYB_1937.html, Retrieved 18 September 2019.
} 
economic approach. While the methods made the coalition highly unpopular the government budget was returned to surplus in 1935 .

The government were not the only ones struggling. By 1933 falling international commodity prices saw New Zealand's export receipts fall by 44 percent from their 1929 levels (Belich, 2001, p. 256) hurting farmers. Real wages remained largely stable as consumer prices fell at least as much as wage rates ${ }^{469}$ but unemployment and underemployment rose. While the harshness of the Depression in New Zealand is not especially clear, consumption of essentials and luxuries fell significantly across the board, even among the wealthy who were less affected (Belich, 2001, p. 256). Faced with these troubles, the government instituted various palliative measures with limited success.

\subsubsection{Urban Versus Rural}

With the Depression worsening in both 1930 and 1931 the government found itself needing to increase tax revenue while having a population base that was struggling to pay existing taxation. This made wide tax increases difficult to justify so a more politically palatable tax swap was implemented instead.

Total land tax for the 1929-1930 financial year was $£ 1,240,000 .{ }^{470}$ This was more than the 1929 's $£ 1,140,324$ but less than the $£ 1,442,000$ predicted. ${ }^{471}$ The special tax raised $£ 240,000$ following the recommendations made by the hardship commission. ${ }^{472}$ Normal land tax returns had fallen alongside the worsening economic conditions as taxpayers lacked the money to pay it. ${ }^{473}$ By 1931 land tax revenue had fallen further to $£ 1,145,617^{474}$ while the budget had returned to deficit.

\footnotetext{
469 Statistics New $\quad$ Zealand, NZY

http://www3.stats.govt.nz/New_Zealand_Official_Yearbooks/1935/NZOYB_1935.html,

Retrieved 18 September 2019.

470 Financial Statement 1930, AJHR, 1930 Session I, B-06, page 35.

$471 \quad$ Refer note 425 page 27.

472 Refer note 470, page 37.

473 Refer note 470, page 27.

474 Financial Statement 1931, AJHR, 1931 Session I-II, B-06-Part01, page 20.
} 
The onset of the Depression shifted the development of land tax from the increases United had campaigned on and implemented in 1929, instead the government's solution in both years was to decrease it while increasing other taxes. In 1930 this took the form of taking land tax rates back to their 1923 state, abolishing both the special tax ${ }^{475}$ and the 5 percent rebate, ${ }^{476}$ while reducing the threshold for farmers to be liable for income tax to an unimproved value of $£ 7,500^{477}$ and increasing income tax by 10 percent. ${ }^{478}$ This was forecast to raise "practically the same revenue". ${ }^{479}$ In 1931 the approach was to simply replace the graduated land tax with a flat land tax of $1 \mathrm{~d}$ per $£ 1$ of land value, ${ }^{480}$ while increasing income tax ${ }^{481}$ and lowering its threshold for farmer liability. ${ }^{482}$

It is inherent in a tax swap that some parties will be worse off while others will benefit. In 1929 United had taken tentative steps to reduce favouritism towards farmers under the existing tax system. In 1930 George Forbes' continued push for that goal, highlighting the worst cases found following the 1929 changes, ${ }^{483}$ but as economic conditions worsened he claimed that the special tax was too blunt a tool to do so. The new changes were suggested to be an attempt to see "the $[\operatorname{tax}]$ burden... more equitably distributed"484 without compromising government revenue but were vague as to how they would actually alter the tax base. The position was best demonstrated by William Downie Stewart who claimed the 1931 changes would see the tax burden would fall largely on the same

\footnotetext{
475 Land and Income Tax Amendment Act 1930, s2.

476 Land and Income Tax (Annual) Act 1930, Schedule, Part I.

477 Land and Income Tax Amendment Act 1930, s4.

Land and Income Tax (Annual) Act 1930, Schedule, Part II, 4.

479 Refer note 470, page 34.

Land and Income Tax (Annual) Act 1931, s2.

$481 \quad$ Refer note 474.

482 Land and Income Tax Amendment Act 1931, s4.

483 Refer note 470 , page 3.

$484 \quad$ Refer note 470, page 34.
} 
shoulders as those paying the existing tax but "the individual incidence will be different". ${ }^{485}$

Despite George Forbes' rhetoric, both 1930 and 1931 saw the pro-farmers bias within the tax system become more entrenched, undoing any progress made in 1929. The government could not, or would not, explain where the new tax burden would fall; ${ }^{486}$ despite William Downie Stewart's claim however, it did not largely fall on the same individuals. The abolition of the special tax and graduation saw significant tax cuts for a group of taxpayers that was disproportionately made up of wealthy farmers. These cuts were paid for by decreasing the general exemption for income tax, which increased the number of liable taxpayers by 36.0 percent, ${ }^{487}$ and a significant increase in the rates. Since only 3,800 farmers nationally were liable for income tax, ${ }^{488}$ most of whom benefited significantly from the land tax cuts, the burden of the revived tax system largely fell on urban residents and businesses who generally paid income tax and got little to no relief from the land tax cuts. Broadly the tax changes gave tax relief to wealthy farmers but significant increases to businesses ${ }^{489}$ and workers. ${ }^{490}$

This was a significant shift of the tax burden onto towns. While government MPs did not describe the policy as such, others did, claiming that it reflected a strong rural bias in the cabinet ${ }^{491}$ which favoured farmers for depression relief. Even one member of Reform was concerned that the policy was "too great an agricultural bias". 492

485 Supplementary Financial Statement 1931, AJHR, 1931 Session I-II, B-06-Part02, page 4.

486 NZPD, Volume 230, 14 October 1931, page 248, William Endean.

$\begin{array}{llll}487 \text { Statistics } & \text { New } & \text { Zealand, }\end{array}$

http://www3.stats.govt.nz/New_Zealand_Official_Yearbooks/1933/NZOYB_1933.html,

Retrieved 18 September 2019. 
Land tax had long been unpopular with farming interests but prior to the Depression that had been insufficient to trigger rollbacks comparable to 1930 and 1931. The Depression changed the status quo however. In 1923 the existence of actual hardship and poor export prices had been used to justify exempting farmers from income tax in order to give them relief. ${ }^{493}$ During the Depression economic conditions were worse than 1923, with the hardship more widespread and apparent, allowing the same argument to be used in the 1930s to more success. In 1930 it was George Forbes's main defence for land tax cuts against the spirit of his party's election campaign, ${ }^{494}$ while William Downie Stewart ${ }^{495}$ and Gordon Coates ${ }^{496}$ used it in 1931 to justify ending graduation.

Arguments of farmer hardship relief should not be taken at face value, however, as the repeals of graduation and the special tax were a largely inefficient way to help. Fewer than 30 percent of farmers ${ }^{497}$ actually paid either the special tax or graduated land tax and the others received no benefit. While the government argued the benefits to small farmers were "too obvious to need an explanation", ${ }^{498}$ Gordon Coates did concede it gave them no help. ${ }^{499}$ Among those who did benefit, only the very wealthy saw significant relief. Some middle class farmers may have even been worse off as they got little land tax relief but found themselves newly liable for the increased income tax, showing that even within the farming sector tax was becoming more regressive.

George Forbes took a different approach for why tax relief appeared to be concentrated mostly on the wealthy. He argued that New Zealand's large landowners were suffering from the depression more than anyone else in the country and the government had an obligation to relieve hardship when it was shown. ${ }^{500}$ The claim was bold and, as Labour

\footnotetext{
493 NZPD, Volume 223, 26 September 1929, page 108, David Jones.

494 NZPD, Volume 225, 21 August 1930, page 459, Rt. Hon. George Forbes.

$495 \quad$ Refer note 485 , page 3.

496 NZPD, Volume 230, 14 October 1931, page 280, Rt. Hon. Gordon Coates.

$497 \quad$ Refer note 411.

498 NZPD, Volume 230, 14 October 1931, page 237, Hon. William Downie Stewart.

499 NZPD, Volume 230, 14 October 1931, page 282, Rt. Hon. Gordon Coates.

500 NZPD, Volume 230, 14 October 1931, page 257, Rt. Hon. George Forbes.
} 
pointed out, "they are not going to the Hospital Boards [for aid] yet". ${ }^{501}$ Whatever hardship the large landowners were suffering they could generally feed their families, while much of the population struggled (Belich, 2001, p. 257) but the government was not in a hurry to help them. This makes George Forbes's assertion that the large landowners were suffering most bizarre, but he simply asserted the tax changes were in the best interest of New Zealand as a whole. ${ }^{502}$

While most farmers do not appear to have benefitted much from the abolition, one occupation group does appear to have received significant relief. Taxpayers operating in banking, insurance and finance had paid an average of $£ 684$ in land tax each year, ${ }^{503}$ more than 31 times the average of $£ 22$ paid by liable farmers. Under the new tax system these taxpayers would see an average tax saving of $£ 482$ each. While the number of taxpayers in the financial sector appears quite small, unlike farmers, they do appear to have generally received significant benefits.

Despite the assistance to those taxpayers operating in banking, finance and insurance, the government did not champion the changes as aid to the sector in the same way it trumpeted the more limited relief to farming; rather it was not mentioned at all. It is possible the government simply had not analysed its legislative proposal in enough detail to know its wider effects but this seems unlikely as Labour expressly complained about banks not needing the relief they were getting. ${ }^{504}$ The more likely reason for the silence is the unpopularity of banks. Traditionally banks had been disliked by New Zealand populism (Belich, 2001, p. 260) and potential tax breaks for them were generally met with hostility. However, with the depression worsening, and banks foreclosing on homes, New Zealand populism had deemed "money power" an enemy of the people (Belich, 2001, p. 260). Silence was likely an attempt to shield the government from political fallout.

Alternatives to land tax cuts were considered. William Downie Stewart proposed a complete repeal of land tax, to be replaced with income tax, in $1930^{505}$ but felt the political

\footnotetext{
501 NZPD, Volume 230, 14 October 1931, page 257, James McCombs.

502 Refer note 500.

503 Refer note 411.

504 NZPD, Volume 230, 14 October 1931, page 244, Frank Langstone.

505 NZPD, Volume 225, 21 August 1930, page 461, Hon. William Downie Stewart.
} 
climate was wrong for doing so. ${ }^{506}$ The idea persisted as a potential cost cutting measure, it was hoped doing so would allow the government to abolish the Valuation Department and half the tax department to save on the cost of running them, ${ }^{507}$ but this does not appear to have gone further. Labour wanted less farmer friendly changes and suggested keeping the special tax but with a higher threshold ${ }^{508}$ and tax cuts only on land worth less than $£ 5,000$ to target relief to those more likely to need it. ${ }^{509}$ The government did not agree however.

\subsubsection{Aftermath}

No party was particularly fond of the 1930 changes. United made it clear that if commodity prices had not fallen they would have re-imposed the special tax and believed that most of those liable would have little trouble paying it, ${ }^{510}$ while Labour thought the changes excessively favoured the wealthy and Reform felt they did not go far enough. Nonetheless the changes they proposed were passed into law with unanimous support.

The 1931 abolition of graduation was more controversial. The United government did not originally plan any significant land tax changes in 1931, only including the flat rate once Reform joined the coalition. This overturned longstanding political consensus and, combined with the Bill's rapid progression through Parliament, ${ }^{511}$ contributed to an impression that the legislation had been hastily drawn up without significant consideration of its effects. ${ }^{512}$ Labour was actively hostile to the measure, seeing it as unfair tax relief for wealthy farmers at the expense of the poor ${ }^{513}$ and tried during the

\footnotetext{
$506 \quad$ Refer note 505.

507 Evening Post, 26 July 1933, Taxation Relief.

508 NZPD, Volume 225, 21 August 1930, page 466, Michael Joseph Savage.

509 NZPD, Volume 230, 14 October 1931, page 236-237, Michael Joseph Savage.

510 NZPD, Volume 225, 21 August 1930, page 490. Rt. Hon. George Forbes.

511 The Bill was passed 12 days after being announced.

512 Refer note 486.

513 NZPD, Volume 230, 14 October 1931, page 272, Walter Nash.
} 
committee stage to both delay its start date ${ }^{514}$ and retain graduation. ${ }^{515}$ Labour's amendment to maintain graduation was supported by defectors from both United and Reform ${ }^{516}$ but their numbers were insufficient and United and Reform easily passed their tax changes, marking the last changes to land taxation until 1936.

Unsurprisingly the changes in both 1930 and 1931 reduced land tax revenue, as shown in Table 2. The abolition of the special tax saw nominal land tax revenue fall and land tax's percentage of total tax revenue the lowest since its implementation. ${ }^{517}$ However, the effect abolishing graduation had on land tax receipts was catastrophic. In 1932 land tax collected less than half of what it had the previous year and fell further as a percentage of government revenue. It was now earning less than beer duty ${ }^{518}$ and continued to fall in subsequent years. While land tax had not been a truly significant source of tax revenue for years, the abolition of graduation largely gutted what use it had in raising revenue for the government.

Table 2. Land Tax Revenue, 1929-1936 519

\begin{tabular}{|r|r|r|}
\hline $\begin{array}{r}\text { Year Ended } \\
\text { 31st March }\end{array}$ & Land Tax Revenue & $\begin{array}{c}\text { Land Tax as a } \\
\text { Percentage of } \\
\text { Total Tax Revenue }\end{array}$ \\
\hline 1929 & $1,140,324$ & $6.39 \%$ \\
\hline 1930 & $1,506,911$ & $7.74 \%$ \\
\hline 1931 & $1,145,617$ & $6.07 \%$ \\
\hline 1932 & 542,128 & $3.11 \%$ \\
\hline 1933 & 498,916 & $2.53 \%$ \\
\hline 1934 & 498,978 & $2.32 \%$ \\
\hline 1935 & 492,526 & $1.99 \%$ \\
\hline 1936 & 458,873 & $1.80 \%$ \\
\hline
\end{tabular}

514 NZPD, Volume 230, 14 October 1931, page 289.

515 NZPD, Volume 230, 14 October 1931, page 293.

516 Refer note 515.

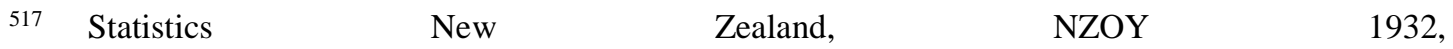
http://www3.stats.govt.nz/New_Zealand_Official_Yearbooks/1932/NZOYB_1932.html, Retrieved 18 September 2019.

$518 \quad$ Refer note 468.

519 Refer note 468. 
The law changes of 1931 capped off a tumultuous three years in land tax reform. In this it somewhat mirrors the wider political landscape of the time, where the Great Depression arose and politicians often found themselves dealing with matters outside their control and competence. The three year period between 1929 and 1931 saw no elections but contained two Prime Ministers, three Ministers of Finance, two different government coalitions and four budgets. This was not a time of stable government.

\subsection{6, First Labour}

The United-Reform coalition persisted until 1935. With public frustration growing, radical organisations across the political spectrum, ranging from communists and Social Credit to the nationalist conservative New Zealand Legion, flourished (Belich, 2001, p. 257). The chief beneficiary was the Labour Party. In the election Labour, led by Michael Joseph Savage, won with 53 of Parliament's 80 seats; Reform and United fell to 9 and 7 seats respectively. After five years under the farmer focused coalition, New Zealand was now headed by the most left wing government outside the Soviet Union (Belich, 2001, p. 259).

Labour's first amendments to the Land and Income Tax Act 1923 saw significant reforms. While income tax had its bracket system simplified and its rates almost doubled, ${ }^{520}$ Labour's changes to the land tax essentially rolled it back to where it had stood in 1930. The centrepiece was the reintroduction of graduation but with a new scale rather than reintroducing the 1930 one. The new scale maintained the flat rate of $1 \mathrm{~d}$ per $£ 1$ of land value for land valued $£ 5,000$ or less; ${ }^{521}$ which had been the threshold for graduated land taxation until 1916. Above $£ 5,000$ the tax rate increased much more rapidly than it previously had, reaching the new maximum rate of $6 \mathrm{~d}$ per $£ 1$ at $£ 45,000$. Compared to the flat tax, taxation on all land valued greater than $£ 5000$ was increased. In an act of consistency previously unseen in land taxation, these rates were maintained for the remainder of Labour's time in office.

\footnotetext{
520 Land and Income Tax (Annual) Act 1936, Schedule, Part II.

521 Land and Income Tax (Annual) Act 1936, Schedule, Part I, 1.
} 
Labour also made several other changes to the land tax; two of which were particularly notable. First, Native land tax was aligned with the Native Land Act $1931^{522}$ so it no longer excluded "half-caste Māori" from being Māori. ${ }^{523}$ This meant that lands owned by "half-caste Māori" were no longer taxable unless they were rented out, reversing a situation that had existed since Reform's first changes to land tax in 1912. Secondly, to combat potential tax avoidance before it began, Labour also reinstated lessee liability for land tax, ${ }^{524}$ previously abolished alongside graduation.

Labour's other changes were to exempt land owned by superannuation funds from land $\operatorname{tax}^{525}$ and further reduce taxation of land held for religious purposes to one quarter of the standard rate. ${ }^{526}$

\subsubsection{Reasoning}

The fall of the coalition triggered another rebalancing of the tax system, with reexamination of whom taxation should fall upon and the ideological influences upon tax policy. Coalition policy had been driven by the farmer backbone but Labour reprioritised tax equity. Labour felt that what was wrong with New Zealand was not a failure of economic production but rather "maldistribution", with the poor having too little. ${ }^{527}$ Instead the party wanted to target the tax system according to wealth and place taxation "on the shoulders of those best able to bear it". ${ }^{528}$ The phase "best able to bear it" had been used to justify a variety of tax measures previously but for Labour this meant removing the burden of taxation from the poorer sections of the community ${ }^{529}$ while imposing taxation that would increase alongside taxpayer buying power and provide

\footnotetext{
$522 \quad$ Native Land Act 1931, s2.

523 Land and Income Tax Amendment Act 1936, s2(1).

524 Land and Income Tax Amendment Act 1936, s3.

525 Land and Income Tax Amendment Act 1936, s4.

526 Land and Income Tax Amendment Act 1936, s5.

527 NZPD, Volume 247, 25 September 1936, page 422, Rt. Hon. Michael Joseph Savage.

528 NZPD, Volume 247, 25 September 1936, page 423, Rt. Hon. Michael Joseph Savage.

529 NZPD, Volume 247, 25 September 1936, page 426, Rt. Hon. Michael Joseph Savage.
} 
revenue that could be used to help the poor and deserving. Labour's concept of tax equity was a system that considered the fairness of taxpayer's liability in relative rather than in absolute amounts; ${ }^{530}$ those with the means to pay more should do so. Michael Joseph Savage described it as "tax that will clip some of what is going to those who are already rich, and give it to those who are poor", 531 or "Christianity in practice". ${ }^{532}$ Labour saw raising the living standard of the poor as a primary concern, preferring to raise taxes rather than "keep some people on the verge of starvation". 533

This was a more redistributive approach to taxation than New Zealand had previously tried. Taxing the wealthy more was established, but state assistance less so. Traditionally taxpayers were given assistance by lowering their tax burden, as in 1931, and while the coalition introduced some assistance schemes during the Depression these were generally targeted at farmers. Labour's approach was much wider and attempts to create this redistributive system went well beyond the land tax. This included aims to make heavier use of income tax and move away from indirect taxation, which fell too heavily on the poor. ${ }^{534}$ Reintroducing graduated land tax was not an especially significant part of the plan from a revenue perspective but it did align with the guiding idea of what fairer taxation looked like.

This reprioritisation of fairness in tax policy development should not be seen as an attack on farmers, New Zealand's populist compact valued sectorial harmony too much for that to be a successful political strategy. Labour's working class roots meant that it could already be seen as an enemy of sectorial harmony (Belich, 2001, p. 259) so the response appears to have been to deemphasise class differences in their tax policy. Labour did not fully reverse New Zealand's tax system to fall excessively on farmers nor did it enact the

\footnotetext{
530 NZPD, Volume 247, 25 September 1936, page 424, Rt. Hon. Michael Joseph Savage.

$531 \quad$ Refer note 527.

532 Refer note 528.

533 Refer note 530.

534 Refer note 529.
} 
heavier tax rates that it had previously considered. Instead it was hoped that non-wealthy farmers would continue to see little tax imposed upon them. ${ }^{535}$

Likewise there was also no mention by Labour of forcing farmers to subdivide their landholdings. Previously Labour had been very supportive of land tax as a subdivision tool and had claimed that a sufficiently higher land tax rate in the past would have made it impossible for large landowners to exist. ${ }^{536}$ While Labour continued to express support for the subdivision of land, ${ }^{537}$ they did not suggest that the land tax was intended to do so. This was not an accidental omission and the Minister for Land later explained that Labour's position was that the primary purpose of the land tax was instead to "provide a return to the State from the individual or company relative to benefits derived through being the owner of land", not to encourage subdivision. ${ }^{538}$ First mentioned in the budget, ${ }^{539}$ this was a reintroduction of Georgist principles, although not the Georgist method, of land taxation to New Zealand's land tax debate rather than continuing with the ideological underpinning that had previously developed in New Zealand. It may also reflect Labour adapting to societal demands changing from farm ownership to general homeownership, which made farm subdivision much less desired, or part of Labour's softening of its more radical policies in an attempt to improve its popularity with voters.

The lack of focus on subdivision also addressed the two longstanding problems with the graduated land tax: the inherent revenue-subdivision contradiction and the lack of evidence that it actually encouraged subdivision. By not linking land tax and subdivision, Labour freed the policy from the inherent paradox that limited its effectiveness and undermined a significant part of the opposition's objections.

Policy opposition was rooted in the farmer backbone, with arguments very similar to those used to justify the 1931 abolition. George Forbes argued farmers and large

535 Financial Statement 1936, AJHR, 1936 Session I, B-06, page 17.

536 NZPD, Volume 230, 14 October 1931, page 237, Rt. Hon. Michael Joseph Savage.

537 NZPD, Volume 247, 25 September 1936, page 420, Hon. Walter Nash.

538 Auckland Star, 14 August 1937, Land Values.

539 Refer note 535, page 17. 
landowners had suffered "the greatest financial difficulty" during the depression ${ }^{540}$ would be unable to pay the restored graduation. ${ }^{541}$ These taxpayers were struggling and National saw it as the responsibility of government to help them, not tax them more. ${ }^{542}$ While this was a strange argument given the widespread hardship during the depression and the coalition's limited help to non-farmers, it clearly demonstrated the farmer backbone mind-set where the concerns of other groups were largely ignored. There were also the standard arguments about rewarding farmers' good character and that many farms could not be subdivided. ${ }^{543}$ However, even the Farmer's Union conceded graduated tax would not fall on most farmers. ${ }^{544}$

There were also objections surrounding fairness and business concerns. Conservatives agreed the existing tax system was not equitable ${ }^{545}$ but saw Labour's redistributive system as establishing a "burglar's paradise", 546 of taking from hard workers to give to the idle. Businesses were worried about increased costs and were concerned it would discourage enterprise. ${ }^{547}$ These were subject to much less attention than farmer issues however.

1936 saw another clash between equity and farming to be the dominant ideological influence on policy. This time equity won out, seeing a significant reversal in reasons justifying land tax. However, this did not reverse the privileged position of farmers within the tax system and Labour's focus on land tax's revenue potential as part of a progressive tax system largely ended views of it as a social policy measure. While the new land tax was stronger than it had been since 1931 it was still a less important part of the tax system.

\footnotetext{
540 NZPD, Volume 247, 25 September 1936, page 420, Rt. Hon. George Forbes.

541 NZPD, Volume 247, 25 September 1936, page 419, Rt. Hon. George Forbes.

542 Refer note 540.

543 NZPD, Volume 247, 25 September 1936, page 435, Hon. Adam Hamilton.

544 New Zealand Herald, 18 October 1937, Graduated Land Tax.

545 NZPD, Volume 247, 29 September 1936, page 481, Rt. Hon. Gordon Coates.

546 NZPD, Volume 247, 24 September 1936, page 384, Sidney Holland.

547 NZPD, Volume 247, 24 September 1936, page 366, Sidney Holland.
} 


\subsection{The Continued Decline of Land Tax 1937 - 1949}

Despite Labour's historical support for increasing land taxation, the party made no significant reforms after 1936. Indeed, while general taxation was significantly overhauled under Labour, land tax experienced a previously unseen period of consistency. No further changes were made to the rates and no major overhauls were made to the land taxation system. Legislative changes for the rest of the 1930s were relatively minor. The most prominent was the establishment of a new land tax hardship committee in $1937,{ }^{548}$ although it was much more restricted than the 1930 version. Parliament acted to override court decisions it disagreed with, affirming lease liability ${ }^{549}$ to overrule the decision of the Court of Appeal in De Luxe Theatre Company, Limited v Commissioner of Taxes ${ }^{550}$ in 1939 and removing land tax from the general anti-avoidance rule $^{551}$ in 1940 to allow apportionment and overrule the Court of Appeal's decision in Charles $v$ Lysons. ${ }^{552}$

While it is not strictly a land tax change, from 1940 Labour allowed land tax to be treated as an expense for the purpose of calculating liability for income tax. ${ }^{553}$ This applied to both individuals and companies and lowered the effective rate of land tax.

\subsubsection{Revenue Following the Reintroduction of Graduation}

With the reintroduction of graduation, Labour had hoped to significantly increase land tax revenue. Initial hopes of $£ 1,300,000^{554}$ proved optimistic and the inability of taxpayers to pay the tax in the poor economy limited revenue to $£ 1,047,877 .{ }^{555}$ Following

\footnotetext{
$548 \quad$ Finance Act 1937 s20.

549 Finance Act 1939, s20(1).

550 De Luxe Theatre Company, Limited v Commissioner Of Taxes - [1939] NZLR 268.

551 Land and Income Tax Amendment Act 1940, s12.

$552 \quad$ Refer note 283.

553 Land and Income Tax Amendment Act 1940, s6.

$554 \quad$ Refer note 535, page 18.

555 Financial Statement 1937, AJHR, 1937 Session I, B-06, page ii.
} 
this the government appears to have decided on a target of $£ 1,000,000$ per year, ${ }^{556}$ which land tax mostly failed to meet. Instead revenue slowly declined until 1948. Some of this was due to land values, which fell consistently from 1930 to 1943 and declined by 19.69 percent nationally. ${ }^{557}$ Even when the economy started to recover, it took until 1951 for land values to return to pre-depression levels.

Further exacerbating the problem was the income tax deduction for land tax that Labour had introduced in 1940. This meant that land tax paid lowered income tax receipts. By 1952 this decrease was estimated to be $£ 400,000$ to $£ 500,000$ yearly. ${ }^{558}$ This meant that the net revenue of land tax was $£ 500,000-£ 600,000$ per year, only slightly more than had been collected when graduation had been abolished.

The slow decline of land tax revenue was worse when considered in the context of New Zealand's tax system at the time. As Table 3 shows, total taxation was significantly increased following Labour's election. Much of the increase was income tax, but most taxes saw large increases. This made land tax revenue largely insignificant as it became one of the smallest sources of taxation (only the film hire tax collected less). For comparison, by 1950 it collected roughly one fifth the revenue beer duty did.

556 Report Upon The Provisions And Operation Of The Land And Income Tax Act 1923 And Its Amendments, 1937, page 214, Archives New Zealand IRW2844 11.

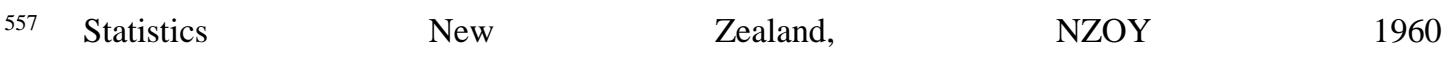
http://www3.stats.govt.nz/New_Zealand_Official_Yearbooks/1960/NZOYB_\%201960.html, Retrieved 18 September 2019.

558 New Zealand Taxation Committee, Report of the Taxation Committee, 1952, page 102. 
Table 3. Land Tax, Income Tax and Total Tax Revenue, 1936-1956

\begin{tabular}{|c|c|c|c|c|c|}
\hline Year & Total Tax Revenue & Land Tax Revenue & $\begin{array}{l}\text { Land Tax as a } \\
\text { Percentage } \\
\text { of Total Tax } \\
\text { Revenue }\end{array}$ & Income Tax & $\begin{array}{l}\text { Income Tax as a } \\
\text { Percentage of } \\
\text { Total Tax } \\
\text { Revenue }\end{array}$ \\
\hline 1929 & $17,832,033$ & $1,140,324$ & $6.39 \%$ & $3,310,877$ & $18.57 \%$ \\
\hline 1930 & $19,471,131$ & $1,506,911$ & $7.74 \%$ & $3,533,764$ & $18.15 \%$ \\
\hline 1931 & $18,878,285$ & $1,145,617$ & $6.07 \%$ & $4,003,606$ & $21.21 \%$ \\
\hline 1932 & $17,405,622$ & 542,128 & $3.11 \%$ & $4,447,814$ & $25.55 \%$ \\
\hline 1933 & $19,703,703$ & 498,916 & $2.53 \%$ & $3,556,775$ & $18.05 \%$ \\
\hline 1934 & $21,470,827$ & 498,978 & $2.32 \%$ & $2,961,243$ & $13.79 \%$ \\
\hline 1935 & $24,737,939$ & 492,526 & $1.99 \%$ & $3,796,477$ & $15.35 \%$ \\
\hline 1936 & $25,478,598$ & 458,873 & $1.80 \%$ & $4,581,328$ & $17.98 \%$ \\
\hline 1937 & $31,181,603$ & $1,047,877$ & $3.36 \%$ & $6,618,716$ & $21.23 \%$ \\
\hline 1938 & $36,798,971$ & $1,038,034$ & $2.82 \%$ & $9,078,763$ & $24.67 \%$ \\
\hline 1939 & $37,797,904$ & $1,058,499$ & $2.80 \%$ & $9,303,495$ & $24.61 \%$ \\
\hline 1940 & $44,522,028$ & $1,019,084$ & $2.29 \%$ & $11,571,247$ & $25.99 \%$ \\
\hline 1941 & $61,360,840$ & 959,418 & $1.56 \%$ & $18,105,614$ & $29.51 \%$ \\
\hline 1942 & $68,163,256$ & $1,009,288$ & $1.48 \%$ & $18,931,852$ & $27.77 \%$ \\
\hline 1943 & $87,940,844$ & 975,824 & $1.11 \%$ & $25,577,874$ & $29.09 \%$ \\
\hline 1944 & $100,839,484$ & 987,707 & $0.98 \%$ & $31,331,801$ & $31.07 \%$ \\
\hline 1945 & $108,681,814$ & 952,622 & $0.88 \%$ & $34,248,067$ & $31.51 \%$ \\
\hline 1946 & $114,954,873$ & 937,395 & $0.82 \%$ & $35,287,883$ & $30.70 \%$ \\
\hline 1947 & $113,119,046$ & 939,559 & $0.83 \%$ & $32,085,057$ & $28.36 \%$ \\
\hline 1948 & $122,275,911$ & 854,456 & $0.70 \%$ & $36,632,581$ & $29.96 \%$ \\
\hline 1949 & $130,440,249$ & 916,120 & $0.70 \%$ & $49,007,672$ & $37.57 \%$ \\
\hline 1950 & $135,556,319$ & 967,386 & $0.71 \%$ & $48,483,450$ & $35.77 \%$ \\
\hline 1951 & $157,946,975$ & $1,043,203$ & $0.66 \%$ & $59,441,839$ & $37.63 \%$ \\
\hline 1952 & $200,549,807$ & $1,137,937$ & $0.57 \%$ & $78,101,503$ & $38.94 \%$ \\
\hline 1953 & $199,770,283$ & $1,315,136$ & $0.66 \%$ & $78,701,376$ & $39.40 \%$ \\
\hline 1954 & $206,802,317$ & $1,615,372$ & $0.78 \%$ & $80,799,719$ & $39.07 \%$ \\
\hline 1955 & $234,766,098$ & 966,632 & $0.41 \%$ & $88,316,880$ & $37.62 \%$ \\
\hline 1956 & $244,828,777$ & $1,227,656$ & $0.50 \%$ & $90,697,965$ & $37.05 \%$ \\
\hline
\end{tabular}

The reintroduction of graduation increased land tax revenue but it did not keep pace with the general increase in taxation and became much less important. New Zealand had entered the era of mass taxation but, contrary to the hopes of those who introduced it back in 1891, land tax was largely insignificant.

\subsubsection{Valuation}

Concerns about overvaluation had been a longstanding objection under the land tax system. Widespread landowner hostility towards land valuations had been found by a 
1915 Commission of Inquiry ${ }^{559}$ but not systemic overvaluation. ${ }^{560}$ The report of the 1930 Hardship Commission reinvigorated the issue when it declared "in the great majority of cases, however, it appeared the unimproved values as assessed were excessive, having regard to the productive capacity of the land". ${ }^{561}$ While this did not provoke a government response, it was the first suggestion by an official body reviewing land tax that the valuation system may have had inherent problems. The 1931 abolition of graduation mitigated potential issues but did not fix anything and by 1934 the Christchurch Chamber of Commerce was campaigning to replace market valuations. ${ }^{562}$

The 1936 reintroduction of graduated land taxation brought renewed focus on the process of valuation. Strenuous, although not necessarily competent, objections were made by the Farmers' Union over everything from the order which unimproved value was calculated $^{563}$ to whether recorded unimproved values included improvements and livestock. ${ }^{564}$ These objections were generally baseless; things previously ruled irrelevant in court ${ }^{565}$ or simply "absurd" 566 but were expected to increase public dissatisfaction with land tax.

There were, however, legitimate problems. Slow land revaluations had been a feature of the land tax system since the 1894 changes and the system was built on the assumption that land values would remain relatively static. Traditionally taxpayers had not complained when government valuations failed to keep pace with appreciating land values, but from 1930 values started falling. Land values were speculated to have reached

\footnotetext{
559 Refer note 330, page iv.

560 Refer note 330, page xxiv-xxvi.

$561 \quad$ Refer note 420, page 4.

562 The Press, 4 October 1934, Valuing Farm Land.

563 Auckland Star, 18 October 1937, System Criticised.

564 Wairarapa Times, 20 July 1937, Land Valuation, Apparent Peculiarities.

565 Thomas $v$ Valuer-General - [1918] NZLR 164, page 175.

566 Horowhenua Chronicle, 14 August 1937, Land Tax And Valuations, Minister Replies To Farmers' Union.
} 
their lowest point in $1934^{567}$ but, due slow revaluations, valuations used for tax purposes continued to fall until 1943.

This upset the status quo and left taxpayers with land valued at more than it was worth. Initially some taxpayers dealt with this by invoking s 45 and s50 of the Valuation of Land Act $1925,{ }^{568}$ which compelled to government to revalue sections or purchase them at the suggested price. The Coalition saw this practice, which forced the government to either undervalue land or purchase property it could not actually use, as a ridiculous abuse of the law $^{569}$ and repealed both sections in 1933.570

Labour denied that overvaluation was occurring ${ }^{571}$ and there was little economic incentive for the government to make faster revaluations if it was, as it would reduce tax revenue, so use of the old values persisted. This meant that taxpayers found themselves paying tax on inflated land values. By the mid-1930s the overvaluation of land which farmers had long complained of was actually occurring but was the result of sluggish revaluations rather than the institutional bias towards high valuations they previously been claimed. ${ }^{572}$

While the problem arose nationally, it was well demonstrated in Auckland. Land in Auckland was not revalued at any point during the 1930s and for the entire decade was taxed based on its value as at 1928. Since New Zealand's land values would not actually equal those of 1928 again until 1951, ${ }^{573}$ this was a problem. As market values fell taxpayers became increasingly unhappy with the situation. Attempts were made to challenge the valuations as excessive under the existing rules but they were denied on the

\footnotetext{
$567 \quad$ Refer note 557.

568 These were the compulsory purchase rules which had been introduced as s31 of the Land and Income Assessment Act 1891.

572 Refer note 330, page iv.

573 Refer note 557.
} 
grounds that the objections had not been made at the time of valuation. ${ }^{574}$ When the city's land was finally revalued in 1940 it saw a 9 percent decrease across the city and a significant decrease in land tax liability. ${ }^{575}$ That more regular revaluations would greatly improve the land tax system and make it fairer was one of the few objections raised by the Farmers' Union ${ }^{576}$ that had a sound basis.

New valuations were not always welcomed, or sufficient to appease taxpayers however. The 1937 revaluation of New Plymouth, which increased land values, met with significant hostility from locals who felt prices had fallen. ${ }^{577}$ In rural areas lower revaluations had the potential to give rise to equity concerns. In a case described as "typical" the 1937 revaluation of the Gisborne district saw the unimproved value of a 1,900 acre farm reduced from $£ 7,800$ to $£ 2,600$. This reduced the owner's land tax liability and exempted them from income tax, despite their yearly profit rising. ${ }^{578}$ Even the writers for New Zealand Herald, a publication with an established dislike of land tax, thought this was unfair.

The reintroduction of graduated taxation did not help things either. Theoretically, increased land tax should be capitalised into land prices, causing prices to fall further behind government valuations. This was largely ignored until the solicitors for the Stonyhurst Estate petitioned the Valuation Department for a lower valuation on that basis in 1939, forcing the department to address the issue. ${ }^{579}$ Using Stonyhurst as a test case, the department estimated that the reintroduction of graduated land tax had lowered its value from $£ 52,525$ to $£ 39,405 .{ }^{580}$ The formula used suggested a fall in the value of all land valued above $£ 5,000$. The Valuation Department eventually agreed to revalue

\footnotetext{
574 New Zealand Herald, 22 July 1937, Land Tax.

575 Auckland Star, 14 November 1940, Down £4,000,000.

576 New Zealand Herald, 23 July 1941, Land Valuation.

577 New Zealand Herald, 8 April 1937, Land Tax Increases.

578 New Zealand Herald, 16 October 1937, £1432 Tax-Free.

579 J Robertson, Memorandum for the Valuer General, Effect of the Graduated Land Tax, 4 April 1939, Archives New Zealand AAVI W3486 32 12/270.

580 R MacLaclan, The Effect Of Graduated Land Tax On Unimproved Value, 19 January 1939, Archives New Zealand AAVI W3486 32 12/270.
} 
Stonyhurst down to $£ 44,900^{581}$ but does not appear to have made any attempt to apply this principle more widely.

Throughout the term of the Labour Government, revaluation remained a slow process. As late as 1952 , the Gibbs Report ${ }^{582}$ into taxation noted that more than a decade passing between valuations was not uncommon and there were still counties using valuations predating the Depression. While there were few complaints when prices were rising it meant that land tax was usually assessed based on out of date data.

Eventually the problem could no longer be ignored and changes were made in the Statues Amendment Act 1946 to require areas revalued after 1947 be revalued at five yearly intervals thereafter. ${ }^{583}$ This returned fixed periodic revaluations to the system for the first time since 1894.

\subsubsection{The Special Committee into Land and Income Tax}

Following the 1936 overhaul of tax law, Walter Nash appointed a special committee of tax experts to analyse the provisions and operation of land and income tax with an eye towards future reforms. This was the first major review of land and income tax since the 1924 commission. Unlike the reports of the 1920s which were more publically focused, the special committee was chaired by the Commissioner of Taxes and there is no evidence to suggest that its report was made publically available or presented to Parliament. ${ }^{584}$

This was a technical analysis of the existing law rather than a higher concept plan for reform. Land tax coverage broadly concerned three topics: weaknesses in the existing law, graduated versus flat land tax and taxation of the unearned increment. Coverage of weaknesses in the existing law mostly focused on how effective the anti-avoidance measures introduced in 1907 still were. These were held to be largely sufficient but some

\footnotetext{
581 E Eggleston, Memorandum for the Valuer General, Graduated Land Tax - Stoneyhurst Estate, 4 April 1939, Archives New Zealand AAVI W3486 32 12/270.

$582 \quad$ Refer note 558, page 101.

$583 \quad$ Statutes Amendment Act 1946, s77.

584 Evening Post, 10 March 1938, Taxes Unaltered.
} 
changes were recommended, noting scope for avoidance. ${ }^{585}$ It also suggested moving the burden of proving whether land should be subject to the unimproved land tax from the tax department to owners, as the department lacked sufficient facilities to actually determine it. ${ }^{586}$

On the matter of whether land should be taxed on a flat or graduated basis the committee followed previous reviews. It suggested the abolition of graduation and replacement with a flat tax based on ease of administration, lesser scope for avoidance, ${ }^{587}$ and graduation's potential to limit enterprise. ${ }^{588}$ The committee speculated such a tax at a rate of $2 \frac{1}{2} \mathrm{~d}$ per $£ 1$ of land value would raise equivalent revenue to the graduated tax. ${ }^{589}$

Taxation of the unearned increment is where the committee differed most from its predecessors. The committee suggested that, while taxing the unearned increment was both just and government policy, existing approaches were inefficient means of doing so; income tax could not catch all of it and land taxes, flat or graduated, were largely arbitrary. ${ }^{590}$ As an alternative the committee proposed just taxing appreciations in land value, essentially a capital gains tax limited to land. To catch properties that were held for extended periods of time this should be levelled on an accrual basis, taxing gains when they were recognised by government valuations. ${ }^{591}$ While the idea was theoretically sound the commission noted several weakness, including needing fast revaluations and a twenty years period before revenue would match that of land tax. ${ }^{592}$

While the committee made valid points about land tax, Labour did not make any of the changes suggested by the committee and buried its report. While this is understandable on the flat tax recommendation, which would undo a change Labour had just made, or

\footnotetext{
$585 \quad$ Refer note 556, page 208.

586 Refer note 556, page 204.

587 Refer note 556, page 200.

588 Refer note 556, page 213.

589 Refer note 556, page 220.

$590 \quad$ Refer note 556, page 219.

591 Refer note 556, page 225.

592 Refer note 556, page 223-227.
} 
the taxation of the unearned increment, which would be significant overhaul of the tax system and threaten revenue at a time when it was needed, there does not appear to be good reasons for not strengthening the anti-avoidance rules.

\subsection{2, The Gibbs Taxation Committee and the National Response.}

The National party replaced Labour as the New Zealand government following the 1949 election. In 1951 the National government established its own committee to examine taxation in New Zealand. Rather than adopt Labour's in-house approach, the Gibbs committee followed the model established by the committees of 1922 and 1924, taking public submissions and having members from a range of industry groups. These groups included the New Zealand Law Society, New Zealand Society of Accountants, the Federation of Labour, Federated Farmers and the Associated Chambers of Commerce. While the committee examined the entirety of the tax system, this study is only concerned with its findings regarding land taxation.

In a sign of the decline in the importance of the land tax, the Committee's assessment of it was less than three pages long, but still noted a variety of issues. Its main concern was with land valuation. In addition to declaring that unimproved value was "an artificial notion" and not consistent across New Zealand, the Committee noted irregularity of revaluations and the differences between areas. It was suggested it was not a fair basis to levy tax upon when some areas were last valued more than twenty years earlier. ${ }^{593}$ This had already been addressed in the Statutes Amendment Act 1946 but it was taking time for the improvements to be implemented.

The Committee also took issue with the uneven nature of the land tax. Major issues included the income tax deduction lowering the effective rate of land tax for those earning the highest incomes (by more than 76 percent in some cases) ${ }^{594}$ and the mortgage exemption allowing landlords to escape taxation while their tenants could not. ${ }^{595}$ The

\footnotetext{
$593 \quad$ Refer note 558, page 101.

$594 \quad$ Refer note 558, page 100.

$595 \quad$ Refer note 558, page 101.
} 
Committee held that, at very least, land tax liability should be unconnected to the existence or size of a mortgage on a property. ${ }^{596}$

The Committee suggested that the land tax was an outdated relic of attempts to break up the large estates ${ }^{597}$ and no longer served a purpose. Describing it as a secondary income tax and "discriminatory, illogical and unequal" ${ }^{598}$ the Committee recommended the complete abolition of the land tax, graduated or otherwise, particularly since lost revenue would be significantly offset by eliminating the income tax deduction. Only the representative of the Federation of Labour disagreed, based on a desire to tax the unearned increment and the belief that payment was not causing undue hardship. ${ }^{599}$

The National government also ignored the Committee's recommendations to abolish the land tax but it did make some changes to it as part of a plan to reduce the number of people liable for the land tax and lower people's living costs. ${ }^{600}$ National had in 1950 raised the tax free threshold to $£ 1,000,{ }^{601}$ citing the growing number of people who were falling outside it and being forced to prepare tax returns. ${ }^{602}$ Following the committee's findings it was raised to $£ 3,000 .{ }^{603}$ To address the committee's concerns about tenants being liable while their landlords were not, lessees' liability was abolished for the second time. ${ }^{604}$ The main change was to simplify the land tax rates, implementing four brackets with rates of $1-4 \mathrm{~d}$ per $£ 1$ of land value. ${ }^{605}$ This saw tax liability static or reduced for most tax payers with only those owning land worth $£ 15,001-£ 28,999$ worse off.

\footnotetext{
596 Refer note 558, page 101.

$597 \quad$ Refer note 558, page 100.

$598 \quad$ Refer note 558, page 102.

599 Refer note 558, page 110.

$600 \quad$ Refer note 535.

601 Land and Income Tax Amendment Act 1950 s3.

602 Financial Statement 1954, AJHR, 1954 Session I, B-06, page 28.

603 Land and Income Tax Amendment Act 1954, s3.

604 Land and Income Tax Amendment Act 1954, s4.

605 Land and Income Tax (Annual) Act 1954, Schedule, Part I.
} 
These changes decreased revenue. Land tax had recovered somewhat after 1948 as land values began to increase rapidly again. By 1954 land tax revenue had increased by 89.05 percent to $£ 1,615,372 .{ }^{606}$ National's new tax rates cut that to $£ 966,632$ but revenue continued to rise as land values continued to inflate and by 1961 more was being collected than before the changes. ${ }^{607}$ Given the rapid appreciation in land values during the $1950 \mathrm{~s}$ and 1960s it is probable that without National's lower tax rates, revenue would have been much higher.

\subsection{Summary}

The development of land tax between 1929 and 1952 was largely a response to economic crisis. While the rise of income tax and the tax reforms of 1923 had already seen land tax marginalised, the Great Depression largely ended it as a significant revenue source. In poor economic conditions it was difficult to collect a tax not related to cash flows, forcing governments to make a variety of concessions that were not always well targeted or effective to ease hardship. Meanwhile 14 years of consistently falling land values eroded the tax base and further reduced what revenue could be collected. Over the same period there was disagreement as to the purpose of land tax and the rural verses urban debate continued to flare. These negative circumstances helped ensure that the land tax did not expand like most other taxes under the Labour administration and by the 1950s it was considered outdated with total abolition recommended. At the same time the farmer backbone began asserting more dominance in ideological land tax debate and managed to temporarily dethrone equity as the primary policy concern. While the benefits of the farmer backbone's influence peaked during the early 1930s, they were not fully rolled back by later governments and instead entrenched into the tax system.

Despite brief expansions in 1929 and 1936, the period of 1929-1952 charts the decline of the land tax after its earlier introduction and growth. This period solidifies its largely

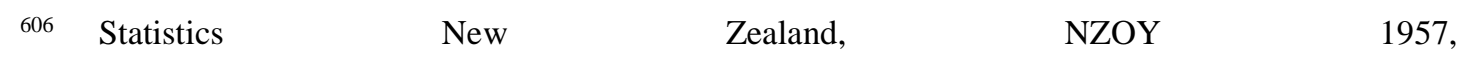
http://www3.stats.govt.nz/New_Zealand_Official_Yearbooks/1957/NZOYB_1957.html, Retrieved 18 September 2019.

607 Statistics New $\quad$ Zealand, $\quad$ NZOY http://www3.stats.govt.nz/New_Zealand_Official_Yearbooks/1962/NZOYB_1962.html, Retrieved 18 September 2019.
} 
unimportant nature within the wider New Zealand tax system; by 1952 not only is its revenue insignificant but it no longer seemed to fulfil any meaningful social policy objectives. The land tax survived by the grace of the first National government but it no longer had any obvious purpose. 


\section{Chapter 8: 1975 - 1991}

This chapter examines land taxation in New Zealand from 1975 to 1991 . The period is characterised by a more revenue focused land tax, and saw land taxation increase in importance for the first time in decades. However, problems developed following the stock market crash of 1987, leading to land tax being abolished in 1990.

\subsection{Before 1975}

New Zealand's economy boomed throughout the 1950s on the back of high export prices (Belich, 2001, p. 444) but problems became apparent by the late 1960s. Following the 1966 collapse in wool prices, the economy entered recession (Gustafson, 2000, p. 92). The situation worsened in the 1970s when Britain joined the European Economic Community, limiting New Zealand's access to its primary export market, and the 1973 oil shock quadrupled the country's petroleum bill (Belich, 2001, pp. 396-397). Problems spread to the government finances too as expenses grew faster than revenue. From 1970 the Government budget operated a deficit and borrowing funded 22.84 percent of government spending by the 1975-1976 financial year. ${ }^{608}$

For New Zealand's land taxation regime the period following 1954 was characterised by relative calm with a burst of action from the late 1960s. Revenue generally rose alongside rising land values before the government increased exemptions or lowered tax rates, after which the process began again. In the background however the demographics of land tax were changing. The Ross Report found ${ }^{609}$ the number of taxpayers had greatly fallen and the burden had mostly moved to companies. Citing the potential benefits to farmers and companies the Ross Report also recommended land tax abolition. ${ }^{610}$

The government did not abolish the land tax but it did make other land tax changes. In 1968 the mortgage deduction was replaced with a higher land tax threshold of $\$ 60,000$

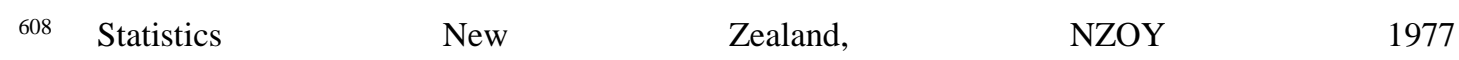
http://www3.stats.govt.nz/New_Zealand_Official_Yearbooks/1977/NZOYB_1977.html, Retrieved 18 September 2019.

609 Taxation Review Committee, Taxation In New Zealand, AJHR, 1967, B-18, page 414.

610 Refer note 609 , page 415.
} 
which exempted most residential property and farms from taxation. ${ }^{611}$ In 1970 farmers were fully exempted from land tax. ${ }^{612}$

The farmer exemption had its roots in replacing land tax's unimproved value base with simple land value. ${ }^{613}$ This had been under consideration since at least $1968^{614}$ but would increase the taxable values for rural property and appears to have been halted over predicted farmer outcry. ${ }^{615}$ Once farmers were exempt, the change was implemented alongside a five year freeze of taxable land values to allow for a national revaluation. ${ }^{616}$

The exclusive focus on gradual changes to the land tax's rates and exemptions meant that by 1975 much of the law was archaic. The last fundamental overhaul had been the 1936 reintroduction of graduation but most of the law was much older and many sections, such as the absentee tax no longer had an obvious purpose. Despite this land tax litigation continued to be limited, with only two cases from 1952-1975. ${ }^{617}$ These decisions had no policy impact. Land tax revenue also continued its relative decline, falling to 0.12 percent of total tax revenue and 0.03 percent of national land values by $1975 .^{618}$

In an attempt to control rapidly appreciating land values, 1973 saw New Zealand introduce another tax on property, the property speculation tax. Taking up the housing affordability issue land tax was supposed to deal with, the property speculation tax imposed a heavy tax on land sales within two years of purchase ${ }^{619}$ in an attempt to limit

\footnotetext{
611 NZPD, Volume 366, 25 June 1970, page 1303, Hon. Robert Muldoon.

612 Land and Income Tax Amendment Act 1970, s4.

613 Valuation Of Land Amendment (No. 2) Bill 1970 (57-1), Explanatory Note, Clause 2.

614 Cabinet Memorandum from Minister of Finance Robert Muldoon, 26 June 1968, Archives New Zealand AAFD W4198 811 Box CAB 127/3/1.

615 Refer note 614.

616 Land and Income Tax Amendment Act 1971, s3.

617 Hallenstein Bros. Ltd. v R. Alston \& Sons Limited and Others [1958] NZLR 171; New Zealand Breweries Limited v Square Freeholds Limited [1965] NZLR 619.

618 Statistics New Zealand, NZY http://www3.stats.govt.nz/New_Zealand_Official_Yearbooks/1976/NZOYB_1976.html, Retrieved 18 September 2019. 
speculation and further price rises. It was not especially successful. Its immediate effect appears to have been significantly reducing the housing supply (Vosslamber, 2015, pp. $182,184)$ which further inflated land prices, ${ }^{620}$ collecting little revenue ${ }^{621}$ and generating significant paperwork. ${ }^{622}$ The property speculation tax was abolished in 1979.

\subsection{6 - 1984, The Search for More Money}

\subsubsection{6}

The 1975 election saw the establishment of the Third National Government. Robert Muldoon served as both Prime Minister and Finance Minister, giving him substantial control over government finances. The new government faced significant budgetary challenges as the deficit had worsened and borrowing was high. Robert Muldoon's response was twofold; vigorous retrenchment while increasing government revenue. Retrenchment was short-lived, mostly occurring during the 1976-1977 period, and cut spending back to 35 percent of GDP but spending ballooned back to 1975 levels by 1984 . Efforts to grow tax revenue lasted longer.

Under the National government, land tax was subject to many minor changes but significant reforms were imposed in 1976, 1981 and 1983. The changes in 1976 budget, announced purely as revenue tools to help meet the deficit, ${ }^{623}$ do not appear especially significant at first glance. The general exemption was increased from $\$ 60,000$ to $\$ 175,000^{624}$ and the 50 percent rebate was abolished ${ }^{625}$ but offset by new lower tax rates to be introduced in 1977. When the introduction of these rates was pushed forward to 1976 it became apparent that they were simply the old rates halved to account for the loss of the rebate. The key change however, was the introduction of the land value base. This was wider and expected to raise more revenue than the unimproved value but the change

\footnotetext{
620 NZPD, Volume 384, 26 July 1973, page 2698, Hon. Robert Muldoon.

621 NZPD, Volume 426, 10 October 1979, page 3466, Hon. Hugh Templeton.

${ }^{622}$ NZPD, Volume 426, 10 October 1979, page 3466-3467, Hon. Hugh Templeton.

623 NZPD, Volume 404, 29 July 1976, page 1150, Rt. Hon. Robert Muldoon.

624 Land and Income Tax Amendment Act (No 2) 1976, s6.

625 Land and Income Tax Amendment Act (No 2) 1976, Schedule 1.
} 
also undid the freeze on taxable land values. The updated values more than tripled the value of the tax base from $\$ 4.17$ billion to $\$ 13.39$ billion. ${ }^{626}$

With the land valuation freeze, land tax revenue had been about $\$ 3.5$ million yearly since 1970. There was some confusion within the government whether the changes would have any effect on revenue ${ }^{627}$ but Robert Muldoon predicted it would increase to $\$ 6$ million. ${ }^{628}$ Actual revenue was $\$ 6.6$ million, ${ }^{629}$ in nominal terms, more than land tax ever earned previously. Since the tax rates were essentially unchanged, the rise in revenue can be traced to the growth of land values since 1970 and the now unfrozen tax base. Revenue rises continued into future years as land values continued to quickly appreciate and the five yearly valuation cycle meant older increases were still being brought within the tax base. By 1981, land tax revenue had risen to $\$ 11.6$ million. ${ }^{630}$ Despite this success, land tax remained one of the government's smallest taxes raising only 0.16 percent of total tax revenue and less than all other taxes except the film-hire tax and domestic air travel tax (\$0.9 and \$3.4 million respectively). It was also a lower portion of national land values than ever before. However, the limited revenue was enough to stop the government considering land tax abolition. ${ }^{631}$

\footnotetext{
626 Statistics New Zealand, NZOY various years, http://archive.stats.govt.nz/yearbooks\#NZ\%20Official\%20yearbooks, Retrieved 18 September 2019.

627 NZPD, Volume 405, 27 August 1976, page 2116, Hon. Peter Wilkinson.

628 Refer note 623.

629 Statistics New $\quad$ Zealand, $\quad$ NZOY http://www3.stats.govt.nz/New_Zealand_Official_Yearbooks/1979/NZOYB_1979.html, Retrieved 18 September 2019.

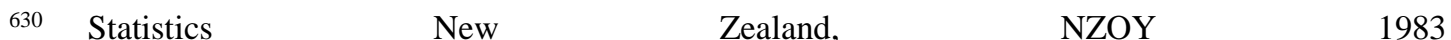
http://www3.stats.govt.nz/New_Zealand_Official_Yearbooks/1983/NZOYB_1983.html, Retrieved 18 September 2019.

631 NZPD, Volume 425, 14 September 1979, page 2953, Hon. Hugh Templeton.
} 


\subsubsection{1, Flat Tax}

By 1981 land value appreciation was slowing, and with that the growth of land tax revenue. In 1981 the government presented its solution, a new flat land tax. Unlike the 1931 flat tax it was a clear tax increase setting the tax rate at 2 percent, higher than any of the previous graduated rates. ${ }^{632}$ Both the Treasury and Inland Revenue supported the change to ease tax administration and raise revenue ${ }^{633}$ but the increase for taxpayers was significant. Treasury submitted that the median increase would be about 200 percent, but had no analysis as to whether taxpayers could afford this. ${ }^{634}$ The government defended the increased liability as targeted and not undue. ${ }^{635}$

Some changes to the land tax exemptions were also made, although the $\$ 175,000$ exemption was notably left unchanged. Land used for sport or racing clubs, previously taxed at concession rates, was given a full tax exemption ${ }^{636}$ to supposedly prevent land tax inhibiting development of bodies providing recreational benefit to the community. ${ }^{637}$ Since most sports clubs did not own land, instead renting it from local governments, and therefore did not pay any land tax, ${ }^{638}$ Treasury analysis suggested the benefit was limited almost entirely to golf courses. ${ }^{639}$ Despite this the exemption was broad enough that it became the core issue of several court cases from 1984. Both Treasury and Inland Revenue opposed the exemption, particularly for for-profit entities. This was on the basis of them operating for private gain ${ }^{640}$ and concerns that the precedent would make future

\footnotetext{
632 Land Tax Amendment Act 1981, s4.

633 Treasury, Report to the Minister of Finance, June 1981, Archives New Zealand AAFD W5331 7581 Box 235 115/15 Part 1.

634 Refer note 633.

635 NZPD, Volume 439, 30 July 1981, page 2130, Hon. Hugh Templeton.

636 Land Tax Amendment Act 1981, s3.

637 NZPD, Volume 438, 9 July 1981, page 1437, Rt. Hon. Robert Muldoon.

638 NZPD, Volume 440, 11 August 1981, page 2508, Hon. Robert Tizard.

639 Treasury, Budget Report 44, 26 May 1981, Archives New Zealand AAFD W5331 7581 Box 235 115/15 Part 1.

640 Memo to the Minister in Charge of the Inland Revenue Department, 13 June 1979, Archives New Zealand AAFD W5331 7581 Box 235 115/15 Part 1.
} 
requests for exemptions difficult to refuse. ${ }^{641}$ Nonetheless the government overruled both departments and introduced a full exemption.

The tax increase was designed to fall upon commercial and industrial land owners, who the government had decided should "make a larger contribution to the funding of government activities". ${ }^{642}$ Why this group was singled out to pay more was never explained but the opposition noted that the tax increase seemed to only fall on "townies", ${ }^{643}$ although some rural taxpayers were liable. ${ }^{644}$ The tax increase also did not fall on workers. This is important as the budget stated that the Federation of Labour had been demanding tax decreases for workers to help maintain real wages in 1981 and negotiations had been difficult. ${ }^{645}$ An increase in taxes paid by workers would have antagonised the Federation but since land tax was not generally paid by workers there was less risk of fallout. Combined with the exemption for farmers, it appears that in this case a key advantage of land tax was that it could be raised without alienating either National's rural voting base or the Federation of Labour.

The land tax increases did not align with the rest of the 1981 budget which was characterised by cuts to income tax to account for fiscal drag and attempt to shield taxpayers' incomes from inflation ${ }^{646}$ while pacifying the Federation of Labour. ${ }^{647}$ Since the government was still running a budget deficit additional revenue was required to offset this. The flat tax raised $\$ 33.8$ million but the deficit was $\$ 1.5$ billion. ${ }^{648}$ By 1984 the government had succeeded in increasing land tax revenue tenfold, as shown in Table 4, but not in making it a significant revenue source.

\footnotetext{
641 Refer note 639. 
Table 4. Land Tax Revenue, 1975-1984 ${ }^{649}$

\begin{tabular}{|c|c|r|}
\hline $\begin{array}{c}\text { Year Ended } \\
\text { 31st March }\end{array}$ & $\begin{array}{c}\text { Land Tax Revenue } \\
\text { (millions of \$) }\end{array}$ & $\begin{array}{r}\text { Yearly Percentage } \\
\text { Change }\end{array}$ \\
\hline 1976 & 3.4 & $0.00 \%$ \\
\hline 1977 & 6.6 & $94.12 \%$ \\
\hline 1978 & 8.4 & $27.27 \%$ \\
\hline 1979 & 9.5 & $13.10 \%$ \\
\hline 1980 & 10.7 & $12.63 \%$ \\
\hline 1981 & 11.6 & $8.41 \%$ \\
\hline 1982 & 33.8 & $191.38 \%$ \\
\hline 1983 & 34.4 & $1.78 \%$ \\
\hline 1984 & 36.2 & $5.23 \%$ \\
\hline
\end{tabular}

To consider further reform to the tax system the government established the Taxation Reform Task Force (the McCaw Committee) to examine the entirety of New Zealand's tax system. The taskforce, which reported in 1982, is something of an outlier among the various bodies that considered land taxation. Noting that the present tax system had no noticeable policy effects and its revenue was limited ${ }^{650}$ the taskforce thought land tax had potential. They thought it was easy to administer and with a wider base could serve a useful purpose and be an important revenue source. ${ }^{651}$ However, the committee was not prepared to recommend reform of any wealth taxes without more knowledge as to how wealth was distributed in New Zealand so the tax burden could be established. ${ }^{652}$

\subsubsection{3, Residential Exemption}

Land tax had never been designed to apply to residential landholdings but by 1983 it was becoming a problem as revaluations began pushing some taxpayers above the $\$ 175,000$ exemption. Newly liable residential taxpayers, who could not deduct land tax against their income tax, felt this was unfair in light of the higher rates since $1981 .{ }^{653}$ The unfavourable

\footnotetext{
649 Refer note 626.

650 The Task Force On Tax Reform, Report Of The Task Force On Tax Reform, 1982, page 230.

651 Refer note 650, page 229-31.

652 Refer note 650, page 229.

653 Gordon Harris, Letter to Hon. John Falloon, 15 April 1983, Archives New Zealand AALR W5427 873 Box 1902 77/1 Part 2.
} 
treatment of residential owners likely arose because residential land liability had not previously been a major issue. But the 1981 tax increase was much less politically palatable when expanded beyond businesses and the government decided to examine the issue.

Treasury and the Inland Revenue recommended that nothing be done in light of existing revenue constraints ${ }^{654}$ but this proved unacceptable to the cabinet. Instead the department's presented two potential solutions: increasing the $\$ 175,000$ exemption, the traditional response to land value creep, or fully exempting residential property. The options were expected to cost $\$ 4$ million and $\$ 150,000$ respectively. ${ }^{655}$ Since the primary objective was only to exempt residential land, cabinet opted for the cheaper residential exemption. At the suggestion of Treasury the exemption was limited to owner occupied land less than $4,500 \mathrm{~m}^{2}$. This stopped taxpayers exempting excessively large land areas, or their holiday homes from tax.

In Parliament there was bipartisan support that residential land should be exempted, although Labour queried who, outside the very wealthy, actually owned a home on land worth more than $\$ 175,000$. ${ }^{656}$ While it did not dispute that there were relatively few people affected, National said it would help "people who had been caught up in a situation", such a pensioners who had owned their homes for decades. ${ }^{657}$ Such a situation was a well-established potential weakness of land taxation and a politically engaged group like the elderly becoming liable for land tax would explain the government's determination to introduce an exemption.

The new exemption did not appease everyone, due to the requirement that exempt residential land be owner occupied. This saw landlords, like farmers in the decades beforehand, stressing their supposedly precarious economic situation and arguing that the additional land tax costs could put them out of business while forcing them to

\footnotetext{
654 Treasury and Inland Revenue, Budget Report 26, 20 June 1983, Archives New Zealand AAFD W5331 7581 Box 235 115/15 Part 1.

655 Treasury, Budget Report 32, 24 June 1981, Archives New Zealand AAFD W5331 7581 Box 235 115/15 Part 1.

656 NZPD, Volume 451, 18 August 1983, page 1559, Trevor de Cleene.

657 NZPD, Volume 451, 18 August 1983, page 1559, Hon. John Falloon.
} 
significantly raise rents. ${ }^{658}$ The Minister for Revenue was unwilling to extend the exemption because renting property was a commercial activity, and it was government policy to levy land tax on anyone who held land for business purposes, ${ }^{659}$ despite the sporting exemption. He was also sceptical of the predicted rent rises, suggesting that the market would not allow the costs to be passed on to tenants. Despite continued landlord protests and rigorous appeals on their behalf from the Minister of Transport, ${ }^{660}$ the government did not expand the exemption.

\subsection{4 -1990 The End}

The Third National Government was replaced by a new Labour government led by David Lange in 1984. Labour ran on a platform of change from the policies of the previous government but was publicly unclear on what they should be replaced with and the government was elected without having to outline an economic policy.

Since Robert Muldoon tainted New Zealand's old approach to economic management and reform in the eyes of the public, the Fourth Labour Government launched a new economic program, nicknamed Rogernomics after Finance Minister Roger Douglas. It was a radical departure from the policy of previous Labour governments, and indeed previous National governments. Simply described it was a programme of "more market, less state" (Belich, 2001, p. 406), influenced by Friedmanite and Chicago School theories, and developed into a policy of reducing and reorganising the state sector and deregulating the economy. The policy's implementation was rapid, likely in an attempt to make it more politically tenable by undermining opposition than any structural need. Roger Douglas himself commented that "the fire of opponents is much less accurate if they have to shoot a rapidly moving target” (1993, p. 225). Similarly, it proceeded with little regard for obstacles, continuing through the 1987 share market crash and the 1988 loss of Roger

658 Hon. George Gair; Letter to Hon. John Falloon, 16 Sep 1983, Archives New Zealand AALR W5427 873 Box 1902 77/1 Part 2.

659 Hon. John Falloon; Letter to Hon. George Gair, 12 Dec 1983, Archives New Zealand AALR W5427 873 Box 1902 77/1 Part 2.

660 Land Tax - Note of Meeting, 7 Oct 1983, Archives New Zealand AALR W5427 873 Box 1902 77/1 Part 2. 
Douglas after he was forced out of the cabinet by David Lange, who had developed concerns about Rogernomics's social costs (Belich, 2001, p. 407). Rogernomics even survived the collapse of the Labour government, with the new National government continuing to apply it from 1990 and expanding it to social welfare, industrial relations and political reform. While the policy was similar to Thatcherism or Reaganism and aligned with a global shift away from interventionist economic policy, the speed and scope of Rogernomics characterised it as among the most radical restructuring in the developed world (Schwartz, 1997, pp. 405-406). Despite frequently being unpopular with the New Zealand electorate, Rogernomics was the primary ideology of the New Zealand government from 1984-1996.

\subsubsection{The Valuation of Wellington and 1988 Tax Relief}

While the Fourth Labour Government took to reforming much of the economy with haste, land tax initially saw little significant change. Land and housing affordability remained a concern but the land tax was not considered as a solution. When Labour had been in opposition it had considered increasing land tax to tax wealth ${ }^{661}$ but this did not align with the new Rogernomic framework and nothing came of it. The most notable change before 1988 was limited exemption reform in 1986, exempting forestry but making airports, harbour boards and energy suppliers taxable. Land tax only became a political issue once the valuation system came under scrutiny.

In 1987 Wellington was revalued after the Wellington City Council (WCC) opted into the Valuation Department's new triennial revaluation system. Changing to the triennial system was supposed to address rating anomalies and "ensure residential property owners were not faced with gigantic rating increases every 5 years" but no one considered the effect it would have on land tax. ${ }^{662}$ Wellington was revalued at the height of the $1980 \mathrm{~s}$ property boom and new valuations, released in September, showed a 630 percent increase in the city's total land value since $1984 .{ }^{663}$ The increase resulted in more people being

\footnotetext{
661 NZPD, Volume 417, 9 June 1978, page 777, Kenneth Comber quoting Jonathan Hunt.

662 Evening Post, 10 November 1987, Valuation Change 'A Mistake'.

663 Jim Belich, Letter to Hon. Trevor de Cleene, 1 February 1988, Archives New Zealand AALR W5427 873 Box 1861 76/4/2 Part 1.
} 
liable for land tax and severe increases for those who already were, by more than 1000 percent in some cases. ${ }^{664}$ The city's new liability was $\$ 80$ million, more than total land tax collected the previous year and more than the rest of the country combined for the $1987-88$ financial year. ${ }^{665}$

The response to the new valuations was predictably negative. The increased land tax was expected to be a significant increase in business costs ${ }^{666}$ and it was expected landlords would pass it on to their tenants. ${ }^{667}$ In this way no central city based businesses would escape its effects and there was concern that it would see consumer prices increase, businesses close ${ }^{668}$ and jobs lost. ${ }^{669}$ The existing land tax situation was worsened when land values started falling after October 1987 Black Tuesday share market crash which contributed to a widespread perception among Wellington's landowners that their land was overvalued, ${ }^{670}$ notwithstanding the District Valuer's assertions to the contrary. ${ }^{671}$ While historic buildings which could not be redeveloped were expected to be worst hit, ${ }^{672}$ headlines predicting the demise of the Wellington central business district were common. ${ }^{673}$ There was also concern as to how the city's residential tenancies would be affected. $^{674}$

\footnotetext{
664 The Dominion Sunday Times, 25 October 1987, Land Tax Threatens To Force Firms Out.

665 The Dominion, 1 December 1987, Land Tax Seen As Threat To City Planning.

666 Refer note 664

667 Morning Report, 23 Mar 1988 7:15am, Revaluation Commercial Land Taxes - Transcript, Archives New Zealand AALR W5427 873 Box 1861 76/4/2 Part 1.

668 Refer note 665.

669 National Business Review, 17 March 1988, Wellington Shopkeepers Seek Land Tax Review.

670 National Business Review, 20 June 1988, Owners Threaten Court Challenge Over Valuations.

671 Evening Post, 19 March 1988, Land Tax Relief Hopes Crushed.

672 Evening Post, 23 September 1987, Land Tax Spells Doom For Older Buildings.

673 Evening Post 23 March 1988, Major Recession Seen For Capital Through Land Tax.

674 Evening Post, 13 April 1988, Land Tax To Hit Tenants; Treasury, Budget Report 137, 27 April 1988, Archives New Zealand AALR W5427 873 Box 1861 76/4/2 Part 1.
} 
The WCC tried to limit the damage through refusing the new valuations but had no power to do so. ${ }^{675}$ Instead they started lobbying the government for land tax reform. ${ }^{676}$ Taxpayers themselves objected to the valuations at a high rate ${ }^{677}$ and threatened court challenges ${ }^{678}$ but had little success. Any relief would require action by Parliament.

While Wellington had the most visible land tax issues, developments in other areas also suggested problems. Since 1983, land tax litigation had increased with more cases than over the preceding 60 years. Most cases focused on the exemptions as taxpayers tried to escape the higher flat land tax. The courts widened the sporting exemption twice to include a golf course run by property developers to enhance the value of surrounding land ${ }^{679}$ and a caravan club, ${ }^{680}$ while exempting a holiday camp under a section for residential body corporates. ${ }^{681}$ Meanwhile the charities exemption was narrowed ${ }^{682}$ and poor legislative drafting meant public sector unions could not be land tax exempt. ${ }^{683}$ There were also multiple cases surrounding what counted as a business for the purposes of the agricultural exemption. ${ }^{684}$

Faced with several problems the government was forced to deal with the land tax, despite not having a policy on it. It was clear Roger Douglas disliked the tax's narrow base and many exemptions ${ }^{685}$ but he had no plan to change it. A review of land tax was planned but the government was reluctant to make land tax policy decisions before finalising plans

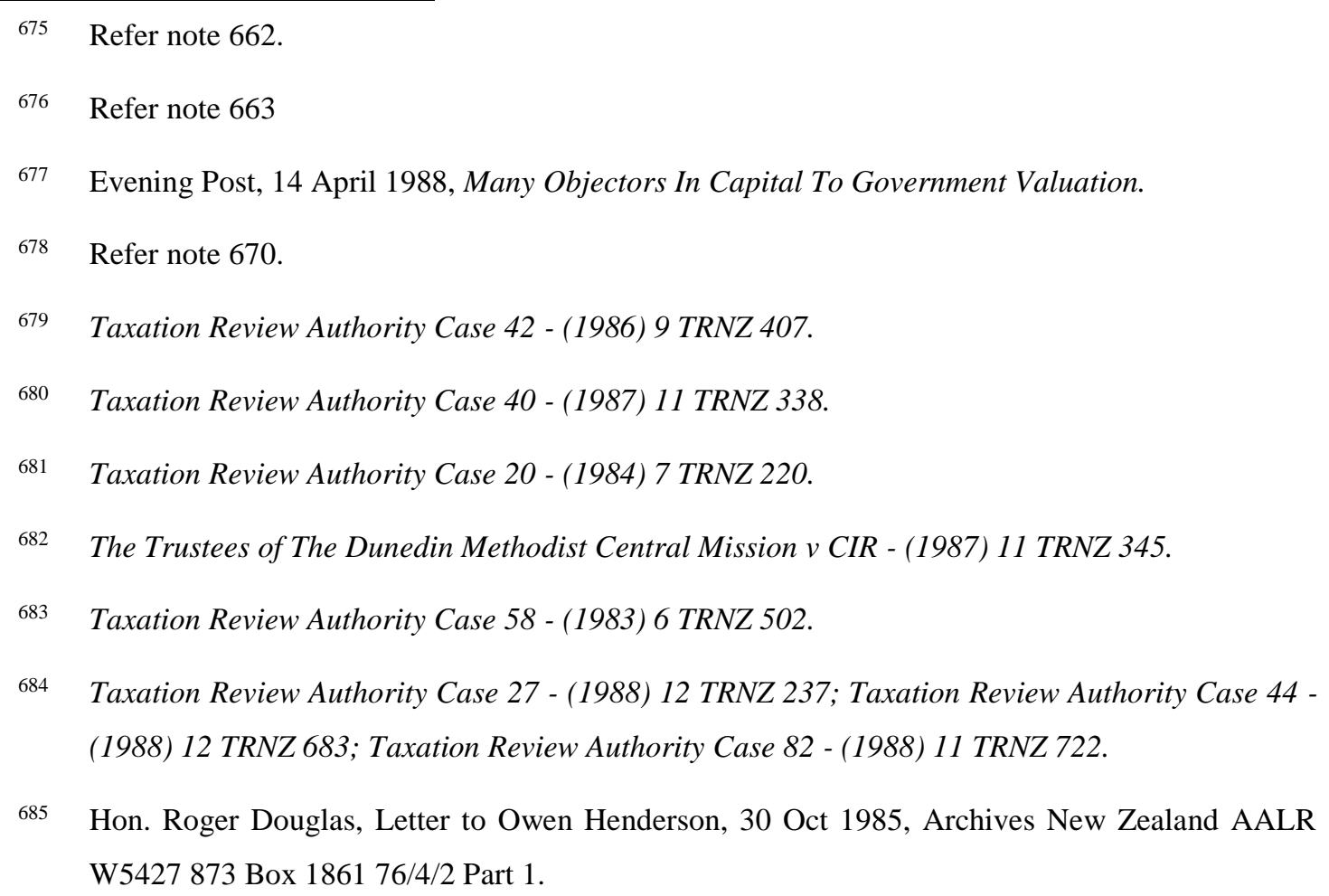


for GST ${ }^{686}$ or a capital gains tax. ${ }^{687}$ Significant land tax reform had been considered in 1986, with Treasury and Inland Revenue each offering their own proposals. Inland Revenue suggested raising the tax rate to 3 percent or 4 percent so it could collect more revenue without having to administer more taxpayers. ${ }^{688}$ Conversely Treasury thought land tax had too many exemptions and wanted the tax abolished when the fiscal position permitted and no changes in the meantime. ${ }^{689}$ There were limited land tax changes in 1986 but the government ignored both departments.

The lack of land tax policy led to a confused government response following the Wellington revaluations. Public pronouncements on land tax policy were largely left to Revenue Minister Trevor de Cleene who refused to grant relief on the grounds the government was running a deficit and needed the revenue. ${ }^{690}$ Public pressure eventually saw that position softened with a Treasury report into land tax reform commissioned ${ }^{691}$ and plans to grant relief by exempting historic buildings. ${ }^{62}$ This was later joined by plans to raise the $\$ 175,000$ exemption. ${ }^{693}$

The limited relief offered did not quell concerns and Wellington interests continued to protest the land tax. The protests saw land tax facing a unified and influential opposition but that opposition was hampered by coming solely from Wellington, ${ }^{694}$ which limited its effectiveness and made the group easier for the government to ignore. While the land tax

686 Hon. Roger Douglas, Letter to A Hall, 13 May 1985, Archives New Zealand AALR W5427 873 Box 1861 76/4/2 Part 1.

687 Treasury, Budget Report 18, 3 April 1985, Archives New Zealand AALR W5427 873 Box 1861 76/4/2 Part 1.

688 Inland Revenue, Letter to the Minister of Finance, 15 July 1986, Archives New Zealand AALR W5427 873 Box 1861 76/4/2 Part 1.

689 Treasury, Budget Report 71, 15 July 1985, Archives New Zealand AALR W5427 873 Box 1861 76/4/2 Part 1.

690 Evening Post, 29 October 1987, Little Hope Of Land Tax Relief.

691 Evening Post, 16 February 1988, Land Tax Options Will Be Scrutinised By Treasury.

692 National Business Review, 8 January 1988, Land Tax Reform On The Cards.

693 Refer note 671.

694 Refer note 671. 
was a major issue in Wellington, it raised little sympathy elsewhere, particular when compared to the plight of others caught by in the aftermath of the government's economic reforms. ${ }^{695}$

Nonetheless the increased opposition forced the government to defend land tax on grounds other than the revenue it raised being needed. This burden largely fell to the Minister of Revenue who resurrected the old fairness arguments to suggest that wealthy people need to pay more tax and only the wealthy and those able to pay would be affected by the land tax. ${ }^{696}$ He saw land tax as a stopgap measure until the government could tax wealth through its planned capital gains tax. ${ }^{697}$ Trevor de Cleene also argued that the heavy land tax would encourage efficient use of land in city development ${ }^{698}$ while spurring regional development. ${ }^{699}$ This had been an element of land tax theory since George's original work but had largely been ignored in New Zealand. None of these arguments aligned with the government's Rogernomics policy or Roger Douglas's belief that taxation should have a neutral effect of business decisions. ${ }^{700}$

The defences were not widely accepted. The WCC resented losing control of city development and the suggestion they should subsidise the development of other regions. ${ }^{701}$ The fairness argument suffered due to concerns that land tax would be passed on to tenants and consumers. Despite claims that the market would prevent landlords

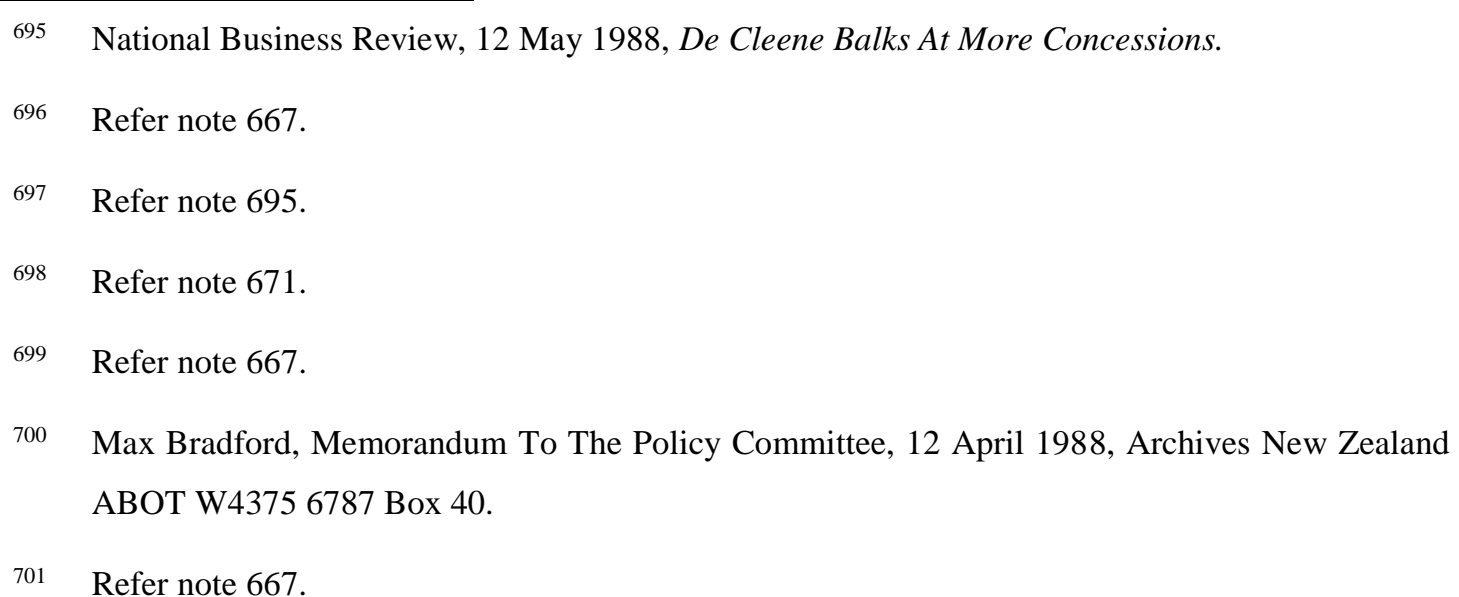


increasing rents ${ }^{702}$ that only held if the tax fell on all land. ${ }^{703}$ By April 1988 Treasury had evidence suggesting that the land tax was adversely affecting the rental market.

When it came time for the government to decide on its land tax reforms Treasury issued two reports, each with a different suggestion. The first recommended no changes be made, including cancelling the exemption for historic buildings the government had raised in January. ${ }^{704}$ The second suggested the removal of all the existing exemptions and lowering the threshold to $\$ 40,000$ to create a broad based land tax that could run alongside a capital gains tax. ${ }^{705}$ The government ignored both reports. Instead they added two new exemption to exclude historic buildings and residential rental property, ${ }^{706}$ over Treasury opposition.

Exempting residential rental property had not previously been mentioned by the government and they had previously shown little concern for the residential rental market. The idea appears have arisen from an April $21^{\text {st }}$ meeting between Inland Revenue, Trevor de Cleene and Roger Douglas after concerns about the effect of land tax on the rental market reached the Ministers, ${ }^{707}$ eight days after the Evening Post ran an article about the land tax increasing residential rents. ${ }^{708}$ The idea itself seems to have been devised by Inland Revenue. ${ }^{709}$ Conspicuously missing from the changes was the announced increase in the $\$ 175,000$ threshold. This meant that most business received no relief under the new act and the Wellington business community saw the law as appeasement of the Labour

\footnotetext{
702 Refer note 667.

703 Treasury, Budget Report 137, 27 April 1988, Archives New Zealand AALR W5427 873 Box 1861 76/4/2 Part 1.

704 Treasury, Report to Minister of Finance, 20 April 1988, Archives New Zealand AALR W5427 873 Box 1861 76/4/2 Part 1.

705 Refer note 703.

Land Tax Amendment Act (No 2) 1988, s2.

707 Refer note 703.

708 Evening Post, 13 April 1988, Land Tax To Hit Tenants.

709 Inland Revenue, Letter to the Ministers of Finance and Revenue, 22 April 1988, Archives New Zealand AALR W5427 873 Box 1861 76/4/2 Part 1.
} 
Party's left wing, promising that they would continue fighting the land tax. ${ }^{710}$ Despite this Trevor de Cleene was adamant that the government would make no more concessions on the issue. ${ }^{711}$

\subsubsection{9, A New Land Tax}

The 1988 Reforms did not improve the government's land tax problem, if anything it got worse. The situation in Wellington deteriorated further as businesses actually had to pay the land tax, seeing increased prices, job losses and business closures. ${ }^{712}$ Faced with government's refusal to grant relief, Wellington's retailers appealed to the WCC for lower rates to decrease their costs but were unsuccessful. ${ }^{713}$ WCC itself continued lobbying the government for land tax relief without success. ${ }^{714}$

Wellington's businesses and council continued to protest but the main problem was elsewhere; the revaluation of Auckland occurred in 1988. Despite the 1987 market crash Auckland saw land values within the central business district increase by 600 percent1300 percent. ${ }^{715}$ Land tax collected in Auckland was expected to rise by between $\$ 60$ million and $\$ 100$ million and the city's business expected to face the same problems as those in Wellington. This left Christchurch the only major New Zealand city yet to be revalued.

Auckland's businesses had not been especially supportive of Wellington following the 1987 revaluation. The limited support apparently stemming from Auckland businesses not fully appreciating the impact of increased land tax ${ }^{716}$ and a belief the Wellington's

\footnotetext{
710 Evening Post, 19 May 1988, Business Community 'Will Fight' Land Tax.

711 Refer note 695.

712 Good Morning New Zealand, 23 November 1988, Land Taxes -Evaluations - Transcript, Archives New Zealand AALR W5427 873 Box 1861 76/4/2 Part 1.

713 Evening Post, 9 June 1988, Rates Relief Unlikely.

714 Checkpoint, 7 April 1989 5:45, Land Tax Campaign in Wellington - Transcript, Archives New Zealand AALR W5427 873 Box 1861 76/4/2 Part 2.

715 National Business Review, 17 November 1988, Auckland’s Land Tax Bill Tipped To Hit \$100m.

716 Refer note 712.
} 
problems were its own fault due to choosing the triennial revaluations. ${ }^{717}$ When faced with their own liability Auckland businesses decided that the land tax needed reform. This saw the land tax opposition increase significantly to include Auckland's business community, City Council, Chamber of Commerce and other organisations such as the Real Estate Institute of New Zealand while local government across New Zealand started to get nervous. ${ }^{718}$ Several of these groups collectively formed the Land Tax Coalition, the unofficial leadership of the land tax reform campaign. Landowning businesses were not the only ones caught by the land tax as commercial landlords passed it on to their tenants. The indirect land tax liability attracted criticism from a variety of small businesses, ${ }^{719}$ and charities who should have been exempt.

The business community suggested numerous approaches for land tax reform. The Real Estate Institute of New Zealand listed the main eight as follows: ${ }^{720}$

- Abolition

- Lower the tax rate

- Increase the $\$ 175,000$ exemption

- A sliding rate

- An equalisation factor similar to that used in New South Wales

- Broaden the base by removing some land use exemption categories and lowering the rate

- Treat like rating (determine how much land tax should raise each year then set the rate accordingly)

- Disregard valuations

Most of these had been proposed before and had significant disadvantages. Abolition, lowering the tax rate and raising the threshold all would reduce government revenue and

717 Real Estate Institute of New Zealand, Land Tax; A Summary And Recommendation, November 1988 , page 5 .

718 Ross Jansen, Letter to the Minister of Finance, 26 January 1989, Archives New Zealand AALR W5427 873 Box 1861 76/4/2 Part 2.

719 S Palmer, Letter to The Minister of Finance, 28 January 1989, Archives New Zealand AALR W5427 873 Box 1861 76/4/2 Part 2.

720 Refer note 717 , page 8-10. 
raising the threshold gave no relief to larger landowners. The sliding rate benefited large landowners as the proposed rate decreased as landholdings increased, giving them most of the benefit, but brought back the administrative complexities of graduation and hardly aligned with New Zealand's generally progressive taxation. Broadening the base and lowering rates granted relief at the expense of those presently not liable for land tax and treating land tax like rating made it more arbitrary and did not improve tax certainty. In the best case scenario disregarding the official valuations in favour of market prices would only affect areas valued before the 1987 crash but the Valuation Department insisted the crash had not materially changed prices in those areas. An equalisation factor may have been the best choice to maintain the existing system but would result in land tax values always being outdated and does not appear to have been seriously considered. Opponents generally campaigned for a rate reduction and base broadening. ${ }^{721}$ Abolition, previously not seen as a realistic option, became preeminent in April 1989 when the Real Estate Institute of New Zealand backed it. ${ }^{722}$

On the political front the government had a variety of problems. Following a falling out between Roger Douglas and David Lange, Roger Douglas resigned from cabinet in December 1988 and Trevor de Cleene resigned in support. They were replaced by David Caygill and Peter Neilson respectively and economic policy continued largely unchanged to avoid the appearance of instability (Lange, 2005, p. 268). Further complicating land tax reform the National Party decided to support land tax abolition from April 1988 so, for the first time in decades land tax did not have bipartisan acceptance. ${ }^{723}$

With pressure on the government increasing, defending the land tax largely fell to David Caygill, who adopted a new government position. Land tax's weaknesses and incompatibility which Rogernomics were acknowledged ${ }^{724}$ but its retention was justified

\footnotetext{
721 Refer note 717 , page 10.

722 2YA 10AM News, 13 April 1989, Real Estate Institute Land Tax/Opposition - Transcript, Archives New Zealand AALR W5427 873 Box 1861 76/4/2 Part 2.

723 Refer note 700.

724 Treasury, Memorandum To Minister of Finance, 9 February 1989, Archives New Zealand AALR W5427 873 Box 1861 76/4/2 Part 2.
} 
due to the revenue it collected, ${ }^{725}$ now $\$ 145$ million. With government finances still precarious, David Caygill was reluctant to make any changes that would undermine the revenue.

This left the problem of what to do about the land tax. Slow revaluations were recognised as a problem so the Minister of Commerce suggested that the entire land tax could be fixed by introducing annual revaluations. ${ }^{726}$ Peter Neilson thought it could be replaced by increased death duties and the capital gains tax announced in the 1988 budget to maintain wealth taxation. ${ }^{727}$ Despite not having a solution, in May it was decided land tax reform should be in the 1989 budget. Revenue remained a problem as a deficit was predicted and the capital gains tax was delayed due to technical difficulties and unpopularity. ${ }^{728}$ With these concerns Treasury was directed to come up with a solution.

Treasury produced two solutions. The first suggested abolishing all land tax's exemptions and the threshold resulting in a tax that fell on all land. ${ }^{729}$ Abolishing the exemptions would allow the rate to be lowered to 0.4 percent while maintaining revenue levels, but Treasury advocated maintaining the rate to increase revenue. Treasury's proposal could raise $\$ 1.48$ billion annually, enough revenue to return government finances to surplus and would be 5.4 percent of the total tax revenue. Treasury also provided a second option of less radical base broadening by abolishing the threshold and lowering the rate to 1.4 percent while maintaining the exemptions. This would grant relief while maintaining revenue but was not intended as a long term solution. Inland Revenue expressed concerns about any base broadening as it was worried as to whether it had the administrative capacity to deal with more taxpayers.

725 Morning Report, 2 March 1989 8:48am, Land Tax/Real Estate Inst, - Transcript, Archives New Zealand AALR W5427 873 Box 1861 76/4/2 Part 2.

726 David Butcher, Press Release: Land Tax Issue Linked To Unreal Property Values, 12 May 1989, Archives New Zealand AALR W5427 873 Box 1861 76/4/2 Part 2.

727 Hon. Peter Neilson, Speech To The Land Tax Forum, 7 April 1989, Archives New Zealand AALR W5427 873 Box 1861 76/4/2 Part 2.

728 National Business Review, 25 May 1989, Caygill Backs Off On Capital Gains Tax.

729 Treasury, Budget Report 86, 1 June 1989, Archives New Zealand AALR W5427 873 Box 1862 76/4/2 Part 2A. 
While Treasury's focus on neutrality in land tax was not embraced by politicians, it was not without basis. The Fourth Labour Government's major tax reform, the introduction GST, followed a similar model to that Treasury proposed for land tax. Goods and Services Tax, introduced in $1986^{730}$ as a replacement for New Zealand's sales tax, operated at broad base approach with few exemptions. A GST with few exemptions was not the approach taken by most countries (Cooper \& Vann, 2000, p. 262) but the New Zealand system was effective and raised significant revenue. ${ }^{731}$ While Treasury did not directly link its proposed land tax reform with the GST model, there were strong parallels. However, GST was developed over more than a year, in a process including an advisory panel, extensive and responsive public consultation, and a significant public relations exercise (Dickson \& White, 2008). The extensive background work gave GST legitimacy and support. Treasury's land tax proposal shortcut the process, so it did not have similar support.

David Caygill countered with a plan to gradually lower the tax rate, to 1.5 percent in the 1989-1990 financial year and 1 percent the following year while removing the threshold from $1990 .{ }^{732}$ All exemptions would, at this stage, remain unchanged but were under review. Treasury analysis suggested this would not maintain revenue, collecting $\$ 65$ million per year less than the existing law, but the only change Treasury recommended was the inclusion of a $\$ 10,000$ de minimis threshold to reduce the number of taxpayers who had to file returns. This was supported by Inland Revenue as it would reduce compliance cost for them and taxpayers. ${ }^{733}$

\footnotetext{
730 Goods and Services Tax Act 1985.

731 Statistics New $\quad$ Zealand, $\quad$ NZOY 1990, https://www3.stats.govt.nz/New_Zealand_Official_Yearbooks/1990/NZOYB_1990.html, Retrieved 7 April 2020.

732 Treasury, Budget Report 105, 20 June 1989, Archives New Zealand AALR W5427 873 Box 1862 76/4/2 Part 2A.

733 Frank Bosch, Memorandum to Secretary of the Treasury, 19 June 1989, Archives New Zealand AALR W5427 873 Box 1862 76/4/2 Part 2A.
} 
In a drive to include it with the other reforms in the 1989 budget, the exemption review was conducted over seven weeks. ${ }^{734}$ The limited time ensured it was not a thorough review; exemptions for farms, forestry and residential land were not considered at all. The Māori land exemption was considered but no changes recommended as there simply was not enough time to figure out how removing it would work. ${ }^{735}$

Between Treasury and Cabinet, the government decided to introduce the largest rollback of exemptions in the land tax's history. Most exemptions for private commercial and industrial land were to be ended. ${ }^{736}$ The exemption for friendly societies was also terminated, addressing the imbalance in land tax liability for private and public sector unions by making all of them liable for land tax. Concessional rates for non-exempt land owned by charities and religious organisations were also abolished over contrary advice from the Working Party for Charites and Sporting Bodies. ${ }^{737}$

Some private exemptions that were subject to review were kept. The exemption for libraries and museums remained, ${ }^{738}$ although abolition was considered, ${ }^{739}$ as did the sporting exemption, which Treasury appears not to have reviewed at all. More surprisingly the exemption for racing clubs was maintained, apparently out of political concerns as Treasury's only analysis of it was to ask "do we want to make an issue of this". 740

The largest changes were related to exemptions for the Crown. This was part of a scheme to align the public sector with the principles of Rogernomics and the State Sector Act

734 Treasury, Review Of Exemptions From Land Taxation, 22 June 1989, Archives New Zealand AALR W5427 873 Box 1862 76/4/2 Part 2A.

735 Refer note 734.

736 Treasury, Budget Report 112, 27 June 1989, Archives New Zealand AALR W5427 873 Box 1862 76/4/2 Part 2A.

737 Treasury, Budget Report 140, 19 July 1989, Archives New Zealand AALR W5427 873 Box 1862 76/4/2 Part 2A.

738 Treasury, Budget Report 113, 27 June 1989, Archives New Zealand AALR W5427 873 Box 1862 76/4/2 Part 2A.

739 Refer note 734.

$740 \quad$ Refer note 734. 
1988, which saw government departments as providers of goods and services to government and the private sector. To encourage efficiency, accountability and transparency it was thought that government departments should face the same cost environment and taxes as the private sector, ${ }^{741}$ operating with "the full cost of resources ... under their control." 742 While this had previously applied to trading departments, particularly those that had been spun off into State Owned Enterprises, Treasury felt that it should also apply to non-trading departments as the private sector could generally provide similar goods or services. To this end Treasury recommended that all government departments should be liable for land tax. Some land would remain exempt based on usage, notably National parks and the Parliamentary grounds, but Crown ownership would no longer give rise to exemption on its own. To ensure departments aligned more with private sector efficiencies and encourage them to review their landholding, it was recommended that they be given no extra funding to cover their land tax liability.

The same rationale could be applied to land owned by local government and Treasury was happy to do so, recommending it too be liable for land tax on its holdings. ${ }^{743}$ It was expected that the volume of local government landholding would make this a significant cost for councils but Treasury thought it could raise $\$ 50$ million annually for central government. ${ }^{744}$ Treasury also thought the policy could be used to extract concessions in upcoming local government funding negotiations, a strategy that would work better if the policy was already announced. ${ }^{745}$

Both David Caygill's tax relief plan and the exemption changes were presented in the 1989 budget. The rate reduction took effect immediately while other changes were implemented from the $31^{\text {st }}$ March 1990. While it was common for politicians to reject Treasury recommendations on political issues, most exemptions were abolished exactly

\footnotetext{
741 Treasury, Budget Report 117, 29 June 1989, Archives New Zealand AALR W5427 873 Box 1862 $76 / 4 / 2$ Part 2A.

742 The Dominion, 28 July 1989, Bitter Opposition Likely To Moves.

743 Refer note 741.

744 Treasury, Budget Report 129, 3 July 1989, Archives New Zealand AALR W5427 873 Box 1862 76/4/2 Part 2A.

$745 \quad$ Refer note 744.
} 
as Treasury had prescribed. The new exemptions, were primarily based on usage rather than a mix of usage and ownership. This left the Māori land exemption in a precarious position; based on ownership it did not align with the new approach and the frequent mention of this in Treasury's exemption reports suggest it was viewed as a problem. Similarly David Caygill's assertion that all land used for commercial or industrial purposes should be taxed ${ }^{746}$ does not explain why agricultural and forestry businesses remained exempt.

The rapid pace of the exemption review quickly led to problems however. By August Treasury's estimate that the changes would only require 9,000 extra returns to be processed annually ${ }^{747}$ was looking dubious. Treasury arrived at this figure early in the review and before the decision to remove the Crown exemption was made. When Inland Revenue examined the underlying data it concluded it may have to process as many as 115,641 extra returns which it lacked the capacity to do without increased funding. ${ }^{748}$ Eventually it was determined that the removal of the exemptions would increase the number taxpayers paying land tax in 1990 to about 48,000, a significant increase on the 8,333 that paid had it the previous year. ${ }^{749}$ Inland Revenue also had concerns about the intended tax liability of a variety of land, including hobby farms, vacant land intended to be used as a road and vacant land intended to be used as a residence ${ }^{750}$ which had never been considered under the previous threshold and exemptions.

\footnotetext{
746 Refer note 742.

747 Kieran Murray, Memorandum to Keith Taylor, 23 August 1989, Archives New Zealand AALR W5427 873 Box 1862 76/4/2 Part 2A.

748 Inland Revenue, Land Tax - Administrative Issues, 16 August 1989, Archives New Zealand AALR W5427 873 Box 1862 76/4/2 Part 2A.

749 Hon. Peter Neilson, Answer to Hon. George Gair, 1990, Archives New Zealand ABOT W4375 6787 Box 40.

750 Inland Revenue, Land Tax Legislative Issues, 19 July 1989, Archives New Zealand AALR W5427 873 Box 1862 76/4/2 Part 2A; Inland Revenue, Land Tax Issues, 5 September 1989, Archives New Zealand AALR W5427 873 Box 1862 76/4/2 Part 2A.
} 
The second issue was the new taxation of hospitals, which was included within the changes. While David Caygill initially defended the taxation ${ }^{751}$ it was unpopular and looked bad, particularly compared to the still untaxed schools. He requested a report from Treasury into the school/hospital discrepancy. Treasury said that was not a policy reason why schools were exempt from land tax while hospitals were liable; rather the old school exemption had been copied into the new act and hospitals, which had previously relied on the Crown exemption, had no exemption to copy. ${ }^{752}$ Treasury acknowledged this was a discrepancy and suggested further changes to the land tax exemptions may be required; their solution being to start taxing schools. Instead David Caygill ordered an exemption for hospitals created. ${ }^{753}$ This ran into its own difficulties over attempts to define exactly what a hospital was and how to narrow said definition so land not used directly for patient care could still be taxed. ${ }^{754}$ When the change was finally presented to Parliament in a second Land Tax Amendment Act. ${ }^{755}$ Labour defended it as a common sense measure that would be generally welcomed by people $\mathrm{e}^{756}$ but gave no explanation for why hospitals had been included in the first place.

While the 1989 changes were a significant overhaul of the land tax system and better aligned it with the government's taxation principles, it was insufficient to pacify the existing land tax opposition. Inside Parliament, National remained committed to land tax abolition; continuing to argue the land tax was discriminatory, selective, impeding economic growth and part of a tax system that was creating a "wall of death around New Zealand". ${ }^{757}$ The corporate opposition outside Parliament saw the reform as too little, too late. The changes aligned with what the Land Tax Coalition had wanted, and the same

\footnotetext{
751 Questions for Written Answer Wednesday 16 August 1989, Archives New Zealand AALR W5427 873 Box 1862 76/4/2 Part 2A.

752 Treasury, Land Tax Hospital and Schools, 21 August, Archives New Zealand AALR W5427 873 Box 1862 76/4/2 Part 2A.

753 Refer note 752.

754 Stuart Shepherd, Letter to Peter Butler, 12 September 1989, Archives New Zealand AALR W5427 873 Box 1862 76/4/2 Part 2A.

Land Tax Amendment Act (No 2) 1989, s15.

756 NZPD, Volume 504, 14 December 1989, page 14618, James Sutton.

757 NZPD, Volume 504, 14 December 1989, page 14623, Ruth Richardson.
} 
policy implemented in 1988 may have been sufficient to appease them, but their position had since shifted to abolition. They continued to publically campaign for abolition although the degree to which this was genuine is debatable. One Coalition member, the Auckland Chamber of Commerce acknowledged in a letter to the Minister of Finance that they would publically criticise the increased taxation of small businesses, arguing that it threatened their survival, but privately the Chamber thanked the Minister for doing so. ${ }^{758}$

\subsubsection{Revenue}

Ascertaining the effect of the 1989 land tax changes on tax revenue is not straightforward. Even without law changes, land tax revenue had risen significantly since the Labour government took office in 1984, as shown in Table 5, although it consistently remained about 0.36 percent of total tax revenue. Growth spiked following the Wellington revaluation and then increased to $\$ 271$ million following the 1989 changes. The increase on its own is slightly misleading. From 1990 the government changed the end date of its financial year 31 March to 30 June, which meant the government's 1989-1990 financial year was 15 months. For taxpayers land tax financial years continued to run from April to March, but the payment date was pushed forward, and as a transitional fix in land tax was changed from a single payment to two equal payments made on 7 May and 7 October. ${ }^{759}$ As such the $\$ 271$ million recorded as revenue for the 1989-1990 year consisted of two parts: 12 months of land tax at 1.5 percent on the old base and the May payment on the expanded base at 1 percent. A similar situation occurs with the 1990-1991 year. The payment changes meant land tax revenue for the 1989-1990 and 1990-1991 years would be high regardless of changes made.

\footnotetext{
758 M Barnett, Letter to the Minister of Finance, 1 August 1989, Archives New Zealand AALR W5427 873 Box $186276 / 4 / 2$ Part 2A.

759 Land Tax Amendment Act (No 2) 1989, s22.
} 
Table 5. Land Tax Revenue, 1985-1991760

\begin{tabular}{|c|r|r|}
\hline Year Ended & $\begin{array}{l}\text { Land Tax Revenue } \\
\text { (millions of \$) }\end{array}$ & $\begin{array}{l}\text { \% Of Total } \\
\text { Tax Revenue }\end{array}$ \\
\hline 1985 & 43.7 & $0.37 \%$ \\
\hline 1986 & 55.9 & $0.39 \%$ \\
\hline 1987 & 63.6 & $0.37 \%$ \\
\hline 1988 & 71.2 & $0.33 \%$ \\
\hline 1989 & 153.3 & $0.67 \%$ \\
\hline 1990 & 271.0 & $1.03 \%$ \\
\hline 1991 & 172.0 & $0.67 \%$ \\
\hline
\end{tabular}

Overall it is difficult to identify the impact of the 1989 reforms on land tax revenue as payment timing issues mean neither of the two years it was in effect are comparable with other years. That said, the closeness of revenue between the 1988-1989 and 1990-1991 years, both in nominal terms and as a portion of total tax revenue, despite 1990-1991 recording an extra half year of revenue suggest that the base broadening did not offset the cut to the tax rate.

\subsubsection{0, The Abolition of Land Tax}

In 1990 the Labour government still had problems. Throughout 1989 Labour had polled badly against the National opposition and the government remained engaged in infighting over Rogernomics (Bassett, 2008, pp. 486-487). David Lange resigned in August and was replaced by his deputy Geoffrey Palmer.

Despite the leadership change, economic policy largely continued along the same path, if somewhat slowed in an attempt to make it more politically palatable (Bassett, 2008, p. 513). Initially Labour's polling recovered but the party had fallen behind again by October (Bassett, 2008, pp. 519-520). By 1990, an election year, Labour was 20 points behind National in the polls (Bassett, 2008, p. 530) and the business community were expecting the government to introduce many tax changes as a matter of political expediency. ${ }^{761}$

\footnotetext{
$760 \quad$ Refer note 626

761 Evening Post, 1 May 1990, Govt Blamed For Drop In Business Confidence.
} 
Meanwhile land tax continued to fester. The 1989 changes had been significant but they had been drawn up rapidly, likely in an attempt to contain political fallout, and were never intended to be the final reforms. ${ }^{762}$ David Caygill had announced further consideration of the land tax within the government's reviews of capital gains taxation ${ }^{763}$ and tax simplification. ${ }^{764}$ While this had not appeased the existing opposition the 1989 changes had generated a new wave of land tax opposition.

\subsubsection{The Second Wave Opposition}

\subsection{Small Business}

Previously opposition to land tax had primarily been driven by large businesses but the lowering of the threshold made smaller businesses liable. New taxation of small businesses was never going to be popular with those businesses but the poor New Zealand economy of the time made it less so and many, like large businesses previously, wondered if they could afford the cost. ${ }^{765}$ The expansion was also resented by those who felt they were being taxed to pay for a tax cut for the wealthy, ${ }^{766}$ or that it was undermining their retirement investments. ${ }^{767}$ Small business discontent was fanned by the Land Tax Coalition who ran a series of seminars nationally to promote land tax abolition, ${ }^{768}$ blaming the land tax a variety of economic issues that could have been more fairly attributed to the economic downturn. David Caygill's assurances that, despite the cost to

\footnotetext{
762 Refer note 752.

763 NZPD, Volume 499, 27 July 1989, page 11558, Hon. David Caygill.

764 Hon. Peter Neilson, Letter to I Roberston, 2 July 1990, Archives New Zealand AALR W5427 873 Box 1862 76/4/2 Part 5.

765 Volker Grunert, Letter to the Minister of Finance, 15 October 1989, Archives New Zealand AALR W5427 873 Box 1862 76/4/2 Part 4.

766 John Stern, Letter to the Prime Minister, 10 August 1989, Archives New Zealand AALR W5427 873 Box 1862 76/4/2 Part 4.

767 R and J Williams, Letter to the Minister of Finance, 30 April 1990, Archives New Zealand AALR W5427 873 Box 1862 76/4/2 Part 5.

768 Real Estate Times, 31 August 1989, Institute Seminar Hammers Government On Land Tax.
} 
some individuals, the changes had made the overall system fairer ${ }^{769}$ were not well received.

The other problem with taxing small businesses was getting them to actually pay. Despite the nine month lead time between announcement of land tax liability and the first payment being due, Inland Revenue had only managed to contact 27,000, out of almost 40,000, new taxpayers in that time. ${ }^{770}$ When the payment fell due many of the new taxpayers did not pay.

\subsection{Non-Profits}

Like small businesses, the non-profit sector had previously found themselves indirectly liable for land tax when they rented space but the 1989 changes worsened the situation for several of them. Religious organisations lost their concession rates for non-exempt land so they saw a tax increase. Arguing that churches provided help for others ${ }^{771}$ they suggested that the government had a "positive obligation in justice"772 to exempt them. David Caygill disagreed and refused to compromise tax neutrality by making any changes. ${ }^{773}$ Meanwhile trade unions were unhappy at the loss of their exemption and thought that the government was singling them out. ${ }^{774}$

The lowering of the land tax threshold also made administration of the still exempt nonprofits more difficult as it was not clear exactly what the exemption covered. Previously most organisations had been excluded based on the threshold rather than the exemption so this was less of a problem. Now Inland Revenue was required to decide what met the

\footnotetext{
769 Hon. David Caygill, Letter to Volker Grunert, 28 September 1989, Archives New Zealand AALR W5427 873 Box 1862 76/4/2 Part 2A.

770 National Property Review, 10 May 1990, Many Miss Tax Deadline.

771 Gordon Copeland, Letter to the Minister of Finance, 31 January 1990, Archives New Zealand AALR W5427 873 Box 1862 76/4/2 Part 5.

772 Gordon Copeland, Letter to the Minister of Finance, 13 October 1989, Archives New Zealand AALR W5427 873 Box 1862 76/4/2 Part 5.

773 Hon. David Caygill, Letter to Gordon Copeland, 12 April 1990, Archives New Zealand AALR W5427 873 Box 1862 76/4/2 Part 5.

774 Ron Burgess, Letter to the Minister of Finance, 23 May 1990, Archives New Zealand AALR W5427 873 Box 1862 76/4/2 Part 5.
} 
exemption. Inland Revenue promptly exercised its new discretion by trying to tax amateur dramatic societies, ${ }^{775}$ before David Caygill and Peter Neilson overruled them. ${ }^{776}$ Inland Revenue was also reluctant to fully exempt land that had a secondary commercial purpose $^{777}$ and tried implementing an apportionment system, ${ }^{778}$ despite the legislation not obviously giving them the power to do that.

\subsection{Local Government}

While local government had been unhappy about land tax potentially driving away their rating base in previous years, it was even less happy about paying land tax itself. While Treasury hoped it would encourage efficiency and accountability, local government saw it as central government attempting to take their revenue. ${ }^{779}$ Local government was even less happy about what it had to pay tax on and wanted land it used to provide public utilities and car parks exempted. ${ }^{780}$ David Caygill refused because doing so would contradict neutrality, giving local government an advantage over the private sector who could provide the same services. ${ }^{781}$ After making no progress, local government tried getting other MPs ${ }^{782}$ and the Minister of Local Government to intervene on their behalf. ${ }^{783}$ They had a similar lack of success.

775 R Prevett, Letter to The Minister Of Finance, 2 May 1990, Archives New Zealand AALR W5427 873 Box 1862 Part 5; Penny Giddens, Letter to the Prime Minister, 2 February 1990, Archives New Zealand AALR W5427 873 Box 1862 76/4/2 Part 5.

776 Hon. David Caygill, Letter to Rt. Hon. Geoffrey Palmer, 7 May 1990, Archives New Zealand AALR W5427 873 Box 1862 76/4/2 Part 5.

777 Jim Hughes, Letter to the Minister of Finance, 19 March 1990, Archives New Zealand AALR W5427 873 Box 1862 76/4/2 Part 5.

778 Refer note 770.

779 K Miller, Letter to the Minister of Local Government, 1 Feb 1990, Archives New Zealand AALR W5427 873 Box 1862 76/4/2 Part 5.

780 W Hoadley and K Mckay, Submission to the Minister of Finance, Archives New Zealand AALR W5427 873 Box 1862 76/4/2 Part 5.

781 Hon. David Caygill, Letter to Jenny Kirk, 4 May 1990, Archives New Zealand AALR W5427 873 Box 1862 76/4/2 Part 5.

782 New Zealand Herald, 9 May 1990, North Shore Raps Govt On Land Tax.

783 Refer note 779. 
Administration of the land tax was not helped by the difficulties local government had applying the existing exemptions. The exemption list included within the Land Tax Amendment Act 1989 was not clear when exemptions applied to local government and later attempts to clarify it made things worse. The situation got so bad the Local Government Association had to get legal advice on the issue, which suggested that Parliament needed to rewrite the law. ${ }^{784}$

\subsection{The Māori Land Exemption}

Increased opposition was not the only problem generated by the 1989 land tax. Publicity brought attention to the Māori land exemption. This exemption was not popular with a segment of New Zealand society that saw it as discriminatory; ${ }^{785}$ Māori being subsidised by the rest of the population. ${ }^{786}$ Asked to justify why the exemption existed, government members mostly sidestepped the issue; it was not new, and would be reviewed in due course. ${ }^{787}$ It is not immediately clear why this answer was better than the truth that Treasury had wanted to remove it but had not had sufficient time to work out how to do so.

\subsubsection{The Repeal}

Initially no major changes to land tax were planned in 1990. Treasury hoped to leave it alone until it could be considered by a wealth tax review the following year. ${ }^{788}$ The first suggestion that land tax abolition was being considered was in March when David Caygill directed Treasury to cost it and a variety of other taxation and spending proposals. ${ }^{789}$ The costed policies were eclectic, ranging from National's education policy to the

784 Brandon Brookfield, Local Authority Land Tax Liability, 30 April 1990, Archives New Zealand AALR W5427 873 Box 1862 76/4/2 Part 5.

785 I Roberston, Letter to the Minister of Finance, 3 April 1990, Archives New Zealand AALR W5427 873 Box 1862 76/4/2 Part 5.

786 William Mackay, Letter to Peter Dunne, 14 November 1989, Archives New Zealand AALR W5427 873 Box 1862 76/4/2 Part 5.

787 Refer note 764.

788 Treasury, Budget Report 71, 17 May 1990, Archives New Zealand AALR W5427 873 Box 1862 76/4/2 Part 5.

789 Treasury, Costing Taxation and Expenditure Changes, 23 March 1990, Archives New Zealand AALR W5427 873 Box 1862 76/4/2 Part 5. 
establishment of a second chamber in Parliament. This suggests inclusion within the costing report was not a decision to abolish land tax but it appears to be the first time the government considered it a valid policy choice.

The abolition decision came in early June when David Caygill told Treasury that he intended to abolish land tax in the 1990 budget. Treasury protested, arguing there was not a clear case for abolition and the distortionary elements could be solved by broadening the base. ${ }^{790}$ This advice was ignored and abolition was finalised, although it would not take effect until the following year.

Exactly why the land tax was abolished is unclear. Abolition was announced in the 1990 budget with no reasoning or fanfare. During the 1990 budget debate only three members of the government even mentioned the land tax. David Caygill, as Minister of Finance, announced the change but gave no reason for it, ${ }^{791}$ Richard Prebble blamed the Third National Government for increasing the land tax in 1981, ${ }^{792}$ and Geoffrey Palmer suggested that the abolition would be of considerable assistance to New Zealand businesses. ${ }^{793}$ None of these members actually said why the change was made however. It was justified to the cabinet as land tax being difficult to apply in a non-distortionary manner and widely being considered unfair, ${ }^{794}$ but Labour had been denying those arguments for years so this is not especially convincing.

More interesting is a comment by David Caygill found within budget documents ${ }^{795}$ and noted by Reece (1993, p. 238). Here the Minister claimed that the tax's exemptions ensured that most land in New Zealand remained outside the tax base, giving rise to distortions, and the Government was left with the choice of "continuing to broaden the

\footnotetext{
790 Treasury, Fiscal Strategy, 1 July 1990, Archives New Zealand AALR W5427 873 Box 1862 76/4/2 Part 5.

791 NZPD, Volume 509, 24 July 1990, page 3009, Hon. David Caygill.

792 NZPD, Volume 509, 24 July 1990, page 3001, Hon. Richard Prebble.

793 NZPD, Volume 509, 7 August 1990, page 3270, Rt. Hon. Geoffrey Palmer.

794 Hon. David Caygill, Taxation Measures For Inclusion In The 1990 Budget, June 29 1990, Archives New Zealand AALR W5427 873 Box 1862 76/4/2 Part 5.

795 Treasury, Chapter 9 Taxation, June 29 1990, Archives New Zealand AALR W5427 873 Box 30 3/3/89/90 Part 3.
} 
base to include land currently exempt, or abolishing the tax." This statement would have been a valid reason for abolition in 1985 or 1986, when the government abolished other minor taxes, but after the government had ignored such arguments to deliberately maintain and expand land tax for several years, this does not explain why they reversed policy in 1990. Additionally, the statement is something of a false dichotomy; there was the option to make no changes. This was option Treasury recommended, as it would give time for the department's already planned land tax review following year and allow an informed decision to be made in $1991 .{ }^{796}$ There is little to suggest that land tax's distortions were severe enough that abolition was urgently required and the government did not provide evidence that it was.

There was speculation from outside the government as to why land tax was abolished but it is not conclusive. The members of the opposition National Party noted that that Labour members had long criticised National's proposed land tax abolition as too costly, ${ }^{797}$ an argument Labour MPs maintained less than a month before abolition, ${ }^{798}$ and, based on the 1989 land tax changes, National thought the government was moving to make land tax a more permanent part of the tax system. ${ }^{799}$ National claimed that the abolition was the result of pressure they had placed on the government, with the government policy change occurring because there was only three months until the 1990 election. ${ }^{800}$ Given the lack of contradictory evidence provided by members of the government, concerns about the upcoming election appear the most likely explanation. Outside Parliament the Real Estate Institute of New Zealand claimed their pressure had led to abolition but as Reece (1993, p. 237) notes, it is not clear that the Real Estate Institute of New Zealand had the required influence and the claim is not convincing.

\footnotetext{
796 Refer note 790.

797 NZPD, Volume 509, 24 July 1990, page 3027, Wyatt Creech.

798 NZPD, Volume 508, 21 June 1990, page 2293, Harold Valentine Ross Robertson.

799 NZPD, Volume 509, 24 July 1990, page 3042, Wyatt Creech.

800 NZPD, Volume 509, 9 August 1990, page 3401-3402, Wyatt Creech.
} 


\subsection{Summary}

The 1975-1990 period sees a new dawn for land taxation, quickly followed by its end. The tax's social policy elements were largely stripped out leaving it to function solely as a revenue tool. On the back of a buoyant property market, tax bracket creep and increased rates it rose to heights not seen in decades. The boom was not permanent however, and following the 1987 market crash the higher rates and inflated land values that land tax growth had been based upon became a hindrance, generated significant hostility from land tax payers who now had to pay in poor economic conditions, without corresponding increases in cash flows. Attempts were made to reform land tax along the principles of Rogernomics and further reform was planned to align it with intended capital gains taxation and make it a useful element of the New Zealand tax system. This did not appease hostile taxpayers and the 1989 reforms created more of them. Land tax became unpopular, created several problems and was difficult to align with the Rogernomics tax neutral ideology, while raising a relatively small amount of revenue to compensate. As the government found itself polling poorly heading into the 1990 election it ultimately decided to abolish the land tax rather than defend it further, ending one of New Zealand's oldest forms of taxation. 


\section{Chapter 9: Ideas}

Land tax was a policy strongly influenced by ideas, which both provided the impetus for its creation and were the main drivers of deliberate change. While many ideas could have influenced land tax in its hundred year existence, there are four that are particularly influential: fairness, the farmer backbone, neutrality and Georgism. These ideas coexisted but they had differing levels of influence that could wax or wane over time, with one tending to be dominant over the others. Much of land tax development can be characterised as a battle between these ideas for influence. That influence would drive policy change in particular directions and lead to favouritism for compatible programmatic ideas. It would also structure the debate on future changes, establishing what were acceptable arguments in the political sphere and forming legacies that would entrench particular decisions.

Ideas are not the only constraints or drivers of the policy but, in the development of land tax, they dominated other influences. The strong devotion to implementing ideas would see political actors push them with little regard for other considerations. This meant ideas would often overrule things like budgetary constraints, administrative practicality and whether the policy would actually work, in all but the rarest circumstances.

\subsection{Fairness}

Among the influences on land tax policy, the idea of fairness is the most prominent. While fairness was the dominant idea when land tax was established, it casts a shadow over much of land tax development. The extent to which fairness is entrenched, both within land tax policy and wider New Zealand society, means other ideas tend to be framed within a fairness lens or in contrast to it. Serving as both a normative influence and a frame through which tax changes are justified, fairness plays an important role in land tax development.

Assigning a specific definition or outline to fairness in the context of land tax development is difficult. The concept is nebulous in general and subject to different interpretations by different actors, while its role in framing land tax debate made things even less clear. For the purposes of this section a particular interpretation of fairness will be focused on. This contains two elements; first an economic part that broadly aligns with 
Marx's "from each according to his ability, to each according to his need"801 approach. This, despite actors never explicitly defining it as such, provides a reasonable summary of the fairness considerations that influenced land tax policy, particularly under the Liberal, First Labour and Third National governments. The focus on ability and need provided a strong guide for policy since implementation, considering both who should pay taxation and what it should achieve. While other interpretations of fairness are seen to influence land tax development these tend to be aligned to other ideological outlooks, such as the farmer backbone or neutrality, and are incorporated within the coverage of those.

In deciding who should pay and benefit from taxation fairness contemplated more than just economic position. The second element of fairness was a moral component that tended to be shaped by wider society and reflect view of particular periods; some were long lasting while others disappeared over time. The key element was the "deservingness" of groups for particular types of treatment. This considered whether the beneficiaries of a policy deserved the assistance and whether the policy's losers deserved to be worse off. Exclusions and exemptions were based on that assessment. This could be decided based on elements ranging from taxpayer character to their contribution to wider society. The deserving element could likewise bring groups within the boundaries of accepted taxability, even if they would otherwise fail to meet the economic criteria.

Among ideas influencing land tax policy, fairness was the most strongly entrenched. Fairness was complementary to the egalitarian elements of New Zealand culture and was strongly engrained in public feeling by $1912 .{ }^{802}$ While the specifics of what was fair tax policy were not entrenched there was a general belief among the public that any taxation should be fair. This limited what were acceptable arguments within the political discourse and contributed to the popularity of using fairness to frame elements of other ideas.

A key influence of fairness was related to the land tax's base. Land tax was designed partially in response to the previous tax system which was heavily reliant on indirect

\footnotetext{
801 Karl Marx, Critique of the Gotha Programme, 1875, https://www.marxists.org/archive/marx/works/1875/gotha/ch01.htm, Retrieved 22 September 2019.

802 Refer note 327.
} 
taxation, and was felt to fall more heavily on the poor. Land tax was intended to remedy this by moving the tax burden onto those best able to afford it ${ }^{803}$ to create an "equality of sacrifice". ${ }^{804}$ Under this system the wealthy would pay more tax which would be used for the benefit of wider society and allow for the reduction of the tax burden upon the poor and productive industry. ${ }^{805}$ United's 1929 special tax worked on the same principle of directing tax increases to the wealthy because they were most able to pay it, ${ }^{806}$ but with more focus on subdivision.

The First Labour Government (1935-1949) expressed a similar intent, aiming to place the tax burden "on the shoulders of those best able to bear it". ${ }^{807}$ Again the plan was to increase taxation upon the wealthy while using the benefits to help the poor. ${ }^{808}$ Even when the influence of fairness waned in land tax development from the 1950s, the view that it was proper for the wealthy to pay it persisted. The Third National Government (19751984) followed it, although retargeting from the generally wealthy to commercial and industrial land owners. ${ }^{809}$ More surprisingly, despite the lesser importance of fairness to the Fourth Labour Government (1984-1990), Revenue Minister Trevor de Cleene defended the land tax with a fairness argument, by saying that it only fell on wealthy and they could afford to pay it, ${ }^{810}$ despite that clashing with his government's push for tax neutrality. Over the life of land tax, fairness considerations heavily pushed towards greater taxation of the wealthy and realignment of the general tax burden in favour of the poor.

In these cases, taxpayers who paid more tax were seen as deserving to do so for a variety of reasons. In many cases they were said to have previously enjoyed disproportionate

\footnotetext{
803 Refer note 105.

804 Refer note 106.

805 Refer note 108.

806 Refer note 431.

$807 \quad$ Refer note 528.

$808 \quad$ Refer note 527.

809 Refer note 642.

$810 \quad$ Refer note 667.
} 
benefits of government policies ${ }^{811}$ and tax cuts ${ }^{812}$ or to not have paid enough tax previously. ${ }^{813}$ Under Richard Seddon this slipped into a pattern where taxing the wealthy more was seen as noble in its own right, rather than a means to an end. However, that view had largely disappeared from the concept of fairness by the 1930s.

In other cases particular individuals were painted as populist enemies, most commonly absentee landholders, land speculators and land monopolists. Such taxpayers engaged activities in which society felt should be discouraged and were portrayed as undermining housing affordability and the ability of New Zealanders to own their own home. This provided sufficient justification that they deserved to be taxed more.

The taxation of Māori land forms a special case as they were generally not wealthy, with attempts to tax them, or expand taxation of them, based almost entirely on deservedness. Early governments saw Māori as inherently less worthy of land ownership than Europeans, ${ }^{814}$ suggesting they were lazy, ${ }^{815}$ limiting settlement ${ }^{816}$ or conspiring to become a landholding aristocracy. ${ }^{817}$ There is a not insignificant element of racism in this. While this treatment of Māori appears incompatible with fairness when examined from modern perspective, it is consistent with widespread morals of the time and the government vigorously argued that it was a fair policy. ${ }^{818}$ Over time Māori came to be seen as less deserving of taxation and were granted gradual relief. This coincided with both a fall in their landholdings and Parliament becoming less openly racist towards them.

The drive to increase taxation of the wealthy is apparent in land tax's design, particularly in the Liberal period (1891-1912). With no established land tax model that conformed to the Liberals' ideas of fairness (the situation with Georgism is explained later) narrower

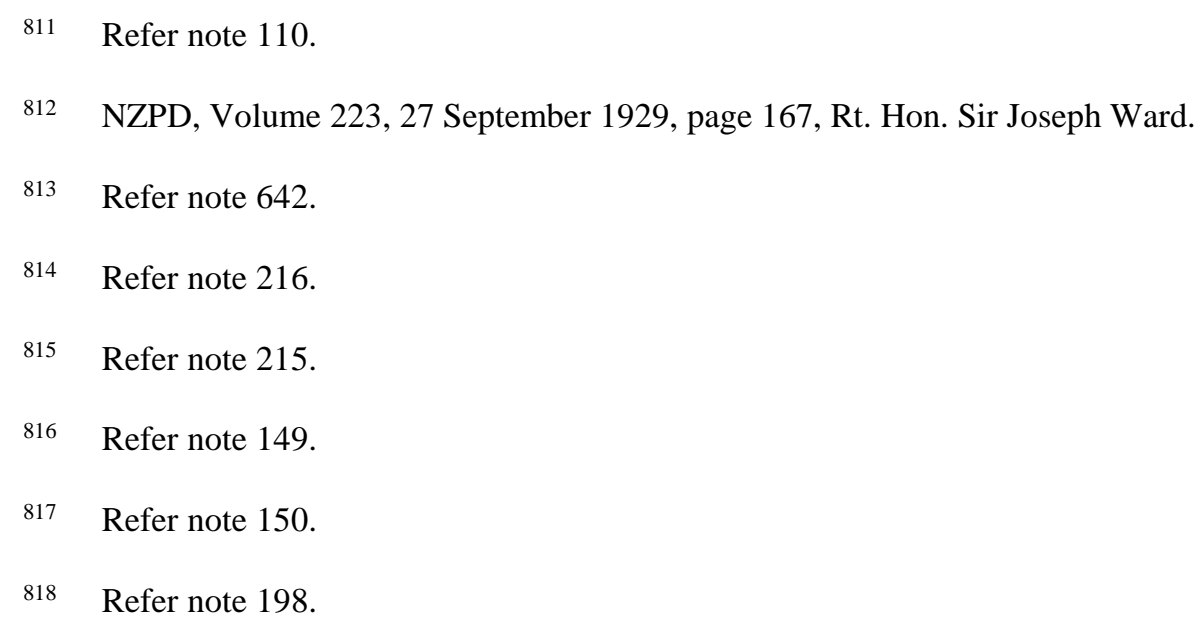


programmatic ideas that supported the government's view thrived. In particular graduated tax flourished within a political environment that heavily valued fairness. Unlike the Georgist model of land tax, the graduated tax conformed to the idea of fairness by increasing burdens on the wealthy, while allowing the poor and middle classes to largely escape taxation. This conformity with the dominant ideology resulted in heavy use of graduation in land tax, but it is dubious whether this actually increased tax paid by most of the wealthy or made taxation materially fairer. The higher brackets were sparsely populated so few taxpayers were affected by the increases.

While land tax was mostly targeted based on the 'ability to pay' element of fairness, the tax's exemptions drew much more from 'deservingness'. Any exemptions were against the principles of neutrality and Georgism but fairness's dominance pushed them through. Initial exemptions were designed to exempt "a large class of the country's most deserving settlers" $" 19$ and the thresholds established to ensure "deserving" settlers, land improvers and small farmers would not be taxed too heavily. ${ }^{820}$ Many of these exemptions were copied from the preceding property tax but the new additions were justified as helping groups that were "doing a lot of good in the colony". ${ }^{821}$ Over time exemptions grew to include quasi-government groups, such as the Apple and Pear Marketing Board, to sports clubs and historic buildings. Most notably owner-occupied residential housing was excluded from 1983 and all residential housing from 1988.

Most of these additions were still argued to be based on fairness. Residential homes were exempted because it was thought unfair to tax them, while sports clubs and the racing were thought to deserve an exemption because they provided recreational benefit to communities. ${ }^{822}$ From the 1970 s exemptions were the dominant method for applying fairness to land tax as they could be used to target whichever group politicians felt needed special treatment. This allowed relief to be granted with a lesser impact on the government's already poor finances.

\footnotetext{
819 Refer note 1.

820 Refer note 98.

821 Refer note 85.

822 Refer note 637.
} 
In many cases it was dubious whether these exemptions contributed to fairer taxation. In 1983 the land tax's threshold was so high it was doubtful that the new housing exemption benefited anyone but the wealthiest families, ${ }^{823}$ while the sporting exemption had limited effect outside some golf clubs because most other sporting groups did not own land. In other cases the exemptions would result in different tax treatment for similar activities, such as forestry being taxable while farming, horticulture and viticulture became exempt. ${ }^{824}$ The changes certainly did not make the law easier to administer, resulting in a significant increase in litigation from 1980 to clarify the breadth of exemptions. Ultimately the push to include fairness within the land tax, and to be seen as doing so, meant that whether the policy changes helped was secondary.

The dominance and widespread use of exemptions, combined with continued high thresholds, did however allow land tax policy makers to adopt new programmatic ideas. The introduction of flat taxation, anathema to fairness since 1891, became acceptable within a fairness dominated environment because exemptions had excluded most of those taxpayers generally protected by fairness. This left a tax base that was relatively wealthy and could be argued as deserving of paying greater taxation.

Fairness likewise had a significant influence on land tax's social policy considerations. The key part of this was a drive to implement fairer land distribution, largely a response to the difficulties many had buying land in the 1890s. The idea was to encourage widespread land landownership among the general population while discouraging land aggregation and speculation, very similar to Georgism. This was generally felt to be fair. The general public, regardless of wealth, was seen as deserving the chance to own land while social dislike of land aggregation and speculation, particularly by absentees, was enough to justify penal taxation of those engaging in such behaviour.

Trying to implement fairness in both the social policy and tax targeting areas of land tax led to problems as they undermine each other. Georgism, which focused on the social policy aspects of land taxation, suggested that to successfully widen landholding while discouraging aggregation and speculation a land tax needed to be broad based with high rates. New Zealand discarded this because universal taxation conflicted with the fairness

\footnotetext{
$823 \quad$ Refer note 656.

824 Land and Income Tax Amendment Act 1970, s4.
} 
derived aim of reducing taxation on the poor and taxed groups not felt to deserve it. This created a narrowed based tax policy that was regarded as a fair means of raising revenue, despite being less effective as a social policy tool, weakening its key aim. This approach to land tax required a choice between whether the government would prioritise fairness for the tax base or policy outcomes. While politicians' rhetoric continued to emphasise fairer land distribution until 1930, politician's actions consistently treated it as subordinate to implementing fairness in the tax base. Even the 1929 special tax, which was argued to be part of a return to the "closer settlement" policy of the Liberal government ${ }^{825}$ prioritised keeping the base narrow.

Even when not the dominant ideological influence on land tax, fairness had a powerful legacy. Its strong entrenchment shaped what was acceptable in land tax policy debates, limiting the influence of the farmer backbone and neutrality and often forcing their proponents to frame those ideas in terms of fairness. This largely shut neutrality out of public debate because it clashed with the progressive taxation fairness encouraged and was difficult to frame in fairness terms. The farmer backbone had more success but having to comply with fairness resulted in a relatively slow and covert rise in the influence in the 1910s and 1920s, and a less overt approach during 1950-1970 period.

The dominance of fairness could be broken by particular events. The Great Depression and the continued economic issues of the 1980s were sufficient to break its control. This allowed other ideas to be implemented with fewer restrictions, in the short term. This did not hold over the longer term and fairness would reassert itself, usually adopted by opposition as a key plank of their resistance to policy changes. This was seen in 1936 and the late 1980s where arguments against previous land tax changes were strongly rooted in fairness.

\subsection{The Farmer Backbone}

Built on the importance of farming to the New Zealand economy and the lionisation of farming as a lifestyle in colonial New Zealand, the farmer backbone provided an alternative policy influence to the progressive fairness that was dominant within the Liberal party in the 1890s and early 1900s. The key implication was that the distribution

\footnotetext{
825 Refer note 414.
} 
of the benefits and burdens of taxation should be directed, not based on a taxpayer's need or ability, but rather their job. The idea held that farmers' importance and character entitled them to better treatment that other taxpayers. ${ }^{826}$

While the farmer backbone is more generally associated with the Reform and National parties it predates their existence and is present from the land tax's implementation in 1891. Both the Liberals and the opposition stressed the importance of not heavily taxing farmers; the key difference was the targeting. The Liberals championed small farmers, who were seen as a special case when setting policy, ${ }^{827}$ but were more hostile to the large landowners they continued to paint as populist enemies. Conversely the conservative opposition was more supportive of large farms, which were seen as essential to the New Zealand economy. ${ }^{828}$ Between the two wings of New Zealand politics all farmers had someone pushing for special treatment of them. This established a privileged land tax position for farmers from the start. Unlike other businesses farmers, were granted an income tax exemption to offset potential land tax liability ${ }^{829}$ and the tax was deliberately designed to fall only lightly on most of them. ${ }^{830}$

By the 1900s both views of farmers had converged and New Zealand had entrenched what William Pember Reeves described as an "agrarian cult" (1903, p. 361) where cities and their inhabitants were seen as inferior to farmers. This formalised a secondary element of the farmer backbone, an urban versus rural divide where policy targeted to help one group was often at the expense of the other.

The convergence also solidified a degree of class identity among farmers; where they were sometimes seen as a single group for policy purposes and changes that affected a subset of farmers could be seen as affecting all of them. This could stifle reform, where tax changes that affected only small numbers of farmers, such as the 1929 special tax, were seen through the farmer backbone as an attack on all farmers. Conversely this also

\footnotetext{
826 Refer note 303.

827 Refer note 268.

$828 \quad$ Refer note 159.

$829 \quad$ Refer note 139.

$830 \quad$ Refer note 98.
} 
meant changes that benefited a few farmers could be justified as benefitting the whole, making their passage easier.

While the farmer backbone became a significant influence on land tax policy, doing so required overcoming New Zealand's engrained dislike of anything resembling class conflict. The entrenchment of the agrarian cult meant the public would accept limited preferential treatment for farmers if it was not too overt. Arguments surrounding the farmer backbone tended to be less prominent and were often framed in terms of fairness or neutrality, while policy decisions tended to convert programmatic ideas generally associated with other ideas. Initial attempts to align farmer concerns to neutrality, such as arguing that land tax placed a comparatively higher burden on farms, ${ }^{831}$ proved largely ineffective and counterproductive. Instead farmer concerns were usually framed through fairness.

The farmer backbone carved out a niche when framing itself within fairness. The landholding of farmers, particularly the larger runholders, meant their wealth was significant enough to be difficult to justify under fairness's economic limb, although attempts were made. Most emphasis instead focused on fairness's moral component. A recurring element of land tax debate across the decades was to stress the good character of farmers, how their farming was the product of their own hard work and that farmers were particularly important to New Zealand economy. These were used as a justification for why farmers should be subject to lower taxation. These characteristics were not exclusive to farmers, many non-farmers could be said to be hard workers of good character, but this was not sufficient grounds to justify tax exemptions for other groups. While fairness was the main approach to framing farmer backbone arguments for public debate, compatibility between the ideas required maintaining a double standard.

After being a secondary concern to fairness the farmer backbone slowly became more important from 1912, under the more farmer focused Reform government. When Reform came to power in 1912 public support for land tax and the idea of fairness was heavily "soaked into the general community" 832 and the new government primarily maintained

\footnotetext{
831 Refer note 102.

832 Refer note 327.
} 
the fairness rhetoric in policy debates. ${ }^{833}$ However, the influence of the farmer backbone was seen in policy changes. Farmers began to see increased benefit from the policy of altering the graduations to be more top heavy. In both 1912 and 1920 cuts to the lower land tax brackets primarily helped smaller farmers but the thresholds from which the corresponding tax increases applied were so high very few people were worse off. In the 1920s the land tax remained relatively static, beyond the removal of wartime levies, and the fairness rhetoric was maintained but changes in the wider tax system generally benefited farmers. The most notable change was the reinstatement of the agricultural exemption to income tax which saw potential land tax liability shield farmers from the heavier income tax, despite any other business being liable for both.

The farmer backbone starts to be explicitly important following the end of the Reform government in 1928. In opposition Reform abandoned much of the fairness argument they had generally championed in government and primarily focused on the farmer backbone. The 1929 special tax was fought primarily on these grounds. Reform argued that the tax was an attempt to push the cities' tax burden onto farmers and that it placed an unreasonably large burden on all farmers, ${ }^{834}$ despite very few actually paying it. Rather than simply argue that farmers should pay less tax, most of the argument was framed by fairness; painting the tax as a penalty on New Zealand's best residents who were doing good work in assisting the production of the country. ${ }^{835}$ Token argument was also made that the policy breached neutrality. ${ }^{836}$ This was ultimately unsuccessful in ending the policy but was popular with farmers and conservative groups outside Parliament and saw the government concede a hardship clause ${ }^{837}$ that largely undermined the policy.

Once Reform became part of the coalition government dealing with the Great Depression in 1931 the farmer backbone became the main driver of government policy, with little influence from fairness. In an attempt to deal with the government's worsening financial

\footnotetext{
$833 \quad$ Refer note 316.

834 NZPD, Volume 223, 26 September 1929, page 89, Charles Wilkinson.

835 Refer note 433.

836 NZPD, Volume 223, 25 September 1929, page 51, Alexander Young.

837 Refer note 447.
} 
position and the hardship faced by farmers, ${ }^{838}$ the government spent the next five years prioritising relief to farmers and largely ignoring everyone else. In the context of taxation this meant the government instituted a tax swap. The abolition of graduated land tax saw the adoption of the flat tax generally associated with neutrality and Georgism but setting it at the lowest previous rate meant it mostly benefited medium and large farmers while the corresponding income tax expansion (which most farmers still did not pay) penalised non-farmers. The changes were sold as an attempt to keep small farmers operating, ${ }^{839}$ despite small farmers not benefiting from the removal of graduated land tax (although they escaped being penalised by the higher income tax).

The tax swap and flat land tax was a massive shift in the tax burden from farmers to urban dwellers, to the point even advocates of the farmer backbone worried it might be too biased. ${ }^{840}$ The change was a policy that only made sense in the context of the farmer backbone. In later years it would be defended as the government fulfilling its responsibility to "do anything during the slump to help the men who were struggling along" 841 and helping those who had suffered "the greatest financial difficulty" ${ }^{842}$ While the assertion that wealthy landowners were the worst affected by the depression is unconvincing, the suggestion that the government was helping those who were struggling is false; only farmer's issues were considered. Despite widespread hardship elsewhere no tax changes made in 1931 were designed to help anyone else and over the following years relief for non-farmers was sporadic and limited. The farmer backbone encouraged prioritising the concerns of farmers but with the limited resources available during the depression prioritising farmers meant excluded the concerns of everyone else, regardless of the hardships they faced. In this context it is unsurprising that land tax remained unchanged and largely purposeless for the next five years; a tax policy seen as benefitting urban residents was not compatible with an ideology that prioritised farmers above all others.

\footnotetext{
838 Refer note 485 , page 3.

839 Refer note 496.

$840 \quad$ Refer note 486.

841 Refer note 540.

842 Refer note 540.
} 
The tax policy's conflict with fairness and New Zealand's dislike for class differences appears not to have been sustainable. The coalition government became highly unpopular and lost the 1935 election. After that, the farmer backbone became less prominent again but still maintained an influence. It appears to have influenced the new Labour government, whose land tax policy had much lower rates than they had previously advocated. Likewise, land tax inertia from 1940, particularly under National, can be explained as wanting to minimise farmer taxation. Apparent throughout this however, is that after the coalition, no government was prepared to completely abandon fairness as a policy consideration.

The last gasp of significant direct influence by the farmer backbone on land tax policy appears to be the 1970 agricultural exemption. The government maintained the farmer backbone influenced desire to reduce taxation of farmers ${ }^{843}$ and the exemption would have been the ideal policy for the farmer backbone before the 1940s. By 1970 however, most farms were already exempted. The change was more a recognition of the situation than an attempt to provide widespread farmer tax relief. This exemption mostly removes the influence of the farmer backbone on land tax; without farmers paying the tax their concerns are less important. From that point the farmer backbone encouraged the use of land tax, as it could be used to limit tax increases to urban taxpayers, ${ }^{844}$ but the idea had limited influence on policy specifics.

The farmer backbone leaves a legacy. Most significantly, farmers are one of the few groups to maintain preferential land tax under the 1989 reforms. This appears to be the result of path dependency and time constraints rather the idea itself, the government did not support the farmer backbone and had previously removed most of the state's preferential treatment for farmers. If land tax had continued beyond 1990 this likely would have been eliminated.

\footnotetext{
843 Refer note 611.

844 Refer note 643.
} 


\subsection{Neutrality}

The next major idea in land tax development was neutrality. Like fairness and the farmer backbone it was part of policy debate since 1891 but was usually weaker than those ideas.

At its most basic, neutrality was the idea that the tax system should treat everyone the same and taxation should have as little influence as possible on taxpayer decision making. ${ }^{845}$ The main advantage of this was that it made tax systems easier to administer but it put neutrality in direct conflict with fairness and the farmer backbone, which both sought to advantage particular groups.

The influence of fairness and land tax's social policy component was never going to leave a lot of room for neutrality to be influential. Since land tax was a deliberate attempt to change taxpayer behaviour regarding land ownership, it conflicted with neutrality on a core level. In the 1890s, argument about whether tax should be used as a social policy tool saw objections primarily rooted in neutrality, leading to calls for greater horizontal equity in taxation instead (specifically that everyone should pay the same, regardless of means or wealth). ${ }^{846}$ The influence of fairness on government thinking saw this view defeated. In an attempt to become more compatible with the prevailing ideological climate, neutrality proponents moved away from extreme horizontal equity and towards advocating traditional flat taxation.

The move by proponents towards advocating less radical neutrality was not especially successful. The programmatic ideas favoured by neutrality, flat taxation and limited exemptions, were incompatible with fairness because they would impose new taxation on much of the country when fairness pushed to move the tax burden onto the wealthy. They were likewise incompatible with the farmer backbone as they would tax small farmers, despite the potential tax decreases for large farmers. Neutrality itself also conflicted with the popular programmatic ideas of graduation and exemptions that dominated land tax policy design until the 1980s. Neutrality tended to be difficult to frame as compatible with the other ideas making it difficult to implement as policy.

\footnotetext{
845 Refer note 700.

846 Refer note 114.
} 
The influence of neutrality was further handicapped by the lack of a political support base, unlike fairness, generally championed by the Liberal and Labour parties, or the farmer backbone, supported by Reform and National. This is not surprising, unlike fairness or the farmer backbone neutrality, by design, did not benefit a particular group so there was not an inherent support base for it. The lack of political support does however limit its ability to generate political change. Support for neutrality was found within the public service, who were less responsive to political influence, generally on the practical grounds it made taxation easier to administer and could raise more revenue. This meant advice given to politicians tended to reflect neutrality, but they would not implement it.

Despite early support in the public service, neutrality did not become influential until the 1980s. The 1981 adoption of the flat land tax saw the implementation of a key programmatic idea associated with neutrality but that was based on fairness. Instead neutrality came to prominence after the 1984 end of the Third National Government. The limited success Robert Muldoon had fixing New Zealand's economic problems tainted previous approaches to economic policy and there was a feeling that something else should be tried. This left a gap for ideas that neutrality, with an established base in the public service and supporters in the new Labour government, was able to fill. Notably it still did not have the popular support comparable to fairness or the longstanding entrenchment of the farmer backbone.

That neutrality would be the main driver of new land tax policy quickly became apparent following the election of the new government. The Rogernomics economic program drew heavily on neutrality and Finance Minister Roger Douglas's early letters critiquing the land tax largely base their arguments on its lack of neutrality, specifically the narrow base and many exemptions. ${ }^{847}$ This aligned with Treasury's view of land tax ${ }^{848}$ but was insufficient to trigger any major changes; land tax was not a major tax and other reforms took priority.

As such the first time the influence of neutrality can be clearly seen in land tax reform is 1986. While relatively minor when considered in isolation, the 1986 changes show an

\footnotetext{
847 Hon. Roger Douglas, Letter to R Knott, 19 Nov 1984, Archives New Zealand AALR W5427 873 Box 1861 76/4/2 Part 1.

848 Refer note 689.
} 
uneasy dual impact of neutrality and fairness. More exemptions are added to the system but these are largely designed to align the treatment of similar taxpayers. Adding more exemptions was not itself a principle of neutrality but the similar treatment they were designed to ensure was. The 1986 changes also mark the first roll back of the exemptions. This was a departure from the dominance fairness had held over exemptions previously.

Neutrality finally managed to significantly affect land tax in 1989. After admitting that the land tax did not conform with the government's commitment to neutral taxation ${ }^{849}$ and faced with public outcry over rising tax liability, the decision was taken to reform the land tax. The job of doing so was given to Treasury, whose institutional ideology strongly valued neutrality. This meant that Treasury had objected to most land tax exemptions proposed for the last decade and its view of land tax was that it had too many exemptions and should be abolished or extended. ${ }^{850}$ By this point land tax's social policy elements had withered away and with them one of neutrality's key conflicts with the system. Given free rein to reform land tax, Treasury's proposals drew heavily on neutrality, making elimination of exemptions their primary focus.

While the government rejected Treasury's proposal for a truly neutral land tax with no exemptions, the 1989 reforms pushed to increase land tax's neutrality significantly beyond what had come before. The intent was to levy land tax upon all land used for commercial or industrial purposes. ${ }^{851}$ This saw the threshold for tax liability reduced to $\$ 10,000$, bringing parity between large and small business and expanded the base beyond businesses in the big cities, making land tax relatively neutral to a taxpayer's location. This approach had previously been advocated by big businesses who wanted more neutrality to deal with the fact they felt the existed system fell disproportionally on them. ${ }^{852}$

Land use became the key basis for the remaining exemptions and several that had previously been granted based on deservedness, such as for charities, disappeared as tax

\footnotetext{
$849 \quad$ Refer note 724.

850 Treasury, Budget Report 71, 15 July 1986, Archives New Zealand AALR W5427 873 Box 1861 76/4/2 Part 1.

$851 \quad$ Refer note 742.

852 Refer note 717, page 10.
} 
treatment of similar activities was aligned. This largely matched the government's philosophy that the state should interfere with the market as little as possible and that market forces should be the primary driver of business decisions. The other key change was the loss of Crown exemptions, which would see most government entities and private industry treated neutrally by the tax system, aligning with the government's broader Rogernomics program. The loss of Crown exemptions was supposed to encourage government entities to operate with more efficiency, accountability and transparency ${ }^{853}$ by forcing them to operate under the same conditions as, and in competition with, the private sector. Treasury felt that neutrality with business would also benefit local governments so their exemption was likewise lost. ${ }^{854}$ Much like changes driven by the farmer backbone, both the reduced exemptions and lowered thresholds were framed as making land tax fairer. ${ }^{855}$ This was likely an attempt to gain public support but the neutral approach to land taxation was unpopular, particularly with taxpayers who only became liable following the changes. Despite the unpopularity the drive to implement neutrality saw the government push ahead.

While 1989 saw an expanded influence for neutrality it also changed what it was supposed to achieve. Neutrality had previously been supported to produce easier tax administration and greater revenue. In the push to increase the influence of market forces, the 1989 changes were expected to both lower revenue and increase administrative complexity. Objections to this were raised by Inland Revenue, ${ }^{856}$ who generally supported the old approach to neutrality, but the more market focused Treasury and Minister of Finance ignored them. The idea of neutrality was so influential that it largely took precedent over whether the system could work in practice.

Despite 1989 being the high point for the influence of neutrality on land tax, it lacked the complete dominance fairness and the farmer backbone previously demonstrated. Even in historically favourable conditions the neutral ideals advocated by Treasury were discarded as politically unfeasible, and limited concession had to be made to

\footnotetext{
853 Refer note 741.

$854 \quad$ Refer note 741.

$855 \quad$ Refer note 769.

856 Refer notes 738; 750.
} 
administrative practicality in the form of the $\$ 10,000$ threshold. Despite its reduced importance fairness continued to be the standard by which the public measured tax reform and even Treasury would not ignore it entirely. ${ }^{857}$ With its popularity falling and an election in 1990, the government was more responsive to those concerns than it previously had been, limiting other potential changes. The taxation of hospitals was abolished less than five months after it was announced as no one could convincingly justify why hospitals deserved to be taxed. Treasury's proposal to solve the issue by making the land tax more neutral and also imposing it on schools appears to have been refused for the same reason. Finally taxation of family homes was never considered by the government, although Treasury did propose it, likely because any taxation of family homes had long been seen as unfair by the public.

Like the farmer backbone in 1936, the fall of neutrality's influence on land tax policy aligns with significant electoral defeat for the government, although in this case the change occurs before the election. Faced with significant public pressure, which had successfully framed land tax as unfair and heavily taxing groups that did not deserve it, and further dwindling popularity, the government simply abolished land tax. Neutrality did not stop being supported by government politicians, or Treasury, but politicians sacrificed commitment to it when faced with an unfavourable political situation and an upcoming election. The fate of neutrality under the Fourth Labour Government suggests that while ideas can be influential, even without popular support, their influence correlates to the government's expected electoral chances; they are more likely to be abandoned in attempts to prevent electoral defeat.

\subsection{Georgism}

One final idea is particularly relevant to the development of the land tax, Georgism, but unlike the others its importance comes from its lack of influence rather than any results. When New Zealand began implementing its land tax in 1891 there was a comprehensive model that could be followed. Georgism, based on Henry George's 1879 work Progress

857 Refer note 724. 
and Poverty, established policy aims for a land tax and how to achieve them. ${ }^{858}$ It had become internationally widespread during the 1880 s and was generally seen by land tax supporters as best practice. It had followers in New Zealand including several Liberal party MPs, most notably Sir George Grey, and had been the most commonly advocated approach to land taxation throughout the $1880 \mathrm{~s}$.

Georgism would have been the expected point to start developing a land tax from; it was well established with national and international recognition and an existing group of powerful supporters, particularly among organised labour and the middle classes. But when the time came for the government to implement a policy Georgism was largely ignored, despite there not being an obvious alternative model. The problem was that elements of Georgism clashed with the dominant normative ideas. Georgism's exemption free flat tax would impose new taxation on much of the country when fairness pushed to move the tax burden onto the wealthy. Similarly the Georgist model was more concerned with the taxation of the unearned increment than the quick subdivision of land the Liberals were hoping to force. At the same time Georgism's proposed taxation of all farmers was incompatible with the farmer backbone ideology and farmer advocates tended to view it very negatively. Conflict with the key ideological pillars of land tax debate (on both the progressive and conservative sides on New Zealand politics) severely limited the influence of Georgism and curtailed the implementation of most of its features. The only significant element that was implemented was the full exemption of improvements from 1893. This exemption was compatible with both fairness, as it imposed no new taxation and encouraged active use of land, ${ }^{859}$ and the farmer backbone, because it gave relief to farmers ${ }^{860}$ (although there was concern that this primarily benefited urban landholders). ${ }^{861}$

\footnotetext{
858 John Stuart Mill's model of land taxation does not have been considered at all by the Liberal Government in 1891. This may have been because Mill's model would not allow the government to quickly raise tax revenue to replace the property tax. The lack of consideration may also stem from the fact Robert Stout, the strongest advocate of Mill's ideas within the Liberal Party (Rogers, 1963) was not in Parliament at the time.

$859 \quad$ Refer note 100.

860 NZPD, Volume 82, 11 September 1893, page 154, Hon. Sir John Hall.

861 Refer note 134.
} 
Following the 1890s Georgism never completely vanishes as an idea in New Zealand politics but it was heavily marginalised. Georgist supporters had planned to gradually introduce the system over the longer term ${ }^{862}$ but the dominant political ideologies did not change enough for Georgism to be acceptable and nothing came of it. Over the years most tax reviews received a few submissions that proposed a Georgist land tax but these are always minority positions and are generally discarded, although the 1967 review thought it was persuasive. ${ }^{863}$ Overall Georgism was mostly insignificant from the 1910s, somewhat mirroring its international decline.

In the longer term several of the programmatic ideas that made up the Georgist model had more success. Georgism aligned closely with neutrality and while this was insufficient to give it influence in the tax policy debate, neutrality largely co-opted its methods. Flat rate taxation with no exemptions became the vision of neutral land tax and found a home within the public service (the tax department and later Treasury) but they had little interest in Georgism's social policy elements. Here the ideas persisted until the ideological climate was more favourable to their implementation. Flat tax was implemented in 1981, after exemptions had become the dominant approach to targeting the land tax, limiting concerns about fairness. Exemptions themselves began being rolled back from 1987, alongside the rise of neutrality. This was not due to the influence of Georgism but was instead a case of programmatic ideas fitting within a normative viewpoint and being adopted into it. The Georgist method had more influence over the land tax once it was divorced from the overall Georgist ideology.

\subsection{An Absence of Ideas?}

While many developments in land tax policy can be explained by the influence of ideas, explaining the abolition of land tax within that context is more difficult. Despite abolition being a significant policy change in a tax that has generally had strong ideological influences, there is no obvious idea driving it.

\footnotetext{
862 Refer note 169.

863 Refer note 609 , page 415.
} 
While all the major ideas could have driven abolition previously, this was inconsistent with 1990 environment. The farmer backbone had pushed for abolition in the past but by 1990 it was irrelevant because farmers did not pay land tax. Treasury had been pushing for abolition based on neutrality as recently as $1986^{864}$ but since then the tax had become significantly more neutral and Treasury now thought it was reasonably efficient. ${ }^{865}$ Finally much of the land tax opposition through the 1980s had been framed in terms of fairness and the Land Tax Coalition was pushing for abolition on those grounds, but the government been ignoring similar fairness concerns for years.

Ultimately the government used fairness and neutrality as the justification for abolition, arguing that land tax could not be applied in a non-distortionary manner and was widely considered unfair. ${ }^{866}$ It appears unlikely that these ideas drove the decision however. Since Treasury, neutrality's strongest supporters, explicitly stated there was no grounds for abolition ${ }^{867}$ that would suggest abolition was not based on neutrality. Meanwhile fairness had had little influence on the government or its policies. Further, the same could be said about land tax any time since, at least, 1987 and that had not prompted consideration of abolition previously. Rather this appears to be a case like those found by Berman and Pagnucco (2010) and Asiskovitch (2009), where politicians would use ideas to justify policy decisions after they had been made, even if they did not personally support those ideas.

This leaves the question of why land tax was abolished. The decision appears to have been made devoid of ideological influence; indeed ideas would suggest the tax be retained. The key difference in 1990 from previous periods is the upcoming election and the government's dismal polling. While in previous years public pressure had only limited success in mitigating the influence of ideas the 1990 abolition does suggest that, in the right circumstances, public pressure can not just limit the influence of ideas but force them completely from the policy making process.

\footnotetext{
$864 \quad$ Refer note 689.

865 Refer note 790.

$866 \quad$ Refer note 794.

867 Refer note 790.
} 


\subsection{Summary}

Ideas are the key drivers of deliberate change in land taxation. Much of the history of land tax is actors trying to develop the system so that it better reflects their preferred ideology. Despite Georgism being the first idea to establish itself regarding land tax, fairness was generally dominant, shaping both the policy itself and the debate around it. The dominance of fairness saw the tax burden pushed onto the rich and those seen as deserving to pay it but was less successful in its social policy aims. In periods where fairness was less dominant supporters of the farmer backbone and neutrality managed to gain control and direct land tax towards their aims but they were never able to entrench that direction.

Actors' commitment to ideas did not necessarily result in better policy however. The drive to implement ideas often saw more practical concerns, such as whether the policy would work and its ease of administration, pushed aside. Sometimes the way ideas were implemented could undermine the aims of those same ideas. This created situations where land tax became more complicated than it needed to be and significantly less effective. While ideas can provide policy inspiration and direction they are not a guarantee of policy competence.

Despite their usefulness, ideas on their own are insufficient to explain all of land tax development. The most obvious issue is the 1990 abolition but they also struggle to explain its persistence when it seems not to align with any idea. To understand these other components of historical institutionalism must also be considered. 


\section{Chapter 10: Path Dependency}

Ideas proved key to shaping the development of land tax, providing direction and inspiration for policy formation and the goals it should achieve. However, ideas are not responsible for maintaining land tax. Rather land tax persistence is a function of path dependency. While political institutions are inherently vulnerable to path dependency (Pierson, 2004, p. 44), land tax displays a particular tendency towards it. Despite a hundred years of existence the fundamentals of land tax usually remained consistent, and the policy could go decades without a major update. This tendency towards inertia helped preserve land tax for a century but it limited its ability to adapt to its environment. As land tax aged, law written decades previously was applied to an environment its creators had not imagined.

The following chapter examines the importance of path dependency in land tax development, with a particular focus on the development of the feedback mechanisms that sustained it.

\subsection{The Elements of Path Dependency}

After implementation, land tax quickly established a path dependent framework that would ensure its future propagation. Under Mahoney's (2000) classifications path dependency has four feedback mechanisms that maintain an institution: legitimation, functional, power and utilitarian. Land tax retention relied on all of these but their importance varied and changed over time.

\subsubsection{Legitimation}

Legitimation is the feedback mechanism most closely tied to ideas, particularly fairness which had wider public support. Since ideas were so important to land tax policy, legitimation was usually one of the most important feedback mechanisms.

Legitimation feedback mechanisms initially developed because land tax was seen as fair. Its goals to make the tax system more progressive, by increasing the burden on the wealthy, while expanding land ownership aligned it with the idea of fairness and what the New Zealand public wanted. It helped that the most visible targets of the land tax were populist enemies; the owners of great estates, land monopolists, foreign landowners and 
big business. These were groups that New Zealand culture did not like or trust, feeling they were detrimental to society. To offset this, much of the public felt it was proper that those groups should pay higher taxation. In this way land tax was widely viewed as a moral approach to taxation, making it popular and difficult to repeal. In addition LeRossignal \& Stewart observed in 1908 that land tax was popular with the public because it shifted "the burden of taxation from their own shoulders to those of their wealthy neighbours" (LeRossignal \& Stewart, 1908, p. 22). This was a significant feature of land tax legitimation feedback mechanisms and it persisted until the 1980s.

The perception of land tax as morally acceptable was widespread, although slightly different under different governments, reflecting each one's interpretation of fairness. The Reform government, not natural supporters of land tax, supported heavier taxation of land monopolists and speculators. ${ }^{868}$ Conversely the First Labour Government saw land tax as a way to ensure the wealthy paid more tax. Finally, the Third National Government saw land tax as a way to keep the tax burden off struggling families and farmers while taxing businesses who were felt to be paying insufficient tax. ${ }^{869}$ These differing interpretations allowed land tax's legitimation feedback mechanisms to be reinforced under a variety of governments, maintaining its path dependency. Changes to land tax that did not align with fairness, such as the 1931 flat tax and the 1989 reforms, struggled to establish legitimation feedback mechanisms and tended to be short lived.

The strength of legitimation feedback mechanisms declined somewhat during the 1920s. While the legitimation elements supporting progressive taxation of the wealthy remained strong, feedback mechanisms based on wider land ownership were eroded. The end of the great estates and increased preference towards urban home ownership rather than farms, meant subdivision was now less important. From this point land tax legitimation was primarily based on its taxation of the wealthy. While land tax did not raise enough revenue to have a significant impact on redistribution efforts, it was seen as proper to tax the wealthy on their landholdings to increase tax equity. This pattern continued after the First Labour Government revived land tax graduation in 1936. Since the land tax was no longer being argued to be a tool to encourage subdivision those elements disappeared.

\footnotetext{
868 Wanganui Herald, 8 September 1920, Tax Bill.

869 Refer note 642.
} 
The new legitimation mechanisms just focused on land tax as a component of fairer taxation, taking from those who were already wealthy to give to those who were poor.

Following the reintroduction of graduation, legitimation was largely responsible for maintaining land tax path dependency until the 1970s. This was sufficient to maintain land tax once Labour lost power. By the 1950s land tax was not being maintained based on a useful purpose but because "the government doubted whether the country [was] ready for land tax to be abolished," $" 870$ the same argument for retention used by William Downie Stewart in $1930 .{ }^{871}$ Given senior National Party ministers strongly disliked the land tax and did not think it was useful, ${ }^{872}$ this appears to be based on concerns that a land tax repeal would be unpopular with the public and seen as a gift to the wealthy. ${ }^{873}$ However, this does appear to be a weaker path dependency than previously as there were no alternative feedback mechanisms to compensate for changes. The continuation of land tax in the 1950s and 1960s may owe more to the lack of a critical juncture occurring during the period and land tax's unimportance as a portion of total tax revenue or a social policy tool ensuring that it seldom drew scrutiny.

Since land tax's legitimation feedback mechanisms were so closely tied to its role of taxing the wealthy few, legitimation became entwined with the land tax base. While the base was narrow and those taxed seen as deserving of taxation, legitimation feedback mechanisms were sustained. Once the base expanded and started to draw in more types of taxpayers, it became less acceptable to the public and legitimation feedback mechanisms were weakened. Historically, high taxable thresholds and regular adjustments to those thresholds had prevented this expansion but it became an issue during the 1980s.

By the 1980s legitimation feedback mechanisms were declining in importance, displaced by functional mechanisms as land tax revenue rose. As the land tax base expanded to include those not seen as deserving of being taxed, the perception of land tax as fair was undermined. The worst cases, such as residential housing and historic buildings, were

\footnotetext{
870 NZPD, Volume 303, 4 August 1954, page 917, John Rae.

871 Refer note 505.

872 NZPD, Volume 303, 27 July 1954, page 711, Rt. Hon. Keith Holyoake.

873 NZPD, Volume 303, 28 July 1954, page 752, Hon. Arnold Nordmeyer.
} 
exempted but this was not enough. The lower real value of the thresholds saw more property investors caught by the land tax. While the public was not against taxing them, the newly liable landlords took to passing land tax costs onto their tenants, ${ }^{874}$ many of whom should have been exempt. In addition to further extending land tax liability beyond those it was supposed to tax, businesses responded to the increased costs by increasing prices and cutting jobs. ${ }^{875}$ As more people became liable for land tax its burden was being pushed further from falling on the wealthy and onto the wider public, making legitimation feedback mechanisms harder to sustain.

While the 1989 land tax reforms were an attempt to make the tax fairer, in the neutrality focused view of the government and Treasury, they further weakened the legitimation feedback mechanisms. Despite neutrality's support among the government, it was not an idea generally supported by the wider electorate and the reforms were not radical enough to make land tax truly neutral anyway. This meant many of land tax's distortions persisted and some that were unpopular, like the Māori land exemption, had more attention called to them. In some cases attempting to remedy distortions, such as the attempted taxation of hospitals, were so unpopular they undermined public support for land tax further. The major problem for legitimation feedback mechanisms however was the base expansion. The expansion clashed with LeRossignal and Stewart's 1908 observation that the public supported the land tax because it was paid by the wealthy instead of them, moving the burden of land taxation beyond the traditionally wealthy and big businesses to the middle classes and groups the public felt more sympathy for. While the expanded land taxation did not affect most people, the changes made it more difficult for the public to see land tax as fair, and campaigns by opposition groups focused on the perceived unfairness. ${ }^{876}$ Ultimately the wider land tax base had too many problems to easily sustain legitimation feedback mechanisms based primarily on fairness.

While legitimation was important to maintain the land tax as a whole, at a more specific level it was particularly important to maintaining land tax's exemptions and preferential

\footnotetext{
$874 \quad$ Refer note 703.

875 Refer note 669.

876 Lawrie Bryant, Memorandum to Max Bradford, 7 April 1988, Archives New Zealand ABOT W4375 6787 Box 40.
} 
treatment. While ideas or power could be levied to establish exemptions, they would not necessarily maintain them; preferential treatment for businesses was granted in 1907 and 1929 before being abolished in 1917 and 1930. Exemptions and preferential treatment that persisted tended to have legitimation feedback mechanisms. The 1891 Act was designed to exempt New Zealand's "most deserving settlers" $" 877$ with the initial exemption list focusing on charities and organisations providing public benefit. The exemptions added by Robert Muldoon's government followed a similar pattern. ${ }^{878}$ Farmers were uniquely able to leverage two ideas, fairness and the farmer backbone, to justify their special treatment, although the fate of the 1931 flat tax demonstrated that the farmer backbone on its own struggled to produce effective legitimation mechanisms. Since most exemptions were felt to be fair they produced legitimation feedback mechanisms that maintained them.

The feeling that exemptions were fair became a problem in 1989. With neutrality pushing for the removal of exemptions and land tax's generally weakened legitimation feedback mechanisms, there was little to prevent exemptions from being abolished. Despite weakened influence for legitimation feedback mechanisms, they were strong enough to sustain some exemptions. The exemptions for residential housing, both owner-occupied and tenanted, were the most obvious. Their retention appears to be based on New Zealanders' dislike for taxing the family home, which granted the exemption a privileged enough position Treasury did not actually review it. ${ }^{879}$ The exemption of schools and hospitals also appears to have kept strong legitimation feedback mechanisms, with the backlash arising from the attempts to tax hospitals showcasing the political risks of trying to break those feedback mechanisms. However, most exemptions could not maintain similar feedback mechanisms and were therefore abolished.

When land tax was abolished in 1990, its legitimation feedback mechanisms were limited beyond some of the remaining exemptions. If land tax had persisted beyond 1990 however, legitimation feedback mechanisms may have been re-established. These would not have been based on fairness as they had been in the past, as the 1989 reforms left little

\footnotetext{
877 Refer note 1.

878 Refer note 637.

879 Refer note 738.
} 
to develop from, but they could have been based on neutrality. The 1989 reform had aligned land tax with the idea of neutrality and the Rogernomics program, which could have provided a foundation for support from within government. There are signs of this support in 1990. Treasury supported retaining land tax because it aligned with what they thought was appropriate taxation, ${ }^{880}$ rather than it presently serving a useful function. Legitimation feedback mechanisms based on neutrality may not have been as effective as those based on fairness, similar to how the farmer backbone did not prevent the abolition of the 1931 flat tax, but they could have been influential within the government and government departments. While this would not guarantee land tax path dependency, it would have seen powerful influences on the land tax policy process motivated to maintain it.

Despite the decline in land tax's legitimation feedback mechanisms in the 1980s, they were the most effective means to establish and maintain lasting path dependency. Legitimation feedback mechanisms were not easy to establish; they could not simply be imposed by government, and instead required a degree of public buy in. These made them effective for land tax however. Since legitimation feedback mechanisms reflected public feeling, politicians, regardless of their personal views, were reluctant to alter it. This reluctance helped maintain land tax for a century under a variety of governments.

\subsubsection{Functional}

While legitimation is the most consistently strong feedback mechanism for land tax, functional mechanisms were also important. Unlike legitimation feedback mechanisms, functional mechanisms are not present throughout the entire land tax period. Instead they are concentrated in the periods 1891-1936 and 1975-1990.

Land tax's functional feedback mechanisms change between these periods. From 18911936 functional mechanisms are based on three elements: breaking up the large estates, the progressive nature of land tax and revenue potential. These were complementary to the legitimation feedback mechanisms and there is a degree of overlap between the two.

$880 \quad$ Refer note 790. 
After 1975 functional feedback mechanisms were based almost entirely on land tax's revenue potential.

In the 1891-1931 period functional feedback mechanisms are secondary to legitimation, particularly post 1893 when land tax's revenue focus was lessened. Like much of land tax design, this was a symptom of the push to implement ideas above practical policy. However, the importance of fairness to land tax, and its alignment with land tax's social policy functions, meant that there was a strong basis from which to establish functional feedback mechanisms. In an environment where fairness was the dominant normative idea, progressive taxation and subdivision were seen as useful purposes that should be encouraged. That this could be done while raising tax revenue and reducing the reliance on customs duties was likewise seen as useful.

That land tax was not obviously effective at its functions does not appear to have undermined its feedback mechanisms. Land tax does not appear to have had a significant effect on subdivision or land affordability, it was not large enough to make overall New Zealand taxation dramatically more progressive and its revenue was never as high as advocates had hoped. Feedback mechanisms appear to have developed based on the aspiration to achieve these aims and a lack of alternative policies to do so. This meant land tax, even at its prime, was not especially effective at achieving its functions but was reinforced because it was the best available option.

Functional feedback mechanisms continued to operate on this basis until the First World War after which they started to weaken. The rise in income tax provided governments an alternative method of progressive taxation; one that was more efficient and could more easily raise revenue. The 1924 Royal Commission into land and income tax even proposed how income tax, with limited modifications, could be made to encourage subdivision. ${ }^{881}$ This made land tax less unique among tax policy and therefore able to be replaced. Indeed both the 1922 and 1924 tax reviews suggested replacing land tax with a more comprehensive income tax. ${ }^{882}$

\footnotetext{
$881 \quad$ Refer note 385 , page 6.

882 Refer notes 376, page 11-12; 385, page 6.
} 
While the government could make income tax a potential tool to encourage subdivision, their reluctance to do so left land tax with a niche within the tax system. However, the decline of the great estates and a shift in landholding preference from small farms to townhouses, which land tax mostly did not affect, made subdivision itself much less desirable. Despite the 1929 super tax being an attempt to re-establish the focus of land tax on subdivision, by 1931 the land policy aspects of land tax had largely disappeared and were unable to form the basis of feedback mechanisms.

The revenue aspect of functional feedback mechanisms persisted longest. Despite land tax raising a smaller portion of government revenue after the First World War, the amount was large enough that the tax could not easily be abolished and the reviews therefore recommended that it be maintained. ${ }^{883}$ When the government's financial position deteriorated after 1929, that revenue became more important. Reluctance to completely forgo land tax's revenue during the Great Depression appears to be a key reason the coalition government kept land tax in any form.

When graduated land tax was re-established in 1936 the policy lacked much foundation from which to develop functional feedback mechanisms. Reflecting changes since the 1920s the old approach could not be re-established. Income tax was the government's primary method of progressive taxation and revenue collection, and better at both than land tax had been. Meanwhile the lesser public demand for subdivision saw it dropped completely as a land tax purpose; with the Minister of Land stating that land tax was not a subdivision tool. ${ }^{884}$

There was also no basis upon which to establish new functional feedback mechanisms. While it was not the intention of the Labour government, 1936 ushered in an era where land tax did not really do, or attempt to do, anything. This made it difficult to establish feedback mechanisms based on social policy goals as it had previously. In the short term the poor state of the government books meant there was limited feedback based on revenue potential, but this was undermined as the economy improved and other taxation was increased.

\footnotetext{
$883 \quad$ Refer note 385 , page 6.

$884 \quad$ Refer note 538.
} 
Functional feedback mechanisms re-emerged in land tax from the late 1970s, a consequence of the 1976 Land Tax Act and the poor economy. Since land tax still lacked an obvious social policy function, the new mechanisms were based on land tax's increasing revenue. Given the poor state of the government's finances, and that land tax did not fall on vulnerable taxpayers, there were strong incentives to maintain a tax which saw growing revenue. Despite functional feedback mechanisms being largely nonexistent before 1976, the government's need for revenue quickly made them very strong. The Third National Government reinforced land tax's use as a revenue tool by increasing the tax rate in 1981 and refusing to increase the thresholds, providing further reason for the land tax to be maintained. Post 1981 functional feedback mechanisms related to land tax's revenue potential were the key basis of land tax's overall path dependency.

Strong functional feedback mechanisms became particularly important from 1984. The rise of neutrality as the dominant idea guiding tax policy meant that land tax, with its narrow base and plentiful exemptions, clashed with the direction of government policy. While the government set about reforming other areas of taxation and economic policy to better align with neutrality, land tax survived with few changes until 1989. That survival was despite being actively disliked by Treasury and the Minister of Finance ${ }^{885}$ and growing public opposition from 1987. This put land tax path dependency in conflict with ideas and power.

While ideas were traditionally the dominant force in land tax policy, the functional mechanisms held until 1989. The government's push to improve New Zealand's financial position and vindicate its financial program, combined with its prioritisation of other reforms deemed more important (including GST and a capital gains tax), ${ }^{886}$ limited land tax changes. The revenue land tax raised had reached $\$ 153$ million by 1989 and the government was reluctant to replace it without an alternative. ${ }^{887}$ Functional feedback mechanisms even had some influence with Treasury and Inland Revenue, both of whom were reluctant to recommend changes that would forego land tax's revenue in the poor

\footnotetext{
885 Refer note 847.

886 Refer note 686.

887 The Dominion, May 11 1989, Nats Challenge Labour With Land Tax Vow.
} 
economic conditions. ${ }^{888}$ However, this meant land tax was vulnerable if New Zealand's finances improved, or an alternative tax source could be found. By 1990 alternative revenue sources had developed. Company tax receipts were unexpectedly high ${ }^{889}$ and an increase in the GST rate from 10 percent to 12.5 percent in $1989^{890}$ helped increase revenue by more than $\$ 1.3$ billion. ${ }^{891}$ While the increases in revenue were not enough to eliminate the budget deficit, as the government came closer to achieving a budget surplus there were fewer functional reasons to maintain land tax. By 1989, when the government was predicting an imminent surplus, ${ }^{892}$ path dependency was weak enough that changes could occur.

In the aftermath of the 1989 reforms, new functional feedback mechanisms could not be established. The government had been committed to land tax's revenue, not the tax itself. That revenue was less important in 1990 and the 1989 changes had reduced it. Without significant revenue generation, land tax did not serve any obvious function. When interests were not appeased by the 1989 reforms and continued to push for abolition, functional feedback mechanisms could not provide an obstacle.

\subsubsection{Power}

As a feedback mechanism power plays an interesting role in the development of land tax path dependency. Unlike other feedback mechanisms, power tended to be in conflict with itself. Most groups that had significant influence in land tax development, such as businesses, farmers or the Treasury, generally advocated land tax changes (see Chapter 12). Only Inland Revenue regularly advocated land tax consistency and the department had little influence.

\footnotetext{
888 Refer note 654.

889 Auckland Star, 9 February 1990, Company Tax Take Ahead Of Latest Estimates.

$890 \quad$ Finance Act 1989, s15.

891 Statistics New $\quad$ Zealand, $\quad$ NZOY 1992, https://www3.stats.govt.nz/New_Zealand_Official_Yearbooks/1992/NZOYB_1992.html, Retrieved 7 April 2020.

892 NZPD, Volume 499, 27 July 1989, page 11550, Hon. David Caygill.
} 
The few powerful land tax advocates meant the scope for power to reinforce land tax path dependency was rather limited, generally occurring when land tax supporting parties were in government. This made power feedback mechanisms relatively simple to establish, requiring limited acceptance by the wider electorate or society, but their effectiveness was variable. As a feedback mechanism power was most important under two governments: the Liberal Government and the First Labour Government. Strong support for land tax among members of both governments ensured that neither party abolished the land tax. Since those parties controlled the legislative process while in government, land tax opposition was unable to pass changes to the land tax for many years. Supporters' control of the legislative process allowed land tax to weather the strong parliamentary opposition that arose to it in the aftermath of implementation and the reintroduction of graduation. Power feedback mechanisms could be established quickly and easily, providing protection for the land tax while other feedback mechanisms developed. The other feedback mechanisms would then maintain path dependency beyond the current government. Rapid formation made power feedback mechanisms particularly useful in the aftermath of land tax changes, before other feedback mechanisms were established.

While power was an effective feedback mechanism under the Liberals and the First Labour Government, it had limits and was often less useful. The pro-farmer positions of the Reform and National parties (pre-1976) meant they were generally unsupportive of land taxation and were often content to adopt a policy of indifference towards it, outside occasional changes to the thresholds. Labour governments may not have been hostile to land tax but they were short lived (Labour was only in government for six years between 1949 and 1984) and prioritised other reforms. Neither party tried to actively undermine the land tax, which helped maintain it, but a refusal to address it saw it atrophy further.

Power as a feedback mechanism is more complicated in the 1980s. The Fourth Labour Government was hostile to land tax while Inland Revenue supported maintaining it. Over the decade Treasury's position alternated between abolition, reform and retention of land tax. Between the support of Inland Revenue and Treasury there was a base to establish power as a feedback mechanism for land tax path dependency. However, neither department wielded sufficient influence to persuade the government against vocal public land tax opposition, so the feedback mechanisms never fully developed. 
Even with government support, there were severe weaknesses with power as a feedback mechanism in land tax; primarily because it was dependent on parties remaining in power. When a government collapsed its members lost the power they previously had and any power-based feedback mechanisms ceased. In cases where power was the primary basis for path dependency this made it easy for the new government to make significant changes to the land tax. This happened twice in land tax history: the conversion of the 1878 land tax to a property tax following the collapse of Sir George Grey's ministry and the 1936 restoration of graduation. In contrast to legitimation or functional feedback mechanisms which persisted under multiple governments with few changes, this made power a less effective basis for long term path dependency.

\subsubsection{Utilitarian}

The continued influence of ideas often marginalised the ability of utilitarian feedback mechanisms to be influential. Land tax policy was usually designed to implement ideas at the expense of administrative simplicity or practicality. The sacrifice of practicality to ideology was most prevalent under the Liberal and Fourth Labour governments where it resulted in complicated graduation systems and anti-avoidance rules, and a system too wide for Inland Revenue to easily administer respectively. While these periods saw land tax at its most complex, the system was never particularly easy to administer or comply with. The complexity did not create an environment that was likely to encourage utilitarian feedback mechanisms, and seemed to actively undermine them. A utilitarian analysis of land tax would suggest that it should be changed rather than maintained. The land tax was, relative to other taxation, complex and costly to maintain and comply with, making it difficult for both taxpayers and administrators to deal with. As late as 1990 it still required taxpayers to individually file costly returns. Over time actors learnt the system enough that they could exploit it to their benefit (through better tax planning and cheaper administration respectively) but alternative tax systems could have had greater gain for each.

The land tax design most likely to generate utilitarian feedback mechanisms was probably the 1931 flat tax. It abolished the graduation that had generally been the most complicated part of land tax administration while maintaining the existing small base. This prevented the tax department being overworked, as in 1989, while ensuring taxpayers maintained 
their existing benefits. The system was closer to Clark's proposed model than land tax would be at any point before 1989. Despite favourable conditions, it is not apparent that utilitarian feedback mechanisms developed. If they did, the abolition of the flat tax suggests they were not particularly strong.

While utilitarian feedback did not have a significant influence on land tax as a whole, it was more important to maintaining parts of the land tax; most obviously the valuation system. Over the 100 years of land tax operation the valuation system proved remarkably consistent. Revaluation periods only changed twice; moving from triennial to discretionary in 1894 and discretionary to quinquennial in 1946. The valuation base only changed once, moving from unimproved land value to simple land value in 1971. Overall land valuation methods were generally stable.

Despite this consistency, the valuation system was not particularly effective. Initially accuracy had been the main priority of valuations but discretionary revaluations replaced periodic revaluations from 1894 to reduce costs and ease administration. When land values began to appreciate from the 1900s, this approach resulted in outdated valuations and became vulnerable to market fluctuations. Despite this, the valuation system persisted. Unlike the other elements of land tax this was not due to functional, power or legitimation factors; there was no powerful group committed to retaining the discretionary system, it was not felt to be the most moral approach to valuation and, while it worked, other approaches could have done better.

Maintaining the system makes more sense on utilitarian grounds. The Valuation Department was used to the slow system, feeling they could run it effectively and more cheaply than alternatives. While faster valuations were acknowledged to make the system more accurate, the cost of doing so was an incentive not to change. ${ }^{893}$ At the same time taxpayers usually benefited from the slow revaluations, which lowered their tax liability provided that values continued to increase. Since the valuation system only came to public attention in periods of economic depression and the slow revaluation system generally benefited land tax's main stakeholders, there was no incentive to change it.

These benefits generally provided sufficient feedback mechanisms to maintain path dependency but it appears to have been contingent on whether the slow revaluations

$893 \quad$ Refer note 727. 
benefited taxpayers. In poor economic conditions, where land values fell, taxpayers found themselves worse off. Since the benefits to them were reduced, the utilitarian feedback mechanisms should be expected to weaken. This coincides with periods where changes to valuation regularity were made (1946) or seriously considered (1989), suggesting a breakdown in path dependency.

However, these changes were not quick; the 1946 reform was a response to the Great Depression while the 1989 consideration of annual revaluation was a response to the 1987 market crash. Some of the delay can be attributed to the government's utilitarian considerations remaining constant but functional elements also appear to be relevant. Since the additional revenue generated by slow valuations raised extra revenue for the government, functional feedback mechanisms developed and limited change. As the economy improved that revenue became less important, weakening those feedback mechanisms and allowing the system to change.

The other area where utilitarian feedback mechanisms appear influential is the exemptions. Historical exemptions had been introduced based on ideas so they were primarily maintained by legitimation. This system broke down in the 1980s when legitimation became much less important to maintaining land tax. As is to be expected, since exemptions clashed with the dominant idea of neutrality, many were removed in 1989.

Some exemptions persisted. The Māori land exemption appears the clearest case of utilitarian feedback mechanisms. It persisted despite being the only remaining exemption based on land ownership and Treasury wanting to abolish it. Treasury decided that removing the exemption would involve consideration of both "the restrictions which are placed on the use of Māori land and possible Treaty [of Waitangi] implications". ${ }^{894}$ These issues were expected to be complex and Treasury did not feel it had sufficient time to examine them. The exemption was kept because replacing it was too complicated.

The other exemption that appears to persist on a utilitarian basis was the exemption of very small landholdings, under a $\$ 10,000$ de minimis threshold. In these cases the primary concern was not the complexity of replacing the exemption but the costs, for both taxpayers and Inland Revenue. Land tax returns were costly to prepare (accounting firms

$894 \quad$ Refer note 734. 
generally charged $\$ 200$ each) ${ }^{895}$ and Treasury and Inland Revenue thought it was an unreasonable cost to impose in cases where preparation costs would be greater than land tax liability. ${ }^{896}$ Inland Revenue was also concerned about the costs associated with processing more land tax returns and generally supported actions to reduce that burden.

Utilitarian feedback mechanisms maintaining some exemptions raises questions as to why those feedback mechanisms did not maintain most exemptions. Utilitarian concerns appear to have been influential in Inland Revenue's thinking, which consistently advocated tax reform that would continue land tax's exemptions. Inland Revenue's position was based on concerns whether the tax department could effectively administer more taxpayers and the costs this would incur. ${ }^{897}$ Removing the exemptions also risked creating a variety of legal grey areas regarding the taxability of certain land classes that had been exempt under other exemptions. ${ }^{898}$ Changes risked taking a tax system that was well understood by Inland Revenue and adding significant confusion and uncertainty. The potential risks of a wider land tax explain much of Inland Revenue's approach to land tax reform since the 1970s. The department's favoured method to increase tax revenue was rates increases, as opposed to the base expansion championed by Treasury. Inland Revenue's reform proposals appear designed to maintain as much of the existing land tax administration system as possible.

The problem was the power dynamics of land tax. While utilitarian feedback mechanisms were influential with Inland Revenue, Inland Revenue was not influential within land tax policy development. The groups with the most influence on tax policy, the government and Treasury, had only limited interaction with, or understanding of, land tax administration. Treasury in particular felt that the significant changes they wanted would have little impact on administration. ${ }^{899}$ The limited interaction meant the benefits those

\footnotetext{
895 Refer note 733.

896 Treasury, Land Tax Reform - Administration and Revenue Implications, 20 June 1986, Archives New Zealand AALR W5427 873 Box 1861 76/4/2 Part 1.

897 Refer note 688.

898 Refer note 750.

899 Treasury, Land Tax Reform - Administration and Revenue Implications, 22 June 1986, Archives New Zealand AALR W5427 873 Box 1861 76/4/2 Part 1.
} 
groups saw from the system were small, regardless of the form land tax took, so there was limited scope for utilitarian feedback mechanisms to influence their actions. While Inland Revenue continued to push to maintain exemptions, acting in accordance with utilitarian feedback, that push was overruled by the government and Treasury. The disconnect between those who benefited from utilitarian feedback and those who were influential in the policy process made utilitarian feedback mechanisms an inefficient way to establish path dependency in land tax; they did not have significant influence over the groups with the greatest power over the system.

\subsection{The Effect of Strong Land Tax Path Dependency}

Land tax's various feedback mechanisms resulted in a strong path dependency that maintained land tax for a century. This was not always helpful as it created a land tax that, outside critical junctures, was resistant to reform in general, making it difficult for land tax to adapt to changes in its environment or fix difficulties that had arisen. In the short term this was not an issue but as the land tax aged it became a problem.

Strong path dependency was a boon for land tax longevity. While some governments, most notably the Liberals and the First Labour Government, believed in the land tax and chose to maintain it, strong path dependency limited the agency of those governments that did not support the land tax. When parties that had been hostile towards the land tax found themselves in government, primarily the Reform Government, the United-Reform coalition and the Fourth Labour Government, strong path dependency limited their options for land tax reform. While the power of Parliament meant the government could technically make any legislative changes they wanted to land tax, changes that did not align with land tax's feedback mechanisms or path dependency risked triggering significant political backlash. This backlash can be seen in the 1935 election, following the implementation of the flat land tax, and in 1989, following the attempt to make hospitals liable for land tax. Since governments were generally reluctant to court backlash, they generally avoided taking land tax policy decisions that breached path dependency. However, this created an environment where land tax was generally very static.

When the Labour government expanded taxation in the 1930s and 1940s the land tax was conspicuous in remaining stagnant. Labour had essentially restored land tax to its pre- 
1931 state with the equivalent nominal revenue but did not make any other significant changes. Land tax's path dependency held and Labour did not implement the more radical land tax they had considered in previous years. While the land tax did not decline, it also did not grow like other taxes did. Under the First Labour Government New Zealand's total taxation increased from $£ 25$ million to $£ 130$ million $^{900}$ but land tax revenue remained consistent at $£ 1$ million. This quickly reduced the importance of land tax as a revenue source. By 1941 Labour's graduated land tax was a smaller percentage of total taxation than the flat tax had been. This decline continued and land tax remained an insignificant revenue source until the late 1970s. Despite Labour revitalising land tax in 1936, the tax's static nature more effectively undermined its importance than anything its conservative opposition ever did.

While land tax's inability to adapt had undermined it as a revenue tool by the 1940s, from the 1950s it caused dramatic changes to the land tax base. As urban land began to appreciate more quickly than rural land, it became an increasingly large portion of the tax base. The lack of detailed records make it difficult to establish exactly how much land tax was being paid by companies relative to other taxpayers but the 1967 Ross Report estimated companies had paid the majority since the early 1950s and the percentage had continued to rise. ${ }^{901}$ This meant that, by the 1960 s, land tax was firmly a business cost and would remain so until the 1990 abolition. The change did not affect land tax's legitimation feedback mechanisms: big businesses were not seen more sympathetically than the other wealthy landowners who had previously made up the tax base. Ultimately this meant that when farmers were exempted from land tax in 1968 it had very little effect. Had the same policy been implemented in previous decades it would have been radically pro-farmer, not even the Coalition had considered implementing it. It would have moved the entire land tax burden onto urban centres and undermined land tax's social policy aims. However, strong land tax path dependency, ensuring that land tax law did not change, achieved the same thing without the public outcry that legislative reform may have triggered.

\footnotetext{
900 Refer note 468; Statistics New $;$ 1950, http://www3.stats.govt.nz/New_Zealand_Official_Yearbooks/1950/NZOYB_1950.html, Retrieved 18 September 2019.

$901 \quad$ Refer note 609 , page 414.
} 
Land tax's path dependency also resulted in the expansion of land tax that was behind the 1970s and 1980s land tax revival. Land values appreciated quickly during the 1970s and 1980s while land tax's thresholds remained constant. More land appreciated through the thresholds, becoming liable for land tax, while already taxable land became worth more. In this, land tax benefited significantly from the base change in the 1950s. Moving the tax burden onto businesses, who the public were not sympathetic towards and lacked the power to influence land tax policy, meant there was little motivation for the government to adjust land tax to limit the increase. This created a growing revenue source at a time when the government was having fiscal difficulties and giving land tax the purpose it had lacked for decades. As explained in the discussion of functional feedback mechanisms, this became the basis for maintaining land tax until 1990 .

While the expanded base resulted in increased revenue, it also laid the foundations for land tax's abolition. As mentioned in the discussion of legitimation feedback mechanisms, the wider land tax expanded the burdens of land tax beyond the wealthy few. Either directly or indirectly more people became liable for land tax. The tendency of landlords to pass the tax on to their tenants effectively split the exemption system: a taxpayer who owned their land could claim an exemption but an otherwise identical taxpayer who was renting would be indirectly liable for land tax. This increased groups that were opposed to land tax beyond big businesses, to include small businesses ${ }^{902}$ and charities. ${ }^{903}$ The public was more sympathetic towards these groups and the campaign against land tax focused heavily on unfairness towards them. ${ }^{904}$ Fairness may not have been an influential idea to the government in deciding land tax policy but it did resonate with the electorate and allowed opposition groups to direct public feeling. In the meantime, land tax's path dependency ensured that the government did not address the issue, maintaining land tax's revenue was seen as more important.

The delay in dealing with land tax created an effective, existing opposition by the time the Government announced the 1989 land tax reforms and undermined a key means

\footnotetext{
902 Refer note 719.

903 J Browne, Letter to The Minister of Finance, 18 June 1989 Archives New Zealand AALR W5427 873 Box 1862 76/4/2 Part 2A.

The Dominion, 29 March 1989, Nerves Prompt Land Tax Review Says National.
} 
through which Rogernomic reforms were achieved. Roger Douglas himself stressed reforms be made rapidly, otherwise vested interests would exert their power to mobilise public feeling against the changes (1993, p. 223). Since there was already an opposition to land tax with public sympathy, there was not a delay while one was organised. This public feeling could be turned against the land tax reforms before the government could entrench them.

\subsection{Summary}

Understanding the role of path dependency is important to understanding the development and story of New Zealand's land tax. Path dependency played the key role in both the static nature of land tax and its longevity. While path dependency can be expected within political institutions, this degree is notable. The key was the feedback mechanisms which, unlike land tax itself, proved adept at adapting to changing environments.

Over time land tax had a variety of different feedback mechanisms of variable importance. Initially the system was supported by legitimation, functional and power feedback mechanisms. These gradually eroded leaving just legitimation by the 1930s before functional elements became dominant in the 1970s and 1980s. Utilitarian feedback mechanisms were much less relevant to most of land tax system but they consistently maintained the valuation system for almost 90 years after it became apparent it was unsuitable and helped maintain some land tax exemptions in 1989. Land tax's feedback mechanisms ensured it remained part of the tax system but they also helped reinforce its inefficiencies.

Despite path dependency resulting in periods of little to no legislative change, the effects and outcomes of land tax were not fixed. The strong path dependency maintained a consistent tax system in an environment its creators had not considered. Early on this undermined land tax's feedback mechanisms and its importance. From the 1970s things became more complicated as the same inertia was responsible for land tax's revival but laid the foundations for its abolition. Applying static land tax thresholds and exemptions to rapidly appreciating land values significantly increased land tax's revenue potential but created significant land tax hostility from land tax payers and undermined later land tax reform. 


\section{Chapter 11: Critical Junctures}

As noted in the previous chapter, land tax's strong path dependency means changes usually occurred slowly. However, particular events could break this pattern, triggering significant change quickly as they overwhelmed path dependent feedback mechanisms. These critical junctures are an important part of land tax development, pushing changes to established systems and providing an outflow for ideas to be influential.

This chapter applies the theory behind critical junctures, laid out in Chapter 5. Analysis is primarily based upon Pierson's (2004, p. 44) four criteria for a critical juncture: multiple equilibria, contingency, sequencing and inertia (see Chapter 5.2.1.2 for more details). Through these it is possible to analyse why events triggered changes in land taxation and how the new approaches were derived.

With the variety of influences on land tax it can be difficult to establish what drives particular changes. To establish potential critical junctures, this chapter focuses on major changes to land tax that do not conform to established path dependencies. This sees four events with the potential to have been caused by critical junctures: the decline of land tax from 1917, the 1931 flat tax, the 1981 flat tax and the 1990 abolition.

\subsection{The Decline of Land Tax, 1917}

Following its introduction in 1891, land tax was New Zealand's dominant form of direct taxation. This was entrenched into its path dependency by legitimation of its social aims, the backing of politicians and because it raised the most revenue. The path dependency broke in 1915 when it was surpassed by income tax, which continued to grow in the following years.

While supplanting land tax with income tax had been proposed since $1891,{ }^{905}$ this was not the result of a gradual change. Income tax revenue growth was not enough that it would be expected to surpass land tax so quickly. However, the outbreak of the First World War required the New Zealand government to fund a large military deployment and significantly increased the need for revenue. Previously, revenue concerns in tax policy had been secondary to social policy, but the war made revenue the most important

$905 \quad$ Refer note 170. 
aspect and destabilised the existing equilibrium. In this environment whether taxation was fair was much less important than its ability to help fund wartime spending.

With the previous equilibrium weakened, land tax entered the multiple equilibria stage of a critical juncture with a variety of different policy options viable. These were based on where the burden of the additional taxation should fall: on the wealthy, farmers, or workers and professionals, and to what degree. ${ }^{906}$ As with any critical juncture, the weakened equilibrium gave politicians more agency to choose policy options than they otherwise would have but the inconclusive election of 1914 required any policy decision to be agreeable to members of both the Liberals and Reform. In practice, the political realities of the coalition government limited potential policy reforms. After first attempting to limit tax increases to the wealthy, the expansion of income tax became the solution; largely by accident as Parliament consistently underestimated the income tax revenue that would arise from changes. Despite being unintentional, the demand for revenue meant Parliament embraced these changes and continued to build upon them.

Contingency is important in the rise of income tax revenue relative to land tax revenue. Heavy use of income tax instead of land tax was an established idea but it was not popular; in general it was felt to benefit farmers and the wealthy at the expense of workers and professionals. Deliberately implementing such a policy would have raised opposition and struggled to get Parliamentary support. The underestimated income tax revenue proved the key event, as accidentally increasing income tax levels sidestepped the need for politicians to actively support the change. By the time the effects were apparent, the revenue had been raised. The revenue focus during the war made the change difficult to undo and encouraged Parliament to maintain it.

As income tax rose, comparable changes to land tax were in flux until 1917. The government had indicated that it was unhappy with the situation, specifically the land tax's comparatively limited revenue, ${ }^{907}$ but no indication had been given to what it envisioned as a solution. When the unified land tax was passed it solidified land tax as lesser than income tax, reversing the standard of the past 26 years. Revenue was increased but no attempts were made to catch the income tax. This was essentially a compromise

\footnotetext{
906 Refer notes $340 ; 342$.

$907 \quad$ Refer note 348.
} 
measure. Allowing land tax to wither would have been seen as removing the tax burden from the wealthy and farmers, but matching income tax revenue would have required either a large increase in the tax rate or an expansion of its traditionally narrow base. Both options risked being incompatible with the idea of fairness and would likely have been unpopular. Despite the greater freedom in a critical juncture, land tax policy is still somewhat constrained by the fairness idea. Land tax becoming secondary to income tax ended any remaining Georgist intentions to implement a single tax in the future and targeted land tax primarily towards its social policy aspects.

The new equilibrium of dominant income taxation and a weaker land tax proved very resistant to change, demonstrating significant inertia. Income tax has remained New Zealand's largest direct tax ever since and has become the primary method of redistributive taxation. Meanwhile land tax entered a period of decline that lasted until the 1970s. The critical juncture left land tax's feedback mechanisms largely intact, if less effective, but maintaining those feedback mechanisms produced its own problems. The same path dependent inertia that kept land tax from being abolished also meant it did not grow and adapt to a new environment, contributing to its persistent lack of an obvious purpose.

That the lesser land tax became entrenched is not particularly surprising. In addition to the maintained feedback mechanisms, conditions during and after the 1917 law change were favourable to stability. On the political front there was little significant opposition. Income tax dominance had been approved by both major political parties so neither were actively pushing to change it. Furthermore, Reform, who remained in government until 1928, showed little interest in overturning a policy generally seen as pro-farmer. On practical grounds there was less need for additional revenue after 1918. The primary reason was the end of the war but in 1919 New Zealand voted against prohibition so the government was not required to find a revenue source to replace alcohol duties; a job for which land tax was being considered. ${ }^{908}$ Without the revenue demand, or the obvious social problems of the 1890 s, there was no incentive to increase land taxation and it was generally left alone or reduced.

908 The Sun, 8 July 1918, Total Prohibition; Poverty Bay Herald, 10 April 1919, To-Day's Polling. 


\subsection{Flat Tax, 1931}

The decision to implement a graduated land tax was one of the key elements that differentiated New Zealand's land tax from Georgist approaches. While unconventional at introduction and unpopular with the wealthiest taxpayers, it was well regarded by most and generally seen as a tool of fairness. Its popularity and link to fairness helped maintain it once the Liberal government fell, but something changed in 1931 and graduation was replaced by flat taxation.

By 1931 the idea of a flat land tax was well established but its implementation does not develop naturally from the previous state of land tax. Support for flat land taxation in the past had generally come from two groups: Georgists, who wanted to better align land tax with the theory of Henry George, and the Tax Department, who thought it would ease land tax administration. ${ }^{909}$ In the 1930s neither group had a significant influence on tax policy. On top of this, the 1931 flat tax was a tax cut while previous flat tax advocates had wanted to use it to increase taxation. More importantly, flat tax was seen as incompatible with fairness and therefore the legitimation component of land tax's existing path dependency.

Overwhelming a path dependency that had been established for four decades requires something significant, particularly since the flat tax did not align with established ideas. The 1931 flat tax was an attempt to help farmers. While farmers had pushed for relief before, 1931 was different because the Great Depression was in full effect. The Depression meant farmers were facing significant hardship. Given farmers' importance to the economy, and the regard New Zealand society held for them, the government scrambled to do something. More importantly the extent of the Depression, and the number of people affected by it, created a sense of crisis. That sense of crisis and desire to do something destabilised land tax's already weakened path dependency and the dominance fairness had over the policy process, giving actors more agency and allowing the implementation of ideas that would otherwise contravene land tax path dependency.

To be a critical juncture the period needs multiple viable equilibria, which it does have. Rather than the flat tax, alterations to the thresholds or lower graduations were proposed

\footnotetext{
909 Refer note 385, page 32.
} 
to target relief to struggling small farmers. ${ }^{910}$ Given the government's focus on operating a budget surplus, raising the land tax also had potential. Indeed this was the direction of other tax policy, particularly income tax which saw significant increases. ${ }^{911}$

While the Great Depression provided the trigger for change, the implementation of the flat tax is the result of contingency and sequence. The policy is largely contingent on the previous political situation, while its passage resulted from the events preceding it. While the farmer backbone had long been influential in the land tax debate, it became more so in the late 1920s. The idea was particularly influential amongst the Reform Party, whose members had been advocating land tax cuts, ${ }^{912}$ but this had limited effect on policy while Reform was in opposition. In the past having to win electoral support had mitigated the worst of Reform's pro-farmer bias, but in 1931 it entered government without going through an election after the coalition of the United and Labour parties collapsed. At the same time United, whose commitment to ideology was not strong to start with, was largely directionless after the death of Sir Joseph Ward in 1930. This resulted in a coalition government where Reform brought a strong farmer backbone perspective and United did not act as a check. The sense of crisis the Depression created permitted actors to exercise much greater agency than they usually could, and allowed them to choose land tax reforms with few restrictions. Ultimately the decision to implement the farmer favouring flat tax was because Reform MPs wanted it and United MPs chose to support the policy to maintain power.

Changes to the preceding sequence of events could have significantly changed the development of land tax. Had the United-Labour coalition persisted Reform would not have got into government, and therefore be unable implement the flat tax. If Sir Joseph Ward had not died, United likely would have had been less likely to acquiesce to Reform's demands. However, the sequence of events that transpired meant that when the time came to respond to the Depression, that response strongly favoured farmers. Abolishing graduation gave significant relief to large farmers, who were more important

\footnotetext{
910 NZPD, Volume 225, 21 August 1930, page 467, Michael Joseph Savage.

911 Land and Income Tax (Annual) Act 1930, Schedule, Part II, 4; Refer note 474.

912 NZPD, Volume 230, 14 October 1931, page 247, William Lysnar.
} 
to the export industry, while demonstrating to smaller farmers the lengths to which the government was prepared to go to help the industry.

While the 1931 flat tax appears to be the result of a critical juncture, it lacks the final of Pierson's criteria, inertia. The flat tax only lasted until 1936, five years, before graduation was re-established. Its failure seems to stem from an inability to establish sustainable feedback mechanisms to entrench a path dependency. Previously land tax had relied on functional and legitimation mechanisms but the flat tax served no useful function as a policy or revenue tool and the wider public did not see it as fair. Instead it persisted based on power, specifically because the coalition supported it. That meant there were very few barriers to changing the land tax once Labour won the 1936 election.

This means that the Great Depression does not appear to be a critical juncture in the life of land tax, although it had the potential to be one. The previous path dependency did break down, but the major change triggered was not sustainable and the tax system soon reverted back to its previous state. Land tax did change in the Depression's aftermath but those changes appear to be a continuation of land tax's gradual decline rather than something new.

\subsection{Flat Tax, 1981}

Other than the period from 1931 to 1936, New Zealand's land tax was generally characterised by two features; it was graduated and revenue potential was a secondary concern to social policy. Both of these elements broke down with the 1981 flat tax, which removed the graduation and converted land tax to a revenue focus.

The change of land tax into a flat tax with a revenue focus was not a natural development from the existing path dependency. Major land tax reforms were rare and tax rate increases had not been seen since 1936. The chosen approach was even more of an enigma; a revenue focused land tax with a high flat rate had never been particularly popular outside the tax department. That such a change could occur suggests a significant break down in path dependency to allow changes that had been resisted since the 1920s.

The path that leads to the 1981 flat tax is relatively complicated. It begins when a succession of economic crises hit the New Zealand economy from 1967, starting with the collapse in wool prices. The decline of New Zealand's major export negatively impacted 
both the wider New Zealand economy and government finances, a problem subsequently made worse by Britain entering the European Economic Community, the 1973 oil shock and low prices for New Zealand's other agricultural exports. From the perspective of land tax policy development, these had three important effects: government revenue fell while expenditure continued to grow; New Zealanders' standard of living decreased; and land values began to rapidly appreciate. Land tax itself was relatively shielded from these effects by the 1970 valuation freeze; it continued to operate almost identically, but the equilibrium of the wider tax system was destabilised.

With the existing tax system in flux, a variety of policy options were considered or tried. The Third Labour Government prioritised slowing land appreciation and introduced a property speculation tax in 1973 with little success. ${ }^{913}$ The Third National Government tried to address the government deficit through a combination of increased taxation and retrenchment, also with limited success (Belich, 2001, p. 400). While there were multiple equilibria, a revenue focused land tax was not an obvious one to entrench.

Arriving at the land tax changes is where sequencing and contingency are particularly important. While the concept of a critical juncture implies speed, in this case the change is more gradual, occurring years after the economic crises that trigger it but while their effects are still felt. As the years passed the government's financial position remained poor and attempts to cut expenditure were ineffective (Belich, 2001, p. 400), necessitating more revenue. However, the economic hardship faced by many people meant the government was reluctant to impose additional taxation that could hurt the vulnerable, generally felt to be families and farmers. This reluctance encouraged exploration of alternative tax sources. At the same time land tax revenue was increasing, as the valuation freeze ended and the land value increases of the previous years were brought within the tax base. Finally, since the 1950s and the 1970 farmer exemption, land tax's base was primarily businesses, the taxation of whom would be politically acceptable. These elements made land tax useful for the government but still did not trigger reform. The tipping point appears to have been the slowdown in land appreciation at the end of the

913 Property Speculation Tax Act 1973. 
1970s which convinced the Minister of Finance and Inland Revenue that land tax would need changes to maintain revenue growth. ${ }^{914}$

The combination of these events resulted in the 1981 land tax change. As its revenue had grown over the previous years a perception of land tax as a revenue source had gradually developed and the government decided that land tax was the ideal solution to its problem of how to raise revenue without impacting the vulnerable. The higher tax rates would increase revenue even in the event of slowing land appreciation.

These changes quickly entrenched themselves, establishing a period of inertia. The key reason for this is that the 1981 land tax changed land tax's feedback mechanisms, establishing a functional basis (revenue potential) for path dependency. Since government deficits and the corresponding need to increase revenue persisted through most of the 1980s, the land tax expansion was largely protected from rollbacks, particularly once land appreciation increased again and revenue rose further. Nine years is a relatively short inertia period when compared to other land tax critical junctures, which were more commonly measured in decades, but it did prove very resistant to change. Unlike the 1931 flat tax, it survived a change of government, despite being incompatible with the ideology of the Fourth Labour Government. It also survived protests of Treasury ${ }^{915}$ and Inland Revenue $^{916}$ and significant public opposition. Despite the short period this does suggest inertia. The 1981 flat land tax's inertia implies that, unlike the 1931 flat tax, this was a critical juncture in the development of land taxation.

\subsection{Abolition, 1990}

Despite the changes to land tax since its 1891 introduction, one element was consistent; it endured. Land tax was maintained for almost a century; despite numerous problems, limited success in meeting its goals, long periods without any obvious goals and New Zealand's tendency to elect pro-farmer governments that did not like it. That changed in 1990 when land tax was abolished.

\footnotetext{
914 Refer note 635.

$915 \quad$ Refer note 689.

916 Refer note 688.
} 
While the changes of other critical junctures broke the existing path dependency, abolition is notable in the degree to which it broke land tax's path dependency. The revenue potential of land tax had been its dominant feedback mechanism since 1981 but it was weakening as government finances improved. This had seen the beginnings of new feedback mechanisms arise as land tax developed Treasury support and was aligned with the Rogernomics program and neutrality. Abolition saw these feedback mechanisms overwhelmed.

What overwhelmed multiple established feedback mechanisms, and managed to trigger the end of the 99-year-old tax, is an intricate question. Land tax policy in 1990, and 1989 to lesser extent, appears to be a response to significant land tax opposition from the public. While particular groups resisting land tax was common throughout its history, widespread public opposition was not. Wider opposition can be dated to the 1987 economic crash. This made the economic position of businesses precarious and they could less easily absorb the large increases in land tax that arose as land was revalued to include the substantial appreciations of the mid-1980s.

While the government attempted to maintain land tax, growth in public opposition appears to have destabilised it and major changes were being considered by 1989 . Multiple viable equilibria are an important part of critical junctures, which are particularly numerous in the late 1980s. These included the 1989 changes, maintaining the status quo, multiple neutrality-based proposals from Treasury and the many proposals of land tax opponents. ${ }^{917}$ These had varying levels of acceptability and practicality, with the 1989 changes probably being the strongest choice, but multiple options were valid.

How those multiple options were whittled down to abolition is a function of sequence and contingency. Before the market crash set the change in motion, two events occur that have a profound effect how the process of land tax change would play out. The first was the election of the Fourth Labour Government which made neutrality the dominant influence on policy, allowing the consideration of new ideas but disfavouring others. The second was the rapid land appreciation in the mid-1980s which made the tax increases triggered by revaluation too large to ignore in the post-crash economic climate.

\footnotetext{
917 Refer note 717 , page 5.
} 
Once the economic crash occurred the government was reluctant to change land tax because it wanted to maintain the growing revenue. Inaction however, let the opposition grow uncontested and the government was eventually forced to commit to making changes before having established a land tax policy. Subsequent policy choice was itself heavily shaped by preceding events. The government's commitment to neutrality meant several options to lessen the land tax burden, such as the introduction of new exemptions which had been used previously, were not a viable choice. Meanwhile, the reduction of the government's operating deficit meant the demand for revenue fell, weakening land tax's functional feedback mechanisms and the government's resistance to policies that would reduce revenue.

Finally, the government appears to have wanted the land tax policy to be popular. Popularity had previously been ignored in Rogernomic reforms but the government's waning popularity, the upcoming 1990 election and issues created by consistent public land tax opposition since 1987 meant this time public opinion was a consideration. Considering public opinion had two further effects on policy. It limited the influence of Treasury proposals, which, while neutral, were likely to be unpopular, and necessitated simple policies that could be quickly implemented, so the government could get the political kudos.

While the government was determined to change land tax in the face of mounting opposition, that determination limited potential options. Initially the 1989 reforms were chosen in an attempt to maintain the revenue but they proved unpopular. By 1990 the weakening of land tax's feedback mechanism had removed most of the restrictions on the agency of government actors. Without those restrictions the government, primarily through the Minister of Finance, could choose the policy reform they most wanted. Faced with a continued fall in the government's popularity, the approaching 1990 election and a land tax the government had never been particularly fond of, ${ }^{918}$ the government felt that abolishing the land tax would be the best way to meet their goals.

Despite the speed with which the abolition decision was made, it has led to a long period of policy inertia. The New Zealand government still does not tax land and has not seriously considered reintroducing it. Of the three tax reviews since land tax was

$918 \quad$ Refer note 725. 
abolished only one has recommended reintroducing a land tax, ${ }^{919}$ and that was ignored by the government. The 2019 Tax Working Group was restricted from considering a broad land tax by its terms of reference. ${ }^{920}$ While taxation of wealth has been considered more seriously in recent times, although not introduced, it appears likely that New Zealand will remain without a land tax for the foreseeable future.

\subsection{Summary}

In a heavily path dependent system, critical junctures are an important part of land tax development, triggering changes when the tax would otherwise trend towards stagnation. While the idea behind such junctures is simple, the process through which they work is more complex. Individual events can trigger change but the form that change takes is shaped by other, less dramatic, events and the order they occurred in.

With land tax, despite its heavier social policy focus, critical junctures tended to be linked to economics, and revenue tends to be more important than elsewhere in the policy process. In 1917 and 1981 increased government revenue demands provided the primary motivation for change while the government's reluctance to abandon land tax's revenue before 1990 is a key part of the sequence of events that develops. This occurs because critical junctures break down the path dependencies that existed beforehand and, for land tax, this generally weakens the otherwise dominant ideas.

Critical junctures result in periods where the aims of land tax tend to be altered. In 1917 this eliminates land tax's more Georgist revenue elements, focusing it on social policy goals and replacing it with income tax as the primary source of direct taxation. In 1981 the opposite can be seen, the abandonment of any social policy aspects and a renewed revenue focus. In 1990 the intent for land tax to accomplish anything is abandoned with its abolition. Such changes could be good or bad; 1917 began decades of land tax decline while 1981 saw it revitalised, but critical junctures were among the few cases of land tax policy actively responding to its external environment.

\footnotetext{
919 Refer note 5.

920 Tax Working Group, Future of Tax: Interim Report, 2018, page 43.
} 


\section{Chapter 12 Power}

Historical institutionalism acknowledges the role of power within policy development. Power generally involves "moving a number of actors in a particular direction" to achieve a certain outcome (Hall \& Taylor, 1998, p. 961). Within a political environment, institutions can increase the power of some groups while minimising that of others (Hall $\&$ Taylor, 1998, p. 961). In the context of land tax, power is one influence on policy development, competing with ideas, path dependency and critical junctures. Of these elements analysis shows that it was the least influential. Parliamentary control, and the highly political nature of land tax, limited the power of external groups, creating significant barriers for those who attempted to influence land tax from outside of Parliament. However, over the time period of land tax's existence, external groups did make significant attempts to influence its development, with varying degrees of success and importance.

\subsection{Politicians}

Despite the large number of politicians in New Zealand between 1891 and 1991, only a few were truly influential in land tax development. Unlike other groups, which tended towards collective action, politics tended to focus on particular individuals. This arose from the lack of checks and balances in the New Zealand political system throughout land tax's existence. The limited checks allowed Cabinet to dominate the legislative process while particularly charismatic and autocratic Prime Ministers could dominate Cabinet (Belich, 2001, p. 396). Meanwhile the Minister of Finance could limit the role of government departments by refusing to recommend their suggestions to Cabinet. This concentration of power meant land tax policy could be driven by the Prime Minister or the Minister of Finance, who had few constraints on their authority. The limited checks meant that politicians could theoretically make radical changes to land tax. However, it was rare that they did so.

Early land tax policy, and therefore future land tax, was heavily shaped by John Ballance and Richard Seddon, the first Liberal Premiers, both of whom were also the Treasurer. While both were trying to implement fairness, and were therefore backed by the wider Liberal Party, they personally influenced land tax to a significant degree. Much of John Ballance's influence derives from him being the first Minister to implement land tax. 
Since there was not a pre-existing land tax system, John Ballance did not have to deal with the path dependency that constrained his successors. This gave him more freedom to shape land tax as he saw fit. Richard Seddon instead levied his populist approach to politics, gaining support for policy changes by targeting the land tax towards the wealthy and other unpopular groups..$^{921}$

Future politicians had less influence. Some of this arose from later governments separating the Prime Minister and Minister of Finance roles, which provided a check on both. Robert Muldoon, whose government was among the few exceptions to this, was more influential with land tax targeting and exemptions from 1975-1984 reflecting his general economic approach of tinkering and his focus on the less well-off. This cannot be the only explanation however, as other leaders, including William Massey, George Forbes and Sidney Holland, also held both positions without comparable influence. Conversely Roger Douglas held only the Minister of Finance role but was very influential in creating an ideological environment that allowed land tax reform. However, he had little role in land tax policy itself, having been replaced as Minister of Finance in 1988.

Examination suggests that politicians were rarely the key drivers of major land tax changes. The three largest changes to land tax outside the Liberal Government; the 1931 flat tax, the 1989 reforms and the 1990 abolition, do not appear to be the result of particular politicians. The 1931 flat tax was unlikely to have come from the Prime Minister, who had wanted heavier land tax 12 months previously, ${ }^{922}$ or the Minister of Finance, who was less pro-farmer than most of the Cabinet (Dale, 1996). Instead the policy appears to have resulted from the influence of the farmer backbone idea. While the government ideology that allowed the 1989 reforms was provided by Roger Douglas, the changes themselves were largely directed by Treasury. Finance Minister David Caygill's primary role was vetoing Treasury's more radical ideas. Abolition appears to have been driven by public pressure and the upcoming election rather than the government, who previously been very committed to maintaining land tax.

This leads to a question: since politicians theoretically have the power to drive significant land tax reforms, why do they appear to have done so only rarely? Grube (2014) suggestes

\footnotetext{
921 NZPD, Volume 126, 23 October 1903, page 736, Rt. Hon. Richard Seddon.

922 Refer note 510.
} 
that a rhetorical path dependency could develop and limit politicians' policy options but that appears to have been less of an issue with land tax. Conservative politicians tended to strongly oppose land tax ${ }^{923}$ but not change it when they had power, while Labour Party politicians previously supported a very heavy land tax which they did not implement. ${ }^{924}$ Most strikingly, United politicians reversed their land tax positions between 1930 and 1931. With the possible exception of George Forbes, whose reputation was undermined by his leadership of the unpopular United-Reform coalition (Belich, 2001, p. 256), there was little public backlash to these changes. In most cases the abandonment of these positions brought politicians actions closer to the period's dominant ideas.

Ideas appear to have been the other major limiter of politicians' power. As noted by Immergut and Anderson (2008), normative ideas tended to shape what was considered a legitimate policy option; proposals that did not align with normative ideas were unlikely to be popular with the public. This limited politicians' power over land tax from its implementation.

\subsection{Significant Taxpayers}

In the formation of tax policy those groups that are expected to actually pay the tax are important interests and those who could exert enough influence may attempt to push for policy more favourable to them. As early as 1908, LeRossignal and Stewart (1908, p. 22) noted that the ability for most taxpayer groups to influence land tax was limited.

\subsubsection{Farmers}

When analysing the power of various groups in land tax development, farmers establish the benchmark against which all others should be measured. Their influence was organised, significant and a feature of land tax since its implementation. Of the groups attempting to influence the land tax over its existence, farmers are the most consistently powerful, showing a remarkable resilience towards both the passage of time and changes in government.

\footnotetext{
923 Refer notes 260; 872.

924 Refer note 508.
} 
This leaves the question of how farmers managed to be so much more powerful than other groups. The first part is the idea of the farmer backbone, the effects and influence of which were outlined in Chapter 9. No other group were the beneficiaries of a widely accepted idea that they were better than everyone else and therefore deserved privileged treatment by government. As a normative idea, the farmer backbone could be used to assemble political support from non-farmers, even if it was against their interests to do so (Immergut \& Anderson, 2008). As early as the 1890s, farmers proved adept at marshalling this idea to extract concessions from politicians and the farmer backbone remained a major feature of land tax debate. However, the limits of farmers' power were linked to the importance of the farmer backbone within the political hierarchy of ideas. When it was ascendant, farmers could exert more influence but they were more limited when fairness or neutrality were dominant.

While the farmer backbone helped establish farmer power, it is not the only reason for it; Parliament itself tended to be very sympathetic to farmer concerns. There are a few reasons for this. Firstly, until 1945, the country quota resulted in smaller, and therefore more, rural electorates. The country quota policy made rural votes worth more and encouraged appeasement of rural interests. Secondly, farmers themselves were disproportionately common as members of Parliament throughout the land tax period (Belich, 2001, p. 402). While they were most associated with the Reform and National parties, for whom farmers were a key part of their support base, farmer politicians could also be found in the Liberal and Labour parties. The level of influence depended on the party in power, National and Reform were more likely to prioritise farmers, but the large number of farmer members ensured that there was always a group of MPs whose personal interests aligned with those of farmers involved in the policy process. The prevalence of farmer politicians gave both the incentive and ability to tilt tax policy in farmers' favour, regardless of who was in power. That power could be further enhanced if farmer members controlled Cabinet, such as during the United-Reform coalition.

The final element of farmers' success was a widespread and organised network of organisations that could lobby politicians and convey farmers' views directly to the public. This was most important in the early $20^{\text {th }}$ century when methods of mass communication were limited but elements persisted longer. When land tax was introduced in 1891, this network consisted of domination of many of New Zealand's Chambers of Commerce but it grew to include the national farmer associations that had arisen since 
the 1880s (Belich, 2001, p. 150) and would remain key farmer advocates into the present day. In addition to personally lobbying politicians, these organisations were able to mobilise their members more effectively than other groups.

That network was supplemented by friendly outlets within the New Zealand media. Several major papers, notably The Press and The New Zealand Herald, had maintained anti-land tax positions since before 1891 and were very sympathetic to farmers. Over time the New Zealand media became less explicitly pro-farmer, but the media remained conservative and from the 1950s generally supported the National Party (Belich, 2001, p. 403), so this did not undermine farmers' interests. Between the lobbying organisations and allied media, farmers were well positioned to influence public feeling and politicians directly. Pressuring politicians would encourage them to act, while generating public sympathy would give those politicians the perception that what they were doing was popular.

Farmer power primarily took the form of land tax exemptions and other preferential treatment. Farmers were entangled within the policy making process itself, receiving representatives on most taxation reviews and the 1929 Hardship Commission (they were the only non-government entity represented at the Hardship Commission). Meanwhile land tax law itself was written to include elements that were designed and targeted to benefit farmers without explicitly referencing them. The most obvious case was the 1931 abolition of graduation, deliberately designed to help farmers, ${ }^{925}$ but land tax thresholds tended to be set to exclude the majority of farmers. ${ }^{926}$ In other cases provisions that were particularly bad for farmers, such as the 1929 special tax, tended to be short lived.

The largest exemption for farmers was the 1970 agricultural exemption from land tax. The agricultural exemption occurred during a period where farmer influence was less obvious and does not appear to have been the result of direct farmer pressure. Instead the government wanted to change the land tax base and appears to have feared the potential farmer backlash if they were not exempted first. ${ }^{927}$ The exemption of farmers was the first case of exempting an entire commercial industry from land tax and resulted in the bizarre

\footnotetext{
$925 \quad$ Refer note 496.

926 Refer notes 98; 509.

927 Refer note 614.
} 
situation where farmers had more favourable land tax treatment than charities. While this was the last major point of farmer influence within the land tax, it is important to note that it appears to have been so engrained within the system that politicians acted in line with it without active pressure to do so. However, the 1970 exemption largely ends direct farmer power over the land tax. Once farmers were no longer liable for land tax, they stopped trying to actively influence it.

Much of the underlying structure of farmer power remained however, which may have limited any considerations of expanding land tax back to farmers in the 1970s and early 1980s, but that structure was weakened under the Fourth Labour Government. By that point farmer power had decreased enough that the government was comfortable unwinding their extensive state support. Farmers maintained their land tax exemption but it was not secure and Treasury was actively pushing to abolish it. ${ }^{928}$

The other important element of farmer influence over land tax is that it limited the power of other taxpayer groups. While the distribution of power within an institutional setting is not expected to be equal, farming interests proved adept at utilising their greater influence to limit that of other groups. Farmers resented paying any tax someone else did not have to, ${ }^{929}$ regardless of their own preferential treatment, so attempts to introduce exemptions for other groups in 1907 and 1929 were rigorously attacked as anti-farmer bias. In these cases farmers could bolster their influence through use of the ideas of fairness, the farmer backbone or neutrality as frames, all of which could oppose exemptions for others, to create a very effective opposition. This opposition appears to have limited the politicians' appetite to implement concessions for other groups and they were rare before the 1970s. Farmers' reluctance to share power resulted in a situation where other taxpayer groups proved incapable of establishing significant influence over land tax concurrently. Eventually other taxpayer groups did gain power but not until after 1970.

\subsubsection{Business}

Compared to farmers, the power of businesses in land tax development was much more limited. Business did have a privileged position and, like farmers, they were embedded

\footnotetext{
$928 \quad$ Refer note 729.

929 Refer note 446.
} 
within aspects of the policymaking process, usually receiving representatives on taxation reviews. However, business lacked anything comparable to the farmer backbone. Despite occasional concern about the impact of land tax on business being voiced in Parliament ${ }^{930}$ or tax reviews, ${ }^{931}$ it was always secondary to the concerns of farmers and the few attempts at giving businesses targeted land tax concessions were attacked by farmer advocates as biased towards cities. ${ }^{932}$ Farmer opposition resulted in very few land tax concessions to businesses. Historically, limited business influence was less of an issue as the high thresholds kept most businesses outside the tax anyway, but became a problem once business became the primary land tax base.

Businesses did not start exerting significant power over land tax until the late 1980s. Before this farmers dominated the system or there was little reason to exert power. Land tax was narrow and not especially heavy, creating only limited inconvenience for the few businesses that were liable for it. The catalyst to attempt to influence policy was the poor post 1987 economy combined with recent revaluations. By this point the exemption of farmers from land tax had left a power vacuum, where no group of taxpayers had a significant influence on land tax. Business, finally unconstrained from farmer influence, stepped in to fill this space.

To establish power in the 1980s business had to take a different approach to that farmers had used. Businesses lacked anything comparable to the farmer backbone, did not have an overly sympathetic Parliament or reserves of public trust, and in the early 1980s the dominant interpretation of fairness had been that business should pay more tax. ${ }^{933}$ Instead business conducted a campaign of encouraging and harnessing public outrage over land tax. The Fourth Labour Government had previously limited this kind of opposition by making policy changes so rapidly that opponents struggled to organise against it (Douglas, 1993, p. 225). However, since the government delayed land tax reforms, allowing the issue to fester for years, this would not work. This gave business opposition

\footnotetext{
$930 \quad$ Refer note 486.

$931 \quad$ Refer note 385 , page 6.

932 Refer note 306.

933 Refer note 642.
} 
a chance to organise which it would not have had if land tax reform had followed the government's typical policy reform strategy. .

Since the business campaign was focused on generating wider public feeling, from 1987 it focused less on how land tax was affecting businesses themselves and instead how it would affect the wider population. To this end the focus was on consumers; suggesting that land tax would lead to higher prices, lost jobs and higher rents. Within the business community itself, larger organisations ran seminars for small businesses to convince them of land tax's problems and persuade them to oppose it. This was an interpretation of land tax designed to make the public more sympathetic, so it did make claims that stretched the truth while deemphasising how land tax changes would benefit the wealthy or big business. ${ }^{934}$ Private appeals to politicians were still utilised but were not the primary focus.

Alongside manipulation of public opinion, the key element of business power in the late 1980s was the size and diversity of the opposition. Due to the narrowness of land tax, historic opposition was primarily from big business, a group the public and politicians were not sympathetic to. The revaluations of Wellington and Auckland expanded the opposition to include smaller businesses who rented their premises, charities and local government. As business land tax opposition became harder for the government to ignore, it joined with other groups, including property investors, to lobby for land tax change. It also gained the support of the parliamentary opposition party. ${ }^{935}$ This increased pressure on the government and provided a longer-term path to instigate policy changes.

As the land tax opposition grew larger, it started to encompass or influence more potential voters and its power grew, a change reflected in its demands. Earlier opposition had focused on rate cuts and base broadening, with abolition not seen as an achievable option. ${ }^{936}$ By 1989 the much larger business opposition seemed to think abolition was realisable and it became the key focus of the reform push.

\footnotetext{
934 Refer note 904.

$935 \quad$ Refer note 700.

936 Refer note 717, page 10.
} 
While the government's 1989 reforms were an attempt to contain land tax opposition, they appear to have had the opposite effect. Lowering the thresholds and removing exemptions saw the existing opposition joined by more small businesses, property investors, non-profits and religious organisations while local government campaigned more strongly. The interests of the various groups did not always align, as many were trying to push their tax burden onto someone else, ${ }^{937}$ but they could be unified around abolition. Attempts to drive public feeling against land tax were also helped by the government's actions, such as the brief attempt to tax hospitals, which were widely unpopular and reduced public confidence. While the business campaign remained focused on public opinion, its numbers made it a potentially important voting base.

Business influence in land tax can first be felt in the 1989 changes. The 1989 desire to change the land tax appears to have been the government bowing to the political pressure from the business campaign. While business managed to trigger the reform, they had less power over what form it took. Business demands do appear to have played a role in the government's decision to lower the tax rate but most of the policy details, particularly those surrounding the exemptions, appear to have come from the Treasury. This was likely a side effect of the business campaign highlighting land tax faults but not providing a clear alternative until April 1989. Notably, while the changes helped the big businesses that were the core of land tax opposition, they were actively detrimental to the smaller businesses that found themselves newly liable and were seen as underwhelming by existing taxpayers.

In 1990 the impetus for land tax change again appears to be the pressure of the business campaign but it now had more influence over what that change would look like. By this point business had settled on abolition as its preferred method of land tax reform and, apparently hoping to quell an unpopular issue before the election, abolition was what the Minister of Finance demanded. This was over the objections of Treasury officials, ${ }^{938}$ who lacked sufficient influence to outweigh political considerations. Abolition was a complete reversal of a government policy established less than one year earlier and therefore not an expected change. The significant influence of the business opposition probably does

\footnotetext{
937 Refer note 758.

938 Refer note 790.
} 
explain the abolition. Land tax abolition is one of very few cases where power was able to overcome both ideas and path dependency to be the dominant driver of policy change. While business power was significant at this time, it is likely that the tipping point was the upcoming 1990 election, which increased the political risks of unpopular decisions by politicians, which could be exploited by business power.

\subsubsection{Property Investors}

The rise of property investors as an influence is late relative to the other groups. This is not because they did not exist previously but rather because they were land tax's target. Property speculation itself was seen as incompatible with fairness and investors/speculators had a long history as populist enemies in New Zealand politics (Belich, 2001, p. 22). Therefore property investors do not have power in the land tax debate until the 1980s.

Property investors were the first group who attempted to fill the power vacuum left by the removal of farmers from the land tax system. In 1983, they attempted to get themselves an exemption from the newly increased land tax by lobbying the Ministers of Revenue and Transport. Property investors efforts largely followed the model established by farmers in previous decades, focusing on the effect of land tax on their finances and suggesting it may force them out of business. This tactic was supplemented by a second strategy where they emphasised how land tax would cause rents to rise, adversely affecting tenants. ${ }^{939}$

Property investors attempts achieved nothing as the government refused to give any concessions, sceptical the market would allow rent increases. ${ }^{940}$ While property investors used a similar strategy to farmers, they lacked anything comparable to the 'farmer backbone' idea and were not a group that was well regarded by populist politics.

Property investors' attempts to influence land tax continued to be handicapped by them not being well liked by the public. After 1987 they aligned themselves with businesses and focused on publicly arguing that land tax was forcing up rents. The government reluctantly exempted residential rental property in 1988 after it was shown rents were

\footnotetext{
939 Refer note 658.

$940 \quad$ Refer note 659.
} 
rising, but it did this to benefit tenants rather than landlords. The owners of commercial property, who had less sympathetic tenants, got no relief. Property investors seem to have had a negative influence on the process; the government saw the possibility of changes benefiting landlords as a justification to not make them. ${ }^{941}$

Ultimately property investors were a group that tried to influence land tax but were so widely disliked by the general public that politicians saw no obligation to consider them. They become something of political bogeyman, their presence in the policy debate actively undermining their aims.

\subsubsection{Māori}

Despite Henry George envisioning land tax as a tool to prevent the alienation of native lands, the policy introduced by the Liberal Government had the opposite aim. Instead Māori in the 1890s found themselves dealing with a system where most politicians viewed them as inherently lesser. While the Māori electorates guaranteed Māori representation in Parliament, they limited the Māori voters in general electorates so most MPs paid little attention to Māori concerns. ${ }^{942}$ This was not an environment conducive to Māori influence and they did badly under land tax from the start. They are one of the few groups that saw their exemption shrink in the shift from property tax to land tax. They then found themselves engaged in an almost four-decade conflict with the tax department as it tried to expand their tax liability. Unlike when the tax department targeted other groups, Parliament largely ignored this, and in 1895 actually changed the law to legitimate the department's actions. Even when Parliament did consider Māori, its actions tended not to be much help and the Liberal and Reform governments spent much of the 19001920 period trying to further limit the definition of exempt native land.

Māori did receive an exemption but it does not appear to have been the result of power or influence. The exemption for Māori owned land was inherited from the preceding property tax and seems to have been maintained, at least in part, because Māori isolation

\footnotetext{
941 Refer note 667.

942 NZPD, Volume 122, 9 September 1902, page 189, Frederick Pirani.
} 
in the early 1900 s made them difficult to collect tax from. ${ }^{943}$ Later that exemption was narrowed multiple times, suggesting that Māori did not have the influence to maintain it.

The closest Māori appear to come to influencing policy is in 1922 when the government responded to concerns raised to the 1922 Committee on Taxation by limiting total Māori land tax liability. Following the committee's report the government amended the land tax to benefit Māori and Māori appear to have had sufficient influence to persuade the government to further decrease that limit in 1926. The change did not discourage the tax department from trying to undermine the limit, but was certainly a better position than Māori had previously had.

Māori largely disappeared from land tax debates after the 1920s. They were not granted further benefits but, in contrast to previously, they did not see a gradual erosion of existing ones. This may have been the result of greater influence but there is also an element of institutional inertia, with those benefits being maintained because they were part of land tax's path dependent model, and people simply forgot those benefits existed. When the Māori land exemption came to further attention in the 1980s it was unpopular with a segment of New Zealand society that saw it as discriminatory ${ }^{944}$ and Treasury, who felt it was distortionary. The Māori land exemption was maintained but not because of any power Māori wielded, rather Treasury lacked time to work out how to actually remove it.

Overall Māori were major stakeholders in land tax policy but never had much influence over it. Early government saw them as a potential target and later they were simply ignored.

\subsection{Treasury}

Treasury was one of the last groups to gain influence in land tax policy development. The department did not acquire its economic advisory role until the 1960s, and was distrusted by Robert Muldoon who, in his role as Minister of Finance, limited its influence. The power of Treasury was inextricably entangled with its institutional commitment to neutrality and Friedmanite economics. This meant its advice and goals were consistent

\footnotetext{
943 Refer note 201.

$944 \quad$ Refer note 786.
} 
but unlikely to be followed by politicians who did not agree with it. In this, Treasury had the misfortune of dealing with Robert Muldoon as Minister of Finance from 1967-1972 and 1975-1984. The Minister's distrust of monetarism and those advocating it saw him limit the department's influence. Instead he would simply ignore Treasury recommendations on a variety issues of varied importance (Gustafson, 2000, p. 385). For land tax this meant reports criticising actions the government wanted to take, such as the 1981 sporting exemption ${ }^{945}$ or the 1983 residential exemption, ${ }^{946}$ were disregarded and the Treasury had little influence.

In 1984 the Treasury found a more agreeable audience in new Finance Minister Roger Douglas. From this point, establishing the degree of Treasury power becomes more challenging. Other works have raised questions as to the degree of power the Treasury held in the Fourth Labour Government, suggesting that, in a case of agency capture, Treasury was seen as the driving force behind the Rogernomic reforms with the Minister merely a puppet (Belich, 2001, p. 411). That level of influence would explain why the policy mirrored the Treasury's views and persisted under the Fourth National Government, but it does not explain the Minister of Finance's consistent reluctance to implement the Treasury's land tax suggestions.

While the Treasury influenced the ideological environment that land tax policy was made within, the department generally did not have much control over policy specifics. While the Fourth Labour Government's various Ministers of Finance and Revenue backed the ideas unpinning the Treasury's land tax proposals, they continued to veto them. The Treasury recommended that land tax be left alone or abolished ${ }^{947}$ but from 1986 the government started making changes to it. Even with a more sympathetic government, the Treasury's commitment to ideology undermined its power. Treasury's policy recommendations were consistent with both its ideology and that of the government, but they were unpopular. The government, unwilling to incur the public backlash that Treasury's ideas would provoke, ignored the department. While the government and the Treasury shared ideology, Treasury did not have sufficient influence to persuade the

\footnotetext{
945 Refer note 639.

946 Refer note 654.

947 Refer note 689.
} 
government to ignore public opinion. With the Treasury refusing to abandon its ideological policy framework, there was little scope in which it could be influential in regards to land tax.

The Treasury had influence in 1989 when public pressure had finally convinced the government to reform the land tax. True to form the Finance Minister rejected both Treasury's proposals but suggested a staggered rate lowering and base broadening that lacked details. ${ }^{948}$ The drive to do something, combined with a lack of clear view as to what that something should be, provided an opportunity for the Treasury. As the department charged with providing economic advice, Treasury had the job of designing what the land tax change should look like. The end result was a land tax policy that broadly reflected the Treasury's ideals, particularly regarding exemptions, and was more aligned with the idea of neutrality than the existing system, but was less radical than its previous proposals. The Treasury then successfully defended this policy from other groups' attempts to influence it, convincing the Minister to ignore conflicting advice from Inland Revenue and the Charities Working Group and proceed with their plan unaltered. In the face of public unpopularity, the Treasury's influence was quickly marginalised. In 1989 the unpopular land tax on hospitals was quickly overturned against the Treasury's recommendation and the Minister does not appear to have even considered its proposal to tax schools. ${ }^{949}$ The decline of Treasury's influence culminated in Treasury's attempts to stop the 1990 abolition, which were completely ignored by the Minister. The Treasury, in its role designing policy, had some influence on the form land tax abolition took but was powerless to alter the inherently political decision to abolish it.

Relative to other groups, the Treasury was influential within the land tax process. While its more radical proposals were limited by the political concerns of government ministers, due to its position as the government's economic advisor it still had significant influence on policy development. It was the most powerful government department and proved adept at limiting the influence of other government organisations.

\footnotetext{
$948 \quad$ Refer note 732.

$949 \quad$ Refer note 752.
} 


\subsection{Tax Department/ Inland Revenue}

The limited power of the tax department over land tax is a consistent part of land tax development. Unlike Treasury, the tax department lacked a commitment to a particular idea. Instead it tended to advocate measures that would raise tax revenue or ease the burden of tax administration. These concepts can be found underpinning its land tax advice in the 1920s, 1930s, 1970s and 1980s. However, it meant that the tax department consistently pursued aims that were politically unpopular, as they often amounted to raising taxes, taxing more people or both, and frequently contradicted the dominant normative ideas. This resulted in the tax department's land tax policies being ignored by politicians and the department having little power within the system.

The dynamics of the relationship between the tax department and politicians were further complicated when Treasury entered the sphere of providing economic advice. Given both departments had different aims it was not uncommon for them to advance conflicting policy. Since the government usually ignored both Inland Revenue and Treasury this was not a problem. However, it became a problem in 1989 when the government took a more hands-off approach to land tax policy.

In 1989 Treasury and Inland Revenue each pushed for incompatible land tax policy changes; requiring one policy to be chosen over the other. In this Inland Revenue found itself at a disadvantage as the review of land tax was primarily run by the Treasury. Since Inland Revenue did not report to the Minister of Finance, it was less close to the decision making and it found itself somewhat removed from the review process. Treasury also marginalised Inland Revenue suggestions, which did not conform to the dominant idea of neutrality, and even in areas where the tax department had the greatest expertise, such as how the system could be run, practical Inland Revenue concerns lost out to Treasury's ideological push. A hierarchy quickly developed within the policy process. The Finance Minister had overall control and below him Treasury had broad discretion to design the system's particulars. Inland Revenue was last with little influence over policy objectives; its primary contribution was minor technical aspects in an attempt to make the system possible to administer.

The tax department was not always so unimportant to the land tax debate. While it usually struggled to push its agenda through Parliament, for land tax's first 40 years its administrative duties gave it significant influence over the land tax system taxpayers 
actually had to deal with. The tax department proved adept at using its greater knowledge of taxation to exploit imprecise legislative drafting and extend policy well beyond what politicians had intended. Since this relied on already passed law, the political process and politicians' concerns were largely sidestepped. The law established limits but the department could push them.

Most notable was the tax department's almost 40-year quest, beginning in the 1890s, to unilaterally expand the taxation of Māori land. This was the tax department at its most powerful, essentially deciding policy without input or oversight from Parliament, simply because nothing within the legislation said they could not. The taxation of Māori land even saw one of the few circumstance where, in 1895, Parliament was forced to fully adopt tax department policy, ${ }^{950}$ as the department levied land tax without legal authority ${ }^{951}$ and then left Parliament with the choice to either retroactively approve the decision or give back the money. Given the government's poor financial situation and the unpopularity of the affected taxpayers it was not much of a choice.

The department never managed to force Parliament's hand again but it spent the next three decades creatively interpreting legislation to tax Māori land more. While such interpretations often did poorly before the courts, ${ }^{952}$ the tax department was still able to exercise a degree of power over land tax unseen among other government departments before or since.

While the department primarily used this power against Māori, it would make attempts against other taxpayers when an opportunity arose. For example, it used the 1924 charge on land rules in a broad attempt to collect previously ignored unpaid land tax. ${ }^{953}$ The difference was that taxing other groups resulted in public outrage and Parliament quickly stepped in to stop it, ${ }^{954}$ limiting the department's power to do so.

\footnotetext{
$950 \quad$ Land and Income Assessment Acts Amendment Act 1895, s7, s8.

951 Refer note 203.

952 Refer notes $241 ; 384$.

953 Evening Post, 24 March 1925, Land Tax Arrears.

954 Refer note 953.
} 
The tax department largely stopped doing this from the 1930s. While it is possible Ministers decided to monitor the department more closely, this also coincides with the period where land tax law begins to stagnate and opportunities to exploit new legislation were fewer. Elements of this behaviour reappear following the 1989 reforms, which again saw Inland Revenue attempt to levy land tax in cases where it lacked the obvious authority to do so. The unilateral expansion was mostly due to Inland Revenue's narrow interpretation of the charities exemption, which saw the department attempt to tax amateur dramatic societies ${ }^{955}$ and implement an apportionment system based on land use, ${ }^{956}$ despite the legislation not providing for such. It is uncertain whether these actions would have seen Parliament step in to overrule Inland Revenue, although the Minister of Finance did intervene to quash the taxation of amateur dramatic societies, ${ }^{957}$ as the 1990 abolition of land tax meant they never had a significant effect.

\subsection{Local Government}

Local government remained largely uninvolved in the land tax process until 1987. Before that low land tax levels and the Crown exemption made land tax mostly irrelevant to them. The 1987 market crash and revaluations provided the impetus for local government to attempt to influence land tax policy. Initially local governments' concerns stemmed from the effects of competition over land as a tax base. This was first seen with the Wellington City Council, who worried that high land tax liability was driving away businesses, ${ }^{958}$ and therefore the Council's rating base, but other councils started to share those concerns after the 1988 Auckland revaluation. ${ }^{959}$ Following the 1989 reforms, councils' concerns were expanded to include their own personal liability, which they saw as a result of government greed. ${ }^{960}$

\footnotetext{
$955 \quad$ Refer note 775.

956 Refer note 770.

957 Refer note 776.

958 Refer note 667.

$959 \quad$ Refer note 718.

960 Refer note 782.
} 
Local government became part of the anti-land tax coalition assembled by business but, despite being a government body, actually had little power. Their access to ministers and attempts to play them off against each other ${ }^{961}$ produced few results. The key problem appears to be how government viewed its relationship with local government. Ministers, and particularly Treasury, appear to view local government as an adversary to be defeated rather than an interest group to engage. Treasury's advice on local government liability for land tax was to implement the policy, regardless of potential issues, so it could be used to extract concessions in upcoming local government funding negotiations. ${ }^{962}$ The Treasury similarly planned to use the 1990 abolition to deny local government requests for new taxation powers. ${ }^{963}$ This meant Ministers were reluctant to give local government exemptions, particular as they conflicted with neutrality, ${ }^{964}$ and Treasury was likely to suggest measures that actively undermined local government's influence.

\subsection{Summary}

Within the history of land tax power is one of the less important elements directing development, traditionally subservient to ideas, path dependency and critical junctures. Notwithstanding this, power does play a part in understanding how land tax policy developed. Much of land tax's history is dominated by farmers, who managed to leverage ideas into a lasting powerbase, and policy generally favoured them more than other groups. The power of farmers limited the influence of other groups until the 1970 exemption saw them vacate their position. After that other groups attempted to gain influence with business and Treasury being the most successful.

The distribution of power was not equal among groups and who could not affect land tax policy is as important as who could. The tax department, despite administering the tax and arguably having the best knowledge of it, was consistently incapable of influencing the policy process. Its advice on issues ranging from administration and revenue potential,

\footnotetext{
$961 \quad$ Refer note 779.

962 Refer note 744.

963 Treasury, Budget Report 85, 11 June 1990, Archives New Zealand AALR W5427 873 Box 1862 76/4/2 Part 5.

964 Refer note 781.
} 
to alternative policy goals was routinely ignored by the Ministers charged with overseeing tax law. Instead it leveraged the administrative process to alter land tax while bypassing the political process. Meanwhile Māori were among the worst treated group of taxpayers, unable to influence the policy process or discourage the tax department from targeting them.

Overall, power explains why some groups tended to do better under the land tax than others, helping to explain things that ideas cannot. Ultimately however, its greatest importance is in the late 1980s. After being a relatively minor influence on land tax development for the past ninety years, it plays a key role in land tax abolition. 


\section{Chapter 13: Conclusion}

This thesis analyses the historical use and development of land taxation in New Zealand from 1891-1991. While providing a broad account of changes to land tax legislation, this research goes beyond a simple narrative history. Through the adoption of a historical institutionalist framework, it examines why land tax developed as it did, focusing on the influence of ideas, path dependency, critical junctures and power. While these concepts are individually important, derivation of a more complete picture is achieved by examining them together and considering their interaction.

The thesis answeres three research questions, focusing on the development, stability and beneficiaries of land taxation, with the aim of informing future debate on land taxation. The findings are summarised in this chapter.

\subsection{Summary}

New Zealand introduced a land tax in 1891 in an attempt to bring a greater social policy focus to a tax system primarily focused of revenue collection. While land tax was a radical idea at the time, the Liberal government implemented it in hopes of widening land ownership and making the tax system fairer. The land tax they chose to implement persisted from 1891-1991 but, despite its long life, it is difficult to describe it as a success.

From the beginning the land tax is characterised by a struggle between four ideas: fairness, the farmer backbone, neutrality and Georgism. While the influence of Georgism was marginalised after the 1900s, the other three feature, with various levels of influence, in land tax policy until abolition, each with a different group of supporters. Fairness was generally dominant but could, particularly in times of economic crisis, be marginalised, allowing other ideas to come to the forefront.

In the formation of land tax policy, ideas gave politicians a direction to aspire to and, as they fought to implement the ideas they backed, these ideas proved influential in the design of the land tax method and base. However, this resulted in taxation policy where ideological consistency was much more important than practical results and land tax suffered for it. The commitment to fairness narrowed the base, crippling land tax's effectiveness as either a revenue or social policy tool, and the rise of the farmer backbone did little to help most farmers. The 1980s push for neutrality made the system more complicated and less popular, helping to abolish it. Despite ideas often making land tax 
ineffective, compliance with them helped establish feedback mechanisms resulting in path dependency that maintained the land tax, even if the tax achieved little.

While ideas were a major influence on land tax policy, they were not the only influence. At the same time various groups tried to push land tax policy in directions that would benefit them. For most, the influence of key ideas was too dominant and they had little success, but farmers were able to leverage the farmer backbone idea and their more cohesive class identity to create a privileged position that mirrored their status in wider society. In the late 1980s, businesses became powerful enough to play a key role in land tax abolition. Meanwhile within the government, the tax department and the Treasury tried to push their preferred land tax policy to generally reluctant politicians.

The way land tax was designed resulted in a limited focus on results. This created a tax system that was largely ineffective; it was too narrow to work as either a revenue or social policy tool and for decades persisted without any obvious purpose. Attempts to revitalise it in the 1980s had some success but did not fix most of its underlying problems. Ultimately land tax was abolished in 1990; not for ideological or functional reasons but because it, and the Fourth Labour Government, were unpopular, an election was imminent and abolition was seen as a way to reduce the chance of the government losing.

\subsection{Research Questions}

Chapter 1 of this thesis outlined three research questions on New Zealand land taxation. These questions and the conclusions arrived at are presented below.

The first question addressed in this thesis is how the New Zealand model of land taxation arose and why it was adopted in New Zealand over potential alternatives. New Zealand's approach to land tax was a product of politics and politicians rather than economic theory or actual results. At the time of implementation, Georgism was the most established model for land taxation but the Liberal government in the 1890s wanted to create an approach that better aligned with the idea of fairness. The Liberals wanted to widen land ownership and did not think small landowners should be penalised. Rather than tax all land at the same rate, as George suggested, which would increase taxes paid by the poor and middle classes, the Liberals chose to focus on the landholders that were seen as undesirable by society: speculators, monopolists and absentees. To this end they 
introduced a land tax with progressive graduations to increase the tax burden on the wealthy and those with more valuable landholdings, exemptions and thresholds; to limit the impact on the poor and deserving, and an additional tax on absentees, to penalise foreign landowners. These elements became the key pillars of the New Zealand model of land tax.

This resulted in a land tax that was more closely aligned with the public's idea of fairness than other tax measures were, a view that persisted until the 1980s. Land tax proved ineffective at controlling the property market so those elements disappeared from land tax policy debates. Instead the idea that land tax was fair, because it was borne by the wealthy, provided legitimation feedback mechanisms for the path dependency, and allowed the model to be maintained.

In the times when fairness was a less dominant influence on policy, land tax could change to reflect other ideas. Under the farmer backbone focused United-Reform coalition of 1931-1935, land tax became more beneficial to farmers and the wealthy, at the expense of everyone else. Conversely the Fourth Labour Government of 1984-1990 made the tax more neutral. While the farmer backbone and neutrality were popular within governments they did not appeal to the wider electorate in the same way as fairness. Those ideas struggled to establish the feedback mechanisms, particularly legitimation ones, which had been so important to maintaining the land tax. Unable to establish a sustainable path dependency, neutrality and farmer backbone focused changes were quickly undone, by the reassertion of fairness in 1936 and abolition in 1990.

The most important change to the New Zealand approach to land tax was not an attempt to diminish it, but the 1981 attempt to make it useful. The 1981 changes solidified revenue as the primary focus of land tax, substituting legitimation feedback mechanisms (e.g. fairness) for functional ones (e.g. economic). While this made land tax more secure in the short term, functional feedback mechanisms proved less reliable than legitimation ones and they were easily weakened by alternative revenue sources. When the 1987 share market crash triggered a critical juncture, the feedback mechanisms that had previously sustained land tax were not strong enough to continue doing so and the tax was able to be abolished.

The second question addressed is how the New Zealand land tax mitigated the administrative and political problems predicted to arise from the use of land value 
taxation. While land value tax literature predicts political and administrative difficulties when operating the system, the New Zealand land tax demonstrated fewer than would be expected. From an administrative perspective it had relatively few problems. While the system was more complex than other taxes and not especially efficient, the tax department ran it with relatively few problems. Meanwhile the valuation system was generally accepted as accurate, even though it was usually out of date due to the slow speed of revaluations. While imperfect, land tax did not generally require significant reforms to maintain.

Land tax was not without problems. Administrative issues were concentrated in the period following the 1989 reforms. The expansion of the land tax base saw Inland Revenue struggle with the extra tax returns, the uncertain tax treatment of some land usages and high levels of taxpayer non-compliance. These were a side effect of aligning the land tax with the idea of neutrality at the expense of concerns of administrative practicality. Inland Revenue, who understood land tax administration and had utilitarian feedback mechanisms encouraging them to maintain the existing tax system, did not have the power to influence government policy to address these concerns. Instead the 1989 land tax was shaped by the government and the influential Treasury, both determined to implement the idea of neutrality. The various administrative issues were seen as an acceptable trade off to achieve ideological purity.

The valuation system could cause problems but these were rare. On the few occasions when land prices fell, the slow revaluations tended to trigger public backlash. While the valuation system was not perfect, it had strong path dependency and therefore saw few changes. Unlike most of the land tax, which persisted based on legitimation or functional feedback mechanisms, the valuation system was maintained based on utilitarian feedback mechanisms. The government found the system was cheap and easy to run while the slow revaluation speed reduced taxpayers' tax liability. The benefits to both parties largely offset the any desire to change.

Land tax proved resistant to political challenges; only 1931 and 1990 saw government significantly roll it back and only the 1990 abolition was permanent. When implemented in 1891, land tax was strongly disliked by conservative interests, particularly farmers, and conservative politicians who stated their intention to abolish it once they gained power. This was prevented by the longevity of the Liberal government, which lasted from 1890- 
1912. This gave time for the Liberals to intertwine land tax with the idea of fairness, aligning it with New Zealand's egalitarian attitudes, and for it to develop public support. The development of public support was helped by the public supporting its land aims and the thresholds and exemptions ensuring that most people did not pay it. By the time conservatives gained power, land tax had established a strong path dependency based on legitimation and functional feedback mechanisms. Strong path dependency saw land tax persist under the new Reform Government. The Reform Government even strengthened its use against the unpopular land speculators and large landowners. The belief that land tax was fair persisted for years, provided strong feedback mechanisms that limited land tax changes. While various groups pushed for changes to the land tax, none had sufficient power to force through significant changes. Land tax proved more vulnerable to change when fairness was not the dominant idea influencing land tax policy. The rise of the farmer backbone saw the coalition government roll back land tax with the 1931 flat tax but when fairness again became dominant with the election of the First Labour Government, those changes were reversed.

From 1940-1970, land tax was not publically prominent enough to generate political issues, existing in the background of the tax system and rarely focused upon. That changed as more taxpayers began to fall over the land tax threshold. However, the additional taxpayers, and therefore additional revenue, resulted in the development of functional feedback mechanisms that gave governments incentives to maintain the land tax rather than abolish it. Caught between the need for land tax's revenue and the potentially unpopular wider taxation, the Third National Government, from 1978, ${ }^{965}$ started exempting some taxpayer groups. Such exemptions tended to be based on what would be popular and aligned with that government's idea of fairness. The same functional feedback mechanisms underpin the Fourth Labour Government's retention of the land tax, despite its clash with their neutrality ideology. Once the critical juncture of the 1987 stock market crash increased land tax opposition and destabilised the existing system, feedback mechanisms proved insufficient to maintain path dependency. In 1989 the government tried to reform the system by aligning it with neutrality but this move could not establish feedback mechanisms. The changes proved to be unpopular and did

965 Land Tax Amendment Act 1978, s4. 
not appease powerful business interests. In 1990, the government responded by simply abolishing land tax.

The final question addressed is to what extent did land tax policies privilege particular groups and why did particular groups gain concessions. Land tax was always intended to be narrow. The Liberals had quickly discounted the Georgist idea of applying it to all land ownership, and there was little serious consideration of doing so later, outside the Treasury and the tax department. This created a tax that was distortionary and would inherently give preferential treatment to certain groups. The Liberals, guided by their idea of fairness, tried to limit land tax to the wealthy; setting exemptions and thresholds to keep out the poor and deserving. This established strong legitimation feedback mechanisms by the land tax which maintained it, and kept its base narrow, until the 1980s. Among other potential taxpayers, benefits tended to be directed towards those with the power to influence the policy debate. Before 1970 farmers benefited from this the most and were able to exploit a political system designed to increase rural influence and a culture where they were glorified. Favourable political conditions were combined with the farmer focused idea of the farmer backbone and the ambiguity of fairness' "deservedness" criteria to push land tax law in a direction that benefited farmers, while minimising preferential treatment for other taxpayer groups.

While farmers were the taxpayer group best positioned to extract land tax concessions, their greater strength was the ability to maintain them. Aligning farmer concessions with ideas, particularly fairness, allowed them to develop legitimation feedback mechanisms that preserved them better than simply relying on power. While this allowed farmers to entrench their benefits, it did put limits on their influence. The 1931 flat tax was a triumph for farmers, but it pushed too far and became incompatible with fairness, limiting its ability to establish a path dependency.

Other groups simply did not have the power to push for benefits or to maintain those they did get. Businesses, the second most influential taxpayer group, only twice got concessions before 1970. Unlike farmers' concessions, business concessions were not aligned to an idea, struggled to establish feedback mechanisms and were quickly abolished. A lack of power comparable to farmers, and business not being viewed particularly sympathetically by the electorate, saw business become the primary land tax base by the 1970 s. 
By the late 1980s the power dynamics of land tax had changed, allowing business to gain more beneficial treatment. Farmers had largely been removed from land tax's power structure through their 1970 exemption, leaving business as the dominant taxpayer group. While preferential treatment for business struggled to align with fairness, and there was no business equivalent to the farmer backbone, businesses were treated more favourably by the neutrality ideology pursued by the Government and Treasury. Following the 1987 stock market crash, business interests were able to lead a coalition of other taxpayers who wanted to change the land tax. With a more receptive government ideology, they were able to push the government to make changes in 1989 and 1990. Despite the coalition including small businesses, local government and charities, changes made to land tax were most favourable to big businesses, the most powerful, organised and vocal member of the group.

Māori were also particularly disadvantaged by the early land tax (1890-1930), despite the legislation initially appearing favourable to them. Māori disadvantage stemmed from two issues: that Māori land was held collectively and the government's attitude to Māori. Communal ownership meant Māori landholdings were often valued above the land tax thresholds but had a large number of owners. If the land had been held under separate titles, as European land was, it likely would have been exempt. Collective land ownership brought Māori within the land tax system, which made politicians' attitudes an issue. The government did not view Māori as deserving, instead feeling they were lesser than European citizens and an obstacle to settlement, and few Māori voted outside Māori electorates. This meant Māori had little influence on MPs or government policy. The lack of Māori power saw the government more reluctant to give Māori concessions, or intervene to help them, than it was in the case of European taxpayers.

Māori were granted an exemption for their land when it was not rented out, based on the difficulties of collecting the tax rather than ideological grounds, but that exemption was limited and not stable. Parliamentary changes to the legal definition of Māori gradually narrowed the exemption and the tax department actively interpreted the law to undermine it. Legislative changes and the efforts of the tax department saw the position of Māori under land tax generally deteriorate until the 1930s, although the courts halted the tax department's more excessive attempts. 
From the 1930s Māori were less disadvantaged under land tax. Their exemptions were expanded and the tax department stopped trying to undermine them. The exemptions largely persisted unchanged after that. In the late 1980s however, the consistency of those exemptions put Māori land in a relatively privileged position; the Māori land exemption was the only ownership based exemption to survive the 1989 reforms. Unlike the benefits for other groups this was not maintained based on functional, power or legitimation feedback mechanisms, rather the exemption was based on utilitarian concerns. While the Māori land exemption had been largely unchanged since the 1930s, the government's interactions with Māori landholding had become more complex. Now dealing with an exemption linked to a complicated array of Treaty of Waitangi concerns, the Treasury thought the process of unravelling it was too complicated. Had land tax lasted longer, Treasury likely would have pushed for the treatment of Māori land to be brought in line with other land.

\subsection{Lessons for the Future}

While the reintroduction of land tax to New Zealand does not appear imminent, examining the historical land tax provides valuable lessons should the policy be considered in the future. Many of these lessons are also applicable to other wealth taxes and parallels can be drawn between land tax and New Zealand's recent failed attempt to implement capital gains taxation.

While there have been a variety of models proposed in the history of land taxation, who to tax has always been a key issue. Exemptions were prevalent within old land tax which made land tax more popular and politically acceptable, easing implementation and entrenchment of the policy. However, these helped to undermine it in the longer term. Applying to so little land meant land tax had little effect on land prices or tax fairness, and was therefore ineffective as a social policy tool, while revenue gained from it was limited.

A wide base, with few exemptions, would be a better choice. This model aligns better with the New Zealand tax system's current focus on board-based taxation and should make the system more effective, allowing it to avoid the problems created by exemptions. A wide base means it has more potential as a revenue tool and can potentially work as a social policy tool. It also limits potential economic distortions. Most importantly, a land 
tax that exempts owner-occupied residential housing likely drives up residential rent, as occurred in the $1980 \mathrm{~s},{ }^{966}$ which risks making the tax system less progressive. On top of this, having no exemptions would make the system less complicated, more certain and easier to administer, while limiting potential court cases.

While a broad-based land tax is likely the best option for a working land tax, its implementation and continuance create significant political problems; simply, the idea would be unpopular. The various interests who opposed the original land tax still exist and as recently as 2017 the New Zealand electorate has made it clear that it views taxing the family home as unpalatable. ${ }^{967}$ Historically land tax limited unpopularity by being seen as fair by the public, but this was linked to the fact most people did not pay it. Getting a similar degree of public acceptance for broader based taxation would likely be more difficult. Limited exemptions could help, at the expense of efficiency, but do not provide a guarantee of popularity. Despite exempting the family home, being predicted to predominantly fall on the wealthy and claims it would increase fairness, ${ }^{968} \mathrm{New}$ Zealand's recent capital gains tax proposal was unpopular ${ }^{969}$ and its introduction was abandoned. Any attempt to reintroduce land tax would also need to mitigate the public opposition in some way or it is unlikely to be successfully implemented.

Even if a government did pass a new land tax it would need to become entrenched so that it is not abolished when the government changes. This requires establishing some manner of path dependency. The approach taken by the Liberal party was dependent on being in government for 21 years, which gave time for strong functional and legitimation feedback

\footnotetext{
966 Refer note 703.

967 Henry Cooke, 14 Sep 2017, Election: Labour Backs Down On Tax, Will Not Introduce Anything From Wrorking Until After 2020 Election, https://www.stuff.co.nz/national/politics/96830392/labour-releases-full-tax-plan-in-response-tocriticism-over-its-working-group, Retrieved 16 July 2019.

Zane Small, 8 April 2019, Pro-Capital Gains Tax Campaigners Tax Justice Aotearoa Protest At Parliament, https://www.newshub.co.nz/home/politics/2019/04/pro-capital-gains-taxcampaigners-tax-justice-aotearoa-protest-at-parliament.html, Retrieved 16 July 2019. Tova O'Brien, 8 April 2019, Large Majority Of New Zealanders Don't Want Capital Gains TaxPoll, https:/www.newshub.co.nz/home/politics/2019/04/large-majority-of-new-zealanders-don-twant-capital-gains-tax-poll.html, Retrieved 17 July 2019.
} 
mechanisms to develop and taxpayers to get used to it, and is likely not a realistic option as no other New Zealand government has served so long. Ideally a combination of feedback mechanisms are best, but to maintain land tax some mechanisms are better than others. Power is unlikely to be practical as a land tax presently has no influential advocates inside or outside Parliament and utilitarian feedback has historically not been very effective. Generating a path dependency based upon legitimation and functional feedback mechanisms is likely to be the most effective means of maintaining land tax when implemented.

Legitimation feedback mechanisms could be developed if the land tax was designed as part of a solution to New Zealand's problems with house prices. This would be similar to how the Liberal's entrenched land tax, but to be sustainable the new land tax would need to achieve something. The problem, demonstrated by land tax's historical ineffectiveness as a social policy tool, is that to have a significant effect on housing affordability a wide base is likely required and will be unpopular. Attempting to cast a narrower land tax as a tax on the wealthy, how land tax legitimation feedback mechanisms historically worked, could be attempted. However, a similar strategy was used with the capital gains tax debate with limited success, ${ }^{970}$ suggesting it would not be successful in the existing political environment.

Functional feedback mechanisms would be easier to establish than legitimation ones. In addition to the improved housing affordability mentioned for legitimation mechanisms, functional feedback could be established based on land tax raising significant revenue. This would also expand New Zealand's tax base to another source to help make the tax system more sustainable, itself a function that could establish feedback mechanisms. The key issue is that land tax would have to raise enough revenue that it could not easily be replaced, similar to the 1980s. Again, this is easier with the unpopular wide base but could be offset by reductions in other taxation as proposed by the 2010 Tax Working Group. ${ }^{971}$

\footnotetext{
970 Henry Cooke, 10 March 2019, Capital Gains Tax Should Be Just The Start, Says Green Co-Leader Marama Davidson, https://www.stuff.co.nz/national/politics/111168958/capital-gains-tax-shouldbe-just-the-start-says-green-coleader-marama-davidson, Retrieved 16 July 2019.

$971 \quad$ Refer note 5, page 11.
} 
Among the key administrative issues for a new land tax would be a requirement for frequent revaluations, ideally annually. Frequent revaluations make the tax system more costly and difficult to administer but they were considered practical and affordable in the 1980s. Furthermore, annual revaluation has several advantages. Annual revaluation limits the potential for public backlash by reducing land tax liability increases following revaluations and quickly recognising falls in land value, so taxpayers are not taxed on non-existent land values. Since land tax is not connected to cash flows, these conditions are when it is most vulnerable to change, or abolition. Annual revaluations mitigate the worst of this, making the tax more sustainable. In addition the greater cost can be slightly offset by tax revenue growing faster as land appreciation is more quickly recognised by the tax base. If the costs were still seen as too high, biannual valuations, as suggested by Mangioni (2018, p. 204), could be used instead.

Historical land tax also offers insights into some more niche approaches to land taxation. A land tax restricted to foreign owned land has been considered in recent years to limit foreign land ownership. ${ }^{972}$ This brings to mind the absentee tax, which functioned on a similar basis, and suggests tax avoidance could be a significant problem. The absentee tax largely fell out of favour as it was easy to avoid through the use of trusts and company structures, while the anti-avoidance measures designed to prevent that were ineffective. Any new land tax focused in the same way is likely to have similar problems dealing with ownership. There are also issues surrounding whether such a land tax would comply with international treaty obligations but it was thought to when considered in $2015 .{ }^{973}$

A land tax on unused land is also currently under consideration. ${ }^{974}$ Historically such a proposal has been popular, but a similar unimproved land tax used from 1920-1976 was largely ineffective. Like many elements of land tax, the unimproved land tax was hindered by land tax's exemptions and thresholds but also because the tax department could not identify land that was unimproved. If recent advice from the Department of Internal

\footnotetext{
972 Refer note 12.

973 Rosanna Price, 12 November 2015, Labour Party Looks To Ban Foreign Buyers, https://www.stuff.co.nz/business/73970396/, Retrieved 13 August 2019.

974 Refer note 13.
} 
Affairs that such identification would now be simple ${ }^{975}$ is accurate, it has the potential to be more successful. Since it could be argued to address a legitimate problem, land banking, and would predominately fall on the still unpopular land speculators, it would also be easier to implement than wider land taxation. It should be noted the policy is opposed by both the Treasury and Inland Revenue, who feel it would be complicated to design and that there is insufficient evidence that it would increase the housing supply or land affordability. ${ }^{976}$ While this could make implementation more difficult, neither department has the power to prevent a determined government from implementing it.

Overall a new land tax could serve a useful function within the New Zealand tax system, expanding taxation to the underutilised wealth base. Based on how the historical model behaved it is likely to be less useful as a tool to influence the property market, particularly if the various exemptions are included to make it more popular. More realistically it could be useful as a revenue source but it would not be easy to implement. In the form where it is most likely to work, land tax will likely be unpopular and vulnerable to political interference. Meanwhile a popular land tax is much less likely to work and risks the problems of the historical system.

To implement an effective social policy focused land tax is possible but New Zealanders would likely have to be convinced it was necessary, a response to a problem they disliked more than land tax and taxing the family home. When the Liberals implemented their land tax that problem was the great estates and housing affordability. Presently New Zealand does not show the same degree of concern for its housing affordability, but if the situation worsens and more people struggle to purchase homes, land tax may come under further consideration.

\subsection{Concluding Remarks}

For the past few years, the press in New Zealand has covered the country's housing crisis, where house prices have risen faster than incomes and first-time buyers struggle to find

\footnotetext{
975 Jenée Tibshraeny, 12 June 2019, Treasury \& The IRD Oppose The One New Housing-Related Tax The Govt's Open To, https://www.interest.co.nz/property/100154/robertson-pushes-ahead-twgrecommendation-investigate-vacant-land-tax-despite, Retrieved 16 July 2019.

976 Refer note 975.
} 
affordable homes. While the notion of history as a cylindrical, repeating process is discredited (Tosh, 2010, p. 38), such concerns are not new. In the 1880s and 1890s the New Zealand media lamented the land boom and the inability of the common man to buy land. ${ }^{977}$ The New Zealand land tax was the historic solution to this still modern problem.

This does not mean that land tax is a policy that can be taken straight from history and implemented in modern society. It had numerous faults and even at its pinnacle it did not work. It is easy to focus on land tax's flaws: its limited success, its complexity or the purposeless relic it became, but that does not give it enough credit. It was, at implementation, a radical attempt by the government to solve the problem of land affordability and did help to make New Zealand tax system fairer and more progressive. The implementation of the land tax should be seen as inspiring, a case of government acting to help the masses, and an example to current policy makers. However, the land tax itself should stand as a warning; even the best of intentions does not guarantee good policy.

977 The Temuka Leader, 11 December 1888, Freetrade In Land. 


\section{References}

\section{Primary References}

Archives New Zealand Unpublished Material

AAFD W4198 Taxation - Land Tax - General $1977^{978}$

811 Box CAB

$127 / 3 / 1$

AAFD W5331 Taxation - Land Tax

1979-1992

7581 Box 235

115/15 Part 1

AALR W5427 Budget reports - General 1989

873 Box 30

3/3/89/90 Part 3

AALR W5427 Taxes on property - Land tax

1984-1989

873 Box 1861

76/4/2 Part 1

AALR W5427 Taxes on property - Land tax

1989

873 Box 1861

76/4/2 Part 2

AALR W5427 Land tax

1989

873 Box 1862

$76 / 4 / 2$ Part $2 \mathrm{~A}$

AALR W5427 Taxes on property - Land tax

1989

873 Box 1862

76/4/2 Part 4

AALR W5427 Taxes on property - Land tax

1989-1991

873 Box 1862

76/4/2 Part 5

AALR W5427 Land Tax

1981-1984

873 Box 1902

77/1 Part 2

978 While officially labelled as only relating to 1977 , documents within file actually cover the period 1967-1977. 
AAVI W3486 32 Graduated Land Tax

$12 / 270$

ABOT W4375 Tax - Land

6787 Box 40

ABOT W4375

6787 Box 40.

IRW2844 11 Legislation - Report Upon The Provisions And

MA19 24

T1 202 23/36
Operation Of The Land And Income Tax Act 1923 And Its Amendments

$$
\text { Tax - Capital Gains }
$$

Tax on Lands Vested in Maori Land Boards -

Administrative papers relating to levying of tax and rates on Native land and returns sent by them showing lands leased under various categories and lands in trust Partly registered correspondence of the Native Department

International War: Taxes - Resolution re

1914
1989-1990

1937

1905-1917

no date - no

date

$1987-1988$

Legislation

Crown and Native Lands Rating Act 1882.

Finance Act 1915.

Finance Act 1917.

Finance Act 1937.

Finance Act 1939.

Finance Act 1989.

Goods and Services Tax Act 1985.

Government Valuation of Land Act 1896.

Income Tax Act 2007.

Land Act Amendment Bill 1906.

Land and Income Assessment Act 1891.

Land and Income Assessment Act 1907. 
Land and Income Assessment Act Amendment Act 1891.

Land and Income Assessment Act Amendment Act 1892.

Land and Income Assessment Act Amendment Act 1903.

Land and Income Assessment Act, 1908.

Land and Income Assessment Acts Amendment Act 1893.

Land and Income Assessment Acts Amendment Act 1894.

Land and Income Assessment Acts Amendment Act 1895.

Land and Income Assessment Amendment Act 1912.

Land and Income Tax (Annual) Act 1923.

Land and Income Tax (Annual) Act 1924.

Land and Income Tax (Annual) Act 1930.

Land and Income Tax (Annual) Act 1931.

Land and Income Tax (Annual) Act 1936.

Land and Income Tax (Annual) Act 1954.

Land and Income Tax (Annual) Act 1962.

Land and Income Tax Amendment Act (No 2) 1976.

Land and Income Tax Amendment Act 1920.

Land and Income Tax Amendment Act 1922.

Land and Income Tax Amendment Act 1924.

Land and Income Tax Amendment Act 1925.

Land and Income Tax Amendment Act 1926.

Land and Income Tax Amendment Act 1929.

Land and Income Tax Amendment Act 1930.

Land and Income Tax Amendment Act 1931.

Land and Income Tax Amendment Act 1936.

Land and Income Tax Amendment Act 1940.

Land and Income Tax Amendment Act 1950. 
Land and Income Tax Amendment Act 1954.

Land and Income Tax Amendment Act 1968.

Land and Income Tax Amendment Act 1970.

Land and Income Tax Amendment Act 1971.

Land Tax Act 1878.

Land Tax Amendment Act (No 2) 1988.

Land Tax Amendment Act (No 2) 1989.

Land Tax Amendment Act 1978.

Land Tax Amendment Act 1981.

Land-tax (Annual) Act 1922.

Native Land Act 1909.

Native Land Act 1931.

Property Assessment Act 1885.

Property Speculation Tax Act 1973.

Property Tax Assessment Act 1879.

Statutes Amendment Act 1946.

Valuation of Land Amendment Act 1933.

Bills

Land And Income Tax Amendment Bill 1929 (68-1).

Valuation Of Land Amendment (No. 2) Bill 1970 (57-1).

\section{Court Cases}

Aotea District Maori Land Board v Commissioner of Taxes - [1927] NZLR 817.

Bell v Commissioner of Taxes - (1895) 14 NZLR 438.

Charles v Lysons - [1922] NZLR 902.

Commissioner of Taxes v Gorman - (1915) 34 NZLR 1029. 
Commissioner of Taxes v Smith - (1907) 26 NZLR 961.

Commissioner of Taxes $v$ Wintle - [1926] NZLR 814.

De Luxe Theatre Company, Limited v Commissioner Of Taxes - [1939] NZLR 268.

Gaisford v Commissioner of Taxes - (1910) 29 NZLR 909.

Hallenstein Bros. Ltd. v R. Alston \& Sons Limited and Others [1958] NZLR 171.

In re Mawhera Block - [1920] NZLR 894.

New Zealand Breweries Limited v Square Freeholds Limited [1965] NZLR 619.

Rhodes v Commissioner of Taxes - (1910) 29 NZLR 725.

Taxation Review Authority Case 20 - (1984) 7 TRNZ 220.

Taxation Review Authority Case 27 - (1988) 12 TRNZ 237.

Taxation Review Authority Case 40 - (1987) 11 TRNZ 338.

Taxation Review Authority Case 42 - (1986) 9 TRNZ 407.

Taxation Review Authority Case 44 - (1988) 12 TRNZ 683.

Taxation Review Authority Case 58 - (1983) 6 TRNZ 502.

Taxation Review Authority Case 82 - (1988) 11 TRNZ 722.

The Trustees of The Dunedin Methodist Central Mission v CIR - (1987) 11 TRNZ 345.

Thomas v Valuer-General - [1918] NZLR 164, page 175.

Wellington Diocesan Board of Trustees v Commissioner of Taxes - (1907) 26 NZLR 1281.

Whiterock Estate Company (Limited) v Commissioner of Taxes- (1911) 30 NZLR 405.

Yule v Commissioner of Taxes - [1918] NZLR 890.

Government Reports and Publications

New Zealand Official Yearbook, (1893-1992)

New Zealand Parliamentary Debates, (1891-1990)

New Zealand Taxation Committee, Report of the Taxation Committee, 1952

Task Force On Tax Reform, Report Of The Task Force On Tax Reform, 1982 
Tax Working Group (2010), A Tax System for New Zealand's Future, 2010

Tax Working Group (2018), Future of Tax: Interim Report, 2018

Appendices to the Journals of the House of Representatives

Annual Report by the Department Of Lands And Survey, AJHR, 1903 Session I, C-01.

Charges Against Mr. Peter Heyes. AJHR, 1910 Session I, B-19.

Cheviot Estate, Copies Of Correspondence Relating To The Acquisition Of The, By

The Government, AJHR, 1893 Session I, C-09.

Country-Land Owners Of Unimproved Value Of £20,000 And Upwards, AJHR, 1914

Session I, B-17a

Financial Statement 1891, AJHR, 1891 Session II, B-06

Financial Statement 1900, AJHR, 1900 Session I, B-06

Financial Statement 1903, AJHR, 1903 Session I, B-06.

Financial Statement 1908, AJHR, 1908 Session I, B-06.

Financial Statement 1912, AJHR, 1912 Session II, B-06

Financial Statement 1915, AJHR, 1915 Session I, B-06

Financial Statement 1916, AJHR, 1916 Session I, B-06

Financial Statement 1917, AJHR, 1917 Session I, B-06

Financial Statement 1922, AJHR, 1922 Session I, B-06

Financial Statement 1924, AJHR, 1924 Session I, B-06

Financial Statement 1925, AJHR, 1925 Session I, B-06

Financial Statement 1927, AJHR, 1927 Session I, B-06

Financial Statement 1929, AJHR, 1929 Session I, B-06

Financial Statement 1930, AJHR, 1930 Session I, B-06

Financial Statement 1931, AJHR, 1931 Session I-II, B-06-Part01

Financial Statement 1936, AJHR, 1936 Session I, B-06

Financial Statement 1937, AJHR, 1937 Session I, B-06

Financial Statement 1954, AJHR, 1954 Session I, B-06 
Financial Statement, AJHR, 1928 Session I, B-06

Graduated Land-Tax: Return Showing Comparison Of Payments Under Present Scale With Payments Under Proposed New Scale In Respect Of Land Other Than Business Premises, AJHR, 1907 Session I, B-24.

Land- And Income-Tax Department, Further Report By The Commissioner, AJHR, 1892 Session I, B-20a.

Land And Income-Tax Department, Report By The Commissioner, AJHR, 1892 Session I, B-20.

Land-Tax And Loss Of Graduated Land-Tax, AJHR, 1907 Session I, B-24b.

Public Accounts For The Financial Year 1903-1904, AJHR, 1904 Session I, B-01

Public Accounts For The Financial Year 1908-1909, AJHR, 1909 Session ii, B-01

Public Accounts For The Financial Year 1913-1914, AJHR, 1914 Session I, B-01Part01.

Report Of The Committee Appointed To Inquire Into The Taxation Of The Dominion Of New Zealand, AJHR, 1922 Session I, B-05

Report Of The Royal Commission Into The Special Land-Tax, AJHR, 1930 Session I, B-11

Report Of Valuation Of Land Commission, AJHR, 1915 Session I, B-17b.

Statistics Relating To The Value And Area Of Freehold Land In The Colony, AJHR, 1907 Session I, B-17a.

Supplementary Financial Statement 1931, AJHR, 1931 Session I-II, B-06-Part02

Taxation Review Committee, Taxation In New Zealand, AJHR, 1967, B-18

The Royal Commission Into Land And Income Taxation, Land And Income Taxation, AJHR, 1924 Session I, B-05

Newspapers and Periodicals

Auckland Star (1915, 1928, 1929, 1937, 1940, 1990)

Chicago Tribune (1916)

Clutha Leader (1912)

Evening Post (1878, 1925, 1933, 1938, 1987, 1988, 1990) 
Evening Star (1907)

Grey River Argus (1891)

Hawkes Bay Herald (1892)

Horowhenua Chronicle (1937)

Manawatu Herald (1891)

National Business Review (1988, 1989)

National Property Review (1990)

New Zealand Herald (1920, 1928, 1929, 1937, 1941, 1990)

Northern Advocate (1928)

Otago Daily Times $(1891,1928)$

Poverty Bay Herald (1891)

Real Estate Times (1989)

South Australian Register (1883)

Stratford Evening Post (1928)

Thames Star (1912)

The Bay of Plenty Times $(1879,1912)$

The Dominion $(1987,1989)$

The Dominion Sunday Times (1987)

The Press (1867, 1872, 1891, 1928, 1933, 1934)

The Star $(1907,1915)$

The Sun (1918)

The Temuka Leader (1888)

Wairarapa Times (1937)

Wanganui Chronicle (1912)

Wanganui Herald (1890, 1920)

Other Publications 
Real Estate Institute of New Zealand, Land Tax; A Summary And Recommendation, November 1988

Websites

interest.co.nz, www.interest.co.nz, (2019)

Marxists Internet Archive, www.marxists.org

Newshub, www.newshub.co.nz, (2019)

Reserve Bank of New Zealand, www.rbnz.govt.nz

stuff.co.nz, www.stuff.co.nz, (2015-2019)

Tax Policy, Inland Revenue, taxpolicy.ird.govt.nz 


\section{Secondary References}

Alawattage, C., \& Wickramasinghe, D. (2009). Institutionalisation of Control and Accounting for Bonded Labour in Colonial Plantations: A historical analysis. Critical Perspectives on Accounting, 20, 701-715.

Anderson, G. (2011). Labour Law in New Zealand. Alphen aan den Rijn: Kluwer Law International .

Asiskovitch, S. (2009). Digging their Own Graves: Unexpected Consequences of Institutional Design and Welfare State Changes. Social Policy and Administration, 43(3), 226-244.

Assensoha, A. B., \& Wahabb, H. (2008). A Historical-Cum-Political Overview of Ghana's National Health Insurance Law. African and Asian Studies, 7(2), 289306.

Atkinson, N. (2015, 11 13). Voting Rights - Votes for Women. Retrieved 03 15, 2016, from Te Ara - the Encyclopedia of New Zealand: http://www.teara.govt.nz/en/voting-rights/page-4

Avi-Yonah, R. S. (2003). Tax Stories and Tax Histories: Is There a Role for History in Shaping Tax Law? Michigan Law Review, 101(6), 2227-2237.

Avi-Yonah, R. S. (2005). All of a Piece Throughout: The Four Ages of U.S. International Taxation. Virgina Tax Review, 25, 313-338.

Barrett, J., \& Veal, J. (2012). Land Taxation: A New Zealand Perspective. eJournal of Tax Research, 10(3), 573.

Bassett, M. (2008). Working With David: Inside The Lange Cabinet. Auckland: Hodder Moa.

Becker, A. P. (1970). Arguments for Changing the Real Estate Tax to a Land Value. Tax Policy, 37(9-12), 15-31.

Beckett, J. V. (1985). Land Tax or Excise: The Levying of Taxation in Seventeenthand Eighteenth-Century England. The English Historical Review, 100(395), 285308.

Béland, D. (2005). Ideas and Social Policy: An Institutionalist Perspective. Social Policy \& Administration, 39(1), 1-18.

Belich, J. (1996). Making Peoples: A History of the New Zealanders from Polynesian Settlement to the End of the Nineteenth Century. Auckland: Penguin.

Belich, J. (2001). Paradise Reforged: A History of the New Zealanders From the 1880s to the Year 2000. Auckland: Penguin Press.

Bell, S. (2011). Do We Really Need a New 'Constructivist Institutionalism' to Explain Institutional Change? British Journal of Political Science, 41(4), 883-906.

Bell, S. (2017). Historical Institutionalism and New Dimensions of Agency: Bankers, Institutions and the 2008 Financial Crisis. Political Studies, 65(3), 724-739. 
Bentick, B. L. (1982). A Tax on Land Value May Not Be Neutral. National Tax Journal, 35(1), 113.

Berman, E. P., \& Pagnucco, N. (2010). Economic Ideas and the Political Process: Debating Tax Cuts in the US House of Representatives. Politics \& Society, 38(3), 347-372.

Bird, R. (1960). A National Tax on the Unimproved Value of Land: The Australian Experience, 1910-1952. National Tax Journal, 13(4), 386-392.

Blyth, M. (1997). "Any More Bright Ideas?" The Ideational Turn of Comparative Political Economy. Comparative politics, 29(2), 229-250.

Bonaparte, T. H. (1987). Henry George's Impact at Home and Abroad: He Won The Workers of Marx's Adopted Country But Through Leninism Marxism Has Won Half The World. The American Journal of Economics and Sociology, 46(1), 109-124.

Bourassa, S. C. (1990). Land Value Taxation and Housing Development: Effects of the Property Tax Reform in Three Types of Cities. American Journal of Economics and Sociology, 49(1), 101-111.

Bowman, J. H., \& Bell, M. E. (2008). Distributional Consequences of Converting the Property Tax to a Land Value Tax: Replication and Extension of England and Zhao. National Tax Journal, 51(4/1), 593-607.

Brooking, T. (2014). Richard Seddon: King of God's Own. Auckland: Penguin.

Broschek, J. (2010). Federalism and Political Change: Canada and Germany in Historical-Institutionalist Perspective. Canadian Journal of Political Science, 43(1), 1-24.

Brown, H. G. (1949). The Challenge of Australian Tax Policy: Can Professional Economists Continue to Ignore Experience with Land Value Taxation? American Journal of Economics and Sociology, 8(4), 377-400.

Burnham, W. D. (1993). Pattern Recognition and "Doing" Political History: Art, Science, or Bootless Enterprise. In L. C. Dodd, \& C. Jillson, The Dynamics of American Politics: Approaches and Interpretations (pp. 59-98). Boulder: Westview Press.

Campbell, J. L. (1997). Recent Trends in Institutional Political Economy. The International Journal of Sociology and Social Policy, 17(7/8), 15-56.

Campbell, J. L. (1998). Institutional Analysis and the Role of Ideas in Political Economy. Theory and Society, 27(3), 377-409.

Campbell, J. L. (2002). Ideas, Politics, and Public Policy. Annual Review of Sociology, 28, 21-38.

Campbell, J. L. (2010). Institutional Reproduction and Change. In The Oxford Handbook of Comparative Institutional Analysis. 
Capoccia, G., \& Kelemen, R. D. (2007). The Study of Critical Junctures: Theory, Narrative, and Counterfactuals in Historical Institutionalism. World Politics, 59(3), 341-369.

Carr, E. H. (1961). What is History? Retrieved 2015, from http://www.trfa.org.uk/sixthform/wp-content/uploads/2014/07/HISTORY-Whatis-history-E.H-Carr.pdf

Casey, T. (1996). Britain's Poll Tax Policy: An Institutionalist Approach. West European Politics, 19(2), 279-302.

Chapman, J. C., Johnston, R. J., \& Tyrrell, T. J. (2009). Implications of a Land Value Tax with Error in Assessed Values. Land Economics, 85(4), 576-584.

Christiansen, P. M., \& Klitgaard, M. B. (2010). Behind the Veil of Vagueness: Success and Failure in Institutional Reforms. Journal of Public Policy, 30(2), 183-200.

Christie, J. (1924). The Legislative Council of New Zealand. Journal of Comparative Legislation and International Law, Third Series, 6(1), 19-26.

Coleman, A., \& Grimes, A. (2010). Fiscal, Distributional and Efficiency Impacts of Land and Property Taxes. New Zealand Economic Papers, 44(2), 179-199.

Coleman, C., \& McKerchar, M. (2008). The History of Land Tax in Australia. In J. Tiley, Studies in the History of Tax Law, Volume 4. Lucy Cavendish College.

Cooper, G., \& Vann, R. (2000). A Few Myths about the GST. University of New South Wales Law Journal, 23(2), 252-263.

Cord, S. (1985). How Much Revenue Would a Full Land Value Tax Yield? In the United States in 1981, Census and Federal Reserve Data Indicate It Would Nearly Equal All Taxes. American Journal of Economics and Sociology, 44(3), 279-293.

Crawford, S., \& Ostrom, E. (1995). A Grammar of Institutions. The American Political Science Review, 89(3), 582-600.

Czech, B. (2009). The Neoclassical Production Function as a Relic of Anti-George Politics: Implications for Ecological Economics. Ecological Economics, 68, 2193-2197.

Dale, S. (1996). Stewart, William Downie. Retrieved September 02, 2019, from Dictionary of New Zealand Biography: https://teara.govt.nz/en/biographies/3s35/stewart-william-downie

Davison, G. (1995). Australia The First Suburban Nation? Journal of Urban History, 22(1), 40-74.

Deeg, R. (2005). Change from Within: German and Italian Finance in the 1990s. In Beyond Continuity: Institutional Change in Advanced Political Economies (pp. 169-202). Oxford University Press. 
Dickson, I., \& White, D. (2008, April). Tax Design Insights From The New Zealand Goods And Services Tax (GST) Model. Retrieved 04 18, 2020, from CAGTR Working Paper Series: https://www.wgtn.ac.nz/sacl/centres-andinstitutes/cagtr/working-papers/WP60.pdf

Dilley, A. (2013, November). Labor, Capital and Land: The Transnational Dimensions of the 1910 Federal Land Tax. Labour History, 105, 113-130.

Douglas, R. (1993). Unifinished Business. Random House New Zealand Ltd.

Douglas, R. W. (1978). Site Value Taxation and Manvel's Land Value Estimates. American Journal of Economics and Sociology, 37(2), 217-223.

Drummond, J. (1907). The Life and Work of Richard John Seddon (Premier of New Zealand, 1893-1906). Christchurch: Whitcombe and Tombs Ltd.

Dwyer, T. M. (1980). A History of the Theory of Land-value Taxation. PhD thesis for Harvard University.

Dwyer, T. M. (2014). Taxation: The Lost History. American Journal of Economics and Sociology, 73(4), 663-988.

Easton, B. (2007). A New Economic History of New Zealand. paper presented at the Asia-Pacific Economic and Business History Conference Sydney, Australia,. Retrieved 07 24, 2015, from http://www.eastonbh.ac.nz/2007/02/a-neweconomic-history-of-new-zealand-some-issues/

Eccleston, R. (2006). 'The Thirty Year Problem': Political Entrepreneurs, Policy Learning and the Institutional Dynamics of Australian Consumption Tax Reform. Law in Context, 24(2), 100-123.

Eccleston, R. (2007). Taxing Reforms: The Complex Dynamic of Tax Policy Change in Australia, Japan, Canada and the United States. What Is Policy Change? Workshop at Governing by Looking Back Conference, 12-14 December 2007. Australian National University.

Edwards, M. E. (1984). Site Value Taxation in Australia: Where Land Is Taxed More and Improvements Less, Average Housing Values and Stocks Are Higher. American Journal of Economics and Sociology, 43(4), 481-495.

England, R. W., \& Zhao, M. Q. (2005). Assessing the Distributive Impact of a Revenue-Neutral Shift from a Uniform Property Tax to a Two-Rate Property Tax with a Uniform. National Tax Journal, 48(2), 247-260.

Feder, K. A. (1993). Issues in the Theory of Land Value Taxation. PhD thesis for Temple University.

Feldstein, M. (1977). The Surprising Incidence of a Tax on Pure Rent: A New Answer to an Old Question. Journal of Political Economy, 85(2), 349-360.

Foldvary, F. E. (2006). The Ultimate Tax Reform: Public Revenue from Land Rent. Civil Society Institute, Santa Clara University. 
Follain, J. R. (1986). Land Versus Capital Value Taxation: A General Equilibrium Analysis. National Tax Journal, 39(4), 451-470.

Franszen, R. C. (2009). International Experience. In R. F. Dye, \& R. W. England, Land Value Taxation: Theory, Evidence, and Practice (pp. 27-47). Lincoln Institute of Land Policy.

Funnell, W. (1998). The Narrative and its Place in the New Accounting History: The Rise of the Counternarrative. Accounting, Auditing \& Accountability Journal, $11(2), 142-162$.

Gaffney, M. (1970). Adequacy of Land as a Tax Base. In D. M. Holland, The Assessment of Land Value (pp. 157-212). Madison: University of Wisconsin Press.

Gaffney, M. (1972). The Property Tax is a Progressive Tax. Proceedings of the sixtyfourth annual conference on taxation. Columbus, $\mathrm{OH}$ : National Tax Association, 408-26.

Gaffney, M. (1973). Tax Reform to Release Land. Modernizing urban land policy, 115152.

Gaffney, M. (1994). The Corruption of Economics. London: Shepheard-Walwyn.

Gaffney, M. (2009). The Hidden Taxable Capacity of Land: Enough and to Spare. International Journal of Social Economics, 36(4), 328-411.

Gardner, W. J. (1996). Forbes, George William. In C. Orange, Dictionary of New Zealand Biography (Vol. 3). Auckland: Auckland University Press.

George, H. (1879). Progress and Poverty. New York: Robert Schalkenbach Foundation.

Gerhard, D. (1956). Periodization in European History. The American Historical Review, 61(4), 900-913.

Gilbert, J. H. (1916). Single-Tax Movement in Oregon. Political Science Quarterly, $31(1), 25-52$.

Goldsmith, P. (2008). We Won, You Lost, Eat That! A Political History of Tax in New Zealand since 1840. Birkenhead: David Ling Publishing.

Goldsmith, P. (2012, 07 13). Taxes - Taxation - 1840 to the 1880s. Retrieved 10 04, 2015, from Te Ara - the Encyclopedia of New Zealand: http://www.teara.govt.nz/en/taxes/page-1

Greener, I. (2005). The Potential of Path Dependence in Political Studies. Politics, 25(1), 62-72.

Greer, S. L. (2008). Choosing Paths in European Union Health Services Policy: A Political Analysis of a Critical Juncture. Journal of European Social Policy, 18(3), 219-231.

Grey, G. (1878). Ceremony of Turning the First Sod of the Thames Valley Railway: Sir Geo. Grey ... Before His Constituents, Saturday, the 21st December, 1878. 
Retrieved 10 04, 2015, from http://nzetc.victoria.ac.nz/tm/scholarly/tei-Stout08t1-g1-t8-body-d2.html

Grosskopf, S. (1981). The Revenue Potential of a Site Value Tax: Extension and Update of a General Equilibrium Model With Recent Empirical Estimates of Several Key Parameters. American Journal of Economics and Sociology, 40(2), 207215.

Grosskopf, S., \& Johnson, M. (1982). Land Value Tax Revenue Potentials: Methodology and Measurements. In R. Lindholm, \& A. D. Lynn, Land Value Taxation.

Groves, H. M. (1949). Taxation in Australia and New Zealand. National Tax Journal, 2(1), 1-11.

Grube, D. (2014). The Gilded Cage: Rhetorical Path Dependency In Australian Politics. In Studies in Australian Political Rhetoric (pp. 99-118). ANU Press.

Gupta, R. (2016). Filling The Land Tax Void: New Zealand Standpoint. eJournal of Tax Research, 14(3), 719-740.

Gustafson, B. (2000). His Way: A Biography Of Robert Muldoon. Auckland: Auckland University Press.

Hagman, D. G. (1964). The Single Tax and Land-Use Planning: Henry George Updated. UCLA Law Review, 12, 762-788.

Hagman, D. G. (1978). Land-Value Taxation. In D. G. Hagman, \& D. J. Misczynski, Windfalls for Wipeouts: Land value Capture and Compensation. Chicago: Planners Press.

Hall, P. A. (1986). Governing the Economy: The Politics of State Intervention in Britain and France. New Yprk: Oxford University Press.

Hall, P. A. (1989). The Political Power of Economic Ideas : Keynesianism Across Nations. Princeton: Princeton University Press.

Hall, P. A. (1993). Policy Paradigms, Social Learning, and the State: The Case of Economic Policymaking in Britain. Comparative Politics, 25(3), 275-296.

Hall, P. A., \& Taylor, R. (1998). The Potential of Historical Institutionalism: A Response to Hay and Wincott. Political Studies, 46(5), 958-962.

Hall, P. A., \& Taylor, R. C. (1996). Political Science and the Three New Institutionalisms. Political Studies, 936-957.

Harrington, A. (2005). The Contribution of the Primary Sector to New Zealandis Economic Growth. Retrieved 05 09, 2016, from New Zealand Treasury: http://www.treasury.govt.nz/publications/research-policy/ppp/2005/05-04/tpp0504.pdf

Harris, P. A. (2002). Metamorphosis of the Australasian Income Tax : 1866 to 1922. Australian Tax Research Foundation. 
Hay, C., \& Wincott, D. (1998). Structure, Agency and Historical Institutionalism. Political Studies, 46(5), 951-957.

Heaton, H. (1925). The Taxation of Unimproved Value of Land in Australia. The Quarterly Journal of Economics, 39(3), 410-449.

Hogan, J. (2007). The Importance of Ideas: An A Priori Critical Juncture Framework. Canadian Journal of Political Science, 40(4), 883-910.

Hooper, K., \& Kearins, K. (2003). Substance But Not Form: Capital Taxation and Public Finance in New Zealand, 1840-1859. Accounting History, 8(2), 101-119.

Hooper, K., \& Kearins, K. (2008). The Walrus, Carpenter and Oysters: Liberal Reform, Hypocrisy and Expertocracy in Maori Land Loss in New Zealand 1885-1911. Critical Perspectives on Accounting, 19, 1239-1262.

Horton, S. (2006). The Public Service Ethos in the British Civil Service: An Historical Institutional Analysis. Public Policy and Administration, 21(1), 32-48.

Hutchinson, A. R. (1945). Public Charges Upon Land Values in Australia: A Study of the Effects of Local Government Rating Systems Upon the Social and Economic Development of the Australian States. Melbourne: Land Values Research Group.

Ikenberry, G. J. (1988). Conclusion: An Institutional Approach to American Foreign Economic Policy. International Organization, 42(1), 219-243.

Immergut, E. M. (1998). The Theoretical Core of the New Institutionalism. Politics and Society, 26, 5-34.

Immergut, E. M., \& Anderson, K. M. (2008). Historical Institutionalism and West European Politics. West European Politics, 31(1-2), 345-369.

Inland Revenue Department \& New Zealand Treasury. (2009). Land tax: Background paper for Session 3 of the Victoria University of Wellington Tax Working Group. Retrieved 06 09, 2015, from http://www.victoria.ac.nz/sacl/centres-andinstitutes/cagtr/twg/publications/3-land-tax-ird_treasury.pdf

Jinno, N., \& DeWit, A. (1998). Japan's Taxing Bureaucrats: Fiscal Sociology and the Property-Tax Revolt. Social Science Japan Journal, 1(2), 233-246.

Kerkhoff, T. (2011). Organizational Reform and Changing Ethics in Public Administration: A Case Study on 18th Century Dutch Tax Collecting. Journal of Public Administration Research and Theory, 21(1), 117-135.

King, M. (2003). The Penguin History of New Zealand. Auckland: Penguin.

Klemme, R. T. (1947). The Graduated Land Tax. A thesis submitted for PhD at Iowa State College.

Knutsen, W. L. (2012). An Institutional Account of China's HIV/AIDS Policy Process from 1985 to 2010. Politics \& Policy, 40(1), 161-192.

Lange, D. (2005). My Life. Auckland: Penguin Group. 
LeRossignol, J. E. (1907). Rating on Unimproved Values in New Zealand. State and Local Taxation: National Conference under the Auspices of the National Tax Association: Addresses and Proceedings, 1, pp. 273-285.

LeRossignal, J. E., \& Stewart, W. D. (1908). Rating on Unimproved Value in New Zealand. Journal of Political Economy, 16(1), 13-22.

LeRossignal, J. E., \& Stewart, W. D. (1910). State Socialism in New Zealand. New York: T.Y. Crowell \& Company.

Lieberman, E. S. (2001). Causal Inference in Historical Institutional Analysis: A Specification of Periodization Strategies. Comparative Political Studies, 34(9), 1011-1035.

Lieberman, E. S. (2001). National Political Community and the Politics of Income Taxation in Brazil and South Africa in the Twentieth Century. Politics and Society, 29(4), 515-555.

Littlewood, M. (2012). The History of Death Duties and Gift Duty in New Zealand. New Zealand Journal of Taxation Law and Policy, 18(1), 66-103.

Mahoney, J. (2000). Path Dependence in Historical Sociology. Theory and Society, 507548.

Mangioni, V. (2018). Land Value Taxation: Opportunity And Challenges For Funding Regional Australia And New Zealand. Australasian Journal of Regional Studies, 24(2), 191-212.

Mares, I., \& Queralt, D. (2015). The Conservative Origin of Income Taxation. History of Accounting eJournal, 8(12).

Marriott, L. (2008). The Politics of Retirement Savings Taxation: A Trans-Tasman Comparison. Victoria University of Wellington.

Marriott, L. (2017). Tax and Corruption: Is Sunlight the Best Disinfectant? A New Zealand Case Study. eJournal of Tax Research, 15(2), 262-289.

McCluskey, W. J., \& Franzsen, R. C. (2001). Land Value Taxation: A Case Study Approach. Lincoln Institute of Land Policy.

McLean, I. (2004). Land Tax: Options For Reform. Nuffield College Politics Working Paper 2004-W7: University of Oxford.

McLean, I., \& Nou, J. (2006). Why Should We Be Beggars with the Ballot in Our Hand? Veto Players and the Failure of Land Value Taxation in the United Kingdom, 1909-14. British Journal of Political Science, 36(4), 575-591.

Merino, B. (1998). Critical Theory and Accounting History: Challenges and Opportunities. Critical Perspectives on Accounting, 9(6), 603-616.

Mill, J. S. (1848). Principles of Political Economy with some of their Applications to Social Philosophy. London: John W. Parker. 
Mill, J. S. (1871). Programme of the Land Tenure Reform Association. London: Longmans, Green, Reader, and Dyer.

Miller, P., Hopper, T., \& Laughlin, R. (1991). The New Accounting History: An Introduction. Accounting, Orgamzations and Society, 16(5), 395-403.

Mills, D. E. (1981). The Non-Neutrality of Land Value Taxation. National Tax Journal, $34(1), 125-129$.

Mills, E. S. (1998). The Economic Consequences of a Land Tax. In D. Netzer, Land Value Taxation: Can It and Will It Work Today? (pp. 31-48). Lincoln Institute of Land Policy.

Ministry for Culture and Heritage. (2012, 12 20). Overview. Retrieved 02 14, 2017, from New Zealand History: https://nzhistory.govt.nz/culture/the-1920s/overview

Ministry for Culture and Heritage. (2012, 12 20). The 1950s. Retrieved 05 09, 2016, from New Zealand History: http://www.nzhistory.net.nz/culture/the1950s/overview

Ministry for Culture and Heritage. (2016, 01 13). The 1960s. Retrieved from New Zealand History: http://www.nzhistory.net.nz/culture/the-1960s/overview

Mitchell, G. W. (1956). Is This Where We Came In? Proceedings of the Annual Conference on Taxation under the Auspices of the National Tax Association, 49, 485-494.

Netzer, D. (1966). Economics of the Property Tax. Washington DC: The Brookings Institution.

Netzer, D. (1984). On Modernizing Local Public Finance: Why Aren't Property Taxes in Urban Areas Being Reformed into Land Value Taxes? American Journal of Economics and Sociology, 43(4), 497-501.

Netzer, D. (2001). What Do We Need to Know about Land Value Taxation? Journal of Economics and Sociology, 60(5), 97-118.

Neuman, W. L. (2004). Basics of Social Research: Qualitative and Quantitative Approaches. Boston: Pearson.

Neuner, E. J., Popp, D. O., \& Sebold, F. D. (1974). The Impact of a Transition to SiteValue Taxation on Various Classes of Property in San Diego. Land Economics, 50(2), 181-185.

Oates, W. E. (1973). The Effects of Property Taxes and Local Public Spending on Property Values: A Reply and Yet Further Results. Journal of Political Economy, 81(4), 1004-1008.

Oates, W. E., \& Schwab, R. M. (1997). The Impact of Urban Land Taxation: The Pittsburgh Experience. National Tax Journal, 50(1), 1.

Olsen, J. P., \& March, J. G. (1989). Rediscovering Institutions: The Organizational Basis of Politics. New York: Free Press. 
Parker, L. D. (1997). Informing Historical Research in Accounting and Management: Tradition Philosphies and Opportunities. The Accounting Historians Journal, 24(2), 111-149.

Pedersen, L. H. (2007). Ideas Are Transformed As They Transfer: A Comparative Study of Eco-Taxation in Scandinavia. Journal of European Public Policy, 14(1), 59-77.

Peters, B. G. (2005). Institutional Theory in Political Science (2nd ed.). Bloomsbury.

Phillips, D. (1994). Periodisation in Historical Approaches to Comparative Education: Some Considerations from the examples of Germany and England and Wales. British Journal of Educational Studies, 42(3), 261-272.

Pierson, P. (1996). The Path to European Integration: A Historical Institutionalist Analysis. Comparative political studies, 29(2), 123 - 163.

Pierson, P. (2000). Increasing Returns, Path Dependence, And The Study Of Politics. The American Political Science Review, 94(2), 251-267.

Pierson, P. (2004). Politics in Time: History, Institutions, and Social Analysis. Princeton University Press.

Plummer, E. (2009). Fairness and Distributional Issues. In R. F. Dye, \& R. W. England, Land Value Taxation: Theory, Evidence, and Practice (pp. 73-98). Lincoln Institute of Land Policy,.

Plummer, E. (2010). Evidence on the Distributional Effects of a Land Value Tax on Residential Households. National Tax Journal, 63(1), 63-92.

Previts, G. J., Parker, L. D., \& Coffman, E. N. (1990). Accounting History: Definition and Relevance. Abacus, 26(1), 1-16.

Raadschelders, J. (2000). Handbook of Administrative History. New Brunswick: Transaction Publishers.

Radaelli, C. (2005). Taxation Research as Political Science Research. In M. Lamb, A. Lymer, J. Freedman, \& S. James, Taxation: An interdisciplinary approach to research. Oxford:: Oxford.

Reece, B. (1993). The Abolition of Land Tax in New Zealand: Searching For Causes and Policy Lessons. Australian Tax Forum, 10(2), 223.

Reeves, W. P. (1903). State Experiments in Australia and New Zealand. New York: E. P. Dutton \& Co.

Reeves, W. P. (1911). Land Taxes in Australasia. The Economic Journal, 21(84), $513-$ 526.

Ricardo, D. (1817). On the Principles of Political Economy and Taxation. London: John Murray.

Roakes, S. L. (1991). The "Golden Key"? Land Value Taxation and Central City Redevelopment in New Zealand. PhD thesis for University of Wisconsin. 
Roakes, S. L. (1996). Reconsidering Land Value Taxation: The Golden Key? Land Use Policy, 13(4), 261-272.

Rogers, F. (1963). The Influence of Political Theories in the Liberal Period, 1890-1912: Henery George and John Stuart Mill. In R. Chapman, \& K. Sinclair, Studies of a Small Democracy, Essays in Honour of Willis Airey (pp. 153-174). Auckland: Auckland University Press.

Ryan, C. K. (2002). Harry Gunnison Brown: An Orthodox Economist and His Contributions. American Journal of Economics and Sociology, 61(5 Supplement), i-270.

Rybeck, W. (1977). Site Value Taxation. Journal of Housing(September), 454-457.

Santayana, G. (1905). The Life of Reason; or, The Phases of Human Progress. New York: C. Scribner's Sons.

Schmidt, V. A. (2011). Reconciling Ideas and Institutions Throung Discursive Institutionalism. In R. H. Daniel Beland, Ideas and Politics in Social Science Research (pp. 47-64). Oxford University Press.

Schneiberg, M. (2005). Combining New Institutionalisms: Explaining Institutional Change in American Property Insurance. Sociological Forum, 20(1), 93-137.

Schwartz, H. M. (1997). Reinvention and Retrenchment: Lessons from the Application of the New Zealand Model to Alberta, Canada. Journal of Policy Analysis and Management, 16(3), 405-422.

Scott, J. (1990). A Matter Of Record. Cambridge: Polity Press.

Shoup, D. C. (1970). The Optimal Timing of Urban Land Development. Papers in Regional Science, 25(1), 33-44.

Sinclair, K. (1991). A History of New Zealand. Auckland: Penguin.

Singleton, J. (2008, 02 10). An Economic History of New Zealand in the Nineteenth and Twentieth Centuries. Retrieved 04 22, 2016, from EH.Net Encyclopedia: https://eh.net/encyclopedia/an-economic-history-of-new-zealand-in-thenineteenth-and-twentieth-centuries/

Skocpol, T. (1992). Protecting Mothers and Soldiers: The Political Origins of Social Policy in the United States. Cambridge: Belknap Press.

Skocpol, T., \& Pierson, P. (2002). Historical Institutionalism in Contemporary Political Science. In I. Katznelson, \& M. H. V, Political Science: State of the Discipline. New York: W.W. Norton.

Smith, A. (1776). An Inquiry into the Nature and Causes of the Wealth of Nations. London: W. Strahan and T. Cadell.

Smith, T. R. (1970). Land Value Versus Real Property Taxation: A Case Study Comparison. Land Economics, 66(3), 305-313.

Stanford, M. (1986). The Nature of Historical Knowledge. Oxford: Blackwell. 
Steinmo, S. (1993). Taxation and Democracy: Swedish, British, and American Approaches to Financing the Modern State. Yale University Press.

Steinmo, S. (2003). The Evolution of Policy Ideas: Tax Policy in the 20th Century. The British Journal of Politics \& International Relations, 5(2), 206-236.

Steinmo, S. (2008). Historical Institutionalism. In D. Della Porta, \& K. Michael, Approaches and Methodologies in the Social Sciences: A Pluralist Perspective (pp. 118-138). Cambridge: Cambridge University Press.

Steinmo, S., \& Tolbert, C. (1998). Do Institutions Really Matter? Taxation in Industrialized Democracies. Comparative Political Studies, 31(2), 165-187.

Stewart, W. D. (1909a). Land Tenure and Land Monopoly in New Zealand: I. Journal of Political Economy, 17(2), 82-91.

Stewart, W. D. (1909b). Land Tenure and Land Monopoly in New Zealand: II. Journal of Political Economy, 17(3), 144-152.

Stone, G. W. (1975). Public Spending, Land Taxes, and Economic Growth: An Empirical Analysis of Land as a Tax Base. American Journal of Economics and Sociology, 34(2), 113-126.

Streeck, W., \& Thelen, K. A. (2005). Introduction: Institutional Change in Advanced Political Economies. In Beyond Continuity : Institutional Change in Advanced Political Economies (pp. 1-39). Oxford University Press USA.

The Maddison Project. (2007). Historical Statistics for the World Economy: 1-2003 AD: Per Capita GDP. Retrieved 04 26, 2016, from The Maddison Project: www.ggdc.net/Maddison/Historical_Statistics/horizontal-file_03-2007.xls

Thelen, K. (1999). Historical Institutionalism in Comparative Politics. Annual Review of Political Science, 2, 369-404.

Thelen, K. (2002). The Explanatory Power of Historical Institutionalism. In R. Mayntz, Akteure-Mechanismen-Modelle. Zur Theoriefähigkeit makro-sozialer Analysen (pp. 91-107). Frankfurt: Campus Verlag.

Thelen, K., \& Steinmo, S. (1992). Historical Institutionalism In Comparative Politics. In S. Steinmo, K. Thelen, \& F. Longstreth, Structuring Politics: Historical Institutionalism in Comparative analysis (pp. 1-32). Cambridge: Cambridge University Press.

Tideman, N., Akobundu, E., Johns, A., \& Wutthicharoen, P. (2002). The Avoidable Excess Burden of Broad-Based U.S. Taxes. Public Finance Review, 30(5), 416441.

Tideman, T. N. (1982). A Tax on Land Value is Neutral. National Tax Journal, 35(1), 109.

Tosh, J. (2010). The Pursuit of History (5th ed.). Dorchester: Pearson. 
Vosslamber, R. (2010). Taxing and Pleasing: The Rhetoric and Reality of Vertical Equity in the Development of the New Zealand Income Tax on Employees, 1891 to 1984. Retrieved 03 25, 2015, from http://ir.canterbury.ac.nz/bitstream/10092/4148/1/thesis_fulltext.pdf

Vosslamber, R. (2012a). Narrating History: New Zealand's "Black Budget" of 1958. Accounting History, 17(3-4), 481-499.

Vosslamber, R. (2012b). Taxation for New Zealand's Future: The Introduction of New Zealand's Progressive Income Tax in 1891. Accounting History, 17(1), 105-122.

Vosslamber, R. (2014). The Road to Freedom? Hayek and New Zealand's Tax Depreciation. Journal of the Australasian Tax Teachers Association, 9(1), 126146.

Vosslamber, R. (2015). "Removing a Parasitic Element": Speculation, Housing Affordability and the 1973 Property Speculation Tax. New Zealand Journal of Taxation Law and Policy, 21(2), 169-190.

Walker, F. A. (1887). Political Economy. New York: Holt.

Walker, M. (1971). Some Observations on Land Value Taxation. Tax Policy, 38(6-7), 3-23.

White, M. G. (1965). Foundations of Historical Knowledge. New York: Harper \& Row.

Widmaier, W. (2016). Breaking Promises and Raising Taxes: Rhetorical Path Dependence and Policy Dysfunction in Time. Australian Journal of Political Science, 51(4), 727-741.

Wildasin, D. E. (1982). More on the Neutrality of Land Taxation. National Tax Journal, $35(1), 105$.

Woodruff, A. M., \& Ecker-Racz, L. L. (1965). Property Taxes and Land Use Patterns in Australia and New Zealand. Tax Executive, 16-63.

Wyatt, M. D. (1994). A Critical View of Land Value Taxation as a Progressive Strategy for Urban Revitalization, Rational Land Use and Tax Relief. Review of radical political economics, 26(1), 1-25.

Young, A. N. (1916). The Single Tax Movement in the United States. Princeton University Press.

Zinn, H. (1991). Declarations of Independence: Cross-examining American Ideology. New York: HarperCollins. 


\section{Appendix A: Uncovered Periods}

\section{Appendix A.1 1921-1929, The Remainder of the Reform Government}

While 1921-1929 is not a period focused on in this study, the following overview is included to provide a more complete understanding as to how land tax developed during this time. The period from 1921 to 1928 covers the remainder of the Reform Government, which held power from 1912-1928. While this was a continuation of the Reform Government covered previously in sections 6.5, 6.6 and 6.7, the Reform Government of the 1920s was generally stronger than it had been in the previous decade. Following the 1919 and 1925 elections Reform achieved outright parliamentary majorities, allowing it to govern without relying on independents and giving it more power than it had previously had.

Conversely the Liberal Party opposition declined significantly as a political force, consistently losing vote share in 1920s elections and being displaced by the Labour Party as the official parliamentary opposition in 1925. The Labour Party meanwhile maintained consistent levels of support throughout the throughout 1920s (Belich, 2001, p. 146), backed by about 25 percent of voters. With the Labour Party static and the Liberals in decline there was little parliamentary challenge for the government.

Meanwhile, the early 1920s saw the New Zealand economy beset by economic problems. (Ministry for Culture and Heritage, 2012), which led the Reform government to undertake two reviews into taxation. Following the reviews the government undertook tax reform, but the poor economic climate and conservative dominance of parliament saw a rather different focus for 1920s tax policy, compared to that of the 1910s.

Feeling that taxation was too heavy ${ }^{979}$ and the wartime tax levels were unsustainable, ${ }^{980}$ the government began reducing taxation, but it also changed which taxes the government sourced the majority of its revenue from. The new tax mix was similar to that conservatives had advocated prior to entering government. The importance of income tax and land tax revenue was significantly reduced while the revenue from customs and death

\footnotetext{
979 Refer note 376 , page 3.

980 Financial Statement 1922, AJHR, 1922 Session I, B-06, page x.
} 
duties greatly rose. From 1923 customs duties were the largest single source of government tax revenue and they were almost half of total tax revenue from $1925 .{ }^{981}$

While the Reform government professed commitment to maintaining land tax as more equitable taxation and a means of discouraging land aggregation, ${ }^{982}$ most changes made to land tax from 1921 to 1928 were cuts. Between 1922 and 1924 the government decreased land tax rates ${ }^{983}$ and increased the threshold for tax liability. ${ }^{984}$ Despite this, the period was characterised by high land tax revenue, particularly compared to later decades, but it consistently declined after 1922 in both real terms and as a portion of total tax revenue. By 1928 land tax revenue was, in real terms less that it had been in 1913 and a smaller portion of total government tax revenue than it had ever been previously. ${ }^{985}$

\section{Appendix A.2 1953-1974, Stagnation}

The second period not focused on in this study is the period 1953 to 1974 . Unlike the 1921-1928 period, which only covered the last half of the Reform Government, between 1953 and 1974 New Zealand has four governments: the remainder of the First National Government (1949-1957), the Second Labour Government (1957-1960), the Second National Government (1960-1972) and the Third Labour Government (1972-1975). Despite the variety of governments and the significant length of time, New Zealand saw few significant land tax changes until the 1970s. The relatively short length of Labour governments meant the National Party dominated government over the period. The National Party, which tended to favour farmers (Belich, 2001, pp. 402-403), was unlikely to support significant reforms to the already weakened land tax but its tendency to

\footnotetext{
$981 \quad$ Refer note 399.

982 Financial Statement 1927, AJHR, 1927 Session I, B-06, page 13.

983 Land-tax (Annual) Act 1922, Schedule; Land and Income Tax Amendment Act 1922, s2; Land and Income Tax (Annual) Act 1923, Schedule Part I; Land and Income Tax (Annual) Act 1924, Schedule Part I.

984 Land and Income Tax Amendment Act 1924, s2.

985 Refer note 626.
} 
prioritise maintaining power meant the National Governments tried to avoid major reforms of most policies, contributing to a state of policy inertia. The Labour Party was in power less often but also did not reform land tax. Land tax was absent from the tax changes in Labour's 1958 "Black Budget” and the Third Labour Government left land tax similarly unchanged, despite facing a rapidly appreciating housing market. While the 1950s and 1960s are the height of land tax stagnation, this matches a wider societal pattern. In the 1950s and 1960s New Zealand as a whole was not particularly dynamic and the period has been referred to as "the most boring time and place on earth" (Belich, 2001, p. 307).

While politics was not pressuring the land tax to change in the 1953-1974 period, neither was the economy. The economy boomed slowly but consistently on the back of high prices for agricultural exports (Belich, 2001, p. 307), providing a high standard of living (Ministry for Culture and Heritage, 2016). However, the state took a greater role in agriculture and granted farmers further preferential treatment, with tax breaks developing for the 1960's and direct subsidies from 1973 (Belich, 2001, p. 311). Land values rose consistently throughout the period, averaging 10.3 percent yearly, but not quickly enough to put pressure on housing affordability, as occurred in the 1970s and 1980s. While the economic downturn set in following the 1967 wool price collapse, that did not start influencing land tax until after 1975. ${ }^{986}$

The lack of external pressures on land tax, and any government desire to reform it, made 1953 to 1974 something of a dark age for land tax. While the regularity of land tax reform declined as it became less important and a slowdown had become evident by the 1940s, between 1953 and 1975 land tax law was almost static with only five changes over that period. In 1954, ${ }^{987} 1962^{988}$ and $1968^{989}$ changes were made to lower tax rates or raise the threshold for land tax liability. These changes offset the bracket creep caused by continued appreciation of land values and limited growth of land tax revenue. The final

\footnotetext{
$986 \quad$ See Chapter 8

987 Refer notes 603; 605 .

988 Land and Income Tax (Annual) Act 1962, Schedule, Part I.

989 Land and Income Tax Amendment Act 1968, s7.
} 
changes were to exempt farmers in 1970 and to change the valuation base to simple land value in $1971 .{ }^{990}$

Since most land tax changes between 1953 and 1974 were cuts it is unsurprising that revenue fell in real terms and as a portion of total tax revenue. While appreciating land values caused nominal land tax revenue to increase between periods when the government cut the land tax rates, revenue consistently fell in real terms. By 1975 land tax was only 0.12 percent of total taxation and was, in real terms, at the lowest point it would reach before abolition..$^{991}$

990 See Chapter 8.1 for more details.

991 Refer notes 626 


\section{Appendix B: Land Tax Revenue Tables}

Table 6. Land Tax Revenue - Nominal and Inflation Adjusted, 1893-1966992

\begin{tabular}{|c|c|c|}
\hline $\begin{array}{l}\text { Year ended } \\
31 \text { March }\end{array}$ & $\begin{array}{l}\text { Land Tax Revenue } \\
\text { Nominal (f) }\end{array}$ & $\begin{array}{l}\text { Land Tax Revenue } \\
\text { Real as at Q4 } 2019 \\
\quad \text { (millions of \$) }\end{array}$ \\
\hline 1893 & 297,181 & 60.04 \\
\hline 1894 & 285,327 & 56.49 \\
\hline 1895 & 280,000 & 55.65 \\
\hline 1896 & 271,394 & 53.90 \\
\hline 1897 & 272,309 & 53.95 \\
\hline 1898 & 267,287 & 51.18 \\
\hline 1899 & 298,053 & 56.94 \\
\hline 1900 & 293,627 & 57.12 \\
\hline 1901 & 294,584 & 55.53 \\
\hline 1902 & 312,836 & 57.28 \\
\hline 1903 & 296,062 & 53.64 \\
\hline 1904 & 334,991 & 61.30 \\
\hline 1905 & 352,854 & 62.99 \\
\hline 1906 & 385,756 & 66.14 \\
\hline 1907 & 447,342 & 76.70 \\
\hline 1908 & 537,846 & 92.65 \\
\hline 1909 & 604,901 & 105.12 \\
\hline 1910 & 642,270 & 111.47 \\
\hline 1911 & 628,723 & 108.97 \\
\hline 1912 & 647,015 & 111.16 \\
\hline 1913 & 728,636 & 121.43 \\
\hline 1914 & 767,451 & 124.50 \\
\hline 1915 & 799,641 & 121.99 \\
\hline 1916 & $1,048,356$ & 148.68 \\
\hline 1917 & 713,118 & 92.52 \\
\hline 1918 & $1,385,708$ & 161.24 \\
\hline 1919 & $1,512,693$ & 158.90 \\
\hline 1920 & $1,557,903$ & 142.99 \\
\hline 1921 & $1,688,979$ & 149.55 \\
\hline 1922 & $1,637,816$ & 164.93 \\
\hline 1923 & $1,541,502$ & 159.05 \\
\hline 1924 & $1,426,463$ & 143.20 \\
\hline 1925 & $1,335,251$ & 134.36 \\
\hline 1926 & $1,266,659$ & 126.02 \\
\hline 1927 & $1,229,067$ & 123.33 \\
\hline
\end{tabular}

992 Refer note 626. 


\begin{tabular}{|c|c|c|}
\hline 1928 & $1,154,479$ & 115.53 \\
\hline 1929 & $1,140,324$ & 114.97 \\
\hline 1930 & $1,506,911$ & 153.50 \\
\hline 1931 & $1,145,617$ & 126.57 \\
\hline 1932 & 542,128 & 65.18 \\
\hline 1933 & 498,916 & 63.23 \\
\hline 1934 & 498,978 & 61.98 \\
\hline 1935 & 492,526 & 59.50 \\
\hline 1936 & 458,873 & 54.08 \\
\hline 1937 & $1,047,877$ & 115.03 \\
\hline 1938 & $1,038,034$ & 110.08 \\
\hline 1939 & $1,058,499$ & 108.60 \\
\hline 1940 & $1,019,084$ & 99.88 \\
\hline 1941 & 959,418 & 90.53 \\
\hline 1942 & $1,009,288$ & 92.80 \\
\hline 1943 & 975,824 & 87.40 \\
\hline 1944 & 987,707 & 86.71 \\
\hline 1945 & 952,622 & 82.55 \\
\hline 1946 & 937,395 & 80.39 \\
\hline 1947 & 939,559 & 79.91 \\
\hline 1948 & 854,456 & 65.69 \\
\hline 1949 & 916,120 & 69.65 \\
\hline 1950 & 967,386 & 70.05 \\
\hline 1951 & $1,043,203$ & 67.99 \\
\hline 1952 & $1,137,937$ & 68.27 \\
\hline 1953 & $1,315,136$ & 75.79 \\
\hline 1954 & $1,615,372$ & 87.91 \\
\hline 1955 & 966,632 & 51.42 \\
\hline 1956 & $1,227,656$ & 63.68 \\
\hline 1957 & $1,399,837$ & 70.62 \\
\hline 1958 & $1,308,455$ & 64.54 \\
\hline 1959 & $1,447,543$ & 67.53 \\
\hline 1960 & $1,526,000$ & 70.88 \\
\hline 1961 & $1,817,000$ & 69.91 \\
\hline 1962 & $2,018,000$ & 89.51 \\
\hline 1963 & $1,150,000$ & 50.06 \\
\hline 1964 & $1,168,000$ & 49.35 \\
\hline 1965 & $1,320,000$ & 53.85 \\
\hline 1966 & $1,600,000$ & 63.19 \\
\hline
\end{tabular}


Table 7. Land Tax Revenue - Nominal and Inflation Adjusted, 1967-1991993

\begin{tabular}{|r|r|r|}
\hline $\begin{array}{c}\text { Year ended } \\
\text { 31 March }\end{array}$ & $\begin{array}{c}\text { Land Tax Revenue } \\
\text { Nominal } \\
\text { (millions of \$) }\end{array}$ & $\begin{array}{c}\text { Land Tax Revenue } \\
\text { Real as at Q4 2019 } \\
\text { (millions of \$) }\end{array}$ \\
\hline 1967 & 3.50 & 64.93 \\
\hline 1968 & 4.40 & 78.81 \\
\hline 1969 & 2.70 & 45.96 \\
\hline 1970 & 2.90 & 46.92 \\
\hline 1971 & 3.10 & 45.18 \\
\hline 1972 & 3.80 & 51.55 \\
\hline 1973 & 3.40 & 42.88 \\
\hline 1974 & 3.30 & 37.84 \\
\hline 1975 & 3.40 & 33.93 \\
\hline 1976 & 3.40 & 28.82 \\
\hline 1977 & 6.60 & 49.07 \\
\hline 1978 & 8.40 & 55.63 \\
\hline 1979 & 9.50 & 55.96 \\
\hline 1980 & 10.70 & 53.45 \\
\hline 1981 & 11.60 & 50.35 \\
\hline 1982 & 33.80 & 125.42 \\
\hline 1983 & 34.40 & 117.87 \\
\hline 1984 & 36.20 & 118.45 \\
\hline 1985 & 43.70 & 122.62 \\
\hline 1986 & 55.90 & 142.05 \\
\hline 1987 & 63.60 & 135.88 \\
\hline 1988 & 71.20 & 143.04 \\
\hline 1989 & 153.3 & 294.90 \\
\hline 1990 & 271.00 & 484.37 \\
\hline 1991 & 172.00 & 299.01 \\
\hline & & \\
\hline & & \\
\hline & &
\end{tabular}

993 Refer note 626. 
Table 8. Land Tax, Income Tax and Total Tax Revenue, 1893-1966994

\begin{tabular}{|c|c|c|c|c|c|c|}
\hline $\begin{array}{c}\text { Year } \\
\text { ended } \\
31 \\
\text { March }\end{array}$ & $\begin{array}{l}\text { Total Tax } \\
\text { Revenue } \\
\quad(£)\end{array}$ & $\begin{array}{l}\text { Land Tax } \\
\text { Revenue } \\
\quad(£)\end{array}$ & $\begin{array}{c}\text { Land Tax } \\
\text { Percentage } \\
\text { of } \\
\text { Total Tax } \\
\text { Revenue }\end{array}$ & $\begin{array}{c}\text { Income Tax } \\
\text { Revenue } \\
\text { (f) }\end{array}$ & $\begin{array}{c}\text { Social } \\
\text { Security } \\
\text { Tax }^{996} \\
(£)\end{array}$ & $\begin{array}{c}\text { Income } \\
\text { Tax } 997 \\
\text { Percentage } \\
\text { of } \\
\text { Total Tax } \\
\text { Revenue }\end{array}$ \\
\hline 1893 & $2,339,511$ & 297,181 & $12.70 \%$ & 67,367 & & $2.88 \%$ \\
\hline 1894 & $2,353,250$ & 285,327 & $12.12 \%$ & 75,238 & & $3.20 \%$ \\
\hline 1895 & $2,300,350$ & 280,000 & $12.17 \%$ & 90,000 & & $3.91 \%$ \\
\hline 1896 & $2,335,761$ & 271,394 & $11.62 \%$ & 92,778 & & $3.97 \%$ \\
\hline 1897 & $2,521,911$ & 272,309 & $10.80 \%$ & 105,504 & & $4.18 \%$ \\
\hline 1898 & $2,678,576$ & 267,287 & $9.98 \%$ & 115,210 & & $4.30 \%$ \\
\hline 1899 & $2,707,099$ & 298,053 & $11.01 \%$ & 115,480 & & $4.27 \%$ \\
\hline 1900 & $2,891,126$ & 293,627 & $10.16 \%$ & 128,721 & & $4.45 \%$ \\
\hline 1901 & $3,042,890$ & 294,584 & $9.68 \%$ & 173,809 & & $5.71 \%$ \\
\hline 1902 & $3,113,079$ & 312,836 & $10.05 \%$ & 179,397 & & $5.76 \%$ \\
\hline 1903 & $3,277,964$ & 296,062 & $9.03 \%$ & 200,684 & & $6.12 \%$ \\
\hline 1904 & $3,649,601$ & 334,991 & $9.18 \%$ & 221,369 & & $6.07 \%$ \\
\hline 1905 & $3,754,379$ & 352,854 & $9.40 \%$ & 253,952 & & $6.76 \%$ \\
\hline 1906 & $3,841,596$ & 385,756 & $10.04 \%$ & 261,816 & & $6.82 \%$ \\
\hline 1907 & $4,264,555$ & 447,342 & $10.49 \%$ & 277,867 & & $6.52 \%$ \\
\hline 1908 & $4,645,754$ & 537,846 & $11.58 \%$ & 304,905 & & $6.56 \%$ \\
\hline 1909 & $4,377,761$ & 604,901 & $13.82 \%$ & 321,044 & & $7.33 \%$ \\
\hline 1910 & $4,180,516$ & 642,270 & $15.36 \%$ & 316,835 & & $7.58 \%$ \\
\hline 1911 & $4,837,322$ & 628,723 & $13.00 \%$ & 407,235 & & $8.42 \%$ \\
\hline 1912 & $5,296,590$ & 647,015 & $12.22 \%$ & 448,935 & & $8.48 \%$ \\
\hline 1913 & $5,606,829$ & 728,636 & $13.00 \%$ & 462,994 & & $8.26 \%$ \\
\hline 1914 & $5,918,034$ & 767,451 & $12.97 \%$ & 554,271 & & $9.37 \%$ \\
\hline 1915 & $5,880,811$ & 799,641 & $13.60 \%$ & 540,318 & & $9.19 \%$ \\
\hline 1916 & $7,266,966$ & $1,048,356$ & $14.43 \%$ & $1,392,119$ & & $19.16 \%$ \\
\hline 1917 & $10,549,654$ & 713,118 & $6.76 \%$ & $4,262,126$ & & $40.40 \%$ \\
\hline 1918 & $12,340,853$ & $1,385,708$ & $11.23 \%$ & $5,619,561$ & & $45.54 \%$ \\
\hline 1919 & $13,801,643$ & $1,512,693$ & $10.96 \%$ & $6,219,336$ & & $45.06 \%$ \\
\hline 1920 & $16,251,769$ & $1,557,903$ & $9.59 \%$ & $6,369,765$ & & $39.19 \%$ \\
\hline
\end{tabular}

994 Refer note 626.

995 For the years ended 1940-1946 amounts include both normal income tax and the war income tax.

996 While not the official income tax, the social security tax (also known as the social security charge and the social security income tax) was also levied on income. It was merged into the income tax from 1970. It is included here to give greater clarity to total taxation borne by income.

997 Calculated using the combined total of income tax and the social security tax in years both are levied. 


\begin{tabular}{|c|c|c|c|c|c|c|}
\hline 1921 & $22,184,414$ & $1,688,979$ & $7.61 \%$ & $8,248,945$ & & $37.18 \%$ \\
\hline 1922 & $16,370,516$ & $1,637,816$ & $10.00 \%$ & $6,002,987$ & & $36.67 \%$ \\
\hline 1923 & $15,715,380$ & $1,541,502$ & $9.81 \%$ & $3,831,932$ & & $24.38 \%$ \\
\hline 1924 & $16,540,438$ & $1,426,463$ & $8.62 \%$ & $3,781,532$ & & $22.86 \%$ \\
\hline 1925 & $16,549,609$ & $1,335,251$ & $8.07 \%$ & $3,386,052$ & & $20.46 \%$ \\
\hline 1926 & $17,254,688$ & $1,266,659$ & $7.34 \%$ & $3,368,516$ & & $19.52 \%$ \\
\hline 1927 & $17,437,827$ & $1,229,067$ & $7.05 \%$ & $3,422,216$ & & $19.63 \%$ \\
\hline 1928 & $17,145,145$ & $1,154,479$ & $6.73 \%$ & $3,273,729$ & & $19.09 \%$ \\
\hline 1929 & $17,832,033$ & $1,140,324$ & $6.39 \%$ & $3,310,877$ & & $18.57 \%$ \\
\hline 1930 & $19,471,131$ & $1,506,911$ & $7.74 \%$ & $3,533,764$ & & $18.15 \%$ \\
\hline 1931 & $18,878,285$ & $1,145,617$ & $6.07 \%$ & $4,003,606$ & 280,829 & $22.70 \%$ \\
\hline 1932 & $17,405,622$ & 542,128 & $3.11 \%$ & $4,447,814$ & $1,217,451$ & $32.55 \%$ \\
\hline 1933 & $19,703,703$ & 498,916 & $2.53 \%$ & $3,556,775$ & $4,099,662$ & $38.86 \%$ \\
\hline 1934 & $21,470,827$ & 498,978 & $2.32 \%$ & $2,961,243$ & $4,413,221$ & $34.35 \%$ \\
\hline 1935 & $24,737,939$ & 492,526 & $1.99 \%$ & $3,796,477$ & $4,561,594$ & $33.79 \%$ \\
\hline 1936 & $25,476,372$ & 458,873 & $1.80 \%$ & $4,581,328$ & $3,921,975$ & $33.38 \%$ \\
\hline 1937 & $31,164,302$ & $1,047,877$ & $3.36 \%$ & $6,618,716$ & $4,224,905$ & $34.80 \%$ \\
\hline 1938 & $36,767,525$ & $1,038,034$ & $2.82 \%$ & $9,078,763$ & $5,105,019$ & $38.58 \%$ \\
\hline 1939 & $37,797,904$ & $1,058,499$ & $2.80 \%$ & $9,303,495$ & $5,461,202$ & $39.06 \%$ \\
\hline 1940 & $44,522,028$ & $1,019,084$ & $2.29 \%$ & $11,571,247$ & $9,529,593$ & $47.39 \%$ \\
\hline 1941 & $61,360,840$ & 959,418 & $1.56 \%$ & $18,105,614$ & $10,741,861$ & $47.01 \%$ \\
\hline 1942 & $68,163,256$ & $1,009,288$ & $1.48 \%$ & $18,931,852$ & $11,063,856$ & $44.01 \%$ \\
\hline 1943 & $87,940,844$ & 975,824 & $1.11 \%$ & $25,577,874$ & $12,188,643$ & $42.95 \%$ \\
\hline 1944 & $100,839,484$ & 987,707 & $0.98 \%$ & $31,331,801$ & $13,377,773$ & $44.34 \%$ \\
\hline 1945 & $108,681,814$ & 952,622 & $0.88 \%$ & $34,248,067$ & $14,260,066$ & $44.63 \%$ \\
\hline 1946 & $114,954,873$ & 937,395 & $0.82 \%$ & $35,287,883$ & $15,167,308$ & $43.89 \%$ \\
\hline 1947 & $113,119,046$ & 939,559 & $0.83 \%$ & $32,085,057$ & $22,403,653$ & $48.17 \%$ \\
\hline 1948 & $122,275,911$ & 854,456 & $0.70 \%$ & $36,632,581$ & $26,176,758$ & $51.37 \%$ \\
\hline 1949 & $130,440,249$ & 916,120 & $0.70 \%$ & $49,007,672$ & $29,378,510$ & $60.09 \%$ \\
\hline 1950 & $135,556,319$ & 967,386 & $0.71 \%$ & $48,483,450$ & $31,702,855$ & $59.15 \%$ \\
\hline 1951 & $157,946,975$ & $1,043,203$ & $0.66 \%$ & $59,441,839$ & $35,766,437$ & $60.28 \%$ \\
\hline 1952 & $200,549,807$ & $1,137,937$ & $0.57 \%$ & $78,101,503$ & $43,612,942$ & $60.69 \%$ \\
\hline 1953 & $199,770,283$ & $1,315,136$ & $0.66 \%$ & $78,701,376$ & $45,507,938$ & $62.18 \%$ \\
\hline 1954 & $206,802,317$ & $1,615,372$ & $0.78 \%$ & $80,799,719$ & $49,717,376$ & $63.11 \%$ \\
\hline 1955 & $234,766,098$ & 966,632 & $0.41 \%$ & $88,316,880$ & $56,175,151$ & $61.55 \%$ \\
\hline 1956 & $244,828,777$ & $1,227,656$ & $0.50 \%$ & $90,697,965$ & $59,911,000$ & $61.52 \%$ \\
\hline 1957 & $252,851,763$ & $1,399,837$ & $0.55 \%$ & $98,117,734$ & $61,635,000$ & $63.18 \%$ \\
\hline 1958 & $244,882,300$ & $1,308,455$ & $0.53 \%$ & $77,787,155$ & $66,256,000$ & $58.82 \%$ \\
\hline 1959 & $305,243,131$ & $1,447,543$ & $0.47 \%$ & $109,405,880$ & $80,615,000$ & $62.25 \%$ \\
\hline 1960 & $297,288,000$ & $1,526,000$ & $0.51 \%$ & \multicolumn{2}{|c|}{$175,900,000$} & $59.17 \%$ \\
\hline 1961 & $334,463,000$ & $1,817,000$ & $0.54 \%$ & $131,530,000$ & $75,390,000$ & $61.87 \%$ \\
\hline 1962 & $358,203,000$ & $2,018,000$ & $0.56 \%$ & $148,137,000$ & $80,378,000$ & $63.79 \%$ \\
\hline 1963 & $342,014,000$ & $1,150,000$ & $0.34 \%$ & $134,059,000$ & $82,328,000$ & $63.27 \%$ \\
\hline 1964 & $371,172,000$ & $1,168,000$ & $0.31 \%$ & $144,341,000$ & $88,890,000$ & $62.84 \%$ \\
\hline
\end{tabular}




\begin{tabular}{|r|r|r|r|r|r|r|}
\hline 1965 & $422,269,000$ & $1,320,000$ & $0.31 \%$ & $181,138,000$ & $92,715,000$ & $64.85 \%$ \\
\hline 1966 & $459,000,000$ & $1,600,000$ & $0.35 \%$ & $200,600,000$ & $102,400,000$ & $66.01 \%$ \\
\hline
\end{tabular}

Table 9. Land Tax, Income Tax and Total Tax Revenue, 1967-1991998

\begin{tabular}{|r|r|r|r|r|r|r|}
\hline $\begin{array}{c}\text { Year } \\
\text { ended } \\
31 \\
\text { March }\end{array}$ & $\begin{array}{c}\text { Total Tax } \\
\text { Revenue } \\
\text { (millions } \\
\text { of } \$ \text { ) }\end{array}$ & $\begin{array}{c}\text { Land Tax } \\
\text { Revenue } \\
\text { (millions } \\
\text { of } \$ \text { ) }\end{array}$ & $\begin{array}{c}\text { Land Tax } \\
\text { Percentage } \\
\text { of } \\
\text { Total Tax } \\
\text { Revenue }\end{array}$ & $\begin{array}{c}\text { Income } \\
\text { Tax } \\
\text { Revenue } \\
\text { (millions } \\
\text { of \$) }\end{array}$ & $\begin{array}{c}\text { Social } \\
\text { Security } \\
\text { Tax } \\
\text { (millions } \\
\text { of \$) }\end{array}$ & $\begin{array}{c}\text { Income } \\
\text { Tax } \\
\text { Percentage } \\
\text { of } \\
\text { Total Tax } \\
\text { Revenue }\end{array}$ \\
\hline 1967 & 988.90 & 3.5 & $0.35 \%$ & 443.4 & 221.0 & $67.19 \%$ \\
\hline 1968 & $1,012.70$ & 4.4 & $0.43 \%$ & 440.3 & 232.5 & $66.44 \%$ \\
\hline 1969 & $1,058.60$ & 2.7 & $0.26 \%$ & 456.7 & 234.8 & $65.32 \%$ \\
\hline 1970 & $1,181.30$ & 2.9 & $0.25 \%$ & 779.2 & & $65.96 \%$ \\
\hline 1971 & $1,445.30$ & 3.1 & $0.21 \%$ & 957.3 & & $66.24 \%$ \\
\hline 1972 & $1,707.20$ & 3.8 & $0.22 \%$ & $1,161.1$ & & $68.01 \%$ \\
\hline 1973 & $1,926.90$ & 3.4 & $0.18 \%$ & $1,314.5$ & & $68.22 \%$ \\
\hline 1974 & $2,395.10$ & 3.3 & $0.14 \%$ & $1,697.9$ & & $70.89 \%$ \\
\hline 1975 & $2,865.60$ & 3.4 & $0.12 \%$ & $2,136.0$ & & $74.54 \%$ \\
\hline 1976 & $3,185.60$ & 3.4 & $0.11 \%$ & $2,295.8$ & & $72.07 \%$ \\
\hline 1977 & $3,845.20$ & 6.6 & $0.17 \%$ & $2,828.5$ & & $73.56 \%$ \\
\hline 1978 & $4,626.30$ & 8.4 & $0.18 \%$ & $3,482.8$ & & $75.28 \%$ \\
\hline 1979 & $4,989.50$ & 9.5 & $0.19 \%$ & $3,655.2$ & & $73.26 \%$ \\
\hline 1980 & $6,020.00$ & 10.7 & $0.18 \%$ & $4,465.6$ & & $74.18 \%$ \\
\hline 1981 & $7,050.50$ & 11.6 & $0.16 \%$ & $5,298.9$ & & $75.16 \%$ \\
\hline 1982 & $8,798.00$ & 33.8 & $0.38 \%$ & $6,514.7$ & & $74.05 \%$ \\
\hline 1983 & $10,097.50$ & 34.4 & $0.34 \%$ & $7,455.5$ & & $73.84 \%$ \\
\hline 1984 & $10,431.20$ & 36.2 & $0.35 \%$ & $7,453.3$ & & $71.45 \%$ \\
\hline 1985 & $11,913.00$ & 43.7 & $0.37 \%$ & $8,348.5$ & & $70.08 \%$ \\
\hline 1986 & $14,235.90$ & 55.9 & $0.39 \%$ & $10,567.2$ & & $74.23 \%$ \\
\hline 1987 & $17,408.10$ & 63.6 & $0.37 \%$ & $12,431.5$ & & $71.41 \%$ \\
\hline 1988 & $21,528.10$ & 71.2 & $0.33 \%$ & $13,799.9$ & & $64.10 \%$ \\
\hline 1989 & $22,863.90$ & 153.3 & $0.67 \%$ & $14,977.9$ & & $65.51 \%$ \\
\hline 1990 & $26,198.10$ & 271.0 & $1.03 \%$ & $16,814.4$ & & $64.18 \%$ \\
\hline 1991 & $25,797.60$ & 172.0 & $0.67 \%$ & $16,369.7$ & & $63.45 \%$ \\
\hline
\end{tabular}

\footnotetext{
$998 \quad$ Refer note 626.

999 Refer note 996.

1000 Refer note 997.
} 
